ROMANIAN ACADEMY

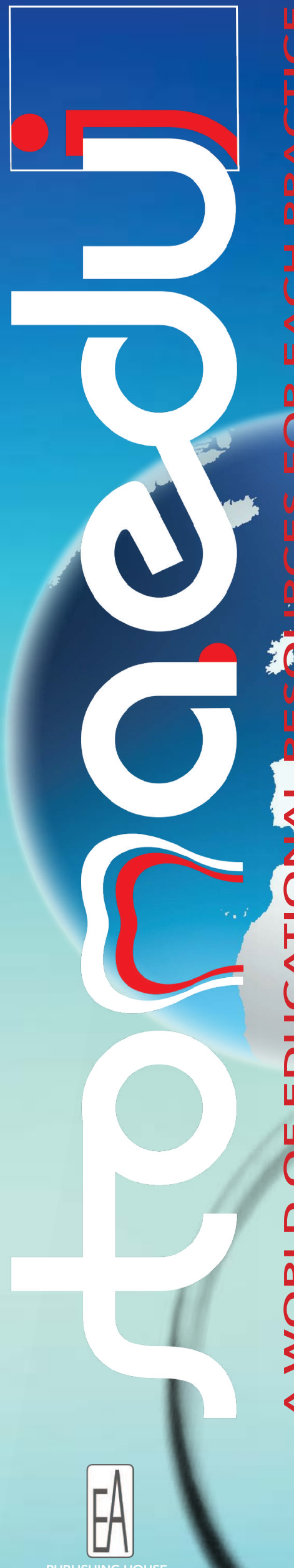

STOMATOLOGY EDU JOURNAL

since 2014

2020 VOLUME 7 ISSUE 4 


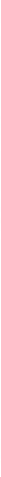

\section{Hofident $Q_{10}$}

Product presentation: Solution for oral hygiene.

Composition (INCI): aqua/water, alcohol, Capsella Bursa Pastoris extract, Plantago Lanceolata extract, Chamomilla Recutita extract, Achillea Millefolium extract, Aesculus Hippocastanum extract, Mentha Piperita extract, Ubiquinone.

Action: The product has antiseptic, healing, hemostatic, anti-inflammatory aєtion, it acts as a antioxidant, detoxifier, deodorant. It is strongly recommended in gingivitis, stomatitis, thrush, compression pain causedby dental prostheses, after tooth extraction, in case of nipple lesion, bleeding gums, mouth and gum ulcers.

Recommendations: It delays dental plaque formation, it prevents bad odour and provides daily mouth hygiene.

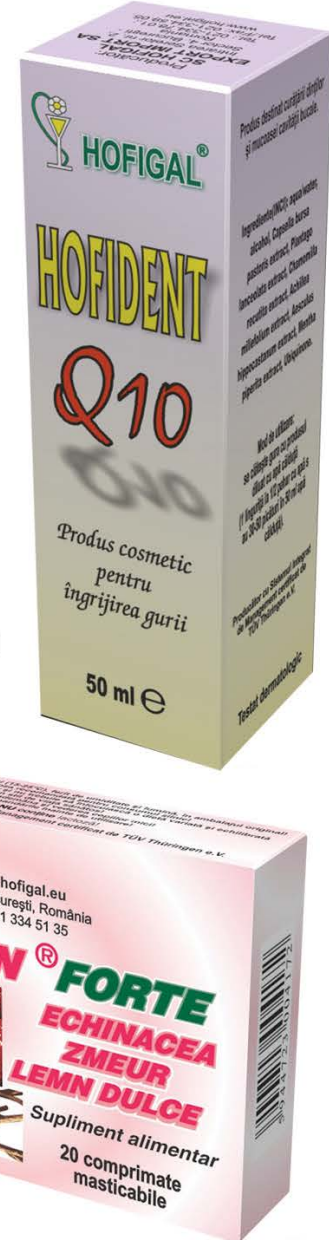

\section{Hoflmun ${ }^{\oplus}$ FORTE}

Product presentation:

Chewable tablets to stimulate the immune system

Composition: Each chewable tablet contains raspberry fruit extract (Rubii idaei fructus), Echinacea extract (Echinacea purpurea), concentrated extract of licorice root (Glycyrrhiza radix), magnesium ascorbate and excipients.

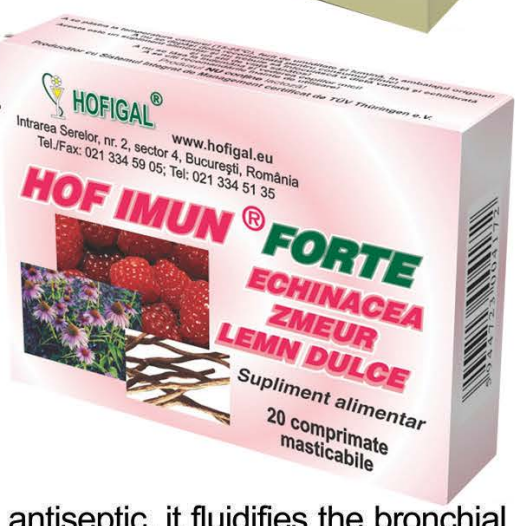

Action:It stimulates the immune system, it is antiinflammatory, antiviral, antiseptic, it fluidifies the bronchial and pharyngeal secretions, antioxidant, cardioprotective, vasoprotective, it has antineoplastic antileukimic action, (due to the ellagic acid), it contributes to wound healing, fortifies and remineralizes (it regulates the potassium balance), it has antiulcer effects and is an overall body tonic.

Recommendations: to supplement the diet with nutrients and bioactive substances in: acute and chronic infections of the upper airways (angina, pharyngitis, laryngitis, bronchitis), prophylactic during periods with increased risk of infection with influenza viruses, it has sweating effects in fever, in recurrent herpes episodes of mucocutaneous rash, frequent urinary tract infections, inflammatory urogenital processes; immunodepression after radiotherapy or chemotherapy, bacterial skin infections, psoriasis, neurodermitis, chronic cardiovascular diseases associated with hypercholesterolemia, adjuvant in the diet indicated in the treatment of gastroduodenal ulcers, tonic during periods of physical and mental strain, exhaustion.

\section{Bucoprotect gel}

Product presentation: Gel for oral hygiene.

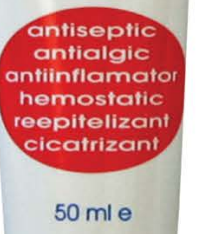

Composition (INCI): aqua, capsella bursa pastoris, calendula officinalis, achillea milefolium, hippophae rhamnoides, olea europea, hypericum perforatum, carbomer triethanolamine, collagen, foeniculum vulgare, mentha piperita, citrus amara.

Action: Antiseptic, anti-inflammatory, healing, stimulates the inside lining of the mouth and gums trophicity, reduces pain caused by specific oral diseases (gingivitis, stomatitis, lesions of the prosthesis, thrush, periodontitis). Recommendations: Fights against bad breath (halitositive nets). 


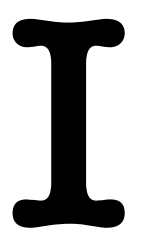

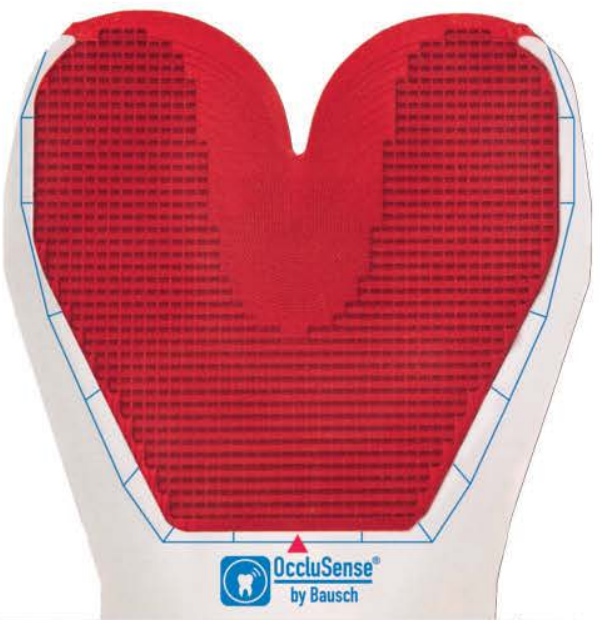

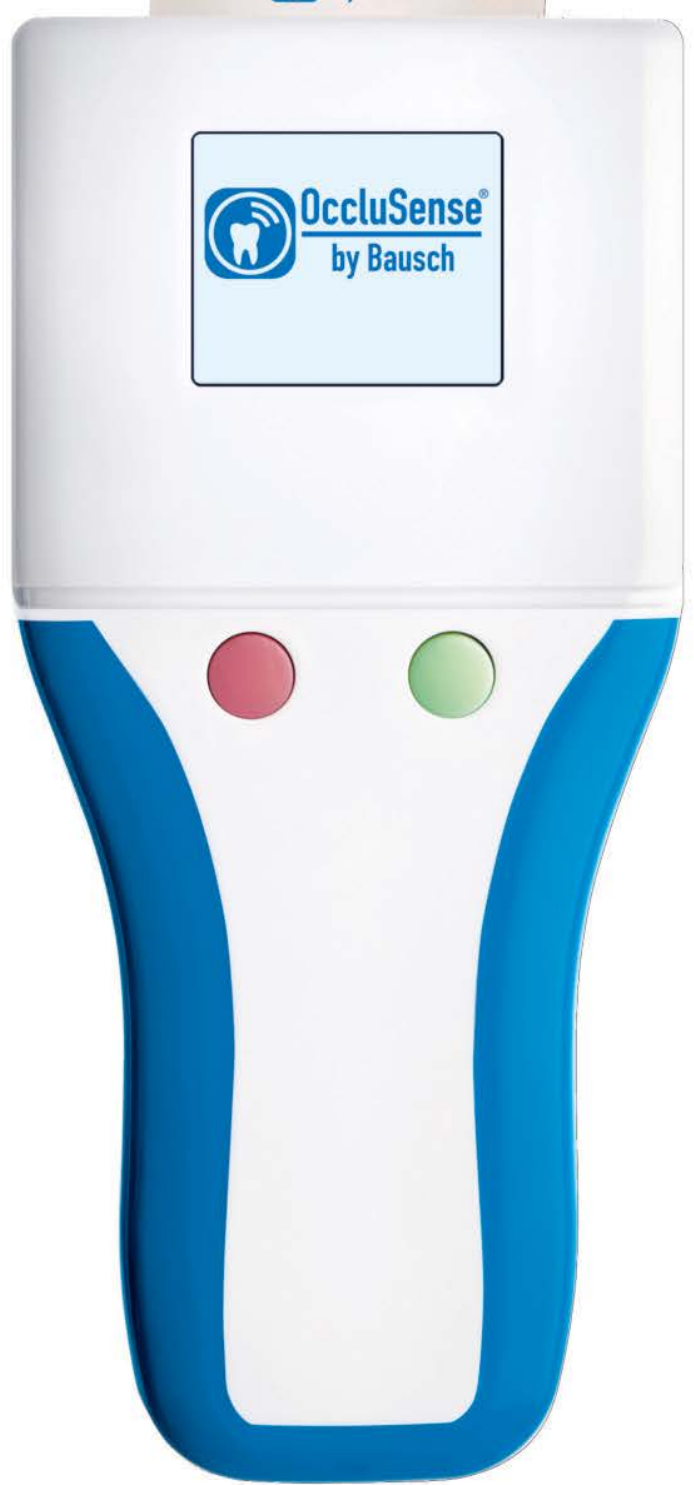

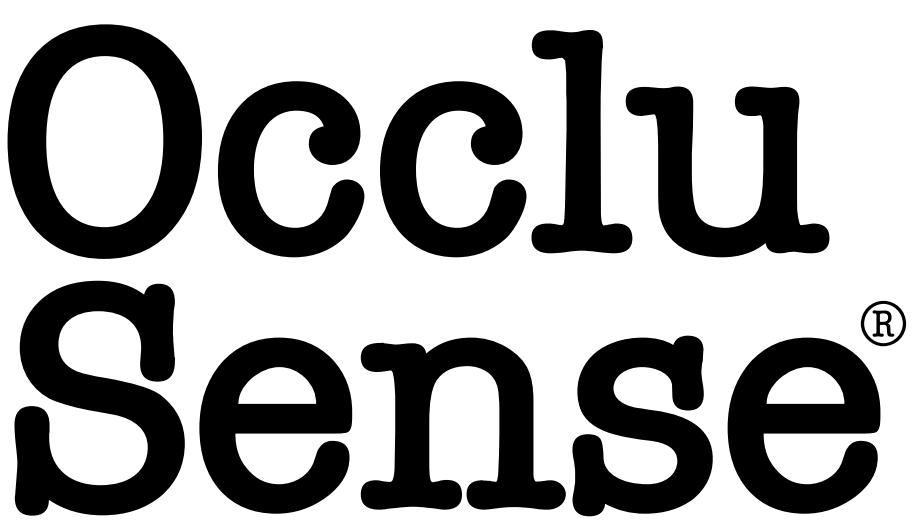

\section{Innovative device for digital occlusion control.}

Take advantage of the award-winning OccluSense ${ }^{\circledR}$ system:

- 60 microns thin, flexible pressure sensors record both static and dynamic occlusion

- Data transfer to OccluSense ${ }^{\circledR}$-iPad-App via wireless network

- Ergonomic design for intuitive handling

- Additionally, red colour coating marks the occlusal contacts on the patient's teeth

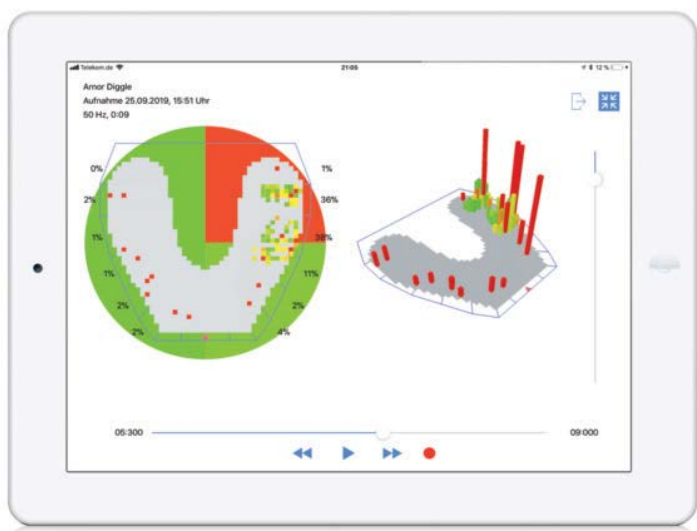

\section{(W) $\frac{\text { OccluSense }}{\text { by Bausch }}$}

WE MAKE OCCLUSION VISIBLE ${ }^{\circledR}$

Dr. Jean Bausch GmbH \& Co. KG | Oskar-Schindler-Str. 4 | 50769 Köln | Germany
More information: www.occlusense.com and YouTube 
2020

Volume 7

Issue 4

Pages 227-306

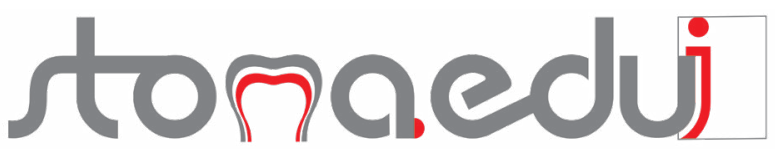

A WORLD OF EDUCATIONAL RESOURCES FOR EACH PRACTICE ISSN (print) 2360-2406; ISSN (on-line) 2502-0285; ISSN-L 2360-2406

\section{EDITORIAL}

227 Annual activity report - measuring the results of the editorial team Marian-Vladimir Constantinescu

do https://doi.org/10.25241/stomaeduj.2020.7(4).edit.1

\section{CONTINUING EDUCATION ONLINE}

231 JADA CE Online

\section{ORIGINAL ARTICLES}

233 DENTAL MATERIALS: The micro-shear bond strength of two different repair

233 systems to indirect restorative materials Ayșe Atay, Lamia Najafova, Huseyin Mehmet Kurtulmus, Aslihan Üşümez

do https://doi.org/10.25241/stomaeduj.2020.7(4).art.1

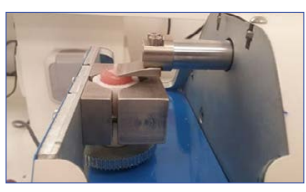

242 COMMUNITY DENTISTRY:Knowledge, awareness and perceptions of Coronavirus Disease 2019 (COVID-19) in a cohort of indian dental professionals: A questionnaire-based study

Niraj Kinariwala, Lakshman Perera Samaranayake, Irosha Rukmali Perera, Zeal Patel

di) https://doi.org/10.25241/stomaeduj.2020.7(4).art.2

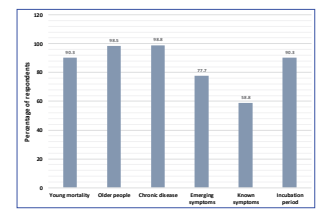

ORAL IMPLANTOLOGY:Temperature changes in bone using an air scaler

252 ExVivo

Dana M. Marzocco, Sean Lee, Kenneth S Kurtz, Javed Fawad, Rafael Delgado-Ruiz, Georgios E Romanos

do) https://doi.org/10.25241/stomaeduj.2020.7(4).art.3

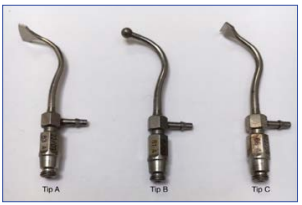

259 ORTHODONTICS AND DENTO-FACIAL ORTHOPEDICS:The effects of tongue plate and tongue appliance on maxillary deficiency in growing patients Abdolreza Jamilian, Ludovica Nucci, Ehsun Amini, Mitra Toliat,

Shima Bagherzadeh Hamedani, Felice Femiano

d.) https://doi.org/10.25241/stomaeduj.2020.7(4).art.4

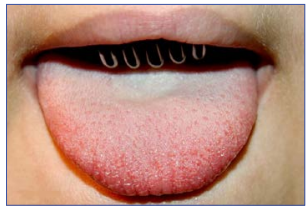

268 morphological analysis of faces: a novel approach for the assessment of facial growth

Daniele Maria Gibelli, Pasquale Poppa, Annalisa Cappella, Riccardo Rosati, Claudia Dolci, Cristina Cattaneo, Chiarella Sforza

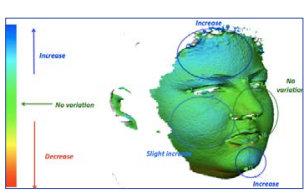

do) https://doi.org/10.25241/stomaeduj.2020.7(4).art.5

\section{REVIEW ARTICLES}

275 practice: why measures to be taken -the experience of an European University Hospital (part 2)

Constantinus Politis, Annette Schuermans, Katrien Lagrou, Mia Vande Putte, Jean-Pierre Kruth

d) https://doi.org/10.25241/stomaeduj.2020.7(4).art.6

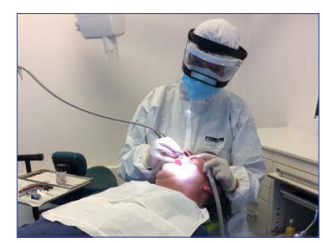


FORENSIC DENTISTRY: Child abuse and neglect: understanding the role

286 of a pediatric dentist

Sowndarya Gunasekaran, Mallikarjun Bhuthanahosur Shanthala, George Babu, Vidhya Vijayan

do) https://doi.org/10.25241/stomaeduj.2020.7(4).art.7

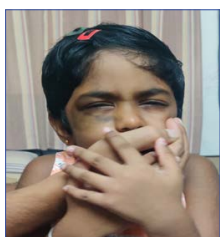

\section{PRODUCT NEWS}

29 The gold standard for visualizing the possibilities of aesthetic dental

295 makeover directly on the patient: IvoSmile

Florin - Eugen Constantinescu

do) https://doi.org/10.25241/stomaeduj.2020.7(4).prodnews.1

\section{BOOK REVIEWS}

$297 \begin{aligned} & \text { Modern Sports Dentistry } \\ & \text { Mark Roettger }\end{aligned}$

d) http://www.stomaeduj.com 10.25241/stomaeduj.2020.7(4).bookreview.1

298 Essential Endodontology: Prevention and Treatment of Apical Periodontitis Dag Ørstavik

d) http://www.stomaeduj.com 10.25241/stomaeduj.2020.7(4).bookreview.2

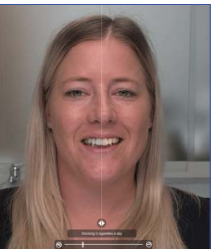
299 Modern Operative Dentistry Principles for Clinical Practice

d) http://www.stomaeduj.com 10.25241/stomaeduj.2020.7(4).bookreview.3

300 Graftless Solutions for the Edentulous Patient

Saj Jivraj

de) http://www.stomaeduj.com 10.25241/stomaeduj.2020.7(4).bookreview.4

301 Implant Restorations: A Step-by-Step Guide

Carl Drago

de) http://www.stomaeduj.com 10.25241/stomaeduj.2020.7(4).bookreview.5
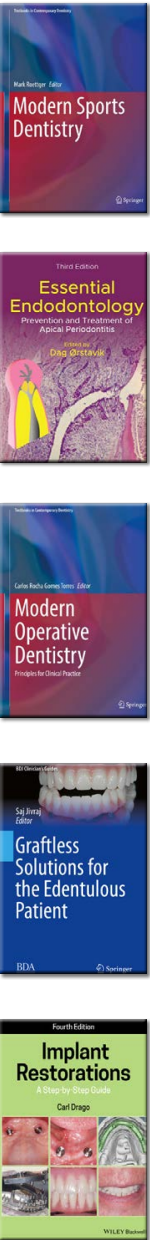

\footnotetext{
302 Essentials of Dental Photography

Irfan Ahmad

dd) http://www.stomaeduj.com 10.25241/stomaeduj.2020.7(4).bookreview.6
}

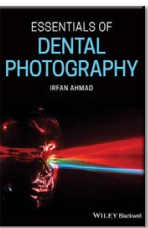

\section{INSTRUCTIONS FOR AUTHORS}

304 instructions for authors 
Eng, PhD, J A Jones Distinguished Professor, Acad (AR)

Constantin lonescu-Târgoviste MD, PhD, Professor, Acad (AR) "Carol Davila" University of Medicine and Pharmacy, Bucharest, Romania
Gabriel Octavian Lazăr
Phys, PhD, Professor "Carol Davila" University of Medicine and Pharmacy, Bucharest, Romania
Gabriel Octavian Lazăr
Phys, PhD, Professor "Vasile Alecsandri" University of Bacău, Bacău, România

\section{CO-EDITORS-IN-CHIEF (AMERICAS)}

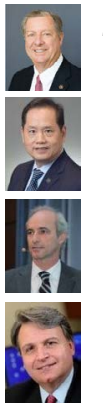

James Richard Hup

BS, DMD, MD, JD, MBA, Professor

Washington State University, Spokane, WA, USA

Hom-Lay Wang

DDS, MSD, PhD, Professor

University of Michigan, Ann Arbor, MI, USA

Mauro Marincola

MD, DDS, Clinical Professor

State University of Cartagena, Cartagena, Colombia

George E. Romanos

Stony Brook University, Stony Brook, NY, USA

CO-EDITORS-IN-CHIEF (ASIA-PACIFIC)

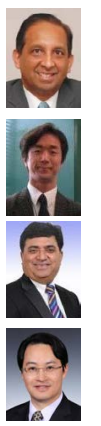

Lakshman Perera Samaranayake

Hon DSC, FDSRCS (Edin), FDS RCPS (Glas), FRACDS, FRCPath (UK), BDS, DDS

(Glas), FHKCPath, FCDSHK, FHKAM (Pathology), FHKAM (Dental Surgery)

Emeritus Professor, Department of Oral Biosciences, Faculty of Dentistry

Immediate-past Dean, University of Hong Kong, Hong Kong

Hiroshi Ogawa

DDS, MDSc, PhD, Associate Professor

Niigata University, Niigata, Japan

Mahesh Verma

BDS, MDS, MBA, FAMS, FDSRCS (England), FDSRCPSG (Glasgow), FDSRCS

(Edinburgh) PhD (HC), Professor

Maulana Azad Institute of Dental Sciences, New Delhi, India

Yongsheng Zhou

DDS, PhD, Professor and Chair, Associate Dean Department of Prosthodontics, School of Stomatology (PKUSS), Peking
University, Beijing, P.R.China

EMERITUS EDITORS-IN-CHIEF



Peter E. Dawson

列

Saint Petersburg, FL, USA

\section{Adi A. Garfunkel}

DMD, PhD, Professor Emeritus

Hadassah Hebrew University, Jerusalem, Israel

\section{Robert Louis Ibsen}

DDS, OD, FAGD, FACD, FICD

Founder \& President DenMat Corporation, Santa Maria, CA, USA

\section{Birte Melsen}

DDS, Dr Odont, Professor

Aarhus University, Aarhus, Denmark

Alexandre Mersel

DDS, PhD, Professor, Director of Studies

Geneva Institute of Medical Dentistry (GIMD), Versoix, Switzerland
CO-EDITORS-IN-CHIEF (EUROPE)

Gavriel Chaushu

DMD, MSc, Professor, Head

Rabin Medical Center, Beilinson Campus, Petah Tikva, Israel The Maurice and Gabriela Goldschleger School of Dental Medicine

Tel Aviv University, Tel Aviv, Israel

Mutlu Özcan

DDS, PhD, Professor, Head Division of Dental Biomaterials Clinic of Reconstructive Dentistry, Center of Dental Medicine (ZZM) University of Zürich, Zürich, Switzerland

Letizia Perillo MD, MS, PhD, Professor
Matizia Perillo Head, Dean, University of Campania Luigi Vanvitelli, Naples, Italy

Hande Şar Sancakli DDS, PhD, Associate Professor

FDI Regional CE Director Europe, Geneva-Cointrin, Switzerland

SENIOR EDITORS

Bruce Robert Donoff

DMD, MD, Professor, Dean Medicine Harvard University, Boston, MA, USA

Rolf Ewers

MD, DMD, PhD Professor and Chairman em. Medical University of Vienna, Vienna, Austria

Adrian Podoleanu Eng, PhD, Professor, FinstP, FOSA, FSPIE, Professor University of Kent, Canterbury, Kent, UK

Kasturi Warnakulasuriya

MDSc (Melb), PhD (Bristol), FDSRCS (Eng) FRACDS, FRCPath (UK), FFOP(RCPA),
FICD FILT FMedSci, Professor
King's College London, London, UK

MDSc (Melb), PhD (Bristol), FDSRCS (Eng) FRACDS, FRCPath (UK), FFOP(RCPA),
FICD FILT FMedSci, Professor
King's College London, London, UK

EMERITUS EDITORS-IN-CHIEF

Prathip Phantumvanit

DDS, MS, FRCDT, Professor Thammasat University, Bangkok, Thailand

Rudolf Slavicek

MD, DMD, Professor
Medical University of Vienna, Vienna, Austria

Jacques Vanobbergen

MDS, PhD, Professor Em. Professor and Chairman Gent University, Gent, Belgium

\section{Julian B. WOELFEL}

DDS, FACD, FICD, Professor Emeritus College of Dentistry, The Ohio State University, Columbus, Ohio, U.S.A

\section{David Wray}

MD (Honours), BDS, MB ChB, FDS, RCPS (Glasgow), FDS RCS (Edinburgh) F Med

Sci Professor Emeritus, Professor, University of Glasgow, Glasgow, UK
ASSOCIATE EDITORS-IN-CHIEF SECTIONS Gottfried Schmalz, DDS, PhD, Drhc, Acad (Leopoldina) - Editor-in-Chief

Basic Research / Dental Materials / Dental Technology Gottfried Schmalz, DDS, PhD, Drhc, Acad (Leopoldina) Section Editor-in-Chief

University of Regensburg, Regensburg, Germany

Annalisa Monaco, DDS, MSc, PhD

University of L'Aquila, L'Aquila, Italy

Clinical Research / Oral and Dental Diagnosis / Dental Radiology / Evidence-Based Dentistry

Amid I Ismail, BDS, MPH, MBA, Dr PH, Dean -

Section Editor-in-Chief

Temple University, Philadelphia, PA, USA

Chiarella Sforza, MD, PhD

University of Milan, Milan, Italy

Community Dentistry / Oral Epidemiology / Oral Health / Dental Public Health / Health Promotion

Poul Erik Petersen, DDS, Dr Odont, BA, MSc, WHO Senior

Consultant - Section Editor-in-Chief

University of Copenhagen, Copenhagen, Denmark
Noemí Bordoni, DDS, PhD, Director Public Health Research Institute, Buenos Aires, Argentina Cariology / Pedodontics / Oro-Dental Prevention Luca Levrini, DDS, PhD - Section Editor-in-Chief University of Insubria, Varese, Italy Ralf Janda, DDS, PhD Heinrich-Heine-University, Düsseldorf, Germany

Minimally Invasive Dentistry / Dental Lase Akira Aoki, DDS, PhD - Section Editor-in-Chief Tokyo Medical and Dental University (TMDU), Tokyo, Japan Roman Šmucler, MD, PhD

Charles University, Prague, Czech Republic

Aestethic Dentistry / Dental Photography Douglas A. Terry, DDS, PhD - Section Editor-in-Chief University of Texas, Houston, TX, USA Galip Gürel, DDS, MSC

Dentis Dental Clinic, Istanbul, Turkiye

Endodontics and Traumatology / Dental Microscopy Arnaldo Castellucci, DDS, PhD - Section Editor-in-Chief Florence, Italy
Zrinka Tarle, DMD, PhD, Dean

University of Zagreb, Zagreb, Croatia

Periodontology / Oral Microbiology / Dental Hygiene Mariano Alonso Sanz, DDS, MSD, PhD -

Section Editor-in-Chief

Complutense University of Madrid, Madrid, Spain

Anton Sculean, DMD, MS, Dr he

University of Bern, Bern, Switzerland

Oral Medicine / Oral Pathology

Mei-Qing Wang, DDS, PhD, Head - Section Editor-in-Chief Air Force Medical University (AFMU), Xi'an, Shaanxi, P.R.China

Maria Greabu, Chem, PhD, Head

"Carol Davila" University of Medicine and Pharmacy Bucharest, Bucharest, Romania

Occlusion and TMJ / Orofacial Pain / Dental Occlusion and Posture

Rafael Benoliel, DDS, PhD, BDS, Associate Dean -

Section Editor-in-Chief

The State University of New Jersey, Newark, NJ, USA

Peter Hermann, DMD, MSc, PhD, Head, Vice-Rector

Semmelweis University Budapest, Budapest, Hungary 
Orthodontics and Dento-Facial Orthopedics

Abdolreza Jamilian, DDS, PhD - Section Editor-in-Chief

Tehran University of Medical Sciences, Islamic Azad University, Tehran, Iran

Ecaterina Ionescu, DDS, PhD, Vice-Rector

"Carol Davila" University of Medicine and Pharmacy Bucharest Bucharest, Romania

Anesthesiology / Dentoalveolar Surgery / Maxillofacial Surgery / Oral Implantology / Emergencies at the Dentist's Michael Frank, DDS, PhD, ERO President, President Dent Chamber Hesse - Section Editor-in-Chief German Dental Chamber, Frankfurt am Main, Germany Giorgio Lombardo, MD, DDS

University of Verona, Verona, Italy

Prosthetic Dentistry / Oral Rehabilitation / Gerodontology Vjekoslav Jerolimov, DDS, PhD, Acad (CASA) -

Section Editor-in-Chief

University of Zagreb, Zagreb, Croati

Veronica Mercut, DMD, PhD

Vice-Rector, University of Medicine and Pharmacy Craiova, Dolj, Romania

Restorative Dentistry / Computerized Dental Prosthetics François Duret, DDS, DSO, PhD, MS, MD, PhD, Acad (ANCD) Section Editor-in-Chief

University of Montpellier, Montpellier, France

Georg B. Meyer, DMD, PhD, Drhc

Chairman, Ernst-Moritz-Arndt University, Greifswald, Germany

\section{ASSOCIATE EDITORS SECTIONS} Fawad Javed, BDS, PhD - Editor-in-Chief

Basic Research / Dental Materials / Dental Technology Vasile Iulian Antoniac, Eng, PhD, Habil, Vice Dean Section Editor-in-Chief

University "Politehnica” of Bucharest, Bucharest, Romania Horia Octavian Manolea, DMD, PhD, Head

University of Medicine and Pharmacy of Craiova, Craiova Romania

Clinical Research / Oral and Dental Diagnosis Dental Radiology / Evidence-Based Dentistry Fawad Javed, BDS, PhD - Section Editor-in-Chief University of Rochester, NY, USA

Dalia Kaisarly, BDS, MDSC, PhD

University of Munich,

Munich, Germany

Cariology / Pedodontics / Oro-Dental Prevention Sorin Andrian, DDS, PhD - Section Editor-in-Chief "Gr. T. Popa" University of Medicine and Pharmacy, lasi, lasi, Romania

Dana Cristina Bodnar, DDS, PhD

"Carol Davila" University of Medicine and Pharmacy

Bucharest, Bucharest, Romania

Aestethic Dentistry / Dental Photography Lucian Toma Ciocan, DMD, PhD, Head

Section Editor-in-Chief

"Carol Davila" University of Medicine and Pharmacy

Bucharest, Bucharest, Romania

Daniele Maria Gibelli, MD, PhD

University of Milan, Milan, Italy

Endodontics and Traumatology / Dental Microscopy

Paula Perlea, DDS, PhD - Section Editor-in-Chief

"Carol Davila" University of Medicine and Pharmacy

Bucharest, Bucharest, Romania

Iulia Romanova, DMS, PhD

Odessa National Medical University "ONMedU”, Odessa,

Ukraine

Periodontology / Oral Microbiology / Dental Hygiene Jon Byron Suzuki, DDS, PhD, MBA, Associate Dean Section Editor-in-Chief

Temple University, Philadelphia, PA, USA

Alina Pürienė, BS, PhD, Dr hábil

Vilnius University, Vilnius, Lithuania

Oral Medicine / Oral Pathology

Mare Saag, DDS, PhD - Section Editor-in-Chief

University of Tartu, Tartu, Estonia

Nikola Petricevic, DMD, PhD

University of Zagreb, Zagreb, Croatia
Occlusion and TMJ / Orofacial Pain / Dental Occlusion and Posture

Noshir R. Mehta, DMD, MDS, MS, Associate Dean -

Section Editor-in-Chief

Tufts University, Boston, MA, USA

Jean-Daniel Orthlieb, DDS, PhD, Vice-Dean

Aix Marseille University, Marseille, France

Orthodontics and Dento-Facial Orthopedics

Alexandru Simion Ogodescu, DDS, PhD, Head

Section Editor-in-Chief

"Victor Babes" University of Medicine and Pharmacy

Timisoara, Timisoara, Romania

Fabrizia d'Apuzzo, DDS, MSc PhD, Research Fellow

University of Campania "Luigi Vanvitelli", Naples, Italy

Anesthesiology / Dentoalveolar Surgery /

Maxillofacial Surgery / Oral Implantology /

Emergencies at the Dentist's

Cristian Niky Cumpătă, DMD, MD, MSc, PhD

Section Editor-in-Chief

"Titu Maiorescu" University Bucharest, Bucharest, Romania

Joel Motta Junior, DMD, PhD

State University of Londrina, Londrina, Brazil

Prosthetic Dentistry / Oral Rehabilitation /

Gerodontology

Anastassia E Kossioni, DDS, PhD

- Section Editor-in-Chief

University of Athens, Athens, Greece

Vygandas Rutkūnas, DDS, PhD

Vilnius University, Vilnius, Lithuania

Restorative Dentistry / Computerized Dental

Prosthetics

Roberto Carlo Spreafico, MD, DMD -

Section Editor-in-Chief

Busto-Arsizio, Milan, Italy

Joannis Katsoulis, DMD, PhD,

University of Bern, Bern, Switzerland

Community Dentistry / Oral Epidemiology / Oral Health / Dental Public Health / Health Promotion Aldo Fabián Squassi, DDS, PhD, Chair

- Section Editor-in-Chief

University of Buenos Aires, Buenos Aires, Argentina

Mihnea loan Nicolescu, DMD, MD, PhD

"Carol Davila" University of Medicine and Pharmacy Bucharest, Bucharest, Romania

EDITORIAL ADVISORY BOARD SECTIONS Stephen F. Rosenstiel, BDS, MSD, Prof. Em.

Editor-in-Chief

Basic Research / Dental Materials / Dental Technology

Nicoleta llie, Dipl-Eng, PhD - Section Editor-in-Chief

Ludwig-Maximilians-Universität München, München, Germany

Bogdan Calenic, DDS, PhD

"Carol Davila" University of Medicine and Pharmacy Bucharest,

Bucharest, Romania

Andrei Cristian Ionescu, DDS, PhD

University of Milan, Milan, Italy

Nikolay Ishkitiev, DMD, PhD

Medical University of Sofia, Sofia, Bulgaria

Clinical Research / Oral and Dental Diagnosis /

Dental Radiology / Evidence-Based Dentistry

Rodolfo Isaac Miralles Lozano, MD, PhD

- Section Editor-in-Chief

University of Chile, Santiago, Chile

Cristina Teodora Preoteasa, DMD, PhD

"Carol Davila" University of Medicine and Pharmacy Bucharest,

Bucharest, Romania

Robert Sabiniu Serban, Eng, PhD, MS

"Carol Davila" University of Medicine and Pharmacy Bucharest,

Bucharest, Romania

Sorin Uram-Ṭuculescu, DDS, PhD

Virginia Commonwealth University, Richmond, VA, USA

Community Dentistry / Oral Epidemiology / Oral

Health / Dental Public Health / Health Promotion Amar Hassan Khamis Mohamed Omer, PhD, DEA, MSc, BSc

- Section Editor-in-Chief

Mohammed Bin Rashid University of Medicine and Health

Sciences, Dubai, UAE

Rayleigh Ping-Ying Chiang, MD, MMS

Taipei Veterans General Hospital, Taipei, Taiwan

Nina Mussurlieva, DDS, PhD

Medical University of Plovdiv, Plovdiv, Bulgaria
Mihaela Răescu, DDS, PhD

"Titu Maiorescu" University, Bucharest, Romania

Cariology / Pedodontics / Oro-Dental Prevention Vlademir Margvelashvili, MD, PhD, DMSci -

Section Editor-in-Chief

Tbilisi State University, Tbilisi, Georgia

Dorjan Hysi, DDS, PhD

University of Medicine of Tirana, Tirana, Albania

Rodica Luca, DDS, PhD

"Carol Davila" University of Medicine and Pharmacy Bucharest, Bucharest, Romania

Tamara Tserakhava, DDS, PhD

Belarusian State Medical University, Minsk, Belarus

Minimally Invasive Dentistry / Dental Lase

Domenico Massironi, DDS-Section Editor-in-Chief

MEG - Master Educational Group, Melegnano (MI), Italy

Claudia Maria de Felicio, MD, PhD

Universidade de São Paulo (USP) Ribeirão Preto, Brazil

Joanna Kempler, DDS, PhD

University of Maryland, Baltimore, MD, USA

Enrico Manca, DDS, PhD

Dental Clinic Dr. Enrico Manca, Cagliari, Italy

Aestethic Dentistry / Dental Photography

Bernard Touati, DDS, PhD - Section Editor-in-Chief

Paris V University, Paris, France

John C. Kois, DMD, MSD

Kois Center, LLC, Seattle, WA, USA

Nissan Joseph, DMD

Tel Aviv University, Tel Aviv, Israe

Sanda-Mihaela Popescu, DDS, MSC, PhD

University of Medicine and Pharmacy of Craiova,

Craiova, Romania

Periodontology / Oral Microbiology / Dental Hygiene Radmila R. Obradović, DDS, PhD-

Section Editor-in-Chief

University of Niš, Niš, Serbia

Petr Bartak, DDS Charles

University in Prague, Prague, Czech Republic

Gabriela Băncescu, MD, MSc, PhD

"Carol Davila", University of Medicine and Pharmacy Bucharest,

Bucharest, Romania

Marian Neguț, MD, PhD, Acad (ASM)

"Carol Davila", University of Medicine and Pharmacy Bucharest,

Bucharest, Romania

Oral Medicine / Oral Pathology

Asja Celebić, DDS, MSc, PhD -

Section Editor-in-Chief

University of Zagreb, Zagreb, Croatia

Romeo Călărașu, MD, PhD, Acad (ASM)

"Carol Davila", University of Medicine and Pharmacy Bucharest,

Bucharest, Romania

Ingrìda Čèma, DDS, PhD

Riga Stradins University, Riga, Latvi

Valeriu Fala, DM, PhD, MSC

"Nicolae Testemițanu" State University of Medicine and Pharmacy,

Chişinău, Republic of Moldova

Occlusion and TMJ / Orofacial Pain /

Dental Occlusion and Posture

Marcus Oliver Ahlers, DDS, PhD

Section Editor-in-Chief

Hamburg University Eppendorf, Hamburg, Germany

Minh Son Nguyen, DDS, PhD, Head

Danang University of Medical Technology and Pharmacy,

Danang, Vietnam

Sever Toma Popa, DDS, PhD

"Iuliu Hațieganu" University of Medicine and Pharmacy, ClujNapoca, Romania

Gregor Slavicek, DDS, PhD

Steinbeis University Berlin, Berlin, Germany

Orthodontics and Dento-Facial Orthopedics

Mariana Păcurar, DDS, PhD -

Section Editor-in-Chief

University of Medicine and Pharmacy, Târgu Mures, Romania

Fabio Savastano, MD, MOrth

Jaume I University, Castellón de la Plana, Castellón, Spain

Elina Teodorescu, DMD, PhD

"Carol Davila" University of Medicine and Pharmacy Bucharest,

Bucharest, Romania

Irina Nicoleta Zetu, DDS, PhD

"Gr. T. Popa" University of Medicine and Pharmacy,

lasi, Romania 
Anesthesiology / Dentoalveolar Surgery /

Maxillofacial Surgery / Oral Implantology /

Emergencies at the Dentist's

Nardi Casap-Caspi, DMD, MD - Section Editor-in-Chie

Hebrew University Hadassah Jerusalem, Jerusalem, Israel

Andrezza Lauria de Moura, DMD, PhD

Federal University of Amazonas (FAO-UFAM)

Manaus - AM, Brazil

Marius Steigmann, DDS, PhD

Steigmann Implant Institute, Neckargemund, Germany

Gianluca Martino Tartaglia, DDS, PhD

University of Milan, Milan, Italy

Prosthetic Dentistry / Oral Rehabilitation /

Gerodontology

Elena Preoteasa, DDS, PhD - Section Editor-in-Chief

"Carol Davila" University of Medicine and Pharmacy

Bucharest, Bucharest, Romania

Emilian Hutu, DDS, PhD

"Carol Davila" University of Medicine and Pharmacy Bucharest, Bucharest, Romania

Marina Meleșcanu-Imre, DDS, PhD

"Carol Davila" University of Medicine and Pharmacy

Bucharest, Bucharest, Romania

Martina Schmid-Schwap, DDS, PhD

Medical University of Vienna, Vienna, Austria
Restorative Dentistry / Computerized Dental Prosthetics

Stephen F. Rosenstiel, BDS, MSD, Prof. Em.

Section Editor-in-Chief

The Ohio State University, Columbus, USA

Henriette Lerner, DMD, PhD

HL Dentclinic \& Academy, Baden-Baden, Germany

Mariam Margvelashvili-Malament, DDS, MSC, PhD

Tufts University, Boston, MA, USA

Alexandru Eugen Petre, DDS, PhD

"Carol Davila" University of Medicine and Pharmacy

Bucharest, Bucharest, Romania

ENGLISH LANGUAGE EDITOR-IN-CHIEF

Roxana-Cristina Petcu, Phil, PhD, Professor

Faculty of Foreign Languages, University of Bucharest

Bucharest, Romania

ENGLISH LANGUAGE EDITORS

Valeria Clucerescu, Bio.

Diana Florea, Phil, PhD

HONORARY STATISTICAL ADVISERS

Radu Burlacu, PhD, Bucharest, Romania

loan Opriș, PhD, Associate Scientist, Miami, USA
BOOKS REVIEWERS

Iulia Ciolachi, DMD, Bucharest, Romania

Florin-Eugen Constantinescu, DMD, PhD Student

Bucharest, Romania

JOURNAL MANAGER

Ioana Bălan, Maths, MSc, Bucharest, Romania

PROJECT EDITOR

Irina-Adriana Beuran, $\mathrm{DMD}, \mathrm{PhD}$

Faculty of Dental Medicine, "Carol Davila" University of Medicine

and Pharmacy Bucharest, Bucharest, Romania

Alexandra Popa, Holistic Dental \& Medical Institute of Bucharest

- ROPOSTURO, Bucharest, Romania

TECHNICAL EDITORS

Gabriel Octavian Lazar, Bucharest, Romania

Valentin Miroiu, Bucharest, Romania

Edgar Moraru, Bucharest, Romania

DTP / GRAPHIC \& WEB DESIGNER

Valentin Miroiu, Bucharest, Romania

www.miroiu.com

\section{INDEXING DATABASES}
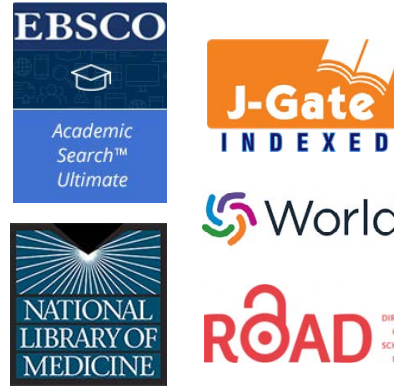

Dimensions KUDOS Crossref

I N D E X E D

II UIVERSITY

5. WorldCat

(a) Scilit

SHERPA

R०MEO Academia, edu

IIIIIIE

INTRRNATIONAL COMMITTFEF OS
MEDICAL JOURNAL EDITORS

ROAD Google publons

INFOBASE INDEX

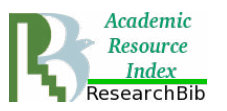

The Stomatology Edu Journal (Stoma Edu J) is a scientific magazine of the Romanian Association of Oral Rehabilitation and Posturotherapy - ROPOSTURO, a partner of the FDI regular member, the Romanian Society of Stomatology - RSS (founded in 1923) under the aegis of The Romanian Academy.

\section{Editor Office}

Stomatology Edu Journal, 102-104 Mihai Eminescu st.

$2^{\text {nd }}$ District, RO-020082 Bucharest, ROMANIA

Tel/Fax: +40314327930

e-mail: stomatology.edu@gmail.com,

www.stomaeduj.com

Editors-in-Chief

Marco Ferrari, Constantinus Politis

Marian-Vladimir Constantinescu

Managing Editor

Florin-Eugen Constantinescu

\section{ROPOSTURO}

Romanian Association of Oral Rehabilitation and

Posturotherapy

10, Ionel Perlea St., ${ }^{\text {st }}$ District

R0-010209 Bucharest, Romania

Tel: +4021314 1062; Fax: +40213121357

e-mail: roposturo@gmail.com

www.roposturo.ro

Technical Editors

Gabriel Octavian Lazar, Valentin Miroiu

Edgar Moraru

Project Editor

Irina-Adriana Beuran

Design Editor

Dragoș Georgian Guțoi

Cover by

Arch. Florin Adamescu

\section{Publisher Office}

Romanian Academy Publishing House

Calea 13 Septembrie, ${ }^{\text {th }}$ District

R0-050711 Bucharest, Romania

Tel: +40213188146

$\mathrm{Fax}+40213182444$

e-mail: edacad@ear.ro

www.ear.ro

Technical Editor

Doina Argesanu

Editorial Assistant

Monica Stanciu

Computer Editing

Iolanda Povară 


\section{Annual activity report - measuring the results of the editorial team}

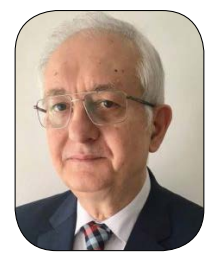

Marian-Vladimir CONSTANTINESCU

DDS, MSc, PhD, Professor

Editor-in-Chief

Dear readers, Dear authors,

Measuring the passage of time is, more often than not, a difficult, challenging occupation. The attempt is all the more interesting as we are looking at a project in which we are totally involved.

Dental professionals in Central and Eastern Europe have limited acccess to listed jourals in order to publish their research so as improve their academic standing, and this motivated and determined me to create a new specialized journal.

In the academic environment, more than 1.8 million dentists worldwide ${ }^{1}$ come from 13,711 higher education institutions (WHO, 2019) ${ }^{2}$ and there are 20,164 titles for oral science, 1,630 titles for oral health and 155 titles in the DENTISTRY category, as well as in ORAL SURGERY \& MEDICINE, listed in the Master Journal List (Web of Science, 2020) ${ }^{3}$.

Let's go through the evolution of the Stomatology Edu Journal (Stoma Edu J) as of the spring of 2013 when we invited Prof. Jean-François Roulet from the University of Florida, USA to take over the coordination of the journal. My request was supported by the fact that he is a renowned researcher and in time has coordinated several such journals as Editor-in-Chief (EiC).

When the first issue of Stoma Edu J was ready, I sent it to be evalauted by the EiC who certifies the quality of the publication, Prof. J-F. Roulet. Each article went through the double-blind review process. That is, it travelled the following course: strict evaluation by two or more reviewers experts in the field approached by the article; the manuscript modified by the authors as a result of the reviewers' recommendations went through the language proofreading by our specialized editor, interpreter and translator certified by the European Institutions, Prof. Roxana Cristina Petcu. The linguistically corrected WORD document is formatted in PDF. The PDF form of the journal is submitted for analysis and final proofreading to the EiC, responsible for the quality of the publication.

The answer I got was, as always, very kind and to the point with reference to each document.

There came a difficult exercise with seven rounds of proofreading, but we finally managed to get some signal copies to be presented to colleagues participating in the 101st FDI Annual World Dental Congress, 28-31 August 2013, Istanbul, Turkey.

After attending a lecture delivered by Prof. Anton Sculean from the University of Bern, I presented him with the journal. He immediately noticed the abstract both in Romanian and English. After expressing his support and acceptance to be a member of the Editorial Board of the journal, he recommended that for it to be successfull, we must delete the Romanian version of the abstract. It was very difficult for me to accept this decision to delete that part in the language of our national poet, Mihai Eminescu.

This editorial process was followed rigorously and consistently to complete each issue until December 2018. Then, making use of his own personal resources, Prof. J-F. Roulet decided to introduce the Manuscript Manager platform (www.manuscriptmanager.com) ${ }^{4}$ in the Stoma Edu J's editorial process. Thus, as of the 2019 first issue of 2019, it was this platform that managed the submission of the manuscripts and all the peerreview process until all the manuscripts were accepted for publication, ie via "transparency in peer review" 
All manuscripts of journals published by Quintessence Publishing, Wiley, Thieme and other recognized publishers use this platform, so over 250 academic journals all over the world.

From the very beginning, since we started publishing the Stoma Edu J, I have aimed towards high standards of quality, attracting articles, performing the final proofreading and the timely publication of each issue. In October 2019, due to the delayed peer-review process, I was notified by Prof. J-F. Roulet and Prof. N. Ilie that the first 2020 issue to be published on March 31 could only be published at the beginning of June 2020 . Given the situation, I wrote a letter to all the Stoma Edu J editors asking if a correct peer-review process could be performed in only 2-3 weeks and NOT 3 months. My approach was justified by the practice of IEEE Access, a journal that requests a review in only 7 days, a request to which I have repeatedly responded. Most respondents confirmed that a correct process can be completed in 2-3 weeks.

Following my last intervention, In November 2019, Prof. J-F. Roulet and Prof. N. llie sent me a common letter, warning me that as a result of my constant pressure to publish the latest issues with their extreme efforts, they jointly decided to withdraw from the management of the platform.

In view of the timely publication of the first 2020 issue, I consulted my good friend, the famous oro-maxillofacial surgeon Prof. Constantinus Politis of the University of Leuven, Belgium to find a realistic solution to manage the editorial managerial crisis. Therfore, we decided to restructure the Editor-in-Chiefs' team. First, for his exceptional merits and venerable age, we decided that Prof. Rolf Ewers of the Medical University of Vienna, Austria, should enhance the Senior Editors' team.

Against this backdrop, Prof. Constantinus Politis accepted the vacant position of Editor-in-Chief. Following my repeated requests addressed to my good friend, the oro-maxillo-facial surgeon, Prof. Gavriel Chaushu of Tel Aviv University, Israel, he generously agreed to take up the decisive position of administrator of the Manuscript Manager platform.

For her merits as a researcher in the field of dental biomaterials, Prof. Mutlu Özcan from the University of Zürich, Switzerland completed the team of Co-Editors-in-Chief (Europe). We still had to fill the position of $\mathrm{EiC}$ with notable skills in restorative dentistry, dental materials and in managing the quality of a specialized journal. Together with Prof. Constantinus Politis, we approached all the academic staff at the University of Leuven, Belgium, then, for more than three months, we contacted various other experts worldwide, but without any concrete results.

At the end of this investigation, I remembered Prof. Marco Ferrari, Dean of the University of Siena, Italy, whose conference I attended during the 106th edition of the FDI World Dental Congress in Buenos Aires, Argentina, 5-8 September 2018. Following my warm invitation to accept the position of EiC and due to the perseverance of my friend Prof. Letizia Perillo, Dean at the University of Campania Luigi Vanvitelli, Naples, Italy, Prof. Marco Ferrari agreed to take over the scientific coordination of the Stoma Edu J. On June 13, 2018, I registered the Stoma Edu J at Clarivate Analytics to have it evaluated according to the 18 criteria.

The American evaluator appointed to assess our journal left the company after a few months and did not complete the evaluation. Meanwhile, the company has increased its level of exigency to a 24 criteria-based evaluation. Because of a lack of administrative synchronization, we have become the beneficiaries of a 24 criteria-based evaluation!

In April 2020, I received the recommendation that each author should be more visible. That is, each author should mention, in addition to his/her education and degrees, as well as his/her institutional affiliation, his/her e-mail, preferably the institutional one, and the registration in ORCID, ie ORCIDiD. Although all this information is requested by the Manuscript Manager platform, few authors rigorously complete this information. Thus, in order to fill this information gap, we created a table on the research profile of each author. Thus, once the proof is sent for correction and it is approved, the corresponding author is requested to fill in this table. Such information allows the reader of each article to better know the scientific contribution of each author.

In November 2020, the evaluator Clarivate Analytics informed us that the Stoma Edu J was still under evaluation, and would receive the evaluation only after Clarivate Analytics had completed the still pending updating of the listed journals. With a complete team, in a more dynamic formula, in 2020 we decided to certify the quality of our publication. The subsequent evolution of the Stoma Edu J comes to contradict Umberto Eco's statement in The Name of the Rose: "After so many years even the fire of passion dies, and with it what was believed the light of truth". First, as shown by the current practice of certified and listed journals, we managed to have each document presented in three variants, JATS-XML, HTML and PDF. Valentin Miroiu, our technical editor, started doing it with the third 2020 issue, going backwards to the first 2018 issue, when the registration was made with Clarivate Analytics.

As a result of the determined, energetic and active involvement of the platform administrator, Prof. Gavriel Chaushu, we would like to mention that, remarkably, each 2020 issue was published before the deadline, 
while also having the DOls activated by Crossref. The new team of Editor-in-Chiefs comes before you, the readers, with a series of achievements. First of all, after 5 years of evaluation, we managed, on May 5, 2020, to conclude an Amendment to License Agreement with President Tim Collins of EBSCO Publishing, Inc. We don't know if this is an achievement for you, authors and readers, but for us it certainly meant an important stage on the Stoma Edu J's roadmap.

I'm sure that for the subsequent listing of the journal, it may not be a top achievement, but for us it means was areal achievement to enter an Amendment with the President of a Publishing House that has more than 3,250 employees and annual sales of more than two billion dollars.

The databases for journals like the Stoma Edu J mention under the Dimensions section 375 publications, 168 citations, with a citation mean 0.45, a Google Scholar 130 citations, h-index 6, i10-index 4, and Scilit a total of approximately 257 articles. Since December 2020 the Stoma Edu J has been under evaluation by Scopus and in the re-evaluation procedure at the Directory of Open Access Journals (DOAJ).

Given the very trying times that we are going through, I feel obliged to mention to you the premature death of three friends of the Stoma Edu J, namely Prof. Alexandru Simion Ogodescu, from the "Victor Babes" University of Medicine and Pharmacy Timisoara, Romania, Editor-in-Chief of the Orthodontics and DentoFacial Section, Dr. loan Opriș Associate Scientist, University of Miami, USA, as Honorary Statistical Adviser, and Acad. Alexandru Surdu, President of the Philosophical, Theological, Psychological and Pedagogical Sciences Section, Director of the Institute of Philosophy and Psychology "Constantin Rădulescu-Motru" of the Romanian Academy, a prominent figure in the Romanian philosophy and culture.

On behalf of the Executive Editorial Board of the Stoma Edu J, please allow me to wish you and your loved ones a blessed Christmas, a happy New Year and to fully enjoy peace, health, well-being and joy in your homes.

Sincerely yours,

Marian-Vladimir Constantinescu ${ }^{\circ}$

Editor-in-Chief

\section{References}

1. https://apps.who.int/gho/data/node.main.HWF

2. https://www.who.int/research-observatory/monitoring/inputs/WHED/en/

3. https://mjl.clarivate.com/search-results

4. https://manuscriptmanager.com/

5. Roulet JF. Transparency in peer review. Stoma Edu J. 2019; 6 (1): 4. 


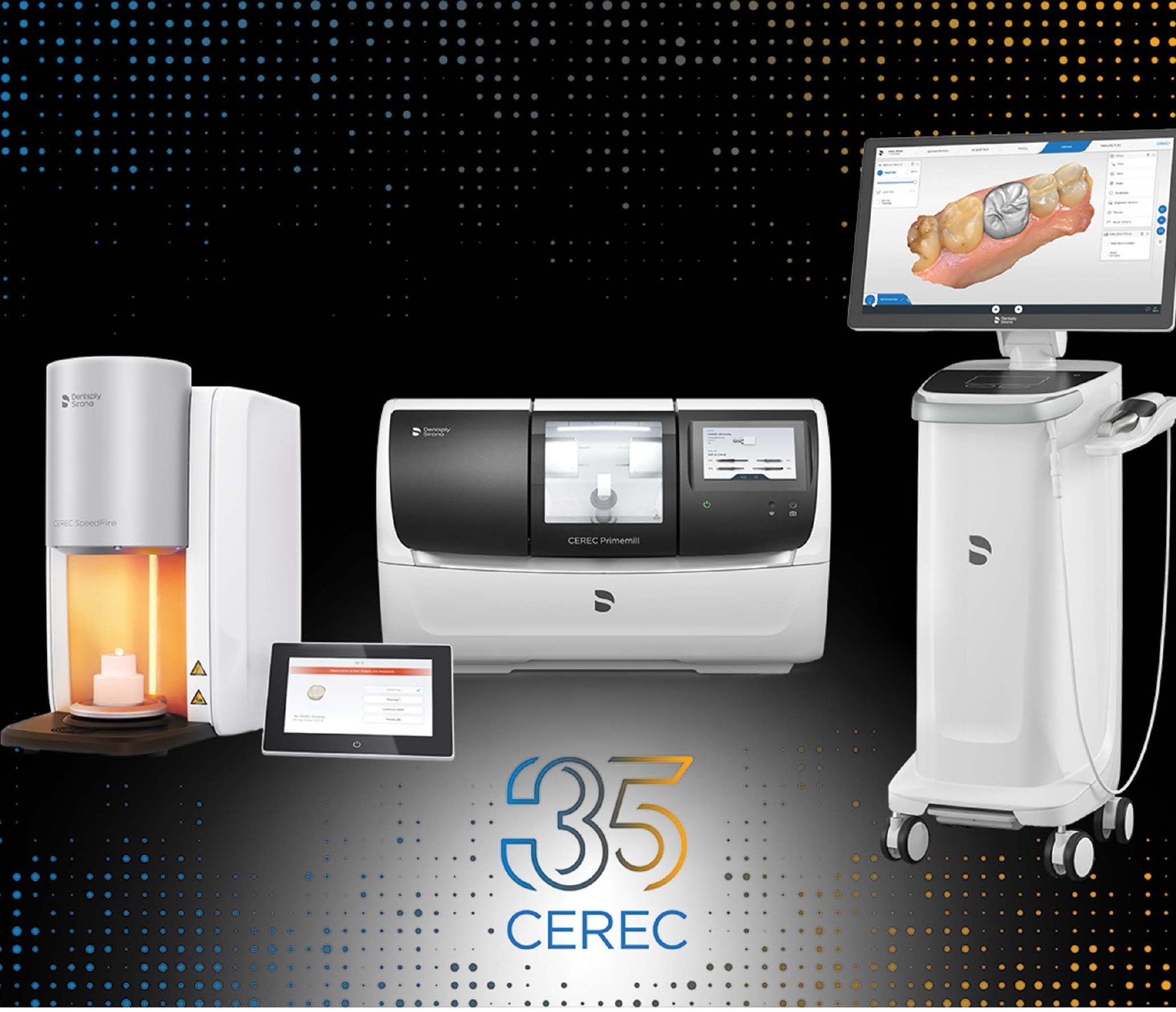

\section{We are celebrating a first-class anniversary with 35 years of CEREC}

Back in 1985 when CEREC was launched it marked the beginning of digitalization in dentistry. Today, with CEREC Primescan, our innovative intraoral scanner, CEREC Primemill, our newest milling and grinding unit, our latest CEREC Software and with the CEREC SpeedFire, Dentsply Sirona is offering dental professionals a world-class chairside system. The all-new CEREC enables dentists to offer patients an unmatched combination of single-visit dentistry and excellent quality. 


\section{stomacdij}

Stoma Edu J. 2020;7(4):231

From The Journal of the American Dental Association

CE Online JADA ONLINE CE EXAMS

http://jada.ada.org/ce/home

http://jada.ada.org/ceworksheets

October 01,2020

K. Brandon Johnson, MS / John B. Ludlow, DDS, MS, FDS RCSEd

\section{INTRAORAL RADIOGRAPHS}

A COMPARISON OF DOSE AND RISK REDUCTION WITH COLLIMATION AND THYROID SHIELDIN

J Am Dent Assoc. 2020 October 01, 151 (10): 726-734. Doi: 10.1016/j.adaj.2020.06.019

https://jada.ada.org/article/S0002-8177(20)30450-5/fulltext

This article has an accompanying online continuing education activity available at:

http://jada.ada.org/ce/home.

DOI: https://doi.org/10.1016/j.adaj.2020.06.019

Copyright $\odot 2020$ American Dental Association. Published by Elsevier Inc. All rights reserved.

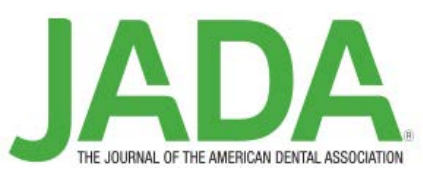




\section{Get rid of your old matrix system. \\ Try now the new \\ Circumferential Matrix \\ System - Palodent ${ }^{\circledR} 360$.}

TT



(NE) Palodent ${ }^{\circledR} 360$

Circumferential Matrix System

Place. Twist. Done. A twist of your fingers is all it takes to achieve tight contacts with anatomically natural contours. No more struggling with an awkward retainer or applicator. No more obstructions to your view or working space. For better restorations, faster and easier than you ever thought possible, Palodent ${ }^{\circledast} 360$ Matrix System. Success comes full circle.

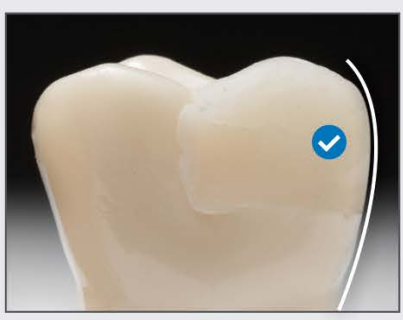

Proper interproximal contours achieved with a Palodent ${ }^{\circ} 360$ matrix system

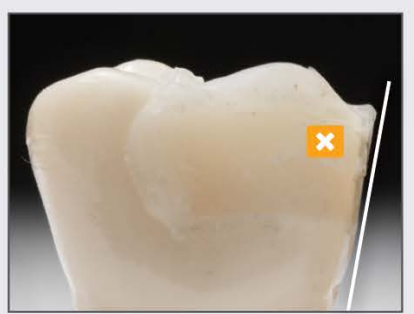

Poor interproximal contours achieved with a classic matrix system 


\title{
THE MICRO-SHEAR BOND STRENGTH OF TWO DIFFERENT REPAIR SYSTEMS TO INDIRECT RESTORATIVE MATERIALS
}

 \\ 'Department of Prosthodontics, Faculty of Dentistry, Altinbaș University, TR-34147, Bakrrkoy/Istanbul, Turkey \\ 2Department of Prosthodontics, Faculty of Dentistry, Istanbul Aydin University, TR-34295, Kucukcekmece//stanbul, Turkey \\ 3Private Clinic, TR-34147, Bakrrkoy/lstanbul, Turkey \\ aDDS, PhD, Assistant Professor; e-mail: ayse.atay@altinbas.edu.tr; ORCIDiD: https:///orcid.org/0000-0002-5358-0753 \\ 'DDS, Lecturer; e-mail: lamia.najaf@gmail.com; ORCIDiD: https://orcid.org/0000-0001-6900-8308 \\ 'DDS, PhD; e-mail:h_kurtulmus@yahoo.com;ORCIDiD: https://orcid.org/0000-0001-5013-3766 \\ ${ }^{d} D D S$, PhD; e-mail: asli_u@hotmail.com; ORCIDiD: https://orcid.org/0000-0002-7222-7322
}

Introduction The aim of this study was to evaluate the micro-shear bond strength ( $\mu \mathrm{SBS}$ ) of different repair systems (Clearfil Repair, iGOS Repair) to restorative materials for CAD/CAM (Cerasmart, Lava Ultimate, InCoris TZI , VITA Suprinity, VITA Mark II, IPS e.max CAD, IPS Empress CAD).

Methodology The 1401.2 mm-thick specimens were prepared from CAD/CAM blocks $(n=20)$ and thermocycled $\left(10,000\right.$ cycles, $5-55^{\circ} \mathrm{C}$, dwell time $\left.20 \mathrm{~s}\right)$. The specimens were randomly divided into two groups according to the repair system: Clearfil Repair (40\% phosphoric acid+mixture of Clearfil Porcelain Bond Activator and Clearfil SE Bond Primer+Clearfil SE Bond+CLEARFIL MAJESTY ES-2) and iGOS Repair (40\% phosphoric acid+ Multi Primer LIQUID+ iGOS Bond+ iGOS Universal). The composite resins were polymerized. All specimens were stored in distilled water at $37^{\circ} \mathrm{C}$ for 24 hours. The $\mu \mathrm{SBS}$ test was performed with a micro-shear testing machine (at $1 \mathrm{~mm} / \mathrm{min}$ ). The data were analyzed using two-way ANOVA, Tukey's multiple comparison tests at a significance level of $p<0.05$. Each failure modes were examined under a stereomicroscope at $\times 16$ magnification.

Results The type of CAD/CAM restorative material and repair system showed a significant effect on the $\mu$ SBS $(p<0.05)$. Specimens repaired with the iGOS Repair system showed the highest $\mu$ SBS values than the Clearfil Repair system among all tested materials except for the InCoris TZI group $(p<0.05)$.

Conclusion All groups, except for the InCoris TZI group, repaired with iGOS Repair system showed higher $\mu$ SBS than Clearfil Repair. The type of restoration and repair material is important in the success of the fracture repair.

\section{KEYWORDS}

Micro-Shear Bond Strength; Repair System; CAD-CAM Materials; Adhesion; Dental Prosthesis Repair.

\section{INTRODUCTION}

Advances in ceramic materials have enabled the production and application of full ceramic restorations without metal. Especially in the last decade, the development of CAD/CAM systems has provided improvement of full ceramic systems and overcoming some of disadvantages of the restorations which arise from traditional construction technique [1-4].

Nowadays, there are many types of CAD/CAM materials mainly metal alloys, ceramic materials, composite resins, and PMMA's. CAD/CAM ceramic blocks could be feldspathic ceramics, lithium disilicate glass ceramics, yttrium tetragonal zirconia polycrystals or leucite-reinforced glass ceramics.

(c) (1) (2) OPEN ACCESS This is an Open Access article under the CC BY-NC 4.0 license. Peer-Reviewed Article

Citation: Atay A, Najafova L, Kurtulmus HM, Üşümez A. The micro-shear bond strength of two different repair systems to indirect restorative materials. Stoma Edu J. 2020;7(4):233-241.

Received: September 16, 2020; Revised: September 27, 2020; Accepted: October 25, 2020; Published: October 26, 2020

*Corresponding author: Assistant Professor Dr. Ayșe Atay, Department of Prosthodontics, Faculty of Dentistry, Altinbaș University, Incirli Avenue No:11/A, 34147, Bakırkoy, Istanbul, Turkey

Tel.: +90-212-709 45 28, Fax: +90-212-44581 71; e-mail: ayse.atay@altinbas.edu.tr

Copyright: $\odot 2020$ the Editorial Council for the Stomatology Edu Journal. 


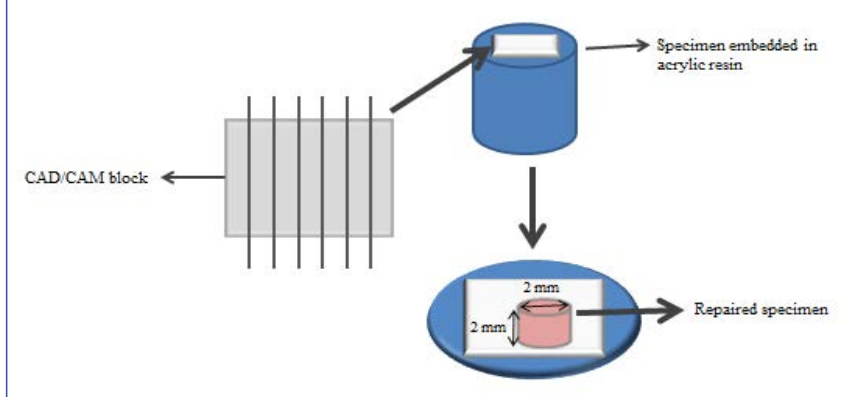

Figure 1. Schematic illustration of specimen preparation

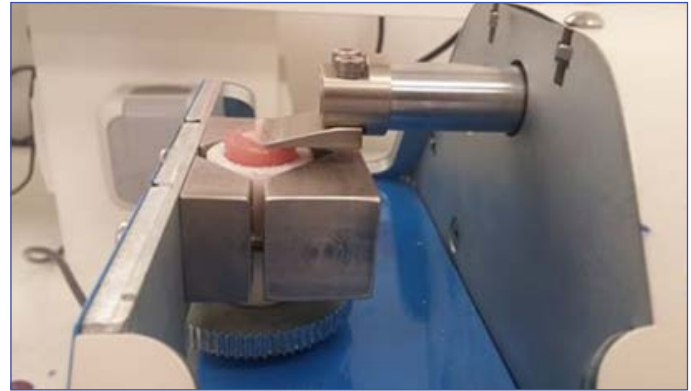

Figure 2. Specimen testing.

ITable 1. Brand names, groups, abbreviations, lot numbers, material types, compositions and manufacturers of the CAD/CAM restorative materials used in the study.

\begin{tabular}{|c|c|c|c|}
\hline Brand Name & Material type & Composition & Manufacturer \\
\hline Cerasmart & Hybrid ceramic & $\begin{array}{l}\text { Matrix: Bis-MEPP, UDMA, DMA } \\
\text { Filler: silica, barium glass nanoparticles (71 wt\%) }\end{array}$ & GC Corp., Tokyo, Japan \\
\hline Lava Ultimate & Resin nano ceramic & $\begin{array}{l}\text { Matrix: Bis-GMA, UDMA, Bis-EMA, TEGDMA } \\
\text { Filler } \mathrm{SiO}_{2^{\prime}} \mathrm{ZrO}_{2^{\prime}} \text { aggregated } \mathrm{ZrO}_{2} / \mathrm{SiO}_{2} \text { cluster } \\
\text { (80wt\%) }\end{array}$ & $\begin{array}{l}\text { 3M ESPE, Seefeld, } \\
\text { Germany }\end{array}$ \\
\hline InCoris TZI & $\begin{array}{l}\text { Zirconium oxide sinter } \\
\text { ceramic }\end{array}$ & $\begin{array}{l}\mathrm{ZrO}_{2}+\mathrm{HfO}_{2}+\mathrm{Y}_{2} \mathrm{O}_{3} \geq 99.0 \%, \mathrm{Y}_{2} \mathrm{O}_{3}>4.5-\leq 6.0 \% \\
\mathrm{HfO}_{2} \leq 5 \% \\
\mathrm{Al}_{2} \mathrm{O}_{3} \leq 0.5 \% \text {, Other oxides } \leq 0.5 \%\end{array}$ & $\begin{array}{l}\text { Sirona Dental Systems } \\
\text { GmbH, Bensheim, } \\
\text { Germany }\end{array}$ \\
\hline VITA Suprinity & $\begin{array}{l}\text { Zirconia-reinforced } \\
\text { lithium silicate ceramic }\end{array}$ & $\begin{array}{l}56-64 \% \mathrm{SiO}_{2}, 15-21 \% \mathrm{Li}_{2} \mathrm{O}, 8-12 \% \mathrm{ZrO}_{2}, 3-8 \% \mathrm{P}_{2} \mathrm{O}_{5^{\prime}} \\
1-4 \% \mathrm{~K}_{2} \mathrm{O}, 0-4 \% \mathrm{CeO}_{2}\end{array}$ & $\begin{array}{l}\text { Vita Zahnfabrik H. Rauter } \\
\text { GmbH, Bad Säckingen, } \\
\text { Germany }\end{array}$ \\
\hline VITA Mark II & Feldspar ceramic & $\begin{array}{l}56-64 \% \mathrm{SiO}_{2^{\prime}}, 20-23 \% \mathrm{Al}_{2} \mathrm{O}_{3^{\prime}} 6-9 \% \mathrm{Na}_{2} \mathrm{O}, 6-8 \% \mathrm{~K}_{2} \mathrm{O}, \\
0.3-0.6 \% \mathrm{CaO}, 0-0.1 \% \mathrm{TiO}_{2}\end{array}$ & $\begin{array}{l}\text { VITA Zahnfabrik, Bad } \\
\text { Säckingen, Germany }\end{array}$ \\
\hline IPS e.max CAD & $\begin{array}{l}\text { Lithium disilicate glass- } \\
\text { ceramic }\end{array}$ & $\begin{array}{l}57-80 \% \mathrm{SiO}_{2^{\prime}}, 11-19 \% \mathrm{Li}_{2} \mathrm{O}, 0-13 \% \mathrm{~K}_{2} \mathrm{O}, 0-11 \% \mathrm{P}_{2} \mathrm{O}_{5^{\prime}} \\
0-8 \% \mathrm{ZrO}_{2^{\prime}} 0-8 \% \mathrm{ZnO}, 0-5 \% \mathrm{Al}_{2} \mathrm{O}_{3} \mathrm{O}-5 \% \mathrm{MgO}, 0-8 \% \\
\text { Colouring oxides }\end{array}$ & $\begin{array}{l}\text { Ivoclar Vivadent, Schaan, } \\
\text { Liechtenstein }\end{array}$ \\
\hline IPS Empress CAD & $\begin{array}{l}\text { Leucite-reinforced glass } \\
\text { ceramic }\end{array}$ & $\begin{array}{l}60-65 \% \mathrm{SiO}_{2}, 16-20 \% \mathrm{Al}_{2} \mathrm{O}_{3^{\prime}}, 10-14 \% \mathrm{~K}_{2} \mathrm{O}, 3.5-6.5 \% \\
\mathrm{Na}_{2} \mathrm{O}, 0.5-7 \% \text { Other oxides, } 0.2-1 \% \text { Pigments }\end{array}$ & $\begin{array}{l}\text { Ivoclar Vivadent, Schaan, } \\
\text { Liechtenstein }\end{array}$ \\
\hline
\end{tabular}

Abbreviations: Bis-MEPP: 2,2-Bis(4- methacryloxypolyethoxyphenyl) propane; UDMA: urethane dimethacrylate; DMA: dimethacrylate; Bis-GMA: bisphenol A-glycidyl methacrylate; Bis-EMA: ethoxylated bisphenol A-glycol dimethacrylate; TEGDMA: triethylene glycol dimethacrylate; $\mathrm{SiO}_{2}$ : silicon dioxide; $\mathrm{ZrO}_{2}$ : zirconium dioxide; $\mathrm{HfO}_{2}$ : hafnium dioxide, $\mathrm{Y}_{2} \mathrm{O}_{3}$ :yttrium Oxide; $\mathrm{Al}_{2} \mathrm{O}_{3}$ : aluminium oxide; $\mathrm{Li}_{2} \mathrm{O}$ : lithium oxide; $\mathrm{P}_{2} \mathrm{O}_{5}$ : phosphorus pentoxide, $\mathrm{K}_{2} \mathrm{O}$ : potassium oxide; $\mathrm{CeO}_{2}$ : cerium oxide; $\mathrm{CaO}$ : calcium oxide; $\mathrm{TiO}_{2}$ : titanium dioxide; $\mathrm{ZnO}$ : zinc oxide; $\mathrm{MgO}$ : magnesium oxide; $\mathrm{Na}_{2} \mathrm{O}$ : sodium oxide.

In addition to these materials, polymer-infiltrated ceramics, nano-particulate resin composite and zirconia-reinforced lithium silicate ceramics have been recently introduced for CAD/CAM use [5].

It is stated that various factors such as failure on the bonding interface, parafunctional habits, internal stress, and inadequate occlusal adjustment can cause failure in spite of improvementsinCAD/CAM materials [6]. In addition to these, chipping is shown as the most common cause of failure due to the brittleness properties of some ceramics $[7,8]$. The fracture rates of restorations are reported approximately $2-16 \%$, and $75 \%$ in the maxilla $[9,10]$. These fractures are classified as cohesive (within repair system or the restorative material), adhesive (between the repair system and restorative material), and mixed (both cohesive and adhesive) [11]. The decision to repair or replace the fracture restoration is based on many factors such as fracture type, material properties and cost $[12,13]$. However, the studies which have revealed higher survival rates when restorations repaired with repair kits compared to replacement of restorations should be considered [14,15]. Today, the repair of ceramic restorations is divided into two as direct (oral repair) and indirect repair (extraoral repair). Indirect repair is not preferred by clinicians because of additional trauma to the restoration and soft tissue [16]. When resin-based cements are used for a full-ceramic cementation protocol, an intraoral repair system should be preferred on account of the difficulty of restoration removal [17]. Repairing a ceramic fracture with composite resin is more conservative, less time consuming, easier and less costly than the complete replacement of the restoration [18]. A number of surface conditioning methods are proposed for restorations to increase bond strength with resin composites. However, there is still no standard protocol for ceramic 
ITable 2. Brand names, chemical compositions and manufacturers of the repair systems used in the study.

\begin{tabular}{|c|c|c|}
\hline Brand & Chemical composition & Manufacturer \\
\hline \multicolumn{3}{|l|}{ Clearfil Repair } \\
\hline Clearfil SE Bond Primer & $\begin{array}{l}\text { MDP, HEMA, dimethacrylate monomer, water, } \\
\text { photoinitator }\end{array}$ & Kuraray, Okayama, Japan \\
\hline $\begin{array}{l}\text { Clearfil Porcelain Bond } \\
\text { Activator }\end{array}$ & Bisphenol a polyethoxy dimethacrylate, MPS & \\
\hline Clearfil SE Bond Bond & Silanated colloidal silica bisphenol A & \\
\hline CLEARFIL MAJESTY ES-2 & $\begin{array}{l}0.37-1.5 \mu \mathrm{m} \text { silanated barium glass filler, } \\
\text { prepolymerized organic filler, BisGMA, hydrophobic } \\
\text { aromatic dimethacrylate, dl-camphorquinone, } \\
\text { accelerators, initiators, pigments, } 78 \% \text { wt filled }\end{array}$ & \\
\hline \multicolumn{3}{|l|}{ iGOS Repair } \\
\hline Multi Primer LIQUID & Ethanol, thiol compound, silane coupling agent & Yamakin CO., LTD., Kochi, Japan \\
\hline iGOS Bond & $\begin{array}{l}\text { ethanol, distillated water, methacrylate monomer, } \\
\text { phosphate monomer, carboxylic monomer, } \\
\text { photopolymerization initiator, etc. }\end{array}$ & \\
\hline iGOS Universal & $\begin{array}{l}\text { Methacrylate monomer, ceramics cluster filler (1-20 } \\
\mu \mathrm{m}) \text {, submicron filler }\left(\mathrm{SiO}_{2}-\mathrm{ZrO}_{2}-\mathrm{Al}_{2} \mathrm{O}_{3}: 200-600 \mathrm{~nm}\right) \text {, } \\
\text { spherical nano-filler }\left(\mathrm{SiO}_{2}: 20 \mathrm{~nm}\right) \text {, fluoride sustained } \\
\text { release filler (glass: } 700 \mathrm{~nm}) \text {, inorganic filler content rate } \\
\text { approximately } 55 \mathrm{vol} \%\end{array}$ & \\
\hline
\end{tabular}

Abbreviations: MDP: 10-Methacryloyloxydecyl dihydrogen phosphate, HEMA: 2-hydroxyethyl methacrylate, MPS: 3- metacryloxypropyl trimethoxysilane, Bis-GMA: bisphenol A-glycidyl methacrylate, SiO2: silicon dioxide, ZrO2: zirconium dioxide, Al2O3: aluminium oxide. .

repair systems [19]. Micromechanical retention and chemical bonding procedures are necessary to increase the bonding strength between the ceramic and resin composite. Mechanical surface treatments provide micromechanical locking by creating micro roughness at the ceramic surface [20]. Hydrofluoric acid (HF) is the most commonly used chemical agent for roughening the porcelain surface. The other micromechanical bonding procedures include airborne particle abrasion by using aluminum oxide, tribochemical silica coating, or laser etching $[21,22]$. Sandblasting with $\mathrm{Al}_{2} \mathrm{O}_{3}$ particles increase the efficiency of the porcelain surface and the resin composite-porcelain bond strength. The application of silane increases the wettability of the ceramic and support the bond between the silica (inorganic phase) in the restorative materials and the methacrylate groups (organic phase) in the resin with Met-methacryloxypropyl trimethoxysilane (MPS) in its content [23-25].

The aim of this study was to investigate the microshear bond strength ( $\mu \mathrm{SBS})$ of two different repair systems to seven different types of CAD/CAM restorative materials and the failure types after $\mu$ SBS test. The null hypotheses for this study were: a) There were no differences among the CAD/CAM restorative materials and $b$ ) between two repair systems.

\section{MATERIALS AND METHODS}

The tested CAD/CAM restorative materials and two ceramic repair systems are shown in Table 1 and Table 2. One hundred and forty $1.2 \mathrm{~mm}$-thick specimens were prepared from CAD/CAM blocks using a low-speed diamond saw (Mecatome T180; Presi, Grenoble, France) under water cooling $(n=20)$. VITA Suprinity and IPS e.max CAD discs were crystallized (VITA Suprinity: $840^{\circ} \mathrm{C}$ for 8 minutes, VITA Vacumat 40, VITA Zahnfabrik; IPS e.max CAD: $770^{\circ} \mathrm{C}$ for $5 \mathrm{~min}$, then $850^{\circ} \mathrm{C}$ for $10 \mathrm{~min}$, Ivoclar Vivadent $A G$ ) following the manufacturers' instructions. InCoris TZI discs were sintered for 2 hours at a temperature starting from $25^{\circ} \mathrm{C}$ to $1510^{\circ} \mathrm{C}$ according to the manufacturer's recommendations. Following the thermocycling $(10,000$ thermal cycles between $5^{\circ} \mathrm{C}-55^{\circ} \mathrm{C}$ with dwell and transfer times of 20 seconds, Thermocycler, Esetron Smart Robotechnologies, Ankara, Turkey), all specimens were embedded in a self-cure acrylic resin (Vertex Self Curing; VertexDental, Netherlands) and polished with 400, 800, and $1200 \mathrm{SiC}$ sheets respectively. The specimens of each CAD/CAM materials were randomly divided into two subgroups to constitute the 14 test groups for repair procedure $(n=10)$.

All tested groups were etched using $40 \%$ phosphoric acid (K-ETCHANT Syringe, Kuraray, Osaka, Japan) for 5 seconds, rinsed under a water spray and dried to clean the adhesive surface except for the InCoris TZI specimens, which Isopropyl alcohol was used for the same aim. For the roughening procedure, InCoris TZI, Lava Ultimate and Cerasmart specimens were sandblasted with $50 \mu \mathrm{m} \mathrm{Al} \mathrm{O}_{3}$ at 2.8 bar pressure (Renfert GmbH, Hilzingen, Germany) for 30 seconds at a distance of $10 \mathrm{~mm}$ according to instruments of 
ITable 3. Results of two-way ANOVA.

\begin{tabular}{|c|c|c|c|c|c|}
\hline Source & Type III Sum of Squares & df & Mean Square & F & Sig. \\
\hline Ceramic type & 291.424 & 6 & 48.571 & 38.480 & .001 \\
\hline Repair system & 187.272 & 1 & 187.272 & 148.367 & .001 \\
\hline Ceramic type * Repair system & 294.759 & 6 & 49.126 & 38.921 & .001 \\
\hline
\end{tabular}

ITable 4. Mean and SD values for $\mu$ SBS (MPa).

\begin{tabular}{|l|c|c|}
\hline & Clearfil Repair & iGoS Repair System \\
\hline Cerasmart & $\begin{array}{c}\boldsymbol{\mu} \text { SBS values } \\
\text { (Mean } \pm \text { SD) }\end{array}$ & $\begin{array}{c}\boldsymbol{\mu S B S} \text { values } \\
\text { (Mean } \pm \text { SD) }\end{array}$ \\
\hline Lava Ultimate & $7.41 \pm 0.70^{\mathrm{A}, \text { abc }}$ & $10.06 \pm 0.63^{\mathrm{B}, \mathrm{a}}$ \\
\hline InCoris TZI & $4.66 \pm 0.90^{\mathrm{A}, \mathrm{d}}$ & $7.16 \pm 1.05^{\mathrm{B}, \mathrm{b}}$ \\
\hline VITA Suprinity & $8.69 \pm 1.03^{\mathrm{A}, \mathrm{c}}$ & $4.76 \pm 1.24^{\mathrm{B}, \mathrm{c}}$ \\
\hline VITA Mark II & $8.17 \pm 1.34^{\mathrm{A}, \mathrm{bc}}$ & $12.80 \pm 1.73^{\mathrm{B}, \mathrm{d}}$ \\
\hline IPS e.max CAD & $7.29 \pm 1.05^{\mathrm{A}, \mathrm{abc}}$ & $8.09 \pm 0.75^{\mathrm{A}, \mathrm{b}}$ \\
\hline IPS Empress CAD & $6.95 \pm 1.01^{\mathrm{A}, \mathrm{ab}}$ & $11.60 \pm 1.18^{\mathrm{B}, \mathrm{de}}$ \\
\hline
\end{tabular}

* Capital superscripts correspond 70the same line, lower case superscripts correspond to the same column.

*Significantly different at $p<0.05$.

ITable 5. Failure mode distribution.

\begin{tabular}{|c|c|c|c|c|c|c|c|c|c|}
\hline & \multicolumn{3}{|c|}{ Adhesive (\%) } & \multicolumn{3}{|c|}{ Cohesive (\%) } & \multicolumn{3}{|c|}{ Mixed (\%) } \\
\hline & $\begin{array}{l}\text { Clearfil } \\
\text { Repair }\end{array}$ & $\begin{array}{l}\text { iGOS } \\
\text { Repair }\end{array}$ & $p$ & $\begin{array}{l}\text { Clearfil } \\
\text { Repair }\end{array}$ & $\begin{array}{l}\text { iGOS } \\
\text { Repair }\end{array}$ & $p$ & $\begin{array}{c}\text { Clearfil } \\
\text { Repair Kit }\end{array}$ & $\begin{array}{l}\text { iGOS } \\
\text { Repair }\end{array}$ & $p$ \\
\hline Cerasmart & 40 & 10 & .303 & 0 & 0 & - & 60 & 90 & .303 \\
\hline Lava Ultimate & 50 & 0 & $.002^{*}$ & 0 & 50 & $.002^{*}$ & 50 & 50 & - \\
\hline InCoris TZI & 0 & 90 & $.001 *$ & 30 & 0 & .211 & 70 & 10 & $.001 *$ \\
\hline VITA Suprinity & 20 & 20 & - & 20 & 20 & - & 60 & 60 & - \\
\hline VITA Mark II & 30 & 30 & - & 20 & 0 & .114 & 50 & 70 & .351 \\
\hline IPS e.max CAD & 0 & 0.2 & .114 & 80 & 50 & .138 & 20 & 30 & .603 \\
\hline IPS Empress CAD & 10 & 0 & .292 & 10 & 30 & .248 & 80 & 70 & .603 \\
\hline
\end{tabular}

*Significantly different at $p<0.001$.

repair kit. IPS e.max CAD and VITA Suprinity were etched $60 \mathrm{sec}$, VITA Mark II and IPS Empress CAD were etched $120 \mathrm{sec}$ with $10 \%$ Hydrofluoric acid [2628] (Angelus, Londrina, PR, Brazil) and then rinsed thoroughly under a water spray for 10 seconds, airdried for 10 seconds according to manufacturer's instruction of repair kits. All of the specimens were cleaned by ultrasonic cleaner for $10 \mathrm{~min}$ and air-dried for 10 seconds.

Following the surface conditioning procedures, a transparent polyvinylchloride cylinder with a hole in the center ( $2 \mathrm{~mm}$ diameter and $2 \mathrm{~mm}$ deep) was used for the application of the repair systems to the ceramic surfaces according to the manufacturer's instructions (Fig. 1). The specimens treated with the Clearfil Repair system, the Clearfil SE Bond Primer and the Porcelain Bond Activator were mixed in a 1:1 ratio and applied for 5 seconds. Then, Clearfil SE Bond was applied and light-cured for 10 seconds (Elipar S 10,
3M ESPE, St Paul, MN, USA) $\left(1200 \mathrm{~mW} / \mathrm{cm}^{2}, 430-480\right.$ $\mathrm{nm})$. The specimens treated with iGOS Repair, Multi Primer LIQUID was applied to the specimen surface and allowed to dry for about 60 seconds. Then iGOS Bond applied and light-cured for 10 seconds, then the composite resins were polymerized with the same curing unit for 20s. After polymerization, the transparent polyvinylchloride cylinder was carefully removed using a scalpel. During the experiment time, all specimens were stored in distilled water at $37^{\circ} \mathrm{C}$ for 3 days.

The $\mu \mathrm{SBS}$ test was performed with a microshear testing device (MOD Dental, Esetron Smart Robotechnologies, Ankara, Turkey) at $1 \mathrm{~mm} /$ min crosshead speed using a knife edge-shaped indenter, which was $5 \mathrm{~mm}$ in diameter and $1 \mathrm{~mm}$ away from the ceramic-composite interface, placed between the composite resin and the CAD/CAM restorative material (Fig. 2). A micro-shear load was 
applied until a fracture occurred, and the value was recorded in Newtons (N). The results were expressed in megapascal ( $\mathrm{MPa}$ ) values. Following $\mu \mathrm{SBS}$ test, the failure modes of specimens were examined under a stereomicroscope (Leica M320, Leica Microsystems (Schweiz) AG, Heerbrugg, Switzerland) at $\times 16$ magnifications and recorded as adhesive, cohesive or mix failure type.

\subsection{Statistical analysis}

All statistical analyses were performed using SPSS for Windows (12.0, SPSS Inc, Chicago, IL, USA). The homogeneity of variance and normality of distribution for variables were evaluated by Levene and Shapiro Wilk test, respectively. Two-way ANOVA and Tukey-HSD multiple comparison tests were used for statistical analyses. In all tests, $p<0.05$ was considered as statistically significant.

\section{RESULTS}

\section{1. $\mu S B S$ test}

The two-way ANOVA revealed that the differences among the CAD/CAM restorative material types and the composite repair material types were statistically significant $(p<0.05)$. There were interactions between surface treatments and the materials $(p<0.05)$ (Table 3). The mean $\mu$ SBS test values and differences among the groups are presented in Table 4.

Specimens repaired with the iGOS Repair system showed the highest $\mu$ SBS values as compared to the Clearfil Repair system among all tested materials except for the InCoris TZI group $(p<0.05)$. The Lava Ultimate group showed the lowest $\mu$ SBS values among the materials repaired with the Clearfil Repair system, while the InCoris TZI group showed the lowest $\mu$ SBS test values among the materials repaired with the iGOS Repair system $(p<0.05)$. Regarding the VITA Mark II group, there was no significant difference in the $\mu$ SBS test values between the Clearfil Repair system $(7.29 \pm 1.05 \mathrm{MPa})$ and the iGOS Repair system $(8.09 \pm 0.75 \mathrm{MPa})(\mathrm{p}>0.05)$. The VITA Suprinity group showed the highest $\mu$ SBS values among the other material groups when repaired with the iGOS Repair system $(p<0.05)$. The $\mu S B S$ values were found in the InCoris TZI (8.69 \pm 1.03$),$ VITA Suprinity $(8.17 \pm 1.34)$, Cerasmart (7.41 \pm 0.70$)$ and VITA Mark II (7.29 \pm 1.05$)$ groups repaired with the Clearfil Repair system, respectively, however, there were statistically insignificant differences among them ( $p>0.05)$.

\subsection{Stereomicroscopic analysis}

The failure mode distribution of different repair systems and different CAD/CAM restorative materials are presented in Table 5 . According to the Chi-square Test, significantly different failure types among the tested groups were observed $(p<0.001)$. Adhesive fractures were mostly obtained in the InCoris TZI group repaired with iGOS Repair system while mix failures were mostly obtained in the InCoris TZI group repaired with the Clearfil Repair system. There were significant differences between the iGOS and Clearfil Repair systems for adhesive and cohesive failures in the Lava Ultimate group $(p<0.001)$.

\section{DISCUSSION}

In the current study, the $\mu$ SBS of two different repair systems to CAD/CAM restorative materials were tested. Based on the results, the null hypotheses that types of CAD/CAM restorative materials and different repair systems would not affect the bond strength were rejected. It was observed that the success of the repair system depends on the CAD/ $C A M$ restorative materials.

All CAD/CAM materials tested in this study are prosthetic restoration materials. Fractures may occur in these materials during usage. Direct application of composite resins is a good alternative to extraoral repair techniques because composite resins are easier to apply, and they are low cost materials. Their usage would depend on the cause and grade of the fractures $[29,30]$. When repairing the fracture, a conditioned surface is required to strengthen the adhesion of the repair material to the restoration surface. It is a challenge for the clinician to choose the right option among many repair systems with different conditioning steps. Surface treatments, including acid etching, sandblasting $(50 \mu \mathrm{m}$ $\mathrm{Al}_{2} \mathrm{O}_{3}$ ), application of a universal adhesive (silane containing) and their combinations are commonly used for intraoral repair or cementation of indirect restorations [31-33]. A low viscosity composite may exhibit a larger volumetric shrinkage. At the same time, they have better surface wetting properties which prevent development of defects during repair. Contrarily, resin composites with higher filler content, would have a high modulus of elasticity which causes a lower volumetric shrinkage and a higher shrinkage stress at the restoration-resin interface. This stress would negatively affect the bond strength. Considering these contradictory effects, it is not easy to project on the success of a chosen material [34]. In the present study, two different types of composites were used: 1) Clearfil Majesty ES-2 is a nanohybrid composite and 2) iGOS Universal is a hybrid composite. The compositions of these composite materials were quite different from each other. The fact that these materials have different flexural strength may explain the different $\mu \mathrm{SBS}$ results of the two repair systems [35].

In the present study, CAD/CAM materials were selected based on their conditioning concepts and compositions. Using the sandblasting method, the surface is blasted with aluminum oxide particles to roughen and increase the bonding surface of the restoration material [36]. Sandblasting reinforces wetting with resin, reduces surface tension, and increases the total surface area [11]. During the use of the HF acid for repairing glassy-matrix ceramics, 
the HF acid creates microporosity on the ceramic surface to provide mechanical locking with the resin. Etching of the bonding surface with $\mathrm{HF}$ acid followed by the application of a silane as a coupling agent is a commonly used technique for bonding. It enhances the bond strength of silica-based ceramics [37]. The HF acid acts on the silicone dioxide present in the glass phase [38]. The silane monomer has a bifunctional group called silanol which interacts with the ceramic surface together with a methacrylate group that co-polymerizes with the organic matrix of composite resins [33]. Silane also increases the wettability of the ceramic surface and allows the resin to penetrate deeper into its microscopic pores. This mechanism also reinforces the ceramic-resin bonding [39]. In the current study, only the specimens in the the InCoris TZI, Lava Ultimate and Cerasmart groups were sandblasted with $50 \mu \mathrm{m} \mathrm{Al}_{2} \mathrm{O}_{3}$ at 2.8 bar pressure, while the VITA Suprinity, VITA Mark II , IPS e.max CAD and IPS Empress CAD groups were treated with HF according to the manufacturer's instructions. However, silane, which is available in the repair system, was applied to the surface of all samples after surface treatment. Düzyol et al. [40]. investigated the HF etching mechanism of several restoration materials and they concluded that, alumina crystals in feldspar ceramic, lithium disilicate crystals in lithium disilicate reinforced ceramic and zirconia fillers and resin matrix in resin nano ceramic are structural parts of these materials that were not affected by the acid etching. Lithium disilicate reinforced ceramic contains a lower percentage of glass phase compared to leucite reinforced and feldspar ceramic. Therefore, in our study IPS Empress CAD and VITA Mark II groups were etched with HF acid for 120 seconds, while IPS e.max CAD group was etched for 60 seconds. Previous studies stated that lithium disilicate reinforced glass ceramic presented higher microtensile bond strength ( $\mu \mathrm{TBS}$ ) compared to feldspatic ceramic and leucite reinforced glass ceramic [40-42]. In the current study, there was no significant difference in bond strength values among the VITA Mark II, IPS e.max CAD and the IPS Empress CAD groups repaired with the Clearfil system. However, the VITA Mark II group repaired with iGOS showed significantly lower $\mu$ SBS compared to the IPS e.max CAD and IPS Empress CAD groups. KarCI et al. [43] investigated SBS of different repair systems to IPS e.max CAD and IPS Empress CAD. They found that the SBS values of the IPS Empress CAD are higher than those for the IPS e.max CAD. On the contrary, in the present study, there was no significant difference between the $\mu$ SBS values of IPS e.max CAD and IPS Empress CAD groups. Üstün et al. [44] stated that the Vita Suprinity group presented lower bond strength values than the other groups (Vita Enamic, IPS e.max CAD, Lava Ultimate) subjected to HF etching because the zirconia-reinforced lithium silicate ceramic group contains $8-12 \% \mathrm{ZrO}_{2}$ by weight. However, in the current study, the $\mu$ SBS values of the VITA Suprinity group repaired with two repair systems showed no significant difference in bond strength compared to the IPS e.max CAD subjected to HF etching. We assume that after silanization, the zirconia content of VITA Suprinity might become more active for bonding and this may positively affect the $\mu$ SBS values of VITA Suprinity. For the iGOS Repair system, the $\mu$ SBS values of all groups were significantly higher compared to the Clearfil repair system except for the InCoris TZI and the VITA Mark II materials. High filler content, homogenization technology and diversity of functional monomers included in the iGOS system might contribute to the adhesive strength of this system [35].

The tested InCoris TZI group repaired with Clearfil showed higher bond strength values than the iGOS group. This should be a result of 10-methacryloyloxydecyl dihydrogen phosphate (MDP) content in the Clearfil SE Bond. MDP containing primers form a chemical bond between resin cements and ceramics [45]. This chemical bond is formed between the hydroxyl groups of zirconia and phosphate ester monomers of MDP [46]. Blatz et al. [47] investigated the effect of $\mathrm{Al}_{2} \mathrm{O}_{3}$ sandblasting on bond strength between zirconia ceramics and self-adhesive resin cements. The sandblasted specimens presented higher bond strength values compared to the groups without sandblasting. The bond strength of MDP containing resin cements was also significantly higher than the other groups.

Previous studies show that low bond strength values are associated with adhesive failures [48,49]. Stawarczyk et al. [34] investigated the tensile bond strength values of resin nano ceramic (Lava Ultimate) specimens which presented mostly cohesive failures. While Üstün et al. [44] reported that the Lava Ultimate and Vita Enamic specimens showed only cohesive failures in their study. In the present study, hybrid ceramic, the Cerasmart group did not show any cohesive failures. The Lava Ultimate group repaired with the iGOS Repair system showed higher $\mu$ SBS values than the Clearfil Repair system which showed no adhesive failure $(0 \%)$ and the fractures were cohesive (50\%) or mixed (50\%). Adhesive fractures were mostly obtained in the InCoris TZI groups repaired with the iGOS Repair system which indicates that the bonding interface was weaker than Clearfil Repair. No adhesive failure was observed in the InCoris TZI material repaired with the Clearfil Repair system. Üstün et al. [44] investigated the SBS of different repair systems (Ceramic Repair and Clearfil repair) to CAD/CAM restorative materials (Vita Suprinity, Lava Ultimate, IPS e.max CAD, and Vita Enamic) and revealed complete adhesive failure in the Vita Suprinity and IPS e.max CAD groups repaired with Clearfil Repair. On the contrary, in the present study, the VITA Suprinity group repaired with both repair sets presented mixed, adhesive and cohesive failures, and the IPS e.max CAD group repaired with the Clearfil Repair system, presented 
$80 \%$ cohesive failure and $20 \%$ mixed failure.

This study has several limitations. The clinical aging of restorative materials would change their chemical and mechanical properties. These changes would affect their repairability as well. In the current study, the specimens were subjected to thermal cycling before they were repaired, because fractures occur during clinical use.

Future studies should be focused on the effect of thermocycling after repair process in order to compare changes. Another limitation of this study is that in order to investigate the bond strength between resin and ceramic, the repaired specimens were only subjected to shear forces. Clinically, repaired restorations are exposed to several intraoral stresses such as tensile, shear, compressive, and oblique forces. Additionally, the bond strength of the repaired restorations should be investigated clinically, in order to verify the outcomes of in vitro studies.

\section{CONCLUSIONS}

Within the limitations of this study, the following conclusions could be drawn:

1. All groups, except for the InCoris TZI group, repaired with iGOS Repair system showed higher $\mu \mathrm{SBS}$ than Clearfil Repair system.
2. The Clearfil Repair system, which contains MDP phosphate monomer, showed higher $\mu$ SBS values than iGOS Repair for InCoris TZI.

3 . The $\mu$ SBS of two different repair systems applied to indirect restorative materials is dependent on the micro-structure of both tested materials. CONFLICT OF INTEREST

The authors declare no conflict of interest.

\section{AUTHOR CONTRIBUTIONS}

AA: Study and experimental design, data gathering, analysis and interpretation of the results, manuscript writing LN: Sample preparation, performed the experiment and manuscript writing HMK: Study and experimental design, manuscript proofreading AU: Study and experimental design, analysis and interpretation of the results, manuscript proofreading.

\section{ACKNOWLEDGMENTS}

None.

\section{REFERENCES}

1. Fasbinder DJ. Computerized technology for restorative dentistry. Am J Dent. 2013;26(3):115-120.

PubMed Google Scholar Scopus WoS

2. Miyazaki T, Nakamura T, Matsumura $\mathrm{H}$, et al. Current status of zirconia restoration. J Prosthodont Res. 2013;57(4):236-261. doi:10.1016/j.jpor.2013.09.001.

Full text links CrossRef PubMed Google Scholar Scopus WoS 3. Harada A, Nakamura K, Kanno T, et al. Fracture resistance of computer-aided design/computer-aided manufacturinggenerated composite resin-based molar crowns. Eur J Oral Sci. 2015;123(2):122-129. doi:10.1111/eos.12173.

Full text links CrossRef PubMed Google Scholar Scopus WoS 4. Awad D, Stawarczyk B, Liebermann A, et al. Translucency of esthetic dental restorative CAD/CAM materials and composite resins with respect to thickness and surface roughness. J Prosthe Dent. 2015;113(6):534-540. doi:10.1016/j.prosdent.2014.12.003. Full text links CrossRef PubMed Google Scholar Scopus WoS 5. Lauvahutanon S, Takahashi H, Shiozawa M, et al. Mechanical properties of composite resin blocks for CAD/CAM. Dent Mater J. 2014;33(5):705-710. doi:10.4012/dmj.2014-208.

Full text links CrossRef PubMed Google Scholar Scopus WoS 6. Latta MA, Barkmeier WW. Approaches for intraoral repair of ceramic restorations. Compend Contin Educ Dent. 2000;21(8):635646.

PubMed Google Scholar Scopus

7. Quinn GD. On edge chipping testing and some personal perspectives on the state of the art of mechanical testing. Dent Mater. 2015;31(1):26-36. doi:10.1016/j.dental.2014.08.378. Full text links CrossRef PubMed Google Scholar Scopus WoS
8. Scherrer SS, Quinn GD, Quinn JB. Fractographic failure analysis of a Procera AllCeram crown using stereo and scanning electron microscopy. Dent Mater. 2008;24(8):1107-1113. doi:10.1016/j. dental.2008.01.002.

Full text links CrossRef PubMed Google Scholar Scopus WoS 9. Walton JN, Gardner FM, Agar JR. A survey of crown and fixed partial denture failures: length of service and reasons for replacement. J Prosthet Dent. 1986;56(4):416-421. doi:10.1016/0022-3913(86)90379-3.

Full text links CrossRef PubMed Google Scholar Scopus WoS 10. Libby G, Arcuri MR, LaVelle WE, et al. Longevity of fixed partial dentures. J Prosthet Dent. 1997;78(2):127-131. doi:10.1016/s00223913(97)70115-x.

Full text links PubMed Google Scholar Scopus WoS

11. Ozcan M, Niedermeier W. Clinical study on the reasons for and location of failures of metal-ceramic restorations and survival of repairs. Int J Prosthodont. 2002;15(3):299-302.

CrossRef PubMed Google Scholar Scopus WoS

12. Gordan VV, Garvan CW, Blaser PK, et al. A long-term

evaluation of alternative treatments to replacement of resinbased composite restorations: results of a seven-year study. $J$ Am Dent Assoc. 2009;140(12):1476-1484. doi:10.14219/jada. archive.2009.0098.

Full text links CrossRef PubMed Google Scholar Scopus WoS

13. Gordan VV, Shen C, Riley J 3rd, et al. Two-year clinical evaluation of repair versus replacement of composite restorations. J Esthet Restor Dent. 2006;18(3):144-154. doi:10.1111/j.1708-8240.2006.00007.x.

Full text links CrossRef PubMed Google Scholar Scopus 
14. Hickel R, Brüshaver K, Ilie N. Repair of restorations--criteria for decision making and clinical recommendations. Dent Mater. 2013;29(1):28-50. doi:10.1016/j.dental.2012.07.006.

Full text links CrossRef PubMed Google Scholar Scopus WoS

15. Tyas MJ, Anusavice KJ, Frencken JE, et al. Minimal intervention dentistry - a review - FDI Commission Project 1-97. Int Dent J. 2000;50(1):1-12. doi:10.1111/j.1875-595x.2000.tb00540.x. Full text links CrossRef PubMed Google Scholar Scopus WoS 16. Fan PL. Porcelain repair materials. Council on Dental Materials, Instruments and Equipment. J Am Dent Assoc. 1991;122(8):124130.

Full text links CrossRef PubMed Google Scholar Scopus WoS 17. Denehy G, Bouschlicher M, Vargas M. Intraoral repair of cosmetic restorations. Dent Clin North Am. 1998;42(4):719-x.

PubMed Google Scholar Scopus

18. Blum IR, Jagger DC, Wilson NH. Defective dental restorations: to repair or not to repair? Part 2: All-ceramics and porcelain fused to metal systems. Dent Update. 2011;38(3):150-158. doi:10.12968/ denu.2011.38.3.150.

CrossRef PubMed Google Scholar

19. Rathke A, Tymina Y, Haller B. Effect of different surface treatments on the composite-composite repair bond strength.

Clin Oral Investig. 2009;13(3):317-323. doi:10.1007/s00784-0080228-2.

Full text links CrossRef PubMed Google Scholar Scopus WoS 20. Hu M, Weiger R, Fischer J. Comparison of two test designs for evaluating the shear bond strength of resin composite cements. Dent Mater. 2016;32(2):223-232. doi:10.1016/j.dental.2015.11.023. Full text links CrossRef PubMed Google Scholar Scopus WoS 21. Filho AM, Vieira LC, Araújo E, et al. Effect of different ceramic surface treatments on resin microtensile bond strength. J Prosthodont. 2004;13(1):28-35. doi:10.1111/j.1532849X.2004.04007.x.

Full text links CrossRef PubMed Scopus Google Scholar 22. Güngör MB, Nemli SK, Bal BT, et al. Effect of surface treatments on shear bond strength of resin composite bonded to CAD/CAM resin-ceramic hybrid materials. J Adv Prosthodont. 2016;8(4):259-266. doi:10.4047/jap.2016.8.4.259.

Full text links CrossRef PubMed Google Scholar Scopus WoS 23. Tian T, Tsoi JK, Matinlinna JP, et al. Aspects of bonding between resin luting cements and glass ceramic materials. Den Mater. 2014;30(7):e147-e162. doi:10.1016/j.dental.2014.01.017. Full text links CrossRef PubMed Google Scholar Scopus WoS 24. Dimitriadi M, Panagiotopoulou A, Pelecanou M, et al. Stability and reactivity of $\mathrm{Y}$-MPTMS silane in some commercial primer and adhesive formulations. Dent Mater. 2018;34(8):1089-1101. doi:10.1016/j.dental.2018.05.006

Full text links CrossRef PubMed Google Scholar Scopus WoS 25. Matinlinna JP, Vallittu PK. Bonding of resin composites to etchable ceramic surfaces - an insight review of the chemical aspects on surface conditioning. J Oral Rehabil. 2007;34(8):622630. doi:10.1111/j.1365-2842.2005.01569.x.

Full text links CrossRef PubMed Google Scholar Scopus WoS 26. Murillo-Gómez F, Palma-Dibb RG, De Goes MF. Effect of acid etching on tridimensional microstructure of etchable CAD/ CAM materials. Dent Mater. 2018;34(6):944-955. doi:10.1016/j. dental.2018.03.013.

Full text links CrossRef PubMed Google Scholar Scopus WoS 27. Barchetta NF, Amaral M, Prochnow C, et al. Strength of a zirconia-reinforced lithium silicate ceramic: acid-etching time and resin cement application effects. Int J Periodontics Restorative Dent. 2019;39(3):431-437. doi:10.11607/prd.411.

Full text links PubMed Google Scholar Scopus WoS

28. Güler AU, Yilmaz F, Yenisey M, et al. Effect of acid etching time and a self-etching adhesive on the shear bond strength of composite resin to porcelain. J Adhes Dent. 2006;8(1):21-25. PubMed Google Scholar Scopus WoS

29. Elsaka SE. Repair bond strength of resin composite to a novel CAD/CAM hybrid ceramic using different repair systems. Dent Mater J. 2015;34(2):161-167. doi:10.4012/dmj.2014-159. Full text links CrossRef PubMed Google Scholar Scopus WoS 30. Bona AD. Bonding to ceramics: scientific evidences for clinical dentistry. 1st ed. Banbury, UK: Scion Publishing Limited; 2009. Google Scholar

31. Valandro LF, Ozcan M, Bottino MC, et al. Bond strength of a resin cement to high-alumina and zirconia-reinforced ceramics: the effect of surface conditioning. J Adhes Dent. 2006;8(3):175181.

Full text links CrossRef PubMed Google Scholar Scopus WoS 32. Blum IR, Nikolinakos N, Lynch CD, et al. An in vitro comparison of four intra-oral ceramic repair systems. J Dent. 2012;40(11):906912. doi:10.1016/j.jdent.2012.07.008.

Full text links CrossRef PubMed Google Scholar Scopus WoS
33. Ozcan M, Valandro LF, Amaral R, et al. Bond strength durability of a resin composite on a reinforced ceramic using various repair systems. Dent Mater. 2009;25(12):1477-1483. doi:10.1016/j.dental.2009.06.020.

Full text links CrossRef PubMed Google Scholar Scopus WoS 34. Stawarczyk B, Krawczuk A, llie N. Tensile bond strength of resin composite repair in vitro using different surface preparation conditionings to an aged CAD/CAM resin nanoceramic. Clin Oral Investig. 2015;19(2):299-308. doi:10.1007/s00784-014-1269-3. Full text links CrossRef PubMed Google Scholar Scopus WoS 35. Yamakin. Home: https://www.yamakin-global.com/igos/ technical qa pp.html\#button Accessed 6/10/19 36. Kern $\bar{M}$, Wegner SM. Bonding to zirconia ceramic: adhesion methods and their durability. Dent Mater. 1998;14(1):64-71. doi:10.1016/s0109-5641(98)00011-6.

Full text links CrossRef PubMed Google Scholar Scopus WoS 37. Panah FG, Rezai SM, Ahmadian L. The influence of ceramic surface treatments on the micro-shear bond strength of composite resin to IPS Empress 2. J Prosthodont. 2008;17(5):409414. doi:10.1111/j.1532-849X.2007.00296.x.

Full text links CrossRef PubMed Google Scholar Scopus 38. Kupiec KA, Wuertz KM, Barkmeier WW, et al. Evaluation of porcelain surface treatments and agents for composite-toporcelain repair. J Prosthet Dent. 1996;76(2):119-124. doi:10.1016/ s0022-3913(96)90294-2.

Full text links CrossRef PubMed Google Scholar Scopus WoS 39. Ozcan M, Vallittu PK. Effect of surface conditioning methods on the bond strength of luting cement to ceramics. Dent Mater. 2003:19(8):725-731. doi:10.1016/s0109-5641(03)00019-8. Full text links CrossRef PubMed Google Scholar Scopus WoS 40. Duzyol M, Sagsoz O, Polat Sagsoz N, et al. The effect of surface treatments on the bond strength between CAD/CAM blocks and composite resin. J Prosthodont. 2016:25(6):466-471. doi:10.1111/ jopr.12322.

Full text links CrossRef PubMed Google Scholar Scopus WoS

41. Neis CA, Albuquerque NL, Albuquerque Ide $S$, et al. Surface treatments for repair of feldspathic, leucite - and lithium disilicate-reinforced glass ceramics using composite resin. Braz Dent J. 2015:26(2):152-155. doi:10.1590/0103-6440201302447.

Full text links CrossRef PubMed Google Scholar Scopus 42. Colares RC, Neri JR, Souza AM, et al. Effect of surface pretreatments on the microtensile bond strength of lithiumdisilicate ceramic repaired with composite resin. Braz Dent J. 2013;24(4):349-352. doi:10.1590/0103-6440201301960. Full text links CrossRef PubMed Google Scholar Scopus 43. Karcı M, Demir N, Subaşı MG, et al. Shear bond strength of a novel porcelain repair system for different computer-aided design/computer-assisted manufacturing ceramic materials. Niger J Clin Pract. 2018;21(4):507-513. doi:10.4103/njcp. njcp_127_17.

Full text links PubMed Google Scholar Scopus WoS 44. Üstün Ö, Büyükhatipoğlu IK, Seçilmiş A. Shear bond strength of repair systems to new CAD/CAM restorative materials. $J$ Prosthodont. 2018;27(8):748-754. doi:10.1111/jopr.12564. Full text links CrossRef PubMed Google Scholar Scopus WoS 45. Dias de Souza GM, Thompson VP, Braga RR. Effect of meta primers on microtensile bond strength between zirconia and resin cements. J Prosthet Dent. 2011;105(5):296-303. doi:10.1016/ S0022-3913(11)60055-3.

Full text links CrossRef PubMed Google Scholar Scopus WoS 46. Khan AA, Al Kheraif AA, Jamaluddin S, et al. Recent trends in surface treatment methods for bonding composite cement to zirconia: a reveiw. J Adhes Dent. 2017;19(1):7-19. doi:10.3290/j.jad. a37720.

Full text links PubMed Google Scholar

47. Blatz MB, Phark JH, Ozer F, et al. In vitro comparative bond strength of contemporary self-adhesive resin cements to zirconium oxide ceramic with and without air-particle abrasion. Clin Oral Investig. 2010;14(2):187-192. doi:10.1007/s00784-0090278-0.

Full text links CrossRef PubMed Google Scholar Scopus WoS 48. Elsaka SE. Effect of surface treatments on the bonding strength of self-adhesive resin cements to zirconia ceramics. Quintessence Int. 2013;44(6):407. doi:10.3290/j.qi.a29572. Full text links PubMed Google Scholar Scopus WoS 49. Reich SM, Wichmann M, Frankenberger R, et al. Effect of surface treatment on the shear bond strength of three resin cements to a machinable feldspatic ceramic. J Biomed Mater Res $B$ Appl Biomater. 2005;74(2):740-746. doi:10.1002/jbm.b.30292. Full text links CrossRef PubMed Google Scholar Scopus WoS 


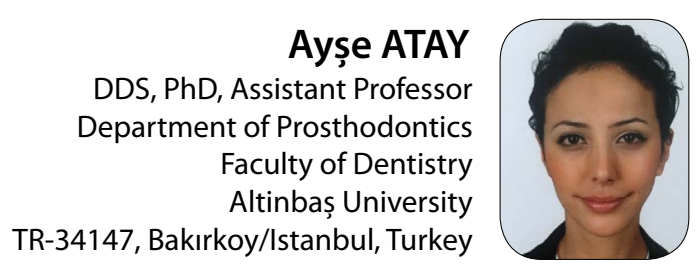

Ayşe Atay graduated from Ege University, Faculty of Dentistry, Izmir, Turkey in 2004. She enrolled on her PhD degree in 2006 and she was awarded her PhD degree by Ege University in 2010. Since 2014, she has been working as an assistant professor at the Department of Prosthodontics within the Faculty of Dentistry of the Altınbaș University.

\section{Orestions}

\section{Choose the appropriate surface treatment method below to repair fractured restorations below:}

$\square$ a. Etching with hydrofluoric acid;

ab. Sandblasting with Al2O3;

Dc. Tribochemical silica coating;

ud. All of them.

\section{What is the effect of silane application in the surface treatment process?}

Da. Increases the wettability of the ceramic;

ab. Creates micro roughness on the ceramic surface;

uc. Cleans the ceramic surface;

dd. Dissolves the glass matrix and the crystalline structure.

3. Which of the following is not one of the advantages of repairing a ceramic fracture with composite resin?

Da. More conservative;

ab. Less time consuming;

ac. Less costly;

ad. None.

4. According to the results of this study, which restorative material repaired with Clearfil Repair system showed favorable shear bond strength than repaired with iGOS Repair system?

Da. Feldspar ceramic;

口b. Lithium disilicate glass-ceramic;

uc. Zirconium oxide sinter ceramic;

ad. Resin nano ceramic. 


\title{
KNOWLEDGE, AWARENESS AND PERCEPTIONS OF CORONAVIRUS DISEASE 2019 (COVID-19) IN A COHORT OF INDIAN DENTAL PROFESSIONALS: A QUESTIONNAIRE-BASED STUDY
}

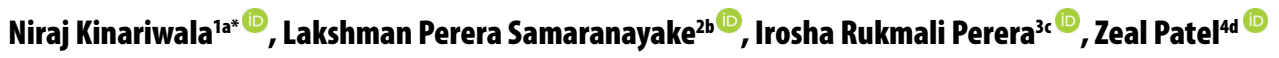 \\ 'Department of Conservative Dentistry, Karnavati School of Dentistry, Karnavati University, Gandhinagar, India \\ 2Department of Oral Biosciences, Faculty of Dentistry, University of Hong Kong, Hong Kong, China \\ ${ }_{3}^{3}$ Preventive Oral Health Unit, National Dental Hospital (Teaching), Colombo, Sri Lanka \\ ${ }^{4}$ Department of Community Dentistry / Public Health Dentistry, Karnavati School of Dentistry, Karnavati University, Gandhinagar, India \\ aBDS, MDS, PhD, Associate Professor; e-mail: niraj@ksd.ac.in; ORCIDiD: https://orcid.org/0000-0002-9038-2035 \\ bDSC, DDS (Glas), FRCPath, FDSRCS(Edin), FRACDS, FDS RCPS (Glas), FHKCPath, FCDSHK, Professor Emeritus; e-mail: lakshman@hku.hk; \\ ORCIDiD: https://orcid.org/0000-0002-9122-336X \\ 'BDS, MDS, Dental Public Health Specialist; e-mail: irosha_rukmali@yaho0.com; ORCIDiD: https://orcid.org/0000-0002-8250-0169 \\ dBDS, MDS, PhD, Associate Professor; e-mail:zeal_86@yahoo.com; ORCIDiD: https://orcid.org/0000-0001-6571-4002
}

d) https://doi.org/10.25241/stomaeduj.2020.7(4).art.2

Objectives COVID-19 is an unprecedented global public health emergency currently impacting heavily on India. The objective of this study was to assess the knowledge, awareness, perceptions of Indian dentists on COVID-19.

Methods A cross-sectional, on-line questionnaire-based study was conducted amongst 403 Indian dentists in solo, and group practices as well as academics. The self-administered questionnaire assessed 1) knowledge/awareness of factors related to COVID-19 patient identification and symptomatology, 2) knowledge/awareness of COVID-19 transmission and 3) perceptions of COVID-19 history taking procedure. Statistical analyses were conducted using Statistical Package for Social Sciences for Windows, version 21.0 (IBM Corp., Armonk, NY, USA). Frequency distributions and logistic regression analyses were used.

Results Indian dentists demonstrated an overall modest level of knowledge on identification of patients with COVID-19. Moreover, they had a high level of awareness of the COVID-19 transmission means, and the generally accepted procedural perceptions on patient history taking. However, there were some gaps in specific aspects of knowledge and perceptions. Those who were aged $\geq 30$-years had a significantly higher level of knowledge of patient identification means than those who were $<30$-years (OR=1.78:1.12-2.83); $\mathrm{p}=0.01$. Moreover, specialized dentists were significantly more knowledgeable of COVID-19 transmission means than general dentists $(\mathrm{OR}=1.89: 1.22-2.93 ; \mathrm{p}=0.004)$.

Conclusion Our findings demonstrate identifiable gaps in knowledge/awareness and perceptions of COVID-19 in Indian dental professionals. These gaps should be fulfilled, at the earliest, due to the rising burden of COVID-19 in India, to ensure safe dental care delivery.

\section{KEYWORDS}

COVID-19; Knowledge; Awareness; Perceptions; Indian Dentists.

\section{INTRODUCTION}

The pandemic of coronavirus disease 2019(COVID-19) that originated in Wuhan, China, in December 2019 has become a major public health challenge for the global community. The disease, caused by a novel coronavirus, severe acute respiratory syndrome coronavirus 2 (SARS-CoV-2) has impacted livelihoods

(c) (1) () OPEN ACCESS This is an Open Access article under the CC BY-NC 4.0 license. Peer-Reviewed Article

Citation: Kinariwala N, Samaranayake LP, Perera IR, Patel Z. Knowledge, awareness and perceptions of coronavirus disease 2019 (COVID-19) in a cohort of Indian dental professionals : a questionnaire-based study. Stoma Edu J. 2020;7(4):242-251.

Received: October 13, 2020; Revised: October 20, 2020; Accepted: October 25, 2020; Published: October 28, 2020

*Corresponding author: Dr. Niraj Kinariwala, Karnavati School of Dentistry, Karnavati University, A/907, Uvarsad, Gandhinagar, Gujarat 382422

Tel /Fax: 079-23970000, 079-61755500; e-mail: drnirajkinariwala@gmail.com; niraj@ksd.ac.in

Copyright: $\odot 2020$ the Editorial Council for the Stomatology Edu Journal. 


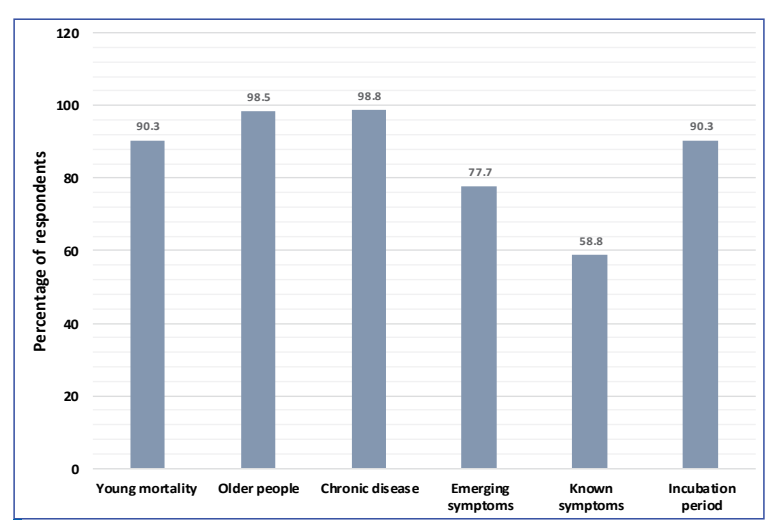

Figure 1. Percentage of respondents who correctly answered questions on knowledge/awareness of COVID-19.

ITable 1. Socio-demographic profile of the responding dentists.

\begin{tabular}{|c|c|c|}
\hline Attribute & Number & $\%$ \\
\hline \multicolumn{3}{|l|}{ Gender } \\
\hline Male & 201 & 49.9 \\
\hline Female & 202 & 50.1 \\
\hline \multicolumn{3}{|l|}{ Age group } \\
\hline$<30$ years & 143 & 35.5 \\
\hline $30-40$ years & 197 & 48.9 \\
\hline $1-50$ ears & 46 & 11.4 \\
\hline$>50$ years & 17 & 4.2 \\
\hline \multicolumn{3}{|l|}{ Professional qualifications } \\
\hline $\mathrm{BDS}^{*}$ & 225 & 55.8 \\
\hline MDS & 178 & 44.2 \\
\hline \multicolumn{3}{|l|}{ Specialization } \\
\hline $\begin{array}{l}\text { Not specialized-General } \\
\text { Practitioner }\end{array}$ & 227 & 56.3 \\
\hline Endodontist & 68 & 16.9 \\
\hline Prosthodontist & 30 & 7.4 \\
\hline Periodontist & 23 & 5.7 \\
\hline Orthodontist & 19 & 4.7 \\
\hline Paedodontist & 14 & 3.5 \\
\hline Oral \& Maxillofacial Surgeon & 14 & 3.5 \\
\hline Oral Radiologist & 8 & 2.0 \\
\hline \multicolumn{3}{|l|}{ Practice Type } \\
\hline Private Solo Practice & 242 & 60.0 \\
\hline Private Group Practice & 87 & 21.6 \\
\hline Academic & 74 & 18.4 \\
\hline \multicolumn{3}{|c|}{ Use of Arogya Setu Mobile Application } \\
\hline No & 153 & 38.0 \\
\hline Yes & 250 & 62.0 \\
\hline \multicolumn{3}{|c|}{$\begin{array}{l}\text { CPE/Webinar Programme } \\
\text { participation on management of } \\
\text { patients during COVID-19 pandemic }\end{array}$} \\
\hline No & 71 & 17.6 \\
\hline Yes & 332 & 83.4 \\
\hline
\end{tabular}

*includes 32 dental postgraduate trainees.

of a substantive proportion of the global community including dentists. Thus, clinical dental practices, academic dental establishments, and similar private and government funded organisations have either closed or curtailed their professional work due, either to the fear of contracting the infection, and/ or the widespread lockdowns initiated by the local, and regional authorities. In India, the first case of COVID-19 was reported on 30th January, 2020, and at the time of writing on 1st October 2020 the patient numbers have risen to over $6,400,000$ with

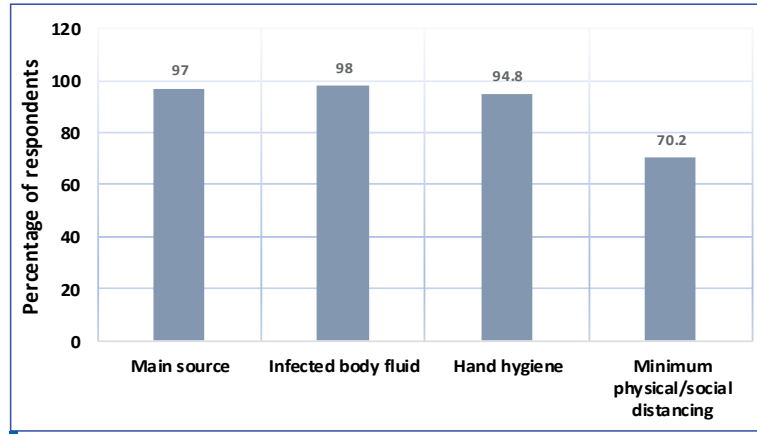

Figure 2. Percentage of respondents who correctly answered questions on COVID-19 transmission sources and routes.

100,000 recorded deaths. First country wide citizen lockdown in India was implemented on 25th March, 2020, and since then the dental practitioners have been instructed by the authorities to carry out only emergency treatment of patients that obviate aerosol production. As in other regions of the World, front line health care workers in India appear to be disproportionately impacted by COVID-19 and dentists, in particular, are likely to be exposed to SARS-CoV-2[1,2]. This is mainly due to their work in close proximity to the patients, and the intrinsic nature of dentistry entailing high-speed instrumentation, and the likelihood of aerosolizing saliva and virus-laden aerosols in inadequately ventilated clinical settings[2]. There are anecdotal reports of dentists expressing fears on the postpandemic dental practice and their professional future, but the extent to which these perceptions are based, as well as their clinical knowledge of COVID-19 is unclear. Such information on the knowledge and perceptions of dentists is needed, on a wider scale, not only to identify existing knowledge gaps but also to articulate optimal measures to prevent COVID-19 transmission in the dental clinic. Additionally, if the disease were to sporadically erupt in local or regional pockets from time to time, and/or the so called second wave of the disease were to transpire then dentists could play an important role in early detection of the disease, for which their knowledge of COVID-19 would be critical, in particular for identification and appropriate referral of patients.

We are unaware of any studies in the literature on the knowledge and perceptions of dental health professionals of India. Therefore, the aims of this study were to assess knowledge and awareness of COVID-19 in a cross section of dental professionals in India.

\section{MATERIALS AND METHODS}

A questionnaire-based, cross-sectional study was conducted amongst Indian dentists in the singlehanded practices, group practices, and academics, irrespective of their specialization. The questionnaire was developed in English to assess the respondents' knowledge, awareness and perceptions of COVID-19. 
I Table 2. Related factors of knowledge/awareness of COVID-19 patient risk stratification, among Indian dentists.

\begin{tabular}{|l|l|l|l|l|}
\hline Factor & $\begin{array}{l}\text { Unadjusted } \\
\text { Odds ratio (95\% Cl) }\end{array}$ & p-value & $\begin{array}{l}\text { Adjusted } \\
\text { Odds ratio (95\% Cl) }\end{array}$ & p-value \\
\hline Gender & & & & \\
\hline Male & 1 & & 1 & \\
\hline Female & $1.46(0.07-2.19)$ & 0.07 & $1.67(1.09-2.56)$ & $\mathbf{0 . 0 2 *}$ \\
\hline Age group & & & & \\
\hline$<30$-years & 1 & & 1 & \\
\hline$\geq 30$-years & $1.71(1.11-2.64)$ & $0.016^{*}$ & $1.78(1.12-2.83)$ & $\mathbf{0 . 0 1 *}$ \\
\hline Qualifications & & & & \\
\hline BDS only & 1 & & 1 & \\
\hline Specialized & $1.27(0.84-1.90)$ & 0.25 & $1.19(0.77-1.82)$ & 0.40 \\
\hline COVID-19 CDE/Webinar participation & & & & \\
\hline No & 1 & & 1 & \\
\hline Yes & $1.51(0.87-2.64)$ & 0.14 & $1.29(0.72-2.31$ & 0.39 \\
\hline Using Arogya Setu mobile application & & & & \\
\hline No & 1 & & 1 & \\
\hline Yes & $0.95(0.63-1.45)$ & 0.82 & $1.07(0.70-1.65)$ & 0.76 \\
\hline
\end{tabular}

*Significance, $p<0.05$.

ITable 3. Demographic data and Related factors of knowledge/awareness of COVID-19 transmission among Indian dentists.

\begin{tabular}{|l|l|l|l|l|}
\hline Factor & Unadjusted Odds ratio (95\% Cl) & p-value & Adjusted Odds ratio (95\% Cl) & p-value \\
\hline Gender & & & & \\
\hline Male & 1 & & 1 & \\
\hline Female & $0.94(0.62-1.42)$ & 0.78 & $0.91(0.59-1.40)$ & 0.66 \\
\hline Age group & 1 & & & \\
\hline$<30-$-years & $1.12(0.73-1.72)$ & & 1 & \\
\hline$\geq 30$-years & & 0.60 & $1.09(0.68-1.72)$ & 0.72 \\
\hline Qualifications & 1 & & & \\
\hline BDS only & $1.89(1.23-2.90)$ & & 1 & \\
\hline Specialized & & $0.004^{*}$ & $1.89(1.22-2.93)$ & $\mathbf{0 . 0 0 4}$ \\
\hline $\begin{array}{l}\text { COVID-19 CPD/Webinar } \\
\text { participation }\end{array}$ & 1 & & & \\
\hline No & 1 & & 1 & 0.35 \\
\hline Yes & $0.91(0.53-1.58)$ & 0.75 & $0.76(0.42-1.36$ & \\
\hline $\begin{array}{l}\text { Using Arogya Setu mobile } \\
\text { application }\end{array}$ & & & & \\
\hline No & 1 & & 1 & \\
\hline Yes & $0.65(0.42-1.00)$ & 0.05 & $1.66(0.42-1.03)$ & 0.07 \\
\hline
\end{tabular}

The questionnaire was compiled using the data garnered on 1st May, 2020, from the websites of the World Health Organization (WHO), US Centre for Disease Control and Prevention (CDC), the Ministry of Health and Family Welfare of the Government of India, and the Dental Council of India (DCI). First, a pilot survey of the questionnaire was conducted amongst randomly selected 20 dentists, and once their response was received, ambiguities in the questionnaire, if any, were rectified prior to the final mass circulation. Participants were assured of the confidentiality of their responses. The pilot-tested dentists were not included in the final study. The survey was conducted online amongst members of a large facebook group entitled Endohaveli, a diverse group of dental professionals with over 52,000 members across the globe. The questionnaire comprised four major components, i) Sociodemographic and personal profile, ii) knowledge/ awareness of factors related to COVID-19 patient risk stratification, iii) knowledge/awareness of prevention and control of COVID-19 transmission, and iv) perceptions of COVID-19 risk assessment, and patient history taking. Once the responses were received, the individual components were scored for the foregoing four major components, as follows. The respondents were dichotomized according to their age as $<30$ years vs $\geq 30$-years, while the dental specialties were segregated into two groups as general dental practitioners vs specialists (which included all dental specialties). The scores were dichotomized as 'good' and 'better' for knowledge/awareness components, and 'less optimal' and 'optimal' for perception component (Fig.1). Univariate associations were assessed for dichotomized outcomes of knowledge and perception components using selected socio-demographic and personal attributes as 
Table 4. Related factors of perceptions of Indian dentists on eliciting COVID-19 risk related history from patients.

\begin{tabular}{|c|c|c|c|c|}
\hline Factor & $\begin{array}{l}\text { Unadjusted Odds Ratio } \\
(95 \% \mathrm{CI})\end{array}$ & p-value & $\begin{array}{l}\text { Adjusted Odds Ratio } \\
(95 \% \mathrm{Cl})\end{array}$ & p-value \\
\hline \multicolumn{5}{|l|}{ Gender } \\
\hline Male & 1 & & 1 & \\
\hline Female & $1.32(0.86-2.04)$ & 0.20 & $1.21(0.77-1.90)$ & $0.41 *$ \\
\hline \multicolumn{5}{|l|}{ Age group } \\
\hline$<30$-years & 1 & & 1 & \\
\hline$\geq 30$ years & $0.63(0.40-0.97)$ & 0.04 & $0.63(0.39-1.00)$ & 0.05 \\
\hline \multicolumn{5}{|c|}{ Qualifications } \\
\hline BDS only & 1 & & 1 & \\
\hline Specialized & $1.02(0.66-1.58)$ & 0.92 & $1.04(0.66-1.64)$ & 0.85 \\
\hline \multicolumn{5}{|c|}{$\begin{array}{l}\text { COVID-19 } \\
\text { CDE/Webinar participation }\end{array}$} \\
\hline No & 1 & & 1 & \\
\hline Yes & $1.07(0.61-1.89)$ & 0.82 & $1.28(0.70-2.38)$ & 0.42 \\
\hline \multicolumn{5}{|c|}{$\begin{array}{l}\text { Using Arogya Setu mobile } \\
\text { application }\end{array}$} \\
\hline No & 1 & & 1 & \\
\hline Yes & $0.63(0.41-0.98)$ & 0.04 & $0.64(0.41-1.01)$ & 0.06 \\
\hline \multicolumn{5}{|c|}{$\begin{array}{l}\text { Knowledge on COVID-19 patient } \\
\text { risk stratification }\end{array}$} \\
\hline Good & 1 & & 1 & \\
\hline Better & $0.62(0.39-0.99)$ & 0.04 & $0.77(0.59-1.01)$ & 0.61 \\
\hline \multicolumn{5}{|c|}{$\begin{array}{l}\text { Knowledge on COVID-19 } \\
\text { transmission }\end{array}$} \\
\hline Good & 1 & & 1 & \\
\hline Better & $1.01(0.64-1.58)$ & 0.98 & $0.96(0.60-1.54)$ & 0.88 \\
\hline
\end{tabular}

*Significance, $p<0.05$.

predictor variables. For perceptions on COVID-19 risk assessment and eliciting patient history, dichotomized knowledge scores were included as additional predictor variables. Moreover, a multiple logistic regression model was fitted to assess the independent associations of predictor variables with the knowledge/awareness and perception outcomes, and Odds ratio (OR), 95\% confidence intervals $(\mathrm{Cl})$, and $\mathrm{p}$-values were calculated. In the unconditional binary logistic regression analysis, enter option was used and $p<0.05$ was used as the criterion for retention in the model. HosmerLemeshow goodness of fit test was used to assess the fitness of model. Statistical analyses were conducted using Statistical Package for Social Sciences (SPSS) for Windows, version 21.0 (IBM Corp., Armonk, NY, USA). The study was approved by the Research Unit, Karnavati School of Dentistry, Karnavati University, India, according to principles of the Helsinki Declaration.

\section{RESULTS}

In total, 403 responses were collected online from a total of 1,200 randomly selected participants, yielding a response rate of $33.6 \%$. Further analysis revealed that a cross-section of dentists from all parts of India had participated in the study, indicating a representative all-Indian response.

\subsection{Demographic data}

Almost one half $(48.9 \%)$ of the participants were between 30-40 years of age, and approximately a third (35.5\%) were younger than 30 years. The gender of the participants was almost equally split between females (50.1\%), and males (49.9\%). Except for a single missing response, all the participants mentioned their nationality as Indian. Approximately one half (55.8\%) of the responding dentists had only a Bachelor of Dental Surgery (BDS) degree, and the remainder (44.2\%) were qualified with a Master's degree (MDS), whilst a majority of the respondents (56.3\%) were general dental practitioners. Endodontists were the predominant group of specialists (16.9\%) followed by prosthodontists (7.4\%) and orthodontists (4.7\%). The majority of general and specialized dentists, $60 \%$ were engaged in singlehanded private practices, while $21.6 \%$ were in group private practices, and another $18.4 \%$ were working in academia. Furthermore, $62 \%$ of participants had used the Arogya Setu mobile application and $83.4 \%$ participants had participated in CPE/Webinars on COVID-19 (Table 1).

\subsection{Participants' knowledge and awareness of} symptomatology of COVID-19.

An overwhelming majority of participants (90.3\%) answered correctly that the incubation period of COVID-19 can be up to 21 days (Fig. 1). 
All participants were aware of the elevated threat posed by COVID-19 to older individuals, and those with chronic diseases, although $9.7 \%$ were unaware of the possible mortality risk of the disease for younger individuals. Approximately, some three quarters of the participants (77.7\%) were aware of acute loss of smell and taste could be an early symptom of the disease, and a just over one-half (58.8\%) were aware of the full spectrum of COVID-19 symptoms.

\subsection{Participants' knowledge and awareness of COVID-19 transmission modes}

The participants knowledge and awareness of major transmission portals of COVID-19, and key features of its prevention and control were relatively high as $97.0 \%, 98 \%$ and $94.8 \%$ were aware of main source of infection transmission, infected body fluids as a source of infection transmission, and the crucial importance of hand-hygiene in prevention and control measures, respectively (Fig. 2). Surprisingly though, only $29.8 \%$ were aware of the 6 -feet distance as the minimum physical/social distance for COVID-19 transmission prevention.

\subsection{Factors related to patient history taking practices}

The vast majority of the respondents (98.3\%) indicated that knowing the patient's residential area was highly important in COVID-19 risk assessment, whilst a similar proportion (93.8\%) perceived the importance of knowing the patient's travel history, prior to treatment provision. On the contrary, two thirds of the respondents (68.0\%) did not wish to offer treatment to patients without the Arogya Setu mobile application. On correlating factors related to knowledge/awareness of the respondents on COVID-19 to patient risk stratification, gender and age were significantly related to the level of knowledge on COVID-19, as female dentists had higher level of knowledge (OR=1.67:1.09-2.56) compared to their male counterparts $(p=0.02)$, whilst those aged $\geq 30$-year-olds had significantly higher level of knowledge than those $<30$ years $(p=0.01 ; O R=1.78: 1.12-2.83)$. However, specialization status, participating in COVID-19 CPD/Webinar programmes, and use of the Arogya Setu mobile application were not significantly related to knowledge/awareness of COVID-19. In terms of the factors related to awareness/knowledge of Indian dentists on SARS-CoV-19 infection transmission, prevention and control, specialized dentists had a significantly higher level of knowledge/awareness on COVID-transmission than the generalists. $(\mathrm{OR}=1.89: 1.22-2.93 ; \quad \mathrm{p}=0.004$; Table 3). None of the other socio-demographic and personal attributes were significantly related to knowledge/awareness. As for the factors related to perceptions of COVID-19 risk, and history taking, except for a marginal significance of the age group $(p=0.05)$, in the direction of younger dentists having better perceptions compared to older dentists, no other factors evaluated were significantly different (Table 4).

\section{DISCUSSION}

One of the high-risk groups susceptible to SARSCoV2 infection is health care providers, specifically dentists, due to the nature of their work that entails aerosol production, and working in extremely close proximity to their patients. Indeed, in a recent analysis by the $O^{*}$ Net Bureau of Statistics of the USA, dentists were considered the highest risk group of health care workers at risk for contracting COVID-19[3].

This was borne out during the Severe Acute Respiratory Syndrome (SARS) outbreak in 2003, with some countries reporting that up to a third infected being health care workers[4]. Hence, in order to institute appropriate professional guidelines and related public health measures, it is important to assess the knowledge and awareness, and institute clinical measures for controlling COVID-19 transmission in dentistry in a country such as India where the pandemic is ferociously spreading. To the best of our knowledge, the current study is the first to assess the latter parameters in a wide crosssection of Indian dentists. The overall response rate of 403 received out of 1200 questionnaires forwarded on-line, was $33.6 \%$ and is considered acceptable for on-line surveys[5]. The low response rate may be due to the rapid nature (conducted over three days) when the country was still under lockdown, and many dentists may have been occupied with emergency procedures or personal commitments. In terms of the response it was notable that four fifths of our respondents were in private practices, and, hence the data can be construed as more representative of the latter group. On the other hand, the gender of the respondents was almost equally split between males and females and the latter had better knowledge of COVID-19 than their male counterparts $(p<0.05)$. Similar gender differences in the knowledge of infections and control measures have been reported in survey of dentists in countries such as Saudi Arabia[6]. In general, older age group dentists (> 30 years) had significantly higher awareness of COVID-19 cross infection risk assessment, and measure impeding infection transmission measures in the clinic, than the younger dentists. One possible reason for this may be the greater exposure of the older dentists to continuing education courses on infection control in comparison to the younger counterparts. This said, it appeared that an overwhelming majority of dentists (83.4\%) had participated in CPE/Webinar programmes on COVID-19 pandemic and dentistry, although such participation did not significantly correlate with their knowledge and perceptions of the disease. In this context, dentists with a postgraduate education also had a significant higher 
level of awareness on COVID-19 transmission than the generalists. In the battle against COVID-19, the Government of India has developed the Arogya Setu (literally, bridge for disease freeness) mobile application to connect essential health services with the people of India. It is designed to keep a user informed in case he/she has crossed paths with a COVID-19 patient, and is widely used by the Indian public. Approximately two thirds of the respondents (62\%) who were users of this mobile app were better prepared with modest concerns than nonusers in providing patient care $(p<0.05)$, while a majority of respondents (68\%) did not wish to treat patients who were not using this application. It is now known that that SARS-CoV-2 infected person can be asymptomatic for up to 21 days. constituting a major potential source of infection[7]. Almost all of the respondents (99\%) were aware of this fact as well as that the older people and those with underlying chronic medical conditions are more prone to disease complications[8]. Additionally, a large proportion (90.3\%) were aware of the possible mortality risk of COVID-19 among young people. However, the knowledge of the responders in terms of the full spectrum of known symptoms of COVID-19 was relatively low (41.2\%) in comparison to the foregoing.

Nevertheless, it was heartening to note that over three quarters of the responders were aware that acute loss of taste (dysgeusia) and smell (anosmia) are early symptoms of the COVID-19, despite the fact that the announcement was made by the US Centers for Disease Control only in mid-April, 2020. As substantiated by our findings, it would be helpful to address this existing core knowledge gaps among Indian dentists by tailored interventions.

The government of India has divided the entire country into Red Zones, Orange Zones and Green Zones implying varying levels of restrictions aimed at containing the spread of the disease, a promulgation that is revised weekly. Almost all the dentists were aware of the importance of the patients' residential areas during history taking, possibly due to the practical utility of implementing the appropriate infection control guidelines.

The COVID-19 pandemic has now spread to more than 200 countries and hence the travel history of a patient could be crucial in determining his/ her risk status. In relation to the final section of the questionnaire, on patient history taking, clearly almost all of the respondents (93.9\%) were aware of the critical importance of ascertaining the recent travel history of the patient. This is likely to be due to their wide and constant media exposure, as well as numerous webinars on awareness on COVID-19 directly targeting the dental professionals.

Yet, recent studies suggest that early detection, hand washing, self-isolation, and household quarantine will likely be more effective than travel restrictions at mitigating this pandemic[9]. Moreover, perceptions of Indian dentists on COVID-19 patient history taking was not significantly related to socio-demographic and personal attributes except that the younger dentists had better perceptions than their older counterpart ( $p=0.05$; Table 4 ). Alike other respiratory diseases, the transmission of SARS-CoV-2 occurs mainly through respiratory droplets and aerosols generated by coughing and sneezing. The analysis of the data related to the spread of the disease in China indicates that close contact increases disease transmission[10]. 97\% dentists were aware of such modes of infection for COVID-19 which is quite high compared to the awaresness of MERS-CoV[11]. The majority of dentists $(94.8 \%)$ were aware of the importance of hand hygiene in the prevention and control of COVID-19, namely greater awareness of hand hygiene than during the MERS-CoV era[12]. Social distancing is a new normal for the entire world. It is strongly recommended to maintain a minimum distance of 6 feet from others to avoid respiratory droplets[13]. Despite the Government's disease education initiatives $29.8 \%$ dentists were not aware of the critcal importance of maintaing the 6 feet of social distancing limit (Fig. 2). Furthermore, our study implies that neither partcipating in continuing dental education (CDE)/Webinar programmes on COVID-19, nor using Arogya setu mobile application were significantly related to levels of knowledge/ awareness and perceptions on COVID-19 patient identification, disease transmission and history taking among Indian dentists (Tables 2,3,4). Such findings merit further investigations. The study has some limitations. First, it was a cross-sectional study that provided a quick snap-shot view and hence cause-effect relationship of knowledge, and awareness could not be ascertained. Second, the response rate, though theoretically acceptable, was low.

\section{CONCLUSION}

Our study has demonstrated that Indian dentists have reasonable knowledge of COVID-19, and its transmission modes, while specialist dentists were significantly better informed than the generalists. Moreover, the older age group showed modest knowledge of the disease symptoms, and this was significantly better among older female dentists compared to their younger male counterparts.

As India is currently experiencing a major threat from the COVID-19 pandemic that will reverberate well into the future, assessment of the knowledge and practices of dental and medical personnel, related to the disease is critical to identify knowledge gaps and formulate and institute standardized, best practice guidelines against the COVID-19 spread. Indeed, the Government of India together with the Dental Council of India need lead this initiative by conducting further comprehensive sub-continentwide surveys on this critically important subject. 
CONFLICT OF INTEREST

None declared.

\section{AUTHOR CONTRIBUTIONS}

NK: composed the questionnaire, disseminated and collated the data and drafted and edited the final manuscript. LPS: conceptualized the study, wrote the original draft, vetted and approved the final draft. IP: curated and analyzed the data, performed the statistical analysis, wrote the original draft and edited the final manuscript. ZP: collated the data and also drafted and edited the final manuscript. All four authors read and approved the final version of the manuscript.

\section{ACKNOWLEDGMENTS}

We thank Dr. Rahul Bisht for his help in data collection. We also thank all the dentists who took the time in their busy schedules to complete the questionnaire.

\section{FUNDING}

This study received no funds or financial support from any profit or not-for-profit organization.

\section{QUESTIONNAIRE SURVEY ON COVID-19 AMONG INDIAN DENTAL RPOFESSIONALS}

(Kinariwala et al 2020)

\section{A. Demographic Data}

1. E-mail id:

2. Your Gender Male Female

3. Nationality Indian Any other

4. Your speciality:

$\square$ General practitioner

$\square$ Endodontist

$\square$ Prosthodontist

$\square$ Orthodontist

$\square$ Periodontist

$\square$ Pedodontist

$\square$ Any other
5. Your education $\square$ B.D.S
$\square$ M.D.S.
$\square$ Dental student

6. Age (in years)

$\square<30$

$30-40$

40-50

$\square>50$

7. What best describes the type of practice you are in?

$\square$ Private group practice $\quad \square$ Academics $\quad \square$ Solo practice

8. Did you attend webinars or continuing education program to manage patients during pandemic COVID-19 infection?

$\square$ Yes

$\square \quad$ No

9. Do you use Aarogya Setu mobile application?

$\square \quad$ Yes

$\square \quad$ No

\section{B. Knowledge and beliefs on identification of COVID-19 patients}

10. What is incubation period of COVID 19 infection?

$\square \quad 1$ day

2-3 days but may take up to 21 days

$\square \quad 28$ days

11. Which are the symptoms of COVID 19 infection? (Select ALL that apply)

$\square$ Fever

$\square$ Tiredness

口 Diarrhea

None of the above

$\square$ Dry cough

Nasal congestion

Aches and pains

12. Do you believe that patients with chronic disease are at higher risk of getting infection with COVID-19 infection?

$\square$ Yes

$\square \quad$ No

13. Do you believe that older population is at higher risk for COVID-19 infections?

$\square \quad$ Yes

$\square \quad$ No

14. Do you believe mortality rate for young population is zero?

$\square$ Yes

$\square \quad$ No 


\section{Knowledge on transmission of COVID-19}

15. Which of the following statement is TRUE?

$\square$ Pet animals are the biggest source of infection.

$\square$ COVID-19 spreads through droplets of saliva or discharge of the nose.

$\square$ COVID-19 is not transmitted via surface contact.

$\square$ Hand hygiene is not important to prevent transmission of COVID-19.

16. Do you believe COVID-19 infection can spread through body fluids of infected persons?
$\square$ Yes
$\square \quad$ No

17. Can the disease be prevented by good hygiene practices?
$\square$ Yes
$\square \quad$ No

18. What is minimum `social distance` advised to prevent COVID-19 spread?
$\square \quad 2$ feet
$\square \quad 4$ feet
$\square \quad 6$ feet
$\square \quad 12$ feet

\section{History taking practice amongst participants}

19. Will you treat patients not using Aarogya Setu mobile application?
$\square$ Yes
$\square \quad$ No

20. How important is it to know patient's residential area?
$\square$ Highly important
$\square \quad$ Not important

21. Will you consider patient's travel history before treating him?
$\square \quad$ Yes
$\square \quad$ No
$\square$ Maybe

\section{E. Fears associated with best management practices}

22. Have you purchased Personal Protection Equipment kits?
$\square$ Yes
$\square \quad$ No

23. Do you have accessibility to N95 masks?

$\square$ Yes

$\square \quad$ No

24. Have you treated any patients within the last month for emergency treatment?
$\square \quad$ Yes
$\square \quad$ No

25. How confident are you about starting your dental practice again this month?
$\square$ Highly confident
$\square$ Confident
$\square$ Hesitant
$\square \quad$ Not confident at all

26. What is your biggest fear for resuming practice after the epidemic?

$\square$ Limited availability of personal protection kits

$\square$ Limited resources to sterilize and disinfect entire clinic and equipments

$\square$ Risk of getting infection from the patient

$\square$ Increased operating cost and unaffordable cost of the treatment

27. Will you ask your patient to get tested for COVID-19 before treatment?

$\square \quad$ Yes, all the patients for aerosol generating procedures should get themselves tested.

$\square \quad$ No

$\square$ May be,only if patient is symptomatic

28. How worried are you about Medico Legal issues once you open up your dental practice? Rate from 1 to $5:$........... (1-Not worried, 5- extremely worried)

29. Government of India and many dental societies have proposed guidelines for dental clinics. Are you able to follow the guidelines so issued?

Rate from 1 to 3:....... (1-yes, 2-some guidelines only. 3-all guidelines)

30. Do you expect Government to pass a Law or singular Guideline securing Legal and Professional concerns of dentists during and after COVID-19 pandemic? Yes/ No

Thank you for your precious time and contributing to the survey. 


\section{REFERENCES}

1. More than 500 healthcare workers in Wuhan have gotten the coronavirus. Business Insider India. HYPERLINK "https:// www.businessinsider.in/science/news/more-than-500healthcare-workers-in-wuhan-have-gotten-the-coronavirusone-study-found-that-29-of-infections-were-in-medical-staff-/ articleshow/74108681.cms" https://www.businessinsider.in/ science/news/more-than-500-healthcare-workers-in-wuhanhave-gotten-the-coronavirus-one-study-found-that-29-ofinfections-were-in-medical-staff-/articleshow/74108681.cms (Accessed Feb 13, 2020)

2. Zemouri C, de Soet H, Crielaard W, Laheij A. A scoping review on bio-aerosols in healthcare and the dental environment. PLoS One. 2017;12(5):e0178007. doi: 10.1371/journal.pone.0178007.

Full text links CrossRef PubMed Google Scholar Scopus WoS

3. Gamio L. The Workers Who Face the Greatest Coronavirus Risk. The New York Times. March 15, 2020. https://www.nytimes.com/ interactive/2020/03/15/business/economy/coronavirus- workerrisk.html

4. Samaranayake L, Peiris M. Severe acute respiratory syndrome and dentistry: a retrospective view. J Am Dent Assoc. 2004;135(9):1292-1302. doi: 10.14219/jada.archive.2004.0405. Full text links PubMed Google Scholar Scopus WoS 5. Funkhouser E, Vellala K, Baltuck C, et al. Survey methods to optimize response rate in the national dental practice-based research network. Eval Health Prof. 2017;40(3):332-358. doi: $10.1177 / 0163278715625738$.

Full text links CrossRef PubMed Google Scholar Scopus WoS 6. Ye F, Xu S, Rong Z, et al. Delivery of infection from asymptomatic carriers of COVID-19 in a familial cluster. Int J Infect Dis. 2020;94:133-138. doi: 10.1016/j.ijid.2020.03.042.

Full text links CrossRef PubMed Google Scholar Scopus WoS 7. Coronavirus disease 2019 (COVID-19) Situation Report - 51. World Health Organization, $11^{\text {th }}$ March, 2020. HYPERLINK"https://www.who.int/docs/default-source/ coronaviruse/situation-reports/20200311-sitrep-51-covid-19. pdf?sfvrsn=1ba62e57_10" https://www.who.int/docs/defaultsource/coronaviruse/situation-reports/20200311-sitrep-51covid-19.pdf?sfvrsn=1ba62e57_10_(Accessed May 18, 2020)
8. Livingston E, Bucher K. Coronavirus disease 2019 (COVID-19) in Italy. JAMA. 2020;323(14):1335. doi: 10.1001/jama.2020.4344. CrossRef Google Scholar

9. Ibrahim NK, Alwafi HA, Sangoof SO, et al. Cross-infection and infection control in dentistry: Knowledge, attitude and practice of patients attended dental clinics in King Abdulaziz University Hospital, Jeddah, Saudi Arabia. J Infect Public Health. 2017;10(4):438-445. doi: 10.1016/j.jiph.2016.06.002.

Full text links CrossRef PubMed Google Scholar Scopus WoS 10. Li Q, Guan X, Wu P, et al. Early transmission dynamics in Wuhan, China, of novel coronavirus-infected pneumonia. N Engl J Med. 2020;382(13):1199-1207. doi: 10.1056/NEJMoa2001316. Full text links PubMed Google Scholar Scopus WoS

11. Jin $\mathrm{YH}$, Cai $\mathrm{L}$, Cheng $\mathrm{ZS}$, et al. A rapid advice guideline for the diagnosis and treatment of 2019 novel coronavirus (2019-nCoV) infected pneumonia (standard version). Mil Med Res. 2020;7(1):4. doi: 10.1186/s40779-020-0233-6.

Full text links PubMed Google Scholar WoS

12. Alfahan A, Alhabib S, Abdulmajeed I, et al. In the era of corona virus: health care professionals' knowledge, attitudes, and practice of hand hygiene in Saudi primary care centers: a cross-sectional study. J Community Hosp Intern Med Perspect. 2016;6(4):32151. doi:10.3402/jchimp.v6.32151.

Full text links CrossRef PubMed Google Scholar Scopus WoS 13. Gaffar BO, El Tantawi M, Al-Ansari AA, et al. Knowledge and practices of dentists regarding MERS-CoV. A cross-sectional survey in Saudi Arabia. Saudi Med J. 2019;40(7):714-720. doi: 10.15537/smj.2019.7.24304.

Full text links CrossRef PubMed Google Scholar Scopus WoS 14. Kinariwala N, Samaranayake LP, Perera I, Patel Z. Concerns and fears of Indian dentists on professional practice during the 2019 coronavirus disease (COVID-19) pandemic. Oral Dis. 2020 Jun 7: 10.1111 / odi.13459. doi: 10.1111 / odi.13459.

Full text links CrossRef PubMed Google Scholar WoS

\section{Niraj KINARIWALA \\ BDS, MDS, PhD, Associate Professor Department of Conservative Dentistry Karnavati School of Dentistry Karnavati University Gandhinagar, India

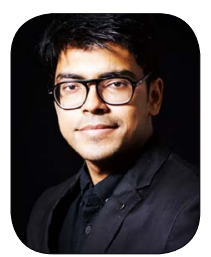

Dr. Niraj Kinariwala is an Associate Professor at the Karnavati University, India. He is a microendodontist and one of the pioneers in field of Guided Endodontics. He is a researcher and eminent speaker. He is Editor and co-Author of the book Guided Endodontics from Springer publishing house. He has published many articles in national and international journals. He has been a guest speaker at ConsAsia 2018, AEEDC Dubai 2019 and APDC 2020. 


\section{Ouestions}

\section{What is the incubation period of COVID-19?}

Da. 1 day;

Db. 2-3 days but may take up to 21 days;

D. 29 days;

Dd. 30 days.

\section{What is the minimum social distance to prevent transmission of COVID-19?}

a. 2 feet;

ab. 4 feet;

ac. 6 feet;

ad. 12 feet.

\section{Which of the following statements is true?}

Da. Pet animals are the biggest source of infection;

ab. Covid-19 spreads through droplets of saliva or discharge of the nose;

ac. Covid-19 is not transmitted via surface contact;

Ud. Hand hygiene is not important to prevent transmission of Covid-19.

\section{Which of the following is not a symptom of Covid19?}

Da. Loss of appetite;

口b. Loss of taste and smell;

ac. Fever;

ad. Dry cough. 


\title{
TEMPERATURE CHANGES IN BONE USING AN AIR SCALER EX VIVO
}

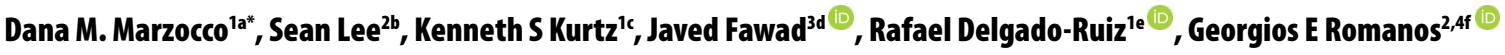 \\ 'Department of Prosthodontics and Digital Technology, Stony Brook University, Stony Brook, New York, USA \\ ${ }^{2}$ Department of Periodontology, School of Dental Medicine, Stony Brook University, Stony Brook, New York, USA \\ ${ }^{3}$ Department of Orthodontics, Eastman Institute for Oral Health, University of Rochester, NY, USA \\ ${ }^{4}$ Department of Oral Surgery and Implant Dentistry, School of Dental Medicine, Johann Wolfgang Goethe University, Frankfurt, Germany
}

aDMD, Clinical Assistant Professor; e-mail: danamarzocco@gmail.com; ORCIDiD:

bDMD; e-mail: sean.t.lee11@gmail.com; ORCIDiD:

'DDS, FACP, Clinical Professor, Director; e-mail: kenneth.kurtz@stonybrookmedicine.edu; ORCIDiD:

dBDS, PhD; e-mail: fawjav@gmail.com; ORCIDiD: https://orcid.org/0000-0002-9253-1989

eDDS, MSc, PhD Associate Professor; e-mail: rafael.delgado-ruiz@stonybrookmedicine.edu; 0RCIDiD: https://orcid.org/0000-0003-1721-0509

'DDS, PhD, DMD, Professor, Director; e-mail: georgios.romanos@stonybrookmedicine.edu; ORCIDiD: https://orcid.org/0000-0002-5952-4752

Introduction Frictional forces induced by osteotomy devices may induce an unwanted temperature increase in bone. This experimental study aimed to evaluate temperature changes produced in dense bone by three different osteotomies produced by an air scaler device.

Methodology Under the same parameters, forty-five linear osteotomies were prepared on the cortical layer of fresh porcine ribs resembling dense bone with three different air scaler insert tips: sagittal saw (Tip A), diamond ball (Tip B) and square chisel (Tip C). The length of the osteotomies was standardized to $10 \mathrm{~mm}$ in length. The depths of cuts ranged from $0.5 \mathrm{~mm}$ to $2.0 \mathrm{~mm}$. The future osteotomy areas were marked with a graphite pen, and thermocouple microprobes were placed $1 \mathrm{~mm}$ lateral at both sides of the marks. The maximum temperature, differential temperature, and time for cut completion were recorded. Analysis of Variance and Kruskal Wallis test were used for the group comparisons.

Results Tip A induced the highest of the maximum temperature recordings (Tip A: $48.0^{\circ} \mathrm{C}$ ). Tip B and C produced comparable maximum temperatures (Tip B: $43.6^{\circ} \mathrm{C}$ and Tip $\mathrm{C}: 44.0^{\circ} \mathrm{C}$ ). Total mean temperature change increased more for Tip B (4.13) and less in Tip C (0.2). Timing of cuts ranged from 30 seconds to 5 minutes $(2.30 \pm 1.76 \mathrm{~min})$. Overall average temperature change was less than $100{ }^{\circ} \mathrm{C}$ within one minute. Conclusion Osseous site preparation can be achieved with the Air scaler and different air scaler inserts without inducing significant critical thermal changes in bone.

\section{KEYWORDS}

Air Scaler; Heat Generation; Osteotomy; Sonic Device; Temperature Change.

\section{INTRODUCTION}

Bone osteotomy is a frequent procedure in oral and orthopedic surgery [1]. In addition to the conventional rotary and manual methods, there are a number of instruments and techniques that can be utilized for an osteotomy. These include laser, water jet, and ultrasonic instruments [2]. The air scaler device may be useful for procedures including implant bed preparation, linear osteotomies, sinus augmentation, bone harvesting and bone splitting. This sonic device operates using compressed air at a lower frequency $(6,000 \mathrm{~Hz})$ than other respective

(c) (1) \& $(9)$ OPEN ACCESS This is an Open Access article under the CC BY-NC 4.0 license. Peer-Reviewed Article

Citation: Marzocco DM, Lee S, Kurtz KS, Calvo-Guirado JL, Fawad J, Romanos GE. Temperature changes in bone using an air scaler Ex Vivo, Stoma Edu J. 2020;7(4):252-258.

Received: October 32, 2020; Revised: November 02, 2020; Accepted: November 13, 2020; Published: November 16, 2020

*Corresponding author: Dana M. Marzocco; School of Dental Medicine, Stony Brook University, 1100 Westchester Hall, Stony Brook, NY $11794-8712$

Tel/Fax: (631) 632-3161; e-mail: danamarzocco@gmail.com

Copyright: $\odot 2020$ the Editorial Council for the Stomatology Edu Journal. 


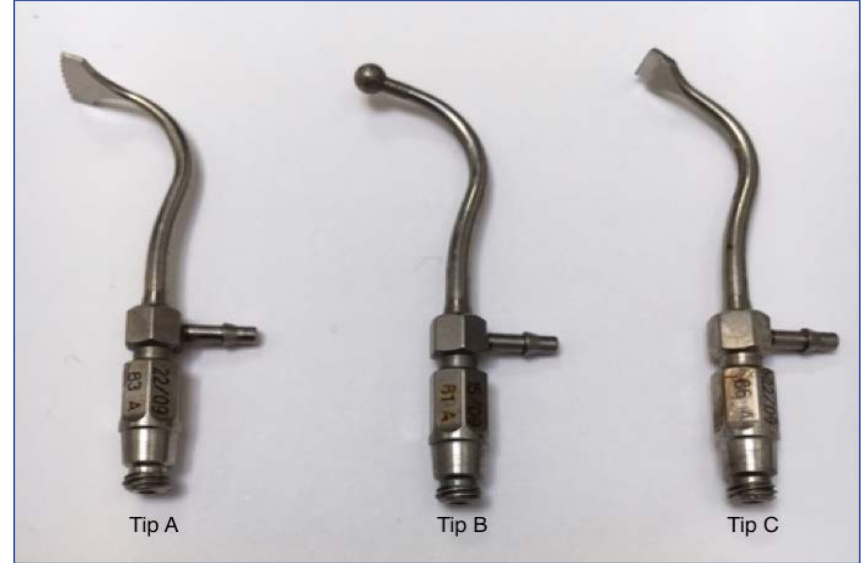

Figure 1. Air scaler tips for the ex vivo study; left to right Tip A (sagittal saw), Tip B (diamond ball), Tip C (square chisel).

devices. The use of an air scaler with internal irrigation is thought to protect the surrounding nerves and soft tissues during the preparation of osseous structures [3]. There have been previous studies, which indicated both sonic and ultrasonic devices resulted in almost no signs of damage to the bone [4]. The thermal changes induced by osteotomy devices can irreversibly affect the bone [5]. It has been demonstrated that an increase in 10 or more degrees (over a normal body temperature of $37^{\circ} \mathrm{C}$ ) for one minute could induce unwanted effects in osseous structures such as osteocyte death, empty lacunae, and reduced vascularization (also called bone osteonecrosis) [6,7].

An additional study [8], also indicated that the bone regeneration was reduced when the temperature was increased. It has been shown that consistent heating over $50^{\circ} \mathrm{C}$ for one min has induced in vitro bone tissue necrosis [9]. As a consequence of the frictional forces exerted by cutting instruments during the osteotomy, the bone temperature is increased. The mechanism for thermal osteonecrosis is multifactorial; the local increment of temperature can induce dehydration of the bone tissues, the osteocytes will suffer rupture of the cellular membrane (apoptosis), and the bone vascularization will be reduced, resulting in bone ischemia. Besides, pre-osteoclastogenic gene expression is increased by initiating bone resorption [10].

The thermal effects induced by the air scaler during osteotomies are unknown; the potential effects of different scaler tips are not clear. The purpose of this study was to assess ex vivo the temperature changes induced by an Air scaler instrument in bone preparation.

\section{METHODOLOGY}

An air scaler (Sonicflex quick 2008/L; KaVo, Biberach an der Riss, Germany) was used in this investigation.

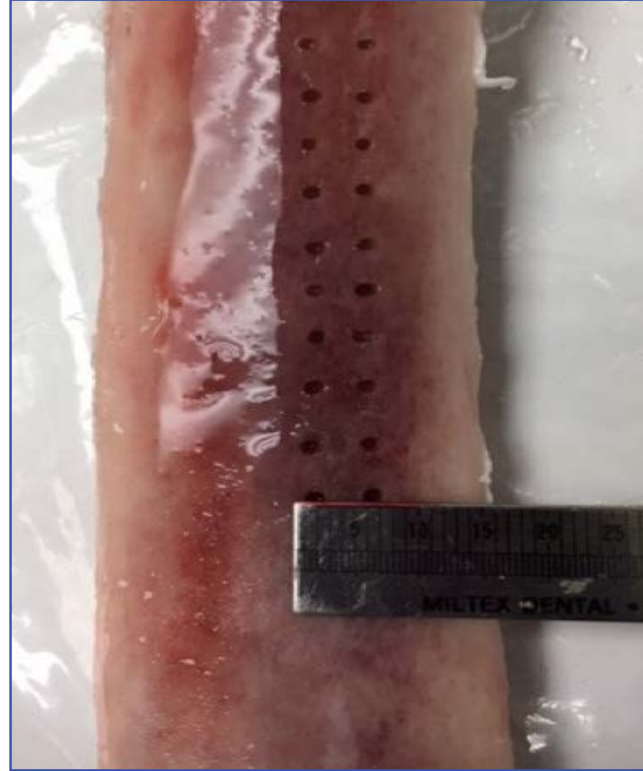

Figure 2. Osteotomies in the bovine rib bone.

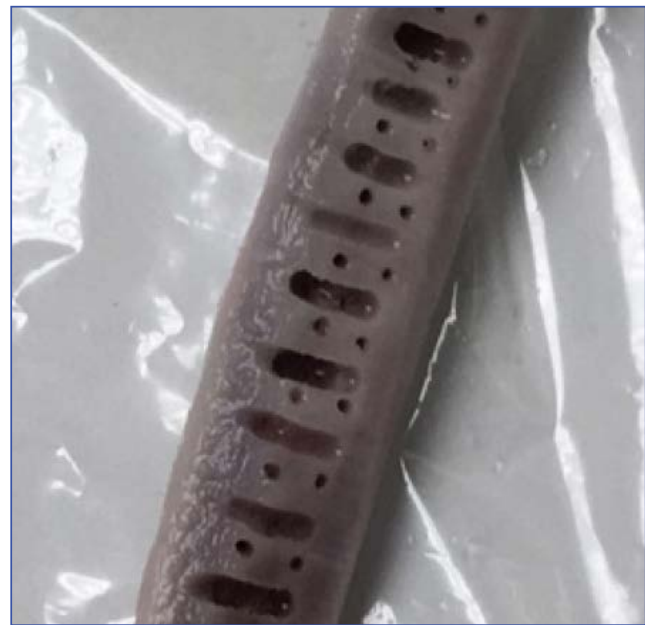

Figure 3. Location of the thermocouples and osteotomies prepared by the air scaler.

The air scaler was set to output level $3(6,000$ $\mathrm{Hz}$, amplitude $240 \mu \mathrm{m}, 71 \mathrm{~dB}$ ). The air scaler was operated using internal irrigation with $50 \%$ of water flow. Three surgical tips were selected for this study (Fig. 1):

- Tip A - Sonicflex bone tip, sagittal saw (\#83),

- Tip B - Sonicflex bone tip, diamond coated ball (\#81) and the

- Tip C - Sonicflex bone tip, square chisel (\#80).

Tip A (sagittal saw) and Tip C (square chisel) had polished, steel cutting surfaces. Tip B (diamond ball), had a rough diamond cutting surface (Fig. 1). For this ex vivo study, cuts were made in fresh dense bovine rib. The rib was denuded from soft tissues and the surface was cleaned with water. The bovine rib was placed on a flat surface for standardization of the osteotomies. Room temperature was used as the initial surface temperature.

A template was prepared and transferred to the rib for each of the tips. The template indicated twenty 
ITable 1. Temperature changes in relation to the used tip of the air scaler.

\begin{tabular}{|l|l|l|l|l|}
\hline Tip & $\begin{array}{l}\text { Mean Temp } \\
\text { Change }\left({ }^{\circ} \mathrm{C}\right)\end{array}$ & $\begin{array}{l}\text { Total Mean } \\
\text { Temp Change }\left({ }^{\circ} \mathrm{C}\right)\end{array}$ & $\begin{array}{l}\text { Standard } \\
\text { Deviation }\left({ }^{\circ} \mathrm{C}\right)\end{array}$ & $\begin{array}{l}\text { Average Standard } \\
\text { Deviation }\left({ }^{\circ} \mathrm{C}\right)\end{array}$ \\
\hline A - Saw & $\begin{array}{l}\text { A1 } 1.38 \\
\text { A2 }-1.41\end{array}$ & -0.01 & $\begin{array}{l}\text { A1 } 6.02 \\
\text { A2 5.8 }\end{array}$ & 5.83 \\
\hline B - Ball & $\begin{array}{l}\text { B1 } 0.2 \\
\text { B2 } 5.58\end{array}$ & 4.13 & $\begin{array}{l}\text { B1 4.08 } \\
\text { B2 4.04 }\end{array}$ & 4.26 \\
\hline C - Chisel & $\begin{array}{l}\text { C1 } 0.2 \\
\text { C2 } 0.2\end{array}$ & 0.2 & $\begin{array}{l}\text { C1 5.8 } \\
\text { C2 4.4 }\end{array}$ & 5.14 \\
\hline
\end{tabular}

ITable 2. Required times for osteotomy procedures using different inserts.

\begin{tabular}{|l|l|l|l|l|l|l|l|l|l|}
\hline Variable & Count & Mean & Minimum & $\begin{array}{l}\text { Lower } \\
\text { Whisker }\end{array}$ & Q1 & Median & Q3 & $\begin{array}{l}\text { Upper } \\
\text { Whisker }\end{array}$ & Max \\
\hline Tip A & 15 & $\begin{array}{l}3.4326 \\
7\end{array}$ & 1 & 1.72685 & 2.01 & 3.3 & 5 & 5.13848 & 5.3 \\
\hline Tip B & 15 & $\begin{array}{l}2.9566 \\
7\end{array}$ & 0.27 & 1.19994 & 1.165 & 3.05 & 5.03 & 4.71339 & 5.05 \\
\hline Tip C & 15 & 1 & 1 & 1 & 1 & 1 & 1 & 1 & 1 \\
\hline
\end{tabular}

Table 3. Maximum temperature changes for different inserts.

\begin{tabular}{|l|l|l|l|l|l|l|l|l|l|}
\hline Variable & Count & Mean & Minimum & $\begin{array}{l}\text { Lower } \\
\text { Whisker }\end{array}$ & Q1 & $\begin{array}{l}\text { Media } \\
\mathrm{n}\end{array}$ & Q3 & $\begin{array}{l}\text { Upper } \\
\text { Whisker }\end{array}$ & Max \\
\hline Tip A & 30 & $\begin{array}{l}26.073 \\
3\end{array}$ & 8 & 19.12287 & 22.475 & 26.9 & 29.75 & 33.0238 & 48 \\
\hline Tip B & 30 & 30.01 & 23.8 & 25.5071 & 27.125 & 29.05 & 31.65 & 34.5129 & 43.6 \\
\hline Tip C & 30 & 31.1 & 25 & 25.59546 & 28 & 30 & 32 & 36.6045 & 44 \\
\hline
\end{tabular}

individual cuts approximately $10 \mathrm{~mm}$ in length (Fig. 2). The width of each cut was indicated by the individual surgical tip.

Agraphitepencil wasutilized to mark the approximate position of the proposed cuts and placement of the thermocouples. Two thermocouples (Model no. IT-23 Thermocouple microprobe, diameter .003" insulated with extruded TFE Teflon, Physitemp instruments, Clifton, NJ, USA) were utilized to assess the thermal changes. One was placed at the coronal end of the proposed cut, the second at mid-length aspect. Thermocouples sites (coronal and mid-length were placed approximately $1 \mathrm{~mm}$ lateral to each proposed cut) (Fig. 3).

The sites for each thermocouple were prepared prior to performing the proposed cuts. Each thermocouple was secured in cortical and cancellous bone. All tips were new and unused. Each tip (A, B, C), was used to make 15 cuts each in the bovine rib; 45 osteotomies were performed in total.

For each subsequent osteotomy, the bovine rib was allowed to return to the room temperature of $21^{\circ} \mathrm{C}$. Thermocouples were relocated to the next osteotomy site and were monitored for their stabilization at room temperature.

Once the room temperature was noted, the next cut could be performed and recorded. Timing was recorded in seconds and minutes with the beginning of the cut and ended when the operator completed the cut. The length of cuts was predetermined to $10 \mathrm{~mm}$ using the template as described previously. All cuts were performed by the same operator. Thermocouples were connected to an electronic digital thermometer system (ADInstruments, Inc., Colorado Springs, CO, USA) that allowed the continuous reading of the temperatures. Each site (coronal and mid-length) had an individual output. The output from each thermocouple was recorded individually. A software program (Lab Chart, ADInstruments, Inc.) was used to record temperature readings (in Celcius), from each thermocouple.

\subsection{Statistical Analysis}

The average temperature change was calculated for the mid-length and laterally positioned 


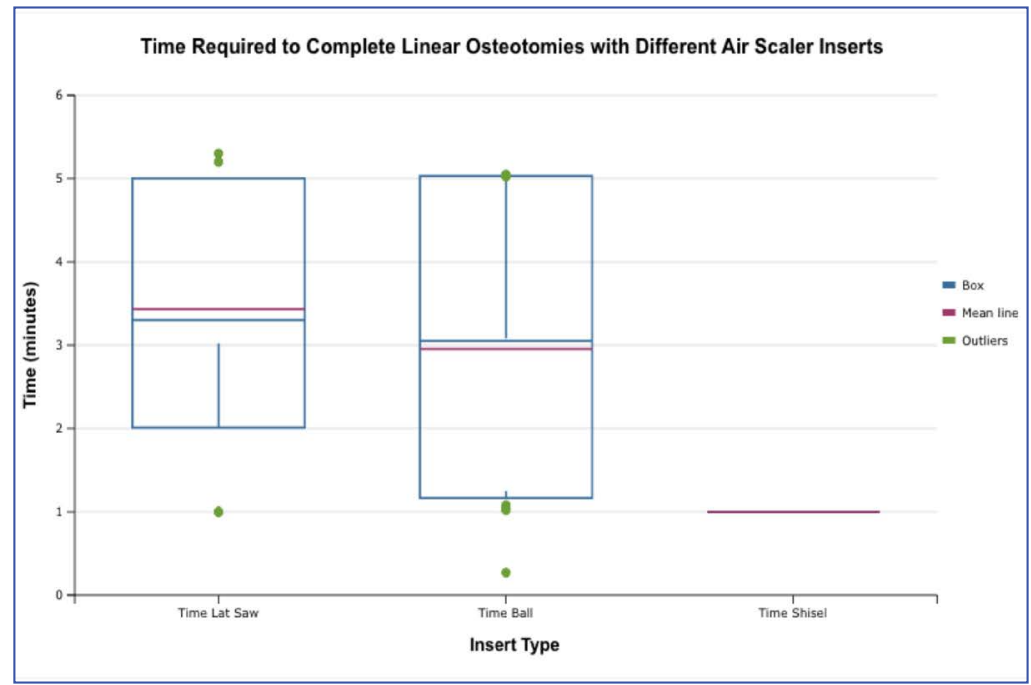

Figure 4. Box plot showing the times required for osteotomies using the different a Air scaler inserts.

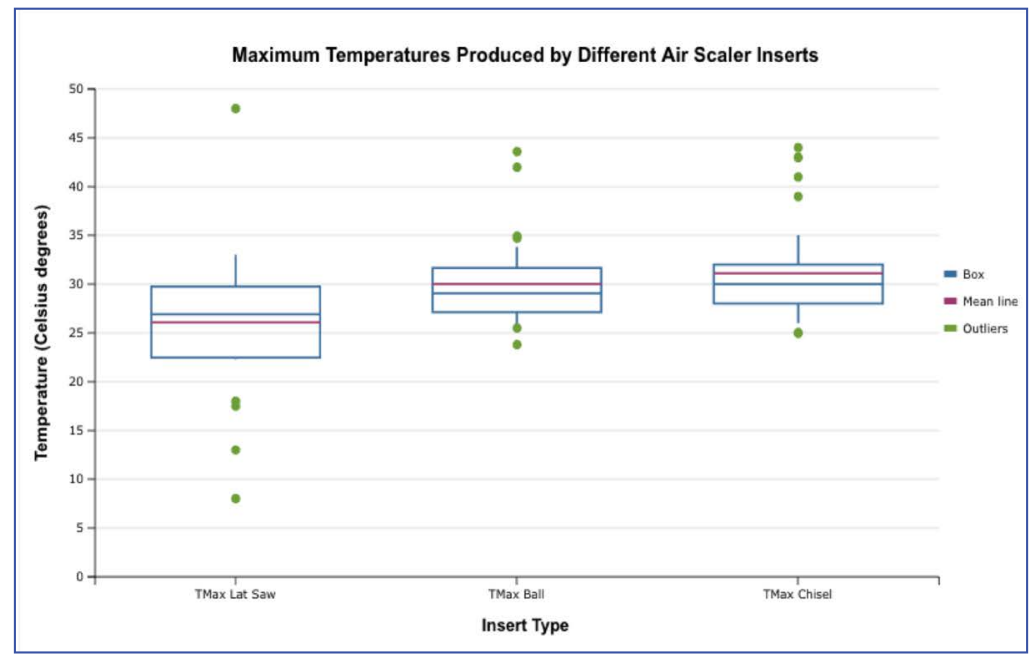

Figure 5. Box plot showing the maximum temperature increase for osteotomies performed ex vivo using an air scaler with different inserts.

thermocouples (Table 1). An average temperature change was determined for each tip $(A, B, C)$. The standard deviation was calculated for the mid-length and lateral thermocouples. An average standard deviation was determined for each tip $(A, B, C)$, as well as time.

Descriptive statistics, mean and standard deviations, and lower and maximum quartiles were used to present the data. ANOVA analysis was used for the comparison of maximum temperatures between groups.

A post-hoc analysis was completed using the Tukey test. The time required to complete the linear osteotomies was compared using the Kruskal Wallis test for multiple independent samples. The software StatPlus: mac, AnalystSoft Inc. -statistical analysis program for macOS. Version v7. See https://www. analystsoft.com/en/ was used for the statistical analysis.

\section{RESULTS}

For each tip $(A, B, C)$, the timing of cuts ranged from $30 \mathrm{sec}$. to $5 \mathrm{~min}(2.30 \pm 1.76 \mathrm{~min}$ ) (Fig. 4 and Table 2 ). The significant lowest time was observed for Tip C $(p=0.00008)$ compared to Tip A and B. The maximum temperatures reached for each tip were as follows: Tip A: $48.0^{\circ} \mathrm{C}$, Tip B: $43.6^{\circ} \mathrm{C}$, and Tip C: $44.0^{\circ} \mathrm{C}$.

Overall the temperature change using the different tips (A, B, C) was less than 10 degrees (Fig. 5). The standard deviations were higher for Tip A. Tip B and Tip $C$ showed comparable standard deviations (Table 3). Statistical comparisons showed a higher maximum temperature for Tip B compared to Tip C $(p=0.00452)$. There were no significant differences between Tip A and Tip B (Table 3).

\section{DISCUSSION}

This experimental study aimed to evaluate the temperature changes and time required to complete linear osteotomies with three different Air scaler inserts. The operators in this study were calibrated, and the experimental design was carefully controlled. The temperature change in this study was less than 10 degrees for all tips $(A, B, C)$ (Fig. 5). This is less than the critical threshold, which could induce unwanted effects in osseous structures (Table 1).

It is possible that the irregular, saw type surface of Tip A contributed to the increased temperature change. 


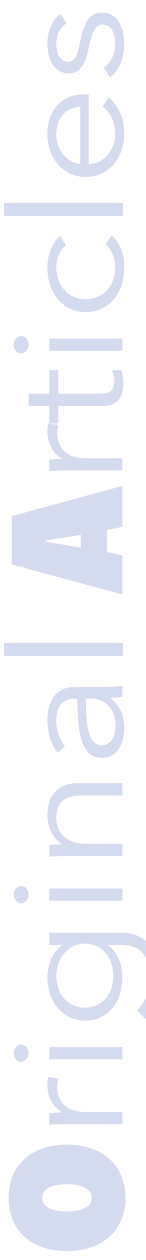

Tip B (ball shape) had a larger cutting surface area as compared to Tip A and Tip C, which was significantly thinner. Tip $B$ had an overall larger surface area as compared to Tip A and C. The diamond cut surface may lead to less heat generation. Tip C (chisel) had a smooth polished surface, which may account for less heat generation. This tip was not sharp and therefore additional mechanical pressure was required in order to create the osteotomy. A previous article [11] has demonstrated that an increase in temperature was inversely proportional to the diameter of the cutting tips.

There are very few studies which examine air scaler heat generation. There are no studies that exist which compare the air scaler to piezoelectic. There are studies which have compared piezoelectric to conventional drilling [12], and ultrasonic to conventional drilling [13].

These comparisons are important for any clinician who is considering adding one of these devices to their clinical practice.

The air scaler has multiple applications in dentistry. It has the capability to perform osteotomies, bone splitting, tooth removal, residual root removal, and window preparations for sinus augmentations [4]. In addition, it has been utilized to perform atraumatic extractions, wisdom tooth extractions, tori removal, endodontic post removal, calculus and caries removal. Because sonic instruments are driven by air compression, they easily connect to an existing dental unit. There is no additional purchase required for an external motor, or an external irrigation source [15]. This helps to minimize the cost incurred by the dentist. It is an appropriate instrument for those practitioners who are concerned with heat generated, while treating osseous tissues.

Other devices, such as piezosurgery have been utilized for dental osteotomy procedures. Piezosurgery has not only been applied in dentistry, but also in cranial and spinal surgery.

There are vast differences between piezosurgery and air scaler instruments. Piezosurgery conducts "piezoelectric vibrations". Piezosurgery operates at a much higher frequency (between 20,000 - 25,000 $\mathrm{Hz}$ ) than sonic instruments (average of $6,000 \mathrm{~Hz}$ ). It must be purchased as a separate device with a separate motor and irrigation source. For this reason, there is a significant cost difference between an air scaler and a piezosurgical unit.

Both air scalers and piezosurgery have been utilized in dentistry. Each instrument has the advantage of altering the osseous tissue, while sparing soft tissue structures. However, previous studies and evidence suggest that piezosurgery may generate a high amount of heat production $[9,15,16]$. Without doubt, it is up to the individual practitioner and the clinical indication which device is appropriate for their clinical practice.

Overall, the air scaler does not induce significant thermal changes in the bone and can be used in a safe manner. The thermal increase induced in the bone by three different air scaler inserts are within a safe range. The experiment conditions along with the continuous irrigation during the procedures potentially contributed to this finding.

Although it was not analyzed in this study, the depth of the cut made depends on the design of the insert tip. Flat tips are more feasible for deeper cuts, while round tips are more feasible for superficial cuts and osteotomies. The time required for the completion of the osteotomies was dependent on the insert design; flat designs were more efficient for the linear osteotomy completion.

This study's strengths are the strict calibration of the operators, and the experimental set-up that allowed the control of all the experimental variables. This study's limitations are that just three air scaler inserts were evaluated, and therefore the results cannot be extrapolated to other air scaler devices and inserts. Given that the air scaler works with the dental unit's air supply, and these vary among dental units, further evaluations are required with different air and power settings.

\section{CONCLUSION}

Osseous site preparation can be achieved with the air scaler; different air scaler inserts may be utilized without inducing significant thermal changes in the bone, as long as the conditions remain within the limits of the above experimental set-up.

\section{CONFLICT OF INTEREST}

None declared.

\section{AUTHOR CONTRIBUTIONS}

DM, GER: Concept. DM, GER, SL, KK: Protocol. DM, SL, GER, FJ: Data gathering and analysis. DM, RDG, KK, GER: Manuscript revision.

\section{ACKNOWLEDGMENTS}

None. 


\section{REFERENCES}

1. Strbac GD, Unger E, Donner R, et al. Thermal effects of a combined irrigation method during implant site drilling. A standardized in vitro study using a bovine rib model. Clin Oral Implants Res. 2014;25(6):665-674. doi: 10.1111/clr.12032. Full text link Pubmed Google Scholar Semantic Scholar Scopus WoS

2. AlAsseri N, Swennen G. Minimally invasive orthognathic surgery: a systematic review. Int J Oral Maxillofac Surg. 2018:47(10):1299-1310. doi: 10.1016/j.ijom.2018.04.017.

Full text link PubMed Google Scholar Scopus WoS

3. Rashad A, Sadr-Eshkevari P, Heiland M, et al. Intraosseous heat generation during sonic, ultrasonic and conventional osteotomy. J Craniomaxillofac Surg. 2015;43(7):1072-1077. doi: 10.1016/j. jcms.2015.05.018.

Full text link PubMed Google Scholar Scopus WoS

4. Stacchi C, Berton F, Turco G, et al. Micromorphometric analysis of bone blocks harvested with eight different ultrasonic and sonic devices for osseous surgery. J Craniomaxillofac Surg. 2016;44(9):1143-1151. doi: 10.1016/j.jcms.2016.04.024.

Full text link PubMed Google Scholar Scopus WoS

5. Eriksson AR, Albrektsson T. Temperature threshold levels for heat-induced bone tissue injury: a vital-microscopic study in the rabbit. J Prosthet Dent. 1983;50(1):101-107. doi: 10.1016/00223913(83)90174-9.

Full text link PubMed Google Scholar Scopus WoS

6. Eriksson AR, Albrektsson T. Assessment of bone viability after heat trauma. A histological, histochemical and vital microscopic study in the rabbit. Scand J Plast Reconstr Surg. 1984;18(3):261268. doi: 10.3109/02844318409052849.

PubMed Google Scholar Scopus WoS

7. Noble B. Bone microdamage and cell apoptosis. Eur Cell Mater. 2003;6:46-55; discusssion 55. doi: 10.22203/ecm.v006a05.

Full text link PubMed Google Scholar Scopus

8. Eriksson AR, Albrektsson T. The effect of heat on bone regeneration: an experimental study in the rabbit using the bone growth chamber. J Oral Maxillofacial Surg. 1984;42(11):705-711. doi: 10.1016/0278-2391(84)90417-8.

Full text link PubMed Google Scholar Scopus WoS
9. Rashad A, Kaiser A, Prochnow N, et al. Heat production during different ultrasonic and conventional osteotomy preparations for dental implants. Clin Oral Implants Res. 2011;12(22):1361-1365. doi: 10.1111/j.1600-0501.2010.02126.x.

Full text link PubMed Google Scholar Scopus WoS

10. Strbac GD, Giannis K, Unger E, et al. A novel standardized bone model for thermal evaluation of bone osteotomies with various irrigation methods. Clin Oral Implants Res. 2014;25(5):622631. doi: $10.1111 / \mathrm{clr}$.12090.

PubMed Google Scholar Scopus WoS

11. Stelzle F, Frenkel C, Reimann M, et al. The effect of load on heat production, thermal effects and expenditure of time during implant site preparation - an experimental ex vivo comparison between piezosurgery and conventional drilling. Clin Oral Implants Res. 2014;25(2):e140-e148. doi: 10.1111/clr.12077. Full text link PubMed Google Scholar Scopus WoS

12. Rashad A, Sadr-Eshkevari P, Heiland M, et al. Practitioner experience with sonic osteotomy compared to bur and ultrasonic saw: a pilot in vitro study. Int J Oral Maxillofac Surg. 2015;44(2):203-208. doi: 10.1016/j.ijom.2014.09.004.

Full text link PubMed Google Scholar Scopus WoS

13. Szalma J, Kiss C, Gurdán Z, et al. Intraosseous heat production and preparation efficiency of surgical tungsten carbide round drills: the effect of coronectomy on drill wear. J Oral Maxillofac Surg. 2016;74(3):442-452. doi: 10.1016/j.joms.2015.11.012. Full text link PubMed Google Scholar Scopus WoS

14. Heinemann F, Hasan I, Kunert-Keil C, et al. Experimental and histological investigations of the bone using two different oscillating osteotomy techniques compared with conventional rotary osteotomy. Ann Anat. 2012;194(2):165-170. doi: 10.1016/j. aanat.2011.10.005

PubMed Google Scholar Scopus WoS

15. Möhlhenrich SC, Modabber A, Steiner T, et al. Heat generation and drill wear during dental implant site preparation: systematic review. Br J Oral Maxillofac Surg. 2015;53(8):679-689. doi: 10.1016/j.bjoms.2015.05.004.

Full text link PubMed Google Scholar Scopus WoS
Dana M. MARZOCCO

DMD, Clinical Assistant Professor Department of Prosthodontics and Digital Technology Stony Brook, New York, USA

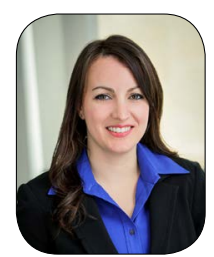

Dr. Dana M. Marzocco works in private practice in New Hyde Park, New York. Her practice is limited to Prosthodontics. She holds a faculty position as a Clinical Assistant Professor at the Stony Brook University, School of Dental Medicine, located in Stony Brook, New York. In addition, Dr. Marzocco lectures on various implant and restorative topics. 


\section{Questions}

1.The Air scaler device operates using compressed air at a frequency of:
Da. $2000 \mathrm{~Hz}$;
Db. $4000 \mathrm{~Hz}$;
]c. $6000 \mathrm{~Hz}$;
d. $8000 \mathrm{~Hz}$.

2. If temperature $\left({ }^{\circ} \mathrm{C}\right)$ were to increase during a procedure, the operator would be concerned. How many degrees of an increase would be a concern?

Da. 8 degrees;

ab. 10 degrees;

ac. 12 degrees;

口d. 15 degrees;

3. An Air scaler device can be utilized in which of the following procedures?
Da. Sinus augmentation;
ab. Harvesting bone;
uc. Osteotomies;
ad. All of the above.

4. Previous studies have shown that heating osseous tissue over $50^{\circ} \mathrm{C}$ for a duration of time has induced in vitro necrosis. After what amount of time does the necrosis occur?
Da. 30 seconds;
ab. 45 seconds;
ac. 1 minute;
ad. 2 minutes. 


\title{
THE EFFECTS OF TONGUE PLATE AND TONGUE APPLIANCE ON MAXILLARY DEFICIENCY IN GROWING PATIENTS
}

\author{
Abdolreza Jamilian ${ }^{1 a^{*}}{ }^{(1)}$, Ludovica Nucci ${ }^{2 b}$, Ehsun Amini ${ }^{3 c}$, Mitra Toliat ${ }^{\text {1d }}$, Shima Bagherzadeh Hamedani ${ }^{4 e}$, \\ Felice Femiano ${ }^{2 f}(\mathbb{D}$ \\ 'Department of Orthodontics, Faculty of Dentistry, Cranio Maxillofacial Research Center, Tehran Medical Sciences, Islamic Azad University, Tehran, Iran \\ 2Multidisciplinary Department of Medical-Surgical and Dental Specialties, Dental School, University of Campania Luigi Vanvitelli, Naples, Italy \\ 3Department of Oral and Maxillofacial Surgery, Dental School, Shahid Beheshti University of Medical Sciences, Tehran, Iran \\ ${ }^{4}$ Clinical Division of Orthodontics, Faculty of Dentistry, Medical University of Vienna, Vienna, Austria
}

aDDS, MSc, PhD, Professor; e-mail: info@jamilian.net; ORCIDiD: https://orcid.org/0000-0002-8841-0447

bDDS, Undergraduate Dental Student; e-mail: ludovica.nucci@virgilio.it; ORCIDiD: https://orcid.org/0000-0002-7174-7596

'DDS, OMFS Resident; e-mail: Ehsun.amini@gmail.com

'DDS; e-mail:Toliatmitra@gmail.com

eDDS; e-mail: ajamilian@yahoo.com

fDDS, PhD, Professor; e-mail: felice.femiano@unicampania.it; ORCIDiD: https://orcid.org/0000-0001-9341-2490

\section{ABSTRACT}

d) https://doi.org/10.25241/stomaeduj.2020.7(4).art.4

Objectives The purpose of this randomized trial study was to compare the effects of tongue plate and tongue appliance in the treatment of Class III malocclusion with maxillary deficiency in growing patients. Material and Methods 40 patients (19 males, 21 females) with maxillary deficiency were selected. 20 patients (9 boys, 11 girls) with the mean age of $9.3 \pm 1.2$ were treated with tongue plate. 20 patients (10 boys, 10 girls) with the mean age of $10.1 \pm 0.7$ were treated by tongue appliance. Lateral cephalograms obtained at the beginning and end of the study were analyzed.

Results Paired t-tests and Wilcoxon test showed that SNA and ANB significantly increased in both groups. The Mann-Whitney test showed that there were no statistically significant differences between the two groups except for Jarabak ratio. Jarabak increased by $0.6 \pm 3.2^{\circ}$ in the tongue appliance group and it decreased $0.4 \pm 1.6^{\circ}$ in the tongue plate group $(p<0.03)$.

Conclusion Both treatment modalities were successful in moving the maxilla forward. The crib of the tongue appliance might bother the tongue and consequently parents are complaining about minor inflammation of the tongue. The smooth surface of the tongue plate might therefore confer some advantages to this system as compared to the tongue plate.

\section{KEYWORDS}

Class III Malocclusion; Tongue Plate; Growth Modification; Maxillary Deficiency; Tongue Appliance.

\section{INTRODUCTION}

Skeletal Class III malocclusion is characterized by mandibular prognathism, maxillary retrusion or a combination of both. Approximately, half of the skeletal Class III malocclusions are reported to result from maxillary deficiency[1].

A series of treatment approaches can be found in the literature regarding orthopedic treatment in Class III malocclusion with maxillary deficiency in growing patients. Delaire[2] developed the orthopedic face mask to stimulate maxillary growth. Reverse-pull headgear was also used to treat this discrepancy $[3,4]$. The use of ankylosed primary canines as anchorage for maxillary orthopedics is a viable alternative method[5,6]. Recently, tongue appliance[7-10], tongue plate[11,12], miniplates[13, 14], bone-anchored maxillary protraction[15-17],

(c) (1) () OPEN ACCESS This is an Open Access article under the CC BY-NC 4.0 license. Peer-Reviewed Article

Citation: Jamilian A, Nucci L, Amini E, Toliat M, Hamedani SB, Femiano F. The effects of tongue plate and tongue appliance on maxillary deficiency in growing patients. Stoma Edu J. 2020;7(4):259-267.

Received: August 07, 2020; Revised: August 24, 2020; Accepted: August 28, 2020; Published: September 01, 2020

*Corresponding author: Professor Abdolreza Jamilian, DDS, MSc, PhD, Department of Orthodontics, Faculty of Dentistry, Cranio Maxillofacial

Research Center, Tehran Medical Sciences, Islamic Azad University, Tehran, Iran

Tel./Fax: 0098-22052228; e-mail: info@jamilian.net

Copyright: $\odot 2020$ the Editorial Council for the Stomatology Edu Journal. 
ITable 1. Pre and post treatment measurements of the tongue plate and tongue appliance.

\begin{tabular}{|c|c|c|c|c|}
\hline $\begin{array}{l}\text { Cephalometric } \\
\text { measurement }\end{array}$ & Groups & $\begin{array}{l}\text { Pre treatment } \\
\text { Mean } \pm \text { SD }\end{array}$ & $\begin{array}{l}\text { Post treatment } \\
\text { Mean } \pm \text { SD }\end{array}$ & p value \\
\hline \multirow[t]{2}{*}{ SNA $^{\circ}$} & Tongue Plate & $76.0 \pm 1.7$ & $78.4 \pm 1.7$ & $0.001^{*}$ \\
\hline & Tongue Appliance & $75.9 \pm 2.8$ & $77.4 \pm 2.7$ & $0.001^{*}$ \\
\hline \multirow[t]{2}{*}{ SNB $^{\circ}$} & Tongue Plate & $76.9 \pm 1.8$ & $77.5 \pm 1.4$ & 0.08 \\
\hline & Tongue Appliance & $77.2 \pm 2.9$ & $77.2 \pm 2.9$ & 1 \\
\hline \multirow[t]{2}{*}{ ANB $^{\circ}$} & Tongue Plate & $-0.9 \pm 1.1$ & $0.7 \pm 1.6$ & $0.001^{*}$ \\
\hline & Tongue Appliance & $-1.4 \pm 1.7$ & $0.2 \pm 1.4$ & $0.001^{*}$ \\
\hline \multirow[t]{2}{*}{$\mathrm{U} 1$ to $\mathrm{SN}^{\circ}$} & Tongue Plate & $99.9 \pm 6.1$ & $103.7 \pm 5.3$ & $0.02^{*}$ \\
\hline & Tongue Appliance & $98.6 \pm 6$ & $99.9 \pm 7.2$ & 0.3 \\
\hline \multirow[t]{2}{*}{ ANS-PNS (mm) } & Tongue Plate & $45.7 \pm 3.1$ & $47 \pm 3$ & $0.001^{*}$ \\
\hline & Tongue Appliance & $45.1 \pm 3.9$ & $45.7 \pm 3.5$ & $0.007^{*}$ \\
\hline \multirow[t]{2}{*}{ Palatal-SN } & Tongue Plate & $10.9 \pm 3.4$ & $10.4 \pm 4.1$ & 0.2 \\
\hline & Tongue Appliance & $9.2 \pm 3$ & $8.4 \pm 2.8$ & 0.2 \\
\hline \multirow[t]{2}{*}{ GoGn (mm) } & Tongue Plate & $65 \pm 4$ & $66.9 \pm 3.8$ & $0.001^{*}$ \\
\hline & Tongue Appliance & $66.4 \pm 7.4$ & $67.5 \pm 8$ & 0.1 \\
\hline \multirow[t]{2}{*}{ Jarabak R. (\%) } & Tongue Plate & $61.7 \pm 3.7$ & $61.3 \pm 3.8$ & 0.3 \\
\hline & Tongue Appliance & $61.7 \pm 3$ & $62.3 \pm 4.4$ & 0.5 \\
\hline \multirow[t]{2}{*}{ U1 to Palatal ${ }^{\circ}$} & Tongue Plate & $108.7 \pm 11.4$ & $111.8 \pm 11.4$ & $0.03^{*}$ \\
\hline & Tongue Appliance & $107.8 \pm 6.3$ & $108.8 \pm 7.8$ & 0.6 \\
\hline \multirow[t]{2}{*}{ Inclination Angle } & Tongue Plate & $81.4 \pm 3.4$ & $83 \pm 4.3$ & $0.05^{*}$ \\
\hline & Tongue Appliance & $83.6 \pm 3.2$ & $85.9 \pm 5.8$ & 0.07 \\
\hline \multirow[t]{2}{*}{ GoGn-SN ${ }^{\circ}$} & Tongue Plate & $35.9 \pm 5.4$ & $36.4 \pm 4.9$ & 0.3 \\
\hline & Tongue Appliance & $35.4 \pm 4.7$ & $34.4 \pm 6.3$ & 0.3 \\
\hline \multirow[t]{2}{*}{$\mathrm{IMPA}^{\circ}$} & Tongue Plate & $92.3 \pm 6.2$ & $87 \pm 6.5$ & $0.001^{*}$ \\
\hline & Tongue Appliance & $88.2 \pm 6.6$ & $83 \pm 5.5$ & $0.001^{*}$ \\
\hline
\end{tabular}

and miniscrew $[18,19]$ have also been used to treat maxillary deficiency. As known, the maxilla cannot be moved after growth cessation; therefore, the common belief is that the treatment of adult patients will eventually need surgery[20].

Both the tongue appliance and tongue plate have recently been introduced to literature and there is no previous comparison between the effects of the two; therefore, the aim of this study was to compare the effects of the tongue plate and tongue appliance in growing patients with class III malocclusion due to maxillary deficiency.

\section{MATERIALS AND METHODS}

In this retrospective study, the patient data were handled according to the requirements and recommendations of the Declaration of Helsinki. The ethical approval was obtained from SBUMS Local Research Ethics Committees. The informed written consent was obtained from the patient and a parent or guardian. A CONSORT diagram showing the flow of patients through the trial is provided in Fig1. Sixty-eight patients were enrolled in this research. 23 patients were excluded due to not meeting the inclusion criteria. Three of the patients in the tongue plate and 2 patients in the tongue appliance dropped out before final assessment. 40 patients (19 males, 21 females) with skeletal Class III malocclusion due to maxillary deficiency were selected. Considering the previous studies, a sample size of 40 patients was chosen for this study[21-23]. All subjects gave their informed written consent and met the following inclusion criteria:

1) Sella-Nasion-A (SNA) $\leq 80^{\circ}$, Sella-Nasion-B (SNB) $\leq$ $80^{\circ}$, A-Nasion-B (ANB) $\leq 0^{\circ}$

2) Class III molar relationship

3) No mandibular shift

4) Concave facial profile

5) Negative overjet

6) No congenital disease or endocrine disorders

7) No previous orthodontic treatment and surgical intervention.

An unstratified subject allocation sequence was generated by a computer program; random numbers were generated and their assignment was concealed from the clinician until the time of the appointment at which the appliance was to be placed. The treating clinician was blinded from the randomization procedure, but because of clear differences in appliance design, blinding was not possible during the treatment period. A table of 


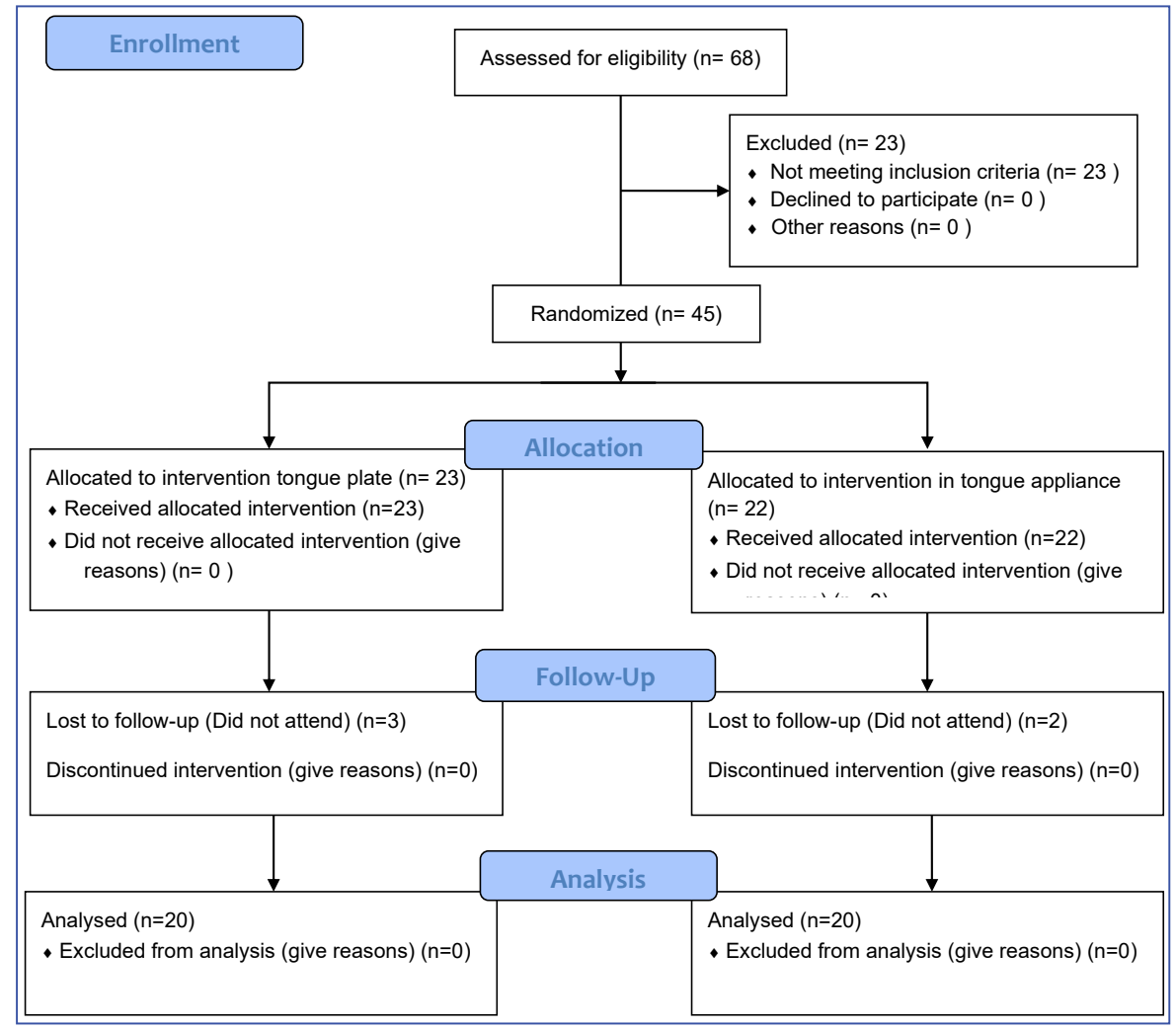

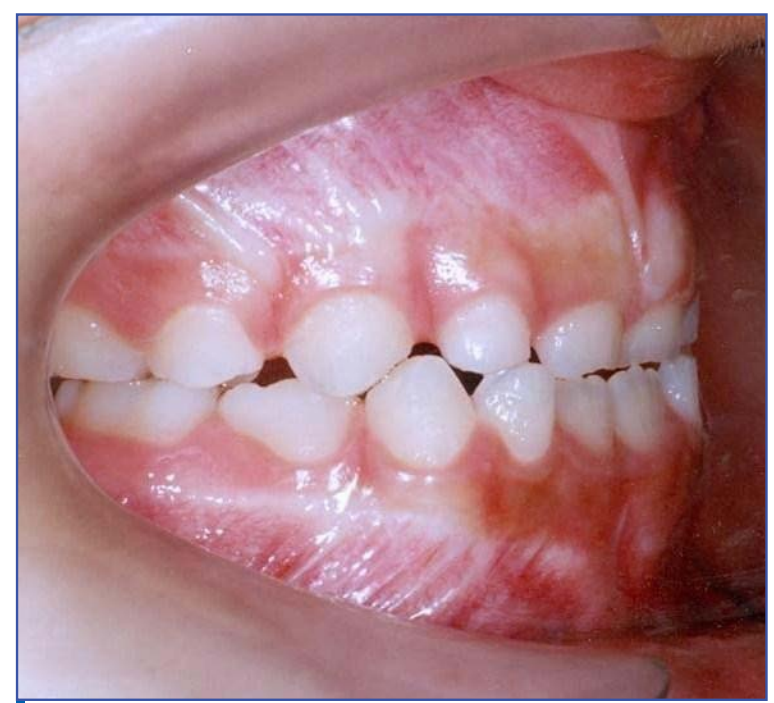

Figure 2. Right view of pretreatment of a tongue plate patient.

random numbers was used to divide the patients into two equal groups. A CONSORT diagram showing the flow of patients through the trial is provided in Fig. 1. The patients were randomly assigned to two equal groups using a standard random number table. The tongue appliance has some $C$ clasps on the upper permanent central or lateral incisors or deciduous canines. An acrylic plate was mounted posterior to the upper incisors. The patient was instructed to wear the appliance full-time except for eating, contact sports and tooth brushing. The active treatment time lasted for 24 months. The patient was examined and progress was observed after each monthly visit. Pre and post photographs and cephalometric images of one of the tongue plate patients can be seen in

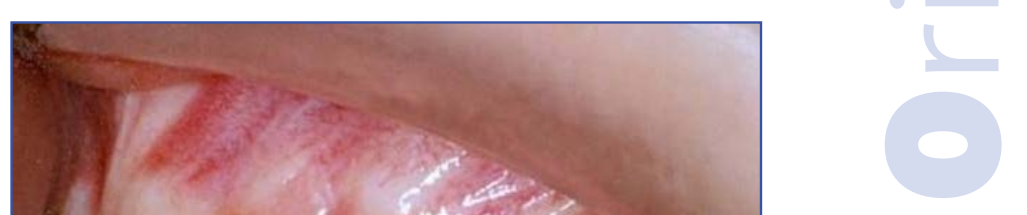

Figs. 2-8. 20 patients (10 boys, 10 girls) with the mean age of $10.1 \pm 0.7$ were treated by tongue appliance. A tightly fitting and well retained upper removable appliance was fabricated with Adams clasps on the upper first permanent molars and two $C$ clasps were placed on the upper permanent central or lateral incisors or deciduous canines. Long tongue cribs were placed in the inter-canine area in an effort to restrict the tongue. These cribs were long enough to cage the tongue and were adjusted to avoid traumatizing the floor of the mouth.

The patients were instructed to wear the appliance full-time except for eating, contact sports and tooth brushing. The active treatment time lasted for $17 \pm 3$ months. The patients were examined and progress 
Iable 2. Comparison of cephalometric changes between tongue plate and tongue appliance.

\begin{tabular}{|c|c|c|c|}
\hline $\begin{array}{l}\text { Cephalometric mea- } \\
\text { surement }\end{array}$ & $\begin{array}{c}\text { Tongue Plate } \\
\qquad \pm \pm S D\end{array}$ & 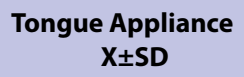 & p Value \\
\hline SNA $\left({ }^{\circ}\right)$ & $2.4 \pm 1.5$ & $1.5 \pm 1.4$ & 0.2 \\
\hline ANB $\left(^{\circ}\right)$ & $1.6 \pm 1$ & $1.6 \pm 1.6$ & 0.6 \\
\hline U1 to $\mathrm{SN}\left({ }^{\circ}\right)$ & $3.8 \pm 6.3$ & $1.3 \pm 5.5$ & 0.2 \\
\hline Palatal-SN $\left(^{\circ}\right)$ & $-0.5 \pm 3.4$ & $-0.8 \pm 2.9$ & 0.6 \\
\hline GoGn (mm) & $1.9 \pm 1.3$ & $1.1 \pm 1.5$ & 0.09 \\
\hline Jarabak R. (\%) & $-0.4 \pm 1.6$ & $0.6 \pm 3.2$ & 0.03 \\
\hline IMPA $\left({ }^{\circ}\right)$ & $-5.3 \pm 3$ & $-5.2 \pm 7.2$ & 0.7 \\
\hline
\end{tabular}

*Statistical significance was set at $\mathrm{p}<0.05$

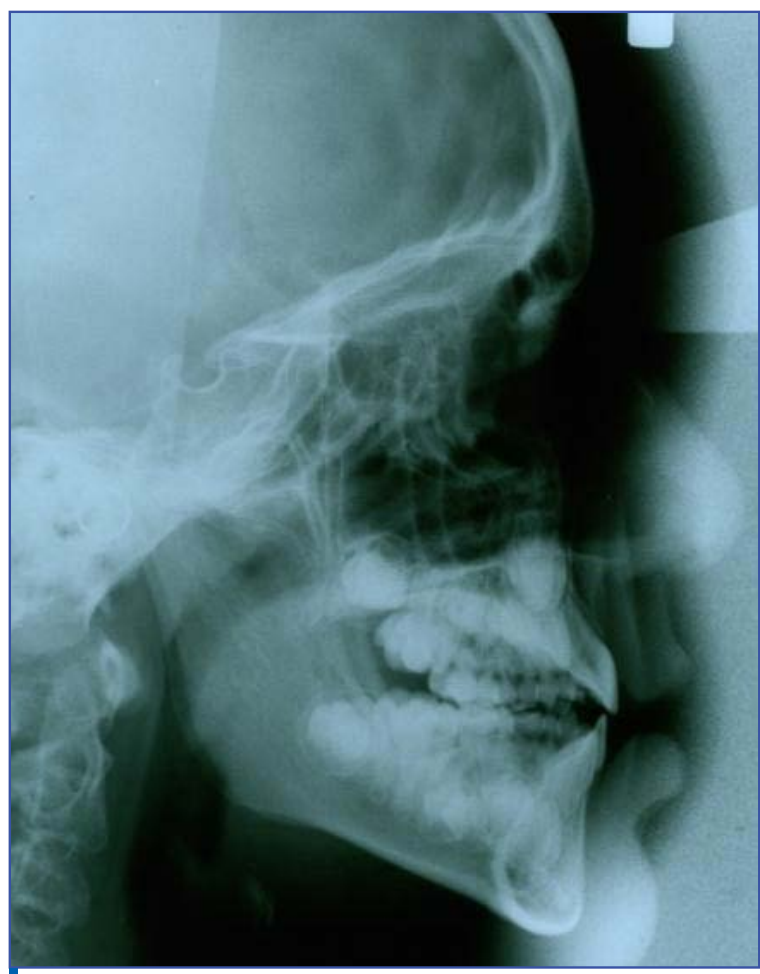

Figure 4. Pretreatment cephalometric of a patient with tongue plate.

was observed after each monthly visit. Pre and post photographs and cephalometric images of one of the tongue appliance patients can be seen in Figs. 9-14. Lateral cephalograms, OPGs, photos, and study casts of patients of both groups were taken before (T1) and after (T2) treatment.

SNA, SNB, ANB, GoGn-Sn (mandibular plane angle), Upper 1 to SN (angle between long axis upper central incisor and anterior cranial base), IMPA (angle between the long axis of the lower central incisor and mandibular plane), Nasolabial angle (the angle formed between the lines tangent to the columella and the upper lip vermillion and intersecting at

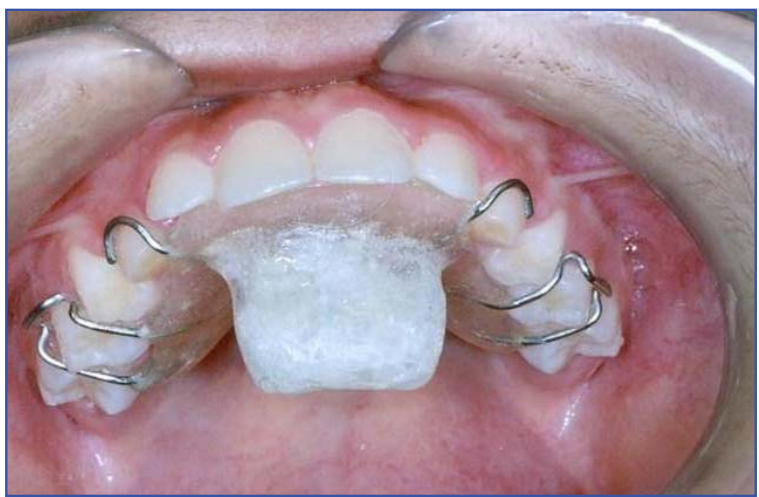

Figure 5. Tongue plate in situe.

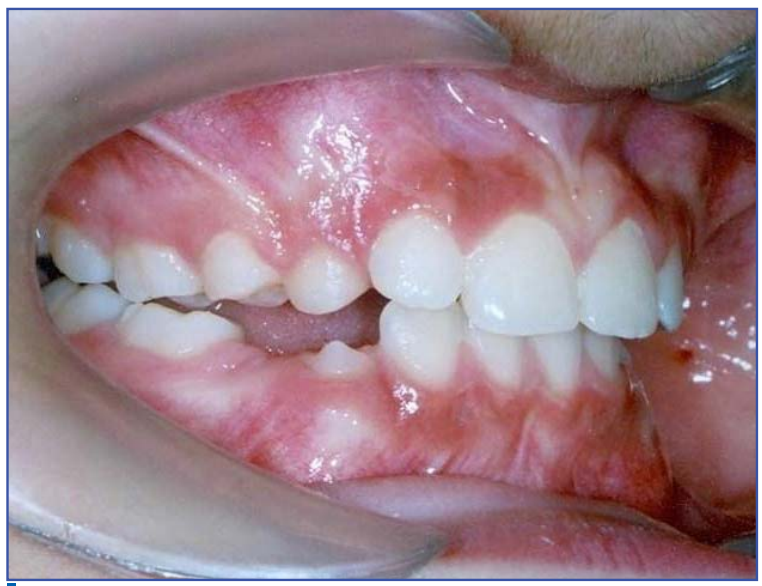

Figure 6. Right view of posttreatment of the same tongue plate patient.

the subnasale), inclination angle (the angle formed between a perpendicular line to soft tissue nasion and the palatal plane), and Jarabak ratio (the ratio between the posterior and anterior face heights; $\mathrm{S}-\mathrm{Go} / \mathrm{N}-\mathrm{Me}$ ) of each patient were measured before and after treatment.

The reliability of the measurements was determined by randomly selecting 16 cephalograms at the beginning and end of the treatment from each group. They were traced twice on two separate occasions 


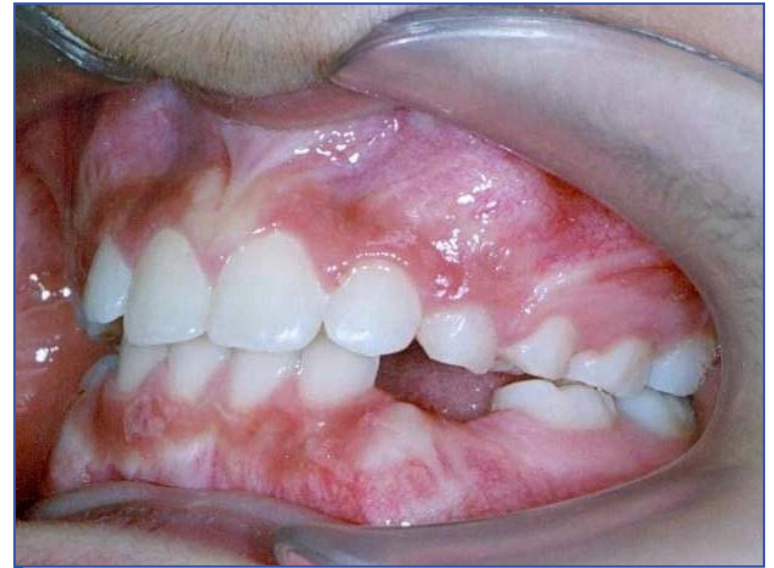

Figure 7. Left view of posttreatment of the same tongue plate patient.

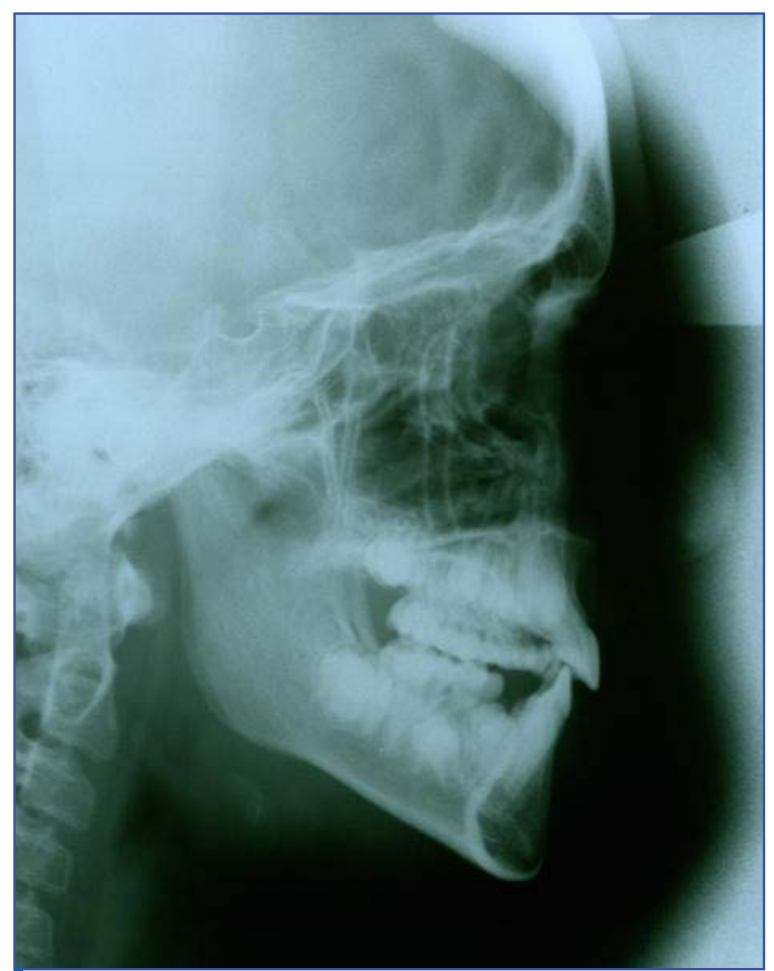

Figure 8. Posttreatment cephalometric of the same patient with tongue plate.

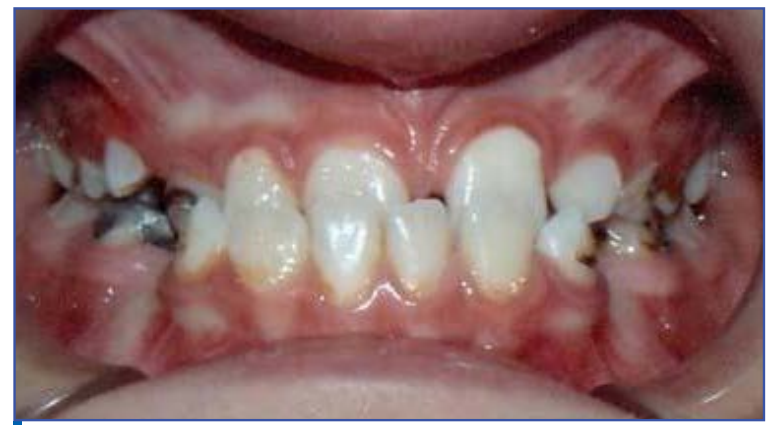

Figure 9. Frontal view of pretreatment of a tongue appliance patient.

after a two-week interval. A paired t-test showed no statistically significant differences between the two measurements.

An intraclass correlation coefficient was also calculated to assess test/retest reliability. The level

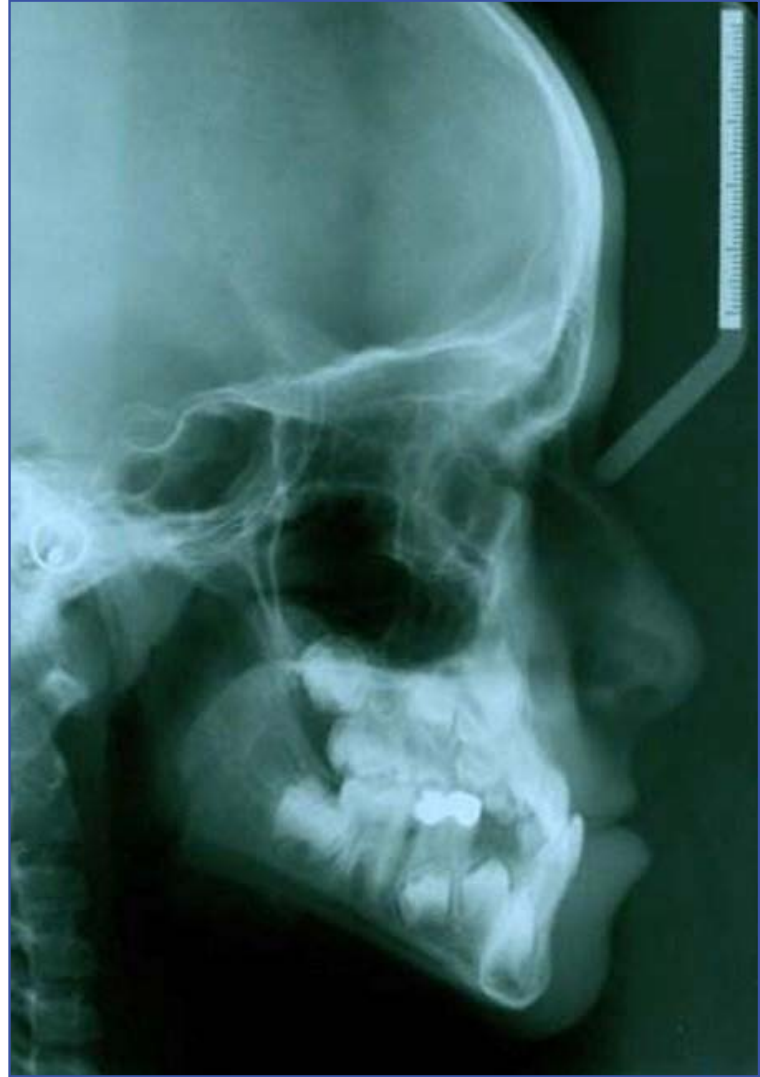

Figure 10. Pretreatment cephalometric of a patient with tongue appliance.

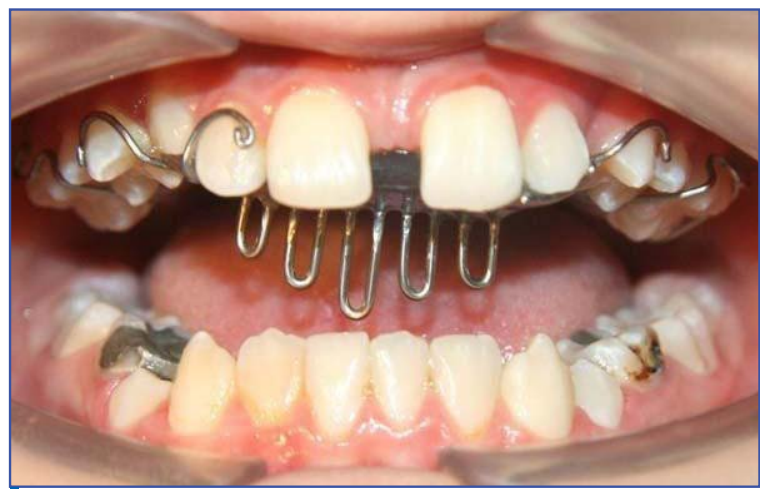

Figure 11. Frontal view of the tongue appliance.

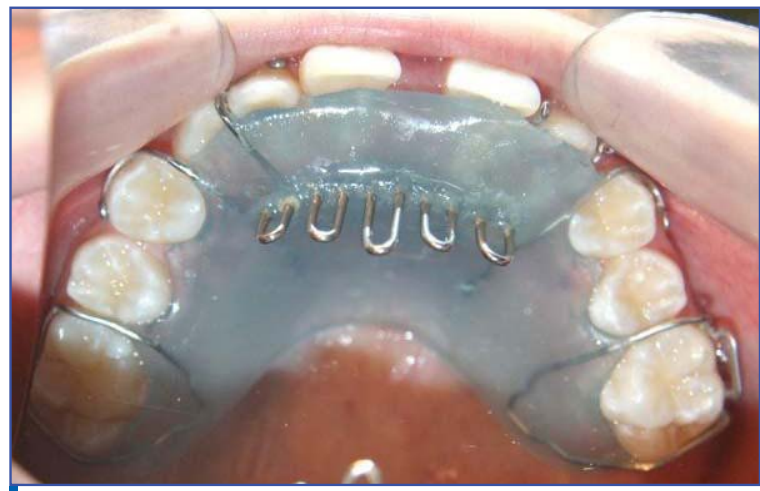

Figure 12. Palatal view of the tongue appliance.

of statistical significance was set at $p<05$. Paired T-tests were used for intra group evaluation if the distribution was normal; otherwise, the Wilcoxon test was used. The Mann-Whitney test was used to compare the data between the two groups. 


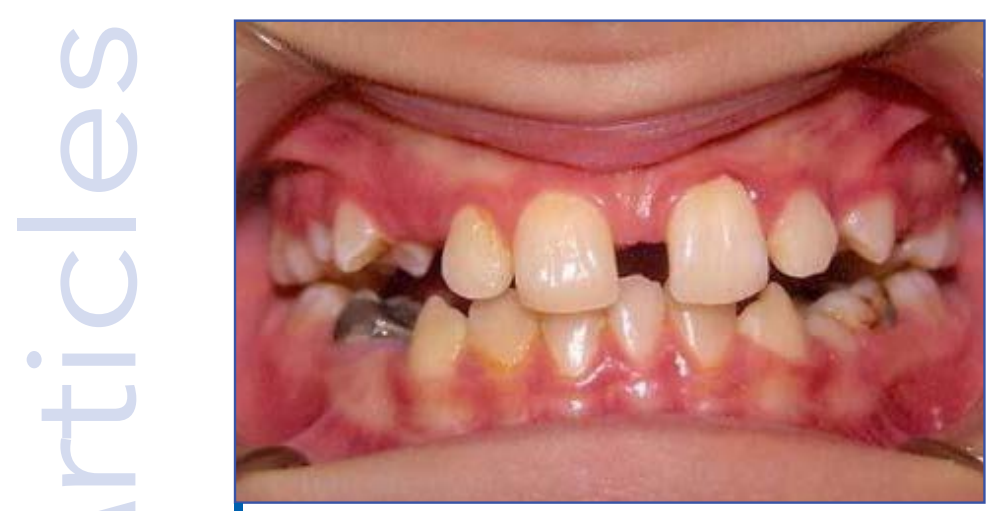

Figure 13. Frontal view of posttreatment of the same tongue appliance patient.

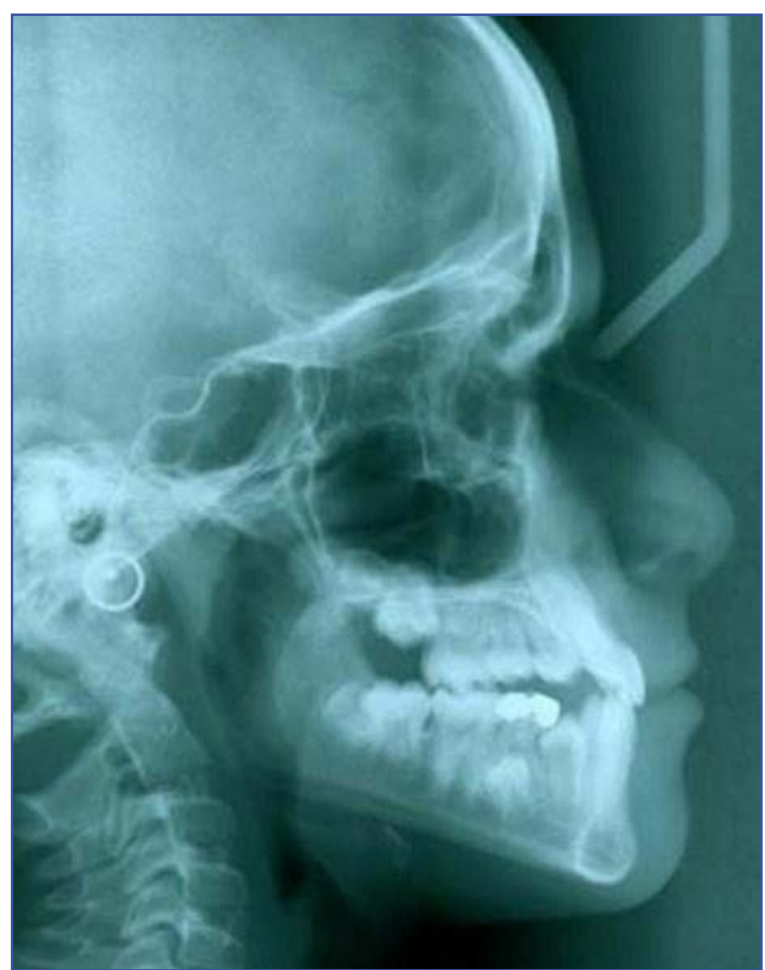

Figure 14. Pretreatment cephalometric of the same patient with tongue appliance.

\section{RESULTS}

The results of this study showed that SNA and ANB increased by $2.4 \pm 1.5^{\circ}(p<0.001)$ and $1.6 \pm 1^{\circ}(p<0.001)$ in the tongue plate group. SNA and ANB also increased in the tongue appliance group by $1.5 \pm 1.4^{\circ}$ $(p<0.001)$ and $1.6 \pm 1.6^{\circ}(p<0.001)$, respectively. The SNB did not show any significant changes in either of the groups. U1 to $\mathrm{SN}$ increased from $99.9 \pm 6.1^{\circ}$ to $103.7 \pm 5.3^{\circ}$ in the tongue plate group $(p<0.02)$ and it increased from $98.6 \pm 6^{\circ}$ to $99.9 \pm 7.2^{\circ}$ in the tongue appliance group $(\mathrm{p}<0.3)$.

The Mann-Whitney test showed that there were no statistically significant differences between the cephalometric data of the two groups; except for the Jarabak ratio. The Jarabak ratio decreased by $-0.4 \pm 1.6$ in the tongue plate group; yet, it increased by $0.6 \pm 3.2$ in the tongue appliance group $(p<0.03)$.

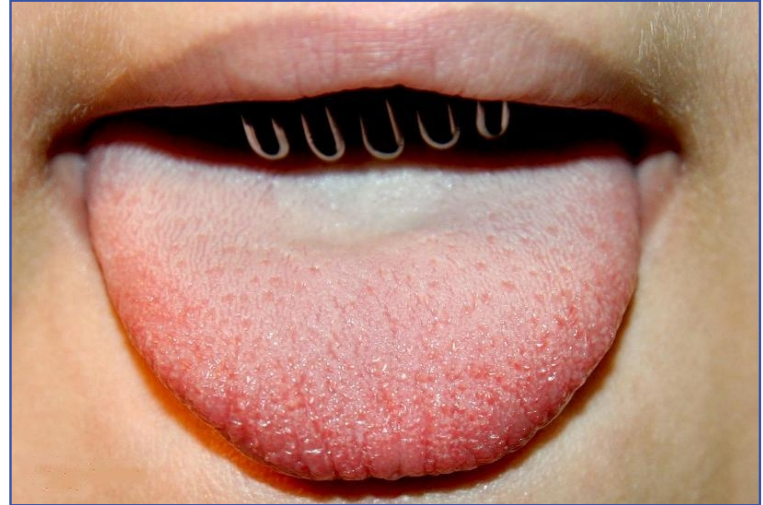

Figure 15. The mark of the tongue appliance on the tongue.

\section{DISCUSSION}

Various techniques and appliances are being used to treat the maxillary deficiency including modified protraction appliance, reverse-pull headgear, facemask, Class III activator, and reverse chin cup [7,8,24-35]. The face mask therapy has become a common technique used to correct the developing Class III malocclusion [36,37]. A search in literature will reveal ample research about the face masks and their effects on the nasomaxillary complex. In addition, the experimental studies constantly demonstrate pronounced forward movement of the maxilla due to the heavy and continuous protraction forces of the face masks [38-40]. However, one of the problems with the face masks is their bulky size and shape, which makes it a discouraging choice for children. Especially patients who wear glasses will be more susceptible to discomfort. This discomfort along with the embarrassment caused by the large size for children, especially at school in front of other peers, might reduce patient compliance. The chin part of the face mask will result in the backward rotation of the mandible and increase in the anterior facial height. Recently, tongue plate and tongue appliance were used to overcome the abovementioned disadvantages. In both appliances a considerable pressure will be transmitted to the deficient maxilla. The mechanism of the force is provided in the following ways:

1. The pressure of the Tongue during swallowing might reach 5 pounds in each swallowing. The frequency of swallowing is about 500 to 1200 times in 24 hours. This intermittent force is transferred through the tongue appliance to the deficient nasomaxillary complex.

2. The tongue generates a considerable force in its rest position while caged behind the cribs or plate. These forces are transmitted by the tongue to the palatal cribs or plate and finally to the nasomaxillary complex consequently pushing the maxilla to a forward position. The more anterior function and position of the tongue, the greater the force will be. The more posterior the crib or plate, the greater the force will be. The application of face masks might cause unfavorable effects on the mandible. 
In other words, backward and downward rotation of the mandible is one of the unfavorable effects of such extra oral appliances. These effects are very unsatisfactory in vertically growing patients. However, the tongue appliance and tongue plate used in this study had no adverse effects on the mandible. Another advantage of the tongue appliance and tongue plate over the other extra oral appliances is that it is less conspicuous and needs less patient compliance. The tongue appliance, tongue plate and facemask lingualize the lower incisors by different mechanisms. The tongue appliance and tongue plate lingualize the lower incisors due to the elimination of the tongue pressure on them. However, the facemask lingualizes the lower incisors due to chin cup pressure. The neutral zone is the area where the displacing forces of the lips and tongue are in balance. The presence of the tongue appliance and tongue plate in the mouth alters the neutral zone. In other words, since the tongue is caged by the crib or plate it does not exert any forces on the lower incisors thus, they are retroclined due to the pressure of the lips. After the appliances are removed, the tongue pressure on the lower incisors will result in their proclination. The force of the tongue transfers to the nasomaxillary complex and that is why the inclination angle is increased in both groups. In this study, both appliances were successful in forward movement of the maxilla. One of the advantages of the tongue plate is that unlike the tongue appliance it does not leave any marks on the tongue of the patient. The tongue appliance might bother the tongue and consequently parents are complaining about minor inflammation of the tongue. As can be seen in Fig. 15, the tongue appliance has left marks on the patient's tongue. It seems that the cooperation of the patient with the tongue plate is better than with the tongue appliance due to the smooth surface area of the tongue plate and lack of irritation of the cribs.

The treatment used in this study was meant to correct a skeletal problem as part of growth modification and further treatment was done by using fixed appliances.

\section{CONCLUSION}

Both treatment modalities were successful in moving the maxilla forward. The crib of the tongue appliance might bother the tongue and consequently parents are complaining about minor inflammation of the tongue. The smooth surface of the tongue plate might therefore confer some advantages to this system as compared to the tongue plate.

\section{CONFLICT OF INTEREST}

The authors declare no conflict of interest.

\section{AUTHOR CONTRIBUTIONS}

AJ: was responsible for the study concept, study design, data interpretation, critical revision, writing and revising the report and final approval of the article. LN: administration, data interpretation, recruitment, statistical analysis. EA: was responsible for data gathering. MT: was responsible for data interpretation, critical revision and final approval of the article. SB: was responsible for literature review. FF: was responsible for drafting, data interpretation, critical revision and final approval of the article.

\section{ACKNOWLEDGMENTS}

None.

\section{REFERENCES}

1. Ellis E 3rd, McNamara JA Jr. Components of adult Class III open-bite malocclusion. Am J Orthod. 1984;86(4):277-290. doi: 10.1016/0002-9416(84)90138-6.

Full Text Link PubMed GoogleScholar Scopus CrossRef WoS 2. Delaire J, Verdon P, Lumineau JP, et al. [Some results of extraoral tractions with front-chin rest in the orthodontic treatment of class 3 maxillomandibular malformations and of bony sequelae of cleft lip and palate]. Rev Stomatol Chir Maxillofac. 1972;73(8):633-642. PMID: 4514929.

PubMed GoogleScholar Scopus

3. Wells AP, Sarver DM, Proffit WR. Long-term efficacy of reverse pull headgear therapy. Angle Orthod. 2006;76(6):915-922. doi: 10.2319/091605-328.

Full-text link PubMed GoogleScholar Scopus CrossRef WoS 4. Jackson DW. The profile enhancer (reverse-pull headgear). Int J Orthod Milwaukee. 2009·20(3):21-25. PMID: 19835183.

PubMed GoogleScholar Scopus

5. Kokich VG, Shapiro PA, Oswald R, et al. Ankylosed teeth as abutments for maxillary protraction: a case report. Am J Orthod. 1985;88(4):303-307. doi: 10.1016/0002-9416(85)90129-0. PubMed GoogleScholar Scopus CrossRef WoS

6. Da Silva Filho OG, Ozawa TO, Okada CH, et al. Intentional ankylosis of deciduous canines to reinforce maxillary protraction. J Clin Orthod. 2003;37(6):315-320. PMID: 12866213.

PubMed GoogleScholar Scopus
7. Jamilian A, Showkatbakhsh R, Boushehry MB. The effect of tongue appliance on the nasomaxillary complex in growing cleft lip and palate patients. J Indian Soc Pedod Prev Dent. 2006;24(3):136-139. doi: 10.4103/0970-4388.27893.

PubMed GoogleScholar Scopus CrossRef

8. Jamilian A, Showkatbakhsh R. The effect of tongue appliance on the maxilla in Class III malocclusion due to maxillary deficiency. Int J Orthod Milwaukee. 2009;20(3):11-14. PMID: 19835181.

PubMed GoogleScholar Scopus

9. Showkatbakhsh R, Jamilian A, Behnaz M, et al. The short-term effects of face mask and fixed tongue appliance on maxillary deficiency in growing patients--a randomized clinical trial. Int $J$ Orthod Milwaukee. 2015;26(1):33-38. PMID: 25881382.

Full Text Link PubMed GoogleScholar Scopus

10. Showkatbakhsh R, Jamilian A, Ghassemi M, et al. Maxillary deficiency treatment by fixed tongue appliance--a case report. Int J Orthod Milwaukee. 2013;24(3):31-34. PMID: 24358655.

Full Text Link PubMed GoogleScholar Scopus

11. Showkatbakhsh R, Jamilian A. A novel method of maxillary deficiency treatment by tongue plate - a case report. Int J Orthod Milwaukee. 2011 2011;22(1):31-34. PMID: 21561019.

Full Text Link PubMed GoogleScholar Scopus

12. Showkatbakhsh R, Toumarian L, Jamilian A, et al. The effects of face mask and tongue plate on maxillary deficiency in growing 
patients: a randomized clinical trial. J Orthod. 2013;40(2):130-136. doi: 10.1179/1465313312Y.0000000036.

Full Text Link PubMed GoogleScholar Scopus CrossRef 13. De Clerck HJ, Cornelis MA, Cevidanes LH, et al. Orthopedic traction of the maxilla with miniplates: a new perspective for treatment of midface deficiency. J Oral Maxillofac Surg. 2009;67(10):2123-2129. doi: 10.1016/j.joms.2009.03.007. Full Text Link PubMed GoogleScholar Scopus CrossRef WoS 14. Showkatbakhsh R, Jamilian A, Behnaz M. Treatment of maxillary deficiency by miniplates: a case report. ISRN Surgery. 2011:854924. doi: 10.5402/2011/854924.

Full Text Link PubMed GoogleScholar CrossRef

15. Baccetti T, De Clerck HJ, Cevidanes LH, Franchi L. Morphomtric analysis of treatment effects of bone-anchored maxillary protraction in growing Class III patients. Eur J Orthod. 2011;33(2):121-125. doi: 10.1093/ejo/cjq170.

Full Text Link PubMed GoogleScholar Scopus CrossRef WoS 16. De Clerck EE, Swennen GR. Success rate of miniplate anchorage for bone anchored maxillary protraction. Angle Orthod. 2011;81(6):1010-1013. doi: 10.2319/012311-47.1. Full Text Link PubMed GoogleScholar Scopus Cross Ref WoS 17. Cevidanes L, Baccetti T, Franchi $L$, et al. Comparison of two protocols for maxillary protraction: bone anchors versus face mask with rapid maxillary expansion. Angle Orthod. 2010;80(5):799-806. doi: 10.2319/111709-651.1.

Full Text Link PubMed GoogleScholar Scopus CrossRef WoS 18. Jamilian A, Showkatbakhsh R. Treatment of maxillary deficiency by miniscrew implants - a case report. J Orthod. 2010;37(1):56-61. doi: 10.1179/14653121042876.

Full Text Link PubMed GoogleScholar Scopus CrossRef 19. Jamilian A, Haraji A, Showkatbakhsh R, Valaee N. The effects of miniscrew with Class III traction in growing patients with maxillary deficiency. Int J Orthod Milwaukee. 2011;22(1):25-30. PMID: 21827052.

Full Text Link PubMed GoogleScholar Scopus 20. Proffit WR, Fields HW, Sarver DM. Orthodontic Treatment Planning: Limitations, Controversies, and Special Problems. In: Proffit WR, Fields HW, Sarver DM, editors. Contemporary orthodontics. 4th ed. St. Louis, Mo.: Mosby Elsevier; 2007. p. 268327

21. Ramadan AA. Response of maxillary retrusion cases to face mask treatment. World J Orthod. 2008;9(2):e29-34. PMID: 19641766.

Full Text Link PubMed GoogleScholar Scopus

22. Yavuz I, Halicioglu K, Ceylan I. Face mask therapy effects in two skeletal maturation groups of female subjects with skeletal Class III malocclusions. Angle Orthod. 2009;79(5):842-848. doi: 10.2319/090308-462.1.

Full Text Link PubMed GoogleScholar Scopus CrossRef WoS 23. Godt A, Zeyher C, Schatz-Maier D, Göz G. Early treatment to correct Class III relations with or without face masks. Angle Orthod. 2008;78(1):44-49. doi: 10.2319/110606-455.1.

PubMed GoogleScholar Scopus CrossRef

24. Kajiyama K, Murakami T, Suzuki A. Evaluation of the modified maxillary protractor applied to Class III malocclusion with retruded maxilla in early mixed dentition. Am J Orthod Dentofacial Orthop. 2000;118(5):549-559. doi: 10.1067/ mod.2000.110169.

PubMed GoogleScholar Scopus CrossRef WoS

25. Satravaha S, Taweesedt N. Stability of skeletal changes after activator treatment of patients with class III malocclusions. Am J Orthod Dentofacial Orthop. 1999;116(2):196-206. doi: 10.1016/ s0889-5406(99)70218-0.

PubMed GoogleScholar CrossRef Scopus WoS

26. Orton HS, Noar JH, Smith AJ. The customized facemask. J Clin Orthod. 1992;26(4):230-5. PMID: 1452725

PubMed GoogleScholar Scopus

27. Suda N, Ishii-Suzuki M, Hirose K, et al. Effective treatment plan for maxillary protraction: is the bone age useful to determine the treatment plan? Am J Orthod Dentofacial Orthop. 2000;118(1):5562. doi: $10.1067 / \bmod .2000 .104491$.

PubMed GoogleScholar CrossRef

28. Showkatbakhsh $\mathrm{R}$, Jamilian A. A novel approach in treatment of maxillary deficiency by reverse chin cup. Int J Orthod Milwaukee. 2010;21(2):27-31. PMID: 20687313.

Full Text Link PubMed GoogleScholar Scopus
29. Jamilian A, Cannavale R, Piancino MG, et al. Methodological quality and outcome of systematic reviews reporting on orthopaedic treatment for class III malocclusion: Overview of systematic reviews. J Orthod. 2016;43(2):102-120. doi: 10.1080/14653125.2016.1155334.

Full Text Link PubMed GoogleScholar Scopus CrossRef WoS 30. Eslami S, Faber J, Fateh A, et al. Treatment decision in adult patients with class III malocclusion: surgery versus orthodontics. Prog Orthod. 2018;19(1):28. doi: 10.1186/s40510-018-0218-0. Full Text Link PubMed GoogleScholar Scopus CrossRef WoS 31. Showkatbakhsh R, Jamilian A, Taban T, Golrokh M. The effects of face mask and tongue appliance on maxillary deficiency in growing patients: a randomized clinical trial. Prog Orthod. 2012;13(3):266-272. doi: 10.1016/j.pio.2011.12.004.

Full Text Link PubMed GoogleScholar Scopus CrossRef 32. Showkatbakhsh R, Jamilian A, Ghassemi M, et al. The effects of facemask and reverse chin cup on maxillary deficient patients. J Orthod. 2012;39(2):95-101. doi: 10.1179/1465312512Z.000000 00011.

Full Text Link PubMed GoogleScholar CrossRef 33. Jamilian A, Showkatbakhsh R, Taban T. The effects of fixed and removable face masks on maxillary deficiencies in growing patients. Orthodontics (Chic.). 2012;13(1):e37-43. PMID: 22567652. PubMed GoogleScholar

34. Showkatbakhsh $R$, Jamilian A, Behnaz M. Treatment of maxillary deficiency by miniplates: a case report. ISRN Surg. 2011;2011:854924. doi: 10.5402/2011/854924.

Full Text Link PubMed GoogleScholar CrossRef

35. Perillo L, Vitale M, Masucci C, et al. Comparisons of two protocols for the early treatment of Class III dentoskeletal disharmony. Eur J Orthod. 2016;38(1):51-56. doi: 10.1093/ejo/ cjv010.

Full Text Link PubMed GoogleScholar Scopus CrossRef WoS 36. Jamilian A, Nucci L, Fateh A, et al. Stability of skeletal Class III malocclusion after orthognathic surgery and orthodontic treatment: a systematic review and meta-analysis. Stoma Edu J. 2020;7(1):52-67.

Full Text Link GoogleScholar CrossRef

37. Jamilian A, Darnahal A, Nucci L, et al. Treatment considerations for missing teeth. Dental Anatomy. Rijeka: Intech; 2018. p. 109-120. CrossRef

38. Cha KS. Skeletal changes of maxillary protraction in patients exhibiting skeletal class III malocclusion: a comparison of three skeletal maturation groups. Angle Orthod. 2003;73(1):26-35. doi: 10.1043/0003-3219(2003)073<0026:SCOMPI> 2.0.CO;2.

PubMed GoogleScholar Scopus WoS

39. Maspero C, Galbiati G, Perillo L, et al. Orthopaedic treatment efficiency in skeletal Class III malocclusions in young patients:

RME-face mask versus TSME. Eur J Paediatr Dent. 2012;13(3):225230. PMID: 22971261

Full Text Link PubMed GoogleScholar Scopus WoS 40. Dellinger EL. A preliminary study of anterior maxillary displacement. Am J Orthod. 1973;63(5):509-516. doi:

10.1016/0002-9416(73)90163-2.

PubMed GoogleScholar Scopus CrossRef

41. Nanda R. Protraction of maxilla in rhesus monkeys by controlled extraoral forces. Am J Orthod. 1978;74(2):121-141. doi: 10.1016/0002-9416(78)90080-5.

PubMed GoogleScholar Scopus CrossRef

42. Kambara T. Dentofacial changes produced by extraoral forward force in the Macaca irus. $A m \mathrm{~J}$

Orthod.1977;71(3):249-277. doi: 10.1016/0002-9416(77)90187-7.

PubMed GoogleScholar Scopus CrossRef

43. Marra P, Nucci L, Abdolreza J, et al. Odontoma in a young and anxious patient associated with unerupted permanent mandibular cuspid: A case report. J Int Oral Health 2020;12(2):182-186. doi: 10.4103/jioh.jioh_287_19.

GoogleScholar Scopus CrossRef

44. Minervini G, Nucci L, Lanza A, et al. Temporomandibular disc displacement with reduction treated with anterior repositioning splint: a 2-year clinical and magnetic resonance imaging (MRI) follow-up. J Biol Regul Homeost Agents. 2020;34(1 Suppl. 1):151160. PMID: 32064850.

PubMed GoogleScholar Scopus 


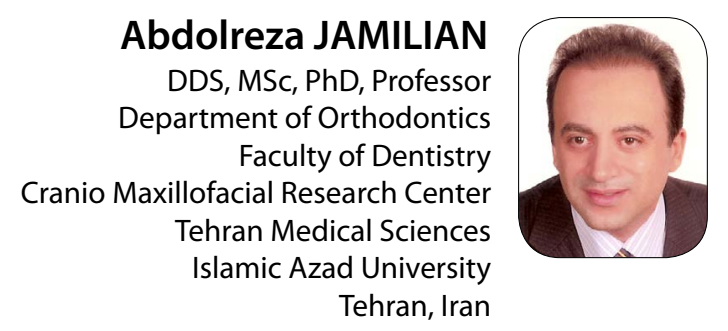

Professor Abdolreza Jamilian is an Orthodontic researcher and specialist. He received his DDS (1991), MSc in Orthodontics (1998), and Fellowship of Orthognathic Surgery \& Craniofacial Syndroms (2010) from the Shahid Beheshti University in Tehran, Iran. He obtained his European Board of Orthodontics in 2013. He is a professor at the Islamic Azad University, Tehran. He practices in orthodontics. He has lectured in several international congresses and has been a consultant for various journals. He has published over 200 original, peer reviewed research and review articles, 15 book chapters and more than 300 scientific communications. He holds 3 patents with the United States Patent and Trademark Office.

Research interests: Class 3 malocclusion, Cleft lip and palate, Orthognathic surgery.

\section{Ouestions}

\section{Which one has been used to treat maxillary deficiency?}

a. Fixed tongue appliance;

ab. Tongue plate;

ac. Tongue appliance;

d. All of them.

\section{Which one is an extra oral appliance?}

口a. Reverse chin cup;

$\square$ b. Tongue appliance;

$\square$ c. Fixed tongue appliance;

ad. Tongue plate.

\section{Which one does the patient wear easily during daily activities?}

a. Reverse chin cup;

ab. Tongue plate;

$\square c$. Face mask;

ad. Chin cap.

\section{Which one has no effect on the patients' vertical growth pattern?}
Da. Face mask;
ab. Chin cap;
ac. Reverse chin cup;
ad. Tongue plate. 


\title{
APPLICATION OF MODERN 3D IMAGE ACQUISITION SYSTEMS TO THE MORPHOLOGICAL ANALYSIS OF FACES: A NOVEL APPROACH FOR THE ASSESSMENT OF FACIAL GROWTH
}

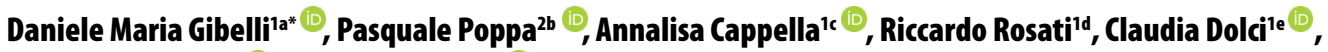 \\ Cristina Cattaneo $^{2 f}\left(\mathbb{0}\right.$, Chiarella Sforza ${ }^{1 g}$ (1) \\ 'Department of Biomedical Sciences for Health, Faculty of Medicine and Surgery, University of Milan, Milan, Italy \\ 2LABANOF, Laboratory of Anthropology and Forensic Odontology, Department of Biomedical Sciences for Health, Faculty of Medicine and Surgery, University \\ of Milan, Milan, Italy
}

aMD, PhD, Associate Professor; e-mail: daniele.gibelli@unimi.it; ORCIDiD: https://orcid.org/0000-0002-9591-1047

'BSC, PhD; pasquale.poppa@unimi.it; ORCIDiD: https://orcid.org/0000-0002-9288-5576

'BSC, MA, PhD; annalisa.cappella@unimi.it; ORCIDiD: https://orcid.org/0000-0002-4527-4203

dDDS, PhD; riccardo.rosati@outlook.com

eMD; claudia.dolci@unimi.it; ORCIDiD: https://orcid.org/0000-0002-3060-4097

fBSc, MD, MA, PhD; cristina.cattaneo@unimi.it; ORCIDiD: https://orcid.org/0000-0003-0086-029X

9MD, Professor, Head; chiarella.sforza@unimi.it; 0RCIDiD: https://orcid.org/0000-0001-6532-6464

\section{ABSTRACT}

d) https://doi.org/10.25241/stomaeduj.2020.7(4).art.5

Introduction The assessment of facial growth has always had a relevant importance in anatomy and morphological sciences. This article aims at presenting a method of facial superimposition between 3D models which provides a topographic map of those facial areas modified by growth.

Methodology Eight children aged between 6 and 10 years were recruited. In December 2010 they underwent a 3D scan by the Vivid 910 laser scanner (Konica Minolta, Osaka, Japan). The same procedures were performed another five times, in June 2011, September 2011, January 2012 and September 2012; in total 6 analyses were performed on the same subjects in a time span of 21 months.

Three-dimensional digital models belonging to the same individual were then superimposed on each other according to 11 facial landmarks. Three comparisons were performed for each individual, referring to the period between December 2010 and June 2011, between June 2011 and January 2012 and between January and September 2012.

Results Results show that the protocol of superimposition gives a reliable image of facial growth with high sensibility: in detail, even the slight facial modifications due to different expressions are recorded. The method can also quantify the point-to-point difference between the two models, and therefore give an indication concerning the general increase or decrease of facial volume.

Conclusion This approach may provide useful indications for the analysis of facial growth on a large sample and give a new point of view of the complex field of face development.

\section{KEYWORDS}

Anatomy; Morphological Sciences; Facial Assessment; Facial Growth; Laser Scanner.

\section{INTRODUCTION}

Facial assessment, performed both from a metrical and morphological point of view, is one of the most ancient issues in anatomical and anthropological sciences, since the face is the main tool for communication and interaction with the environment; pionieristic studies were performed by Leonardo da Vinci and Albrecht Dürer, and deal with the graphical methods useful to describe the

(c) (1) ) () OPEN ACCESS This is an Open Access article under the CC BY-NC 4.0 license. Peer-Reviewed Article

Citation: Gibelli DM, Poppa P, Cappella A, Rosati R, Dolci C, Cattaneo C, Sforza C, Application of modern 3d image acquisition systems to the morphological analysis of faces: a novel approach for the assessment of facial growth. Stoma Edu J. 2020;7(4):268-273

Received: October 12, 2020 Revised: October 23, 2020; Accepted: October 25, 2020; Published: October 27, 2020

*Corresponding author: Prof. Daniele Maria Gibelli, Dipartimento di Scienze Biomediche per la Salute, Facoltà di Medicina e Chirurgia, Università

degli Studi di Milano, V. Mangiagalli 31, Milan, Italy

Tel: +39-02-50315339; Fax: +39-02-50315724; e-mail: daniele.gibelli@unimi.it

Copyright: $\odot 2020$ the Editorial Council for the Stomatology Edu Journal. 


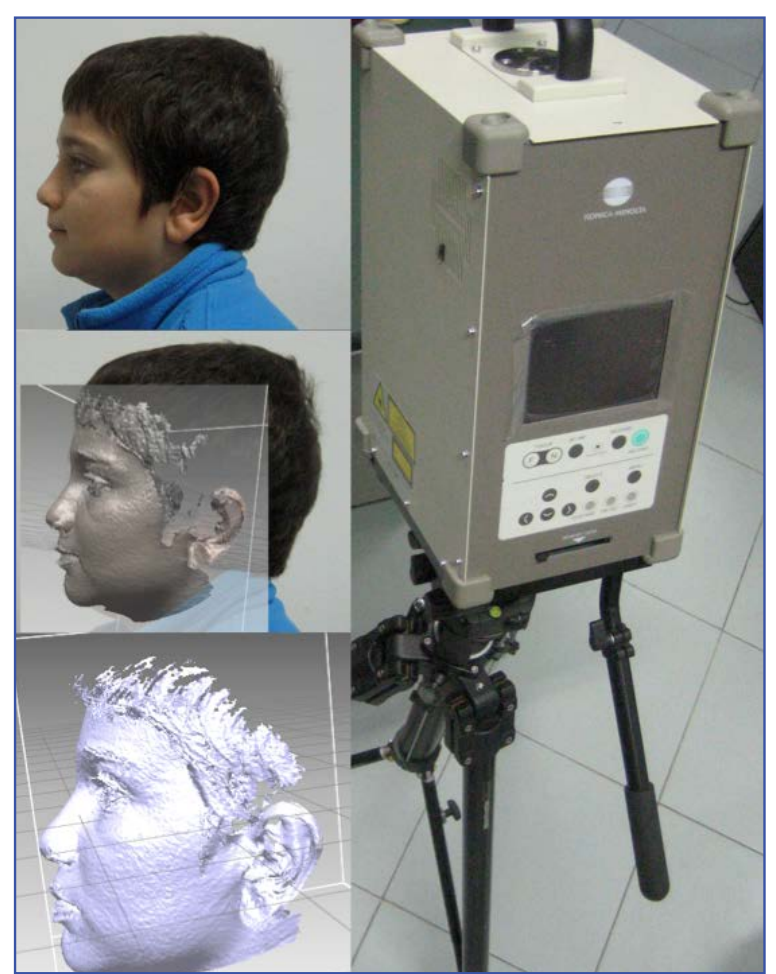

Figure 1. on the right, 3D laser scanner (Konica Minolta, Vivid 910); on the left, example of acquisition of the face of a child recruited in the study.

facial morphological variation [1]. Charles Darwin first analysed the facial expressions and explored the importance of the face in evolutionary programs of interaction between individuals of the same species [2]. In the $19^{\text {th }}$ century, with the beginning of modern forensic anthropology, the metrical analysis of the face was analysed with identification purposes by Alphonse Bertillon who developed a system of recording called bertillonage [3]; in the early $20^{\text {th }}$ century, the importance of the face was explored for what concerns the relation between personality, moral behaviour and morphological facial traits, by Lombroso [4]. The revolutionary discovery of $X$-rays allowed scientists to perform more precise analyses of facial morphology, which was one of the main issues of the new technology [5]: however, only in the last 30 years the study of the face has gained popularity as shown by the huge increase of studies published on this topic thanks also to the introduction of more advanced diagnostic technologies such as CT scan and MRI (magnetic resonance imaging). Since the early eighties, both ot them have been widely applied to the 3D study of cranium and facial soft tissues [6]. Also, modern 3D image acquisition systems, both based on a non-contact (laser scanner, stereophotogrammetry) and contact approach (electromagnetic and electromechanical digitizers, ultrasound probes) have been introduced for anthropological, anatomical and clinical investigations [7]. The use of such technologies allowed the operators to perform an easier recording and quantification of facial metrical parameters, in order to increase data and to analyse the chances of practical application of the information obtained. As to the relation between craniometric measurements and age, literature provides several articles dealing with the development of different facial traits in children and juveniles; Farkas for example analysed the degree of growth of different cranial and facial parameters, pointing out the percentual modifications [8]. In more recent times, different studies have been published concerning the sectorial development of single facial areas, such as lips [9], ears [10,11], nose [12] and the orbital region $[13,14]$. The modification of face with age was improved by analyses concerning the movement of facial landmarks with time, with consequent modifications of facial profiles $[15,16]$; in detail, literature ascertained that between 6 and 11 years of age the vertical diameters of the face increase, especially in the middle and upper thirds of faces: then, at 10 years circa in females and at 13 years circa in males the facial profiles are close to the adult model, with a dislocation of the main landmarks. Up to 11 years the trend is similar in both genders; then females show a spurt at 11-12 years circa, followed by a progressive decrease of bodily development. On the other hand males are affected by a delayed growth, which remains constant from 11-12 to 1617 years. As a consequence, at 14-15 years of age females have a facial configuration similar to the adult one, whereas males of the same age are still in active growth. In females, the upper and lower thirds have their higher degree of development up to 11-12 years circa; on the other side, males begin to increase the lower third from 12 to 13 years.

As one can notice, most of the literature actually deals with linear measurements which remain the traditional way to explore facial morphology: in such cases, the increase of single parameters is usually assessed as a percentage of the adult measurements. In time, the linear approach to facial growth has provided epidemiological information concerning the modification of different parameters; in the last years, research in this field has known a relevant improvement thanks to the advanced 3D image acquisition techniques: the main advantage consists in the chance of measuring dimensional parameters which cannot be evaluated in vivo (for example, geometrical areas and volumes included within facial landmarks). This was an attempt both at applying the 3D image acquisition systems and at finding the same standardization as for linear measurements $[12,13]$. However the measurement of facial surfaces and volumes is only one of the advantages deriving from the application of modern technologies: in fact these methods allow the operators to acquire a 3D digital model of face, which can be used in a virtual space and, for example, superimposed to other images. The main task consists in performing a pointto-point comparison between the two surfaces. An example of such application derives from the study of facial motion and mimicry, provided by Popat et al. who used a stereophotogrammetric motion 


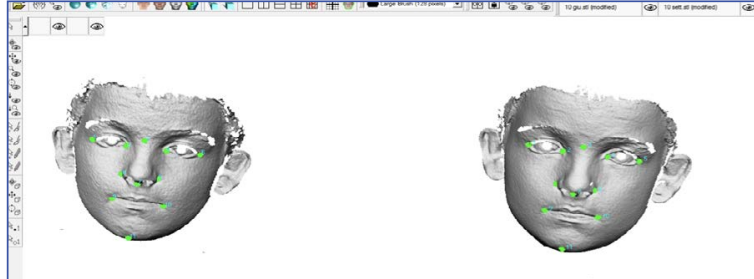

Figure 2. definition of 11 landmarks for facial superimposition.
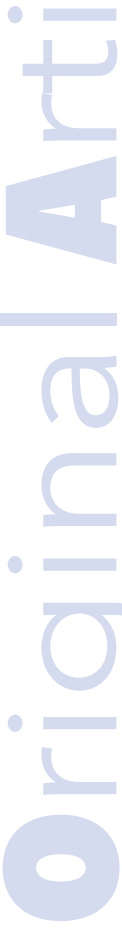
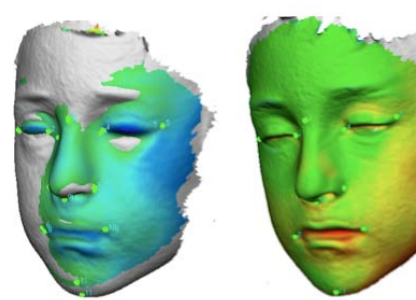

Figure 4. chromatic figures of growth in child $n^{\circ} 1$.

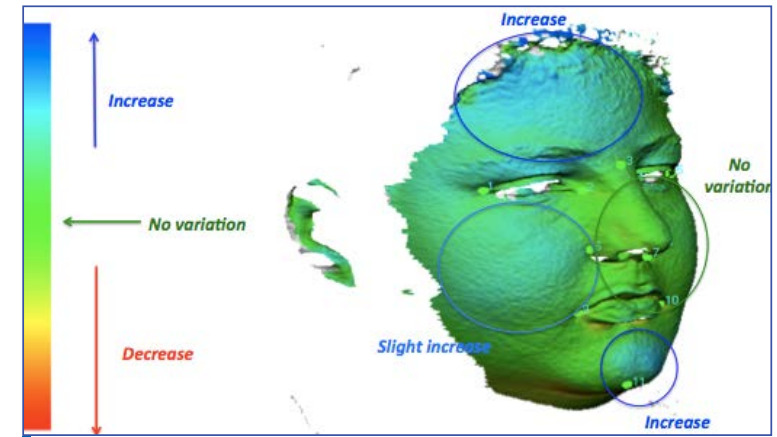

Figure 3. example of chromatic sheet of comparison between two 3D models from the same individual.

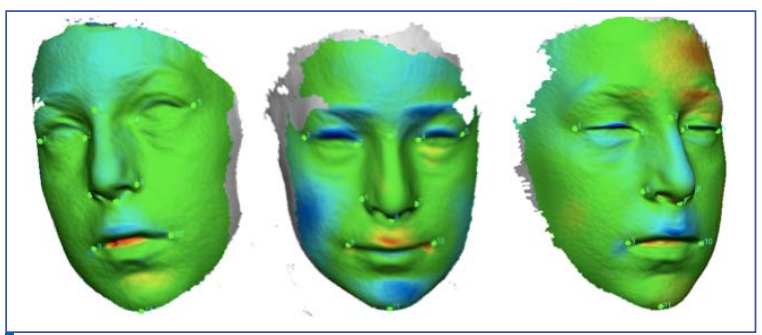

Figure 5. chromatic figures of growth in child $n^{\circ} 2$.

and left $3 / 4$ position (Fig.1). The same procedures were performed another five times, in June 2011, September 2011, January 2012 and September 2012; in total 6 analyses were performed on the same subjects in a time span of 21 months.

The modification of facial morphology on 3D scans was evaluated from a qualitative point of view following a protocol of facial comparison. In detail, 11 facial landmarks (right and left endocanthion, exocanthion, alare, chelion: in the midline selion, gnathion, subnasale) were identified on all the 3D scans from the same individual by VAM (Canfield Scientific, NJ, USA) software. The system was required to superimpose two $3 \mathrm{D}$ models from the same subject in order to reduce the distance between the corresponding points (Fig. 2). In order to follow facial growth, three comparisons were performed for each individual, referring to the period between December 2010 and June 2011, between June 2011 and January 2012 and between January and September 2012. This procedure allowed the operator to obtain a chromatic sheet of the face, where the growing zones are colored in blue and the zones which showed a reduction are in red.The unchanged areas are indicated in green (Fig. 3).

\section{RESULTS}

Eight children, aged between 6 and 10 years, four males $\left(n^{\circ} 1,2,5,7\right)$ and four females $\left(n^{\circ} 3,4,6,8\right)$ were recruited: subjects affected by facial pathologies and deformities were excluded. All the following analyses were performed after signature of a specific consent by the parents. In December 2010 the eight children underwent a 3D scan by Vivid 910 laser scanner (Konica Minolta, Osaka, Japan); a 3D digital model was built by five scans obtained in five positions (frontal view, right and left profile, right
Subject $n^{\circ} 1$ (male, analysed between 80 and 101 months of age) showed an increase in the lower third of the face between December 2010 and June 2011: limited areas of increase are observed also in the palpebral regions, although they may be due to the different position of the eyelids during the second scanning (the child had his eyes closed during the second scan, whereas they were open 


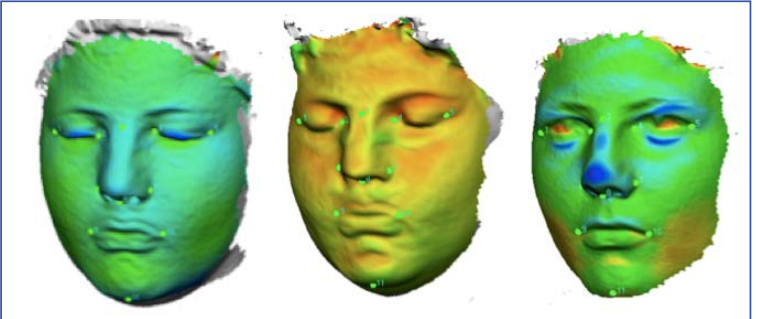

Figure 6. chromatic figures of growth in child $n^{\circ} 5$.

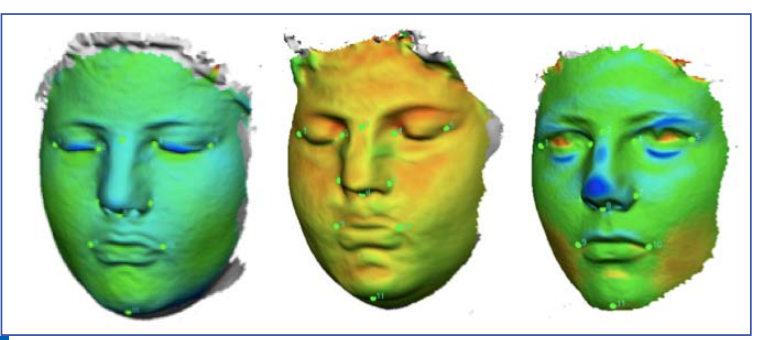

Figure 8. chromatic figures of growth in child $n^{\circ} 3$.

during the first one). In January 2012 there was an increase of the entire face, but only on the left side in the perioral region and nose, whereas the right side did not show modifications. At the end of the data collection, the same region was affected by a slight decrease (Fig. 4).

Child $\mathrm{n}^{\circ} 2$ (male, analysed between 123 and 144 months of age) first showed an increase in the frontal area, and at the second comparison an increase in the malar region, bilaterally. However, also in this case, the increase may be due to the smiling expression of the child. At the end of the experiment, the areas with a true increase were the nose and the perioral region (Fig. 5). Subject $n^{\circ} 5$ (male, analysed between 131 and 152 months of age) showed an increase at first limited to the left side of the face, whereas in the second comparison the entire face was affected by a decrease in size. In the last time point assessment, the nose and the right and left malar zones showed an increase in size (Fig. 6).

Subject $n^{\circ} 7$ (male, analysed between 102 and 123 months of age) showed an increase at the nose, bilateral malar zones and perioral region. However, since the second comparison, the entire face was affected by a strong decrease, first limited to the left side of the face, and then extended to the right side (Fig. 7). On the other hand, the girls analysed showed different modifications: subject $n^{\circ} 3$ (analysed between 86 and 107 months of age) in all the comparisons showed an increase of the oral region, with limited modifications (slightly prone to the decrease) in the rest of the face (Fig. 8).

However, also in case of the females, strong differences between age ranges within the same individual were noticed; subject $\mathrm{n}^{\circ} 4$ (analysed between 108 and 129 months of age) both during the first and second comparison was affected by a decrease of facial areas, followed by an increase of the entire facial zone in the last time point (Fig. 9).

The same differences, although with a stronger trend

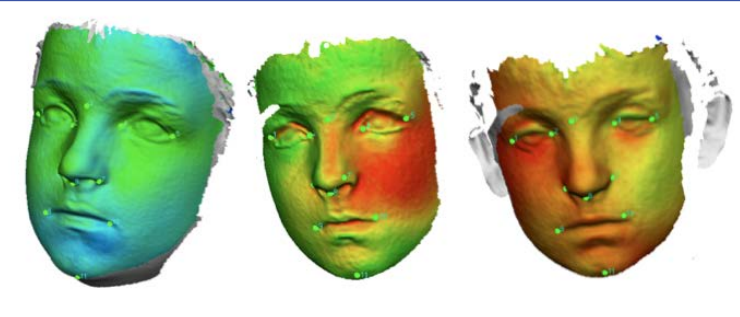

Figure 7. chromatic figures of growth in child $n^{\circ} 7$.

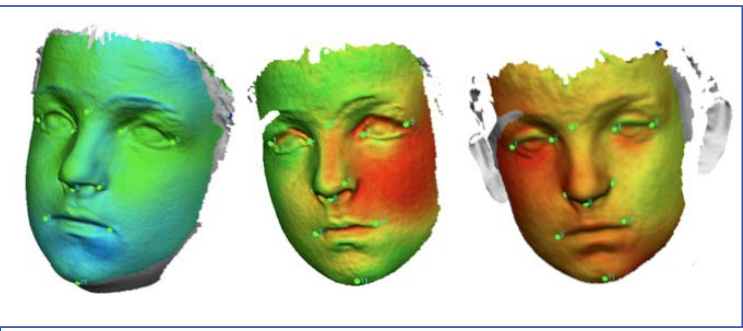

Figure 9. chromatic figures of growth in child $n^{\circ} 4$.

towards increments in facial dimensions, are shown by the three comparisons of subject $n^{\circ} 6$ (analysed between 119 and 140 months of age) (Fig. 10).

Subject $n^{\circ} 8$ (analysed between 72 and 93 months of age) showed an increase at the left malar zone; at the second and third comparison, an increase was observed at the cheek: however, also in this case, the different expression of the child may have played a role (Fig. 11).

\section{DISCUSSION}

The study of facial growth has always been one of the most interesting and frequently treated topics in anatomy and morphology, so far conducted through the assessment of linear measurements, as stated in Farkas' study [8]. The introduction of modern 3D technologies gave a relevant impulse to the analysis of deeper dynamics of facial development by the metrical assessment of surfaces and volumes $[20,21]$. However, additional information may be available by the superimposition of 3D models from the same individual, which may provide a topographic pointto-point visualization of growth processes.

The study aimed at verifying the relation of a novel protocol for the superimposition of 3D models, as a study model for the assessment of facial growth: the preliminary results showed interesting starting points for further research.

First, the analysis of facial surfaces pointed out that the increase of surfaces does not show a progressive trend in time; this indicates that the modification of facial surfaces is affected by other variables in specific periods, such as environmental and individual factors.

Another interesting information deriving from the analysis of facial surfaces in vivo is the general lack of symmetry in growth for both males and females. This is an interesting datum, since it confirms the general information concerning the asymmetry of 


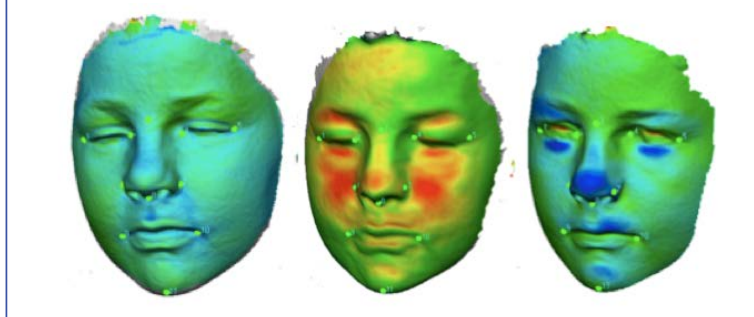

Figure 10. chromatic figures of growth in child $n^{\circ} 6$.

facial measurements [19,22]. The asymmetry of the face is well known, and is observed both in adults and children: the actual study points out that facial growth also seems to follow the same asymmetry. Finally, the method of superimposition was able to detect the slight modifications due to the different facial expressions: this provides an additional indication concerning the sensitivity of the approach.

\section{CONCLUSION}

From this point of view, the actual study points out that the superimposition of 3D models may provide additional information, especially with respect to the sectorial development of facial areas. The application of this technique to few children provided some insight into a deeper analysis of the phenomenon of facial growth: clearly further studies are needed, on larger samples, in order to test the new protocol and provide a more decisive contribution to the analysis of facial age-related modifications. Nonetheless, in

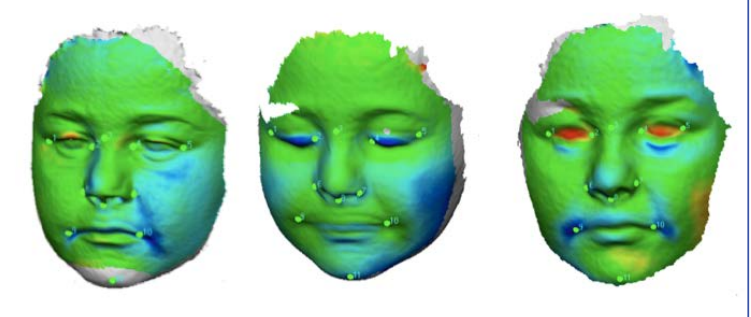

Figure 11. chromatic figures of growth in child $n^{\circ} 8$.

general, the present technical note has shown the large potential of the applied method in the study of facial morphology.

\section{CONFLICT OF INTEREST}

None.

\section{AUTHOR CONTRIBUTIONS}

DG: concept, protocol, data gathering, data analysis, data interpretation, revision of the manuscript, PP: protocol, data gathering, data analysis, AC: data gathering, data analysis, data interpretation, RR: data gathering, data analysis, data interpretation, CD: data gathering, data analysis, data interpretation, CC: concept, data interpretation, revision of the manuscript, CS: concept, data interpretation, revision of the manuscript.

\section{ACKNOWLEDGMENTS}

None.

\section{REFERENCES}

1. Peck S, Peck L. Selected aspects of the art and science of facial esthetics. Semin Orthod. 1995; 1(2):105-126. doi: 10.1016/s10738746(95)80097-2.

CrossRef PubMed Google Scholar Scopus

2. Darwin C. The expression of emotions in man and animals. London, UK: John Murray, Albemarle Street; 1872.

Google Scholar

3. Bertillon A. Signaletic instructions including the theory and practice of anthropometrical identification. Chicago, IL: The Werner Company; 1896.

CrossRef Google Scholar

4. Lombroso C. [The delinquent man]. Milano, IT: Hoepli; 1876.

5. Broadbent BH Sr, Broadbent BH Jr, Golden WH. Bolton

standards of dentofacial developmental growth. Saint Louis, MO:

CV Mosby Co; 1975. doi:10.1097/00006534-197701000-00023.

CrossRef Google Scholar

6. Adams GL, Gansky SA, Miller AJ, et al. Comparison between traditional 2-dimensional cephalometry and a 3-dimensional approach on human dry skulls. Am J Orthod Dentofacial Orthop. 2004;126(4):397-409. doi: 10.1016/j.ajodo.2004.03.023.

Full text links CrossRef PubMed Google Scholar Scopus WoS

7. Gibelli D, Dolci C, Cappella A, Sforza C. Reliability of optical devices for three-dimensional facial anatomy description: a sistematic review and meta-analysis. Int J Oral Maxillofac Surg. 2020;49(8):1092-1106. doi: 10.1016/j.ijom.2019.10.019.

Full text links CrossRef PubMed Google Scholar

8. Farkas LG. Anthropometry of the head and face. 2nd ed. New York, NY: Raven Press; 1994.

9. Ferrario VF, Sforza C, Schmitz JH, et al. Normal growth and development of the lips: a 3-dimensional study from 6 years to adulthood using a geometric model. J Anat. 2000;196 (Pt 3) (Pt 3):415-23. doi: 10.1046/j.1469-7580.2000.19630415.x. PMID: 10853963; PMCID: PMC1468077.

Full text links CrossRef PubMed Google Scholar Scopus WoS
10. Ferrario VF, Sforza C, Ciusa V, et al. Morphmetry of the normal human ear: a cross-sectional study from adolescence to midadulthood. J Craniofac Genet Dev Biol. 1999;19(4):226-233. PMID: 10731092.

PubMed Google Scholar

11. Sforza C, Grandi G, Binelli M, et al. Age- and sex-related changes in the normal human ear. Forensic Sci Int. 2009;187(13):110.e1-7. doi: 10.1016/j.forsciint.2009.02.019.

Full text links CrossRef PubMed Google Scholar Scopus WoS 12. Sforza C, Grandi G, De Menezes M, et al. Age- and sex-related changes in the normal human external nose. Forensic Sci Int 2011;204(1-3):205.e1-9. doi: 10.1016/j.forsciint.2010.07.027. Full text links CrossRef PubMed Google Scholar Scopus WoS 13. Sforza C, Grandi G, Catti F, et al. Age- and sex-related changes in the soft tissues of the orbital region. Forensic Sci Int 2009;185(1-3):115.e1-8. doi: 10.1016/j.forsciint.2008.12.010. Full text links CrossRef PubMed Google Scholar Scopus WoS 14. Ferrario VF, Sforza C, Colombo A, et al. Morphometry of the orbital region: a soft-tissue study from adolescence to midadulthood. Plast Reconstr Surg. 2001;108(2):285-292; discussion 293. doi: 10.1097/00006534-200108000-00001.

Full text links CrossRef PubMed Google Scholar Scopus WoS 15. Ferrario VF, Sforza C, Serrao G, et al. Growth and aging of facial soft tissues: a computerized three-dimensional mesh diagram analysis. Clin Anat. 2003;16(5):420-433. doi: 10.1002/ca.10154. CrossRef PubMed Google Scholar Scopus WoS

16. Ferrario VF, Sforza C, Poggio CE, et al. Facial volume changes during normal human growth and development Anat Rec. 1998;250(4):480-487. doi: 10.1002/(SICI)10970185(199804)250:4<480::AID-AR12>3.0.CO;2-K.

Full text links CrossRef PubMed Google Scholar WoS

17. Popat H, Richmond S, Playle R, et al. Three-dimensional motion analysis - an exploratory study. Part 1: assessment of facial movement. Orthod Craniofac Res. 2008;11(4):216-223. doi: 10.1111/j.1601-6343.2008.00433.x.

Full text links CrossRef PubMed Google Scholar Scopus WoS 
18. Popat H, Richmond S, Playle R, et al. Three-dimensional motion analysis - an exploratory study. Part 2: reproducibility of facial movement. Orthod Craniofac Res. 2008;1 1(4):224-228. doi: 10.1111/j.1601-6343.2008.00435.x.

Full text links CrossRef PubMed Google Scholar Scopus WoS 19. Ferrario VF, Sforza C, Poggio CE, et al. Distance from symmetry: a three-dimensional evaluation of facial asymmetry. $J$ Oral Maxillofac Surg. 1994;52(11):1126-1132. doi: 10.1016/02782391(94)90528-2.

Full text links CrossRef PubMed Google Scholar Scopus WoS 20. Gibelli D, Pucciarelli V, Cappella A, et al. Are portable stereophotogrammetric devices reliable in facial imaging? A validation study of VECTRA H1 device. J Oral Maxillofac Surg.
2018;76(8):1772-1784. doi: 10.1016/j.joms.2018.01.021.

Full text links CrossRef PubMed Google Scholar

21. Gibelli D, Pucciarelli V, Poppa P, et al. Three-dimensional facial anatomy evaluation: reliability of laser scanner consecutive scans procedure $\mathrm{n}$ comparison with stereophotogrammetry Craniomaxillofac Surg. 2018;46(10):1807-1813. doi: 10.1016/j. jcms.2018.07.008.

CrossRef Google Scholar

22. Ferrario VF, Sforza C, Miani A Jr, et al. A three-dimensional

evaluation of human facial asymmetry. J Anat. 1995;186 ( Pt 1)(Pt

1):103-110. PMID: 7649806; PMCID: PMC1167276.

Full text links PubMed Google Scholar Scopus

\title{
Daniele Maria GIBELLI \\ MD, PhD, Associate Professor \\ Department of Biomedical Sciences for Health \\ Faculty of Medicine and Surgery \\ University of Milan \\ Milan, Italy

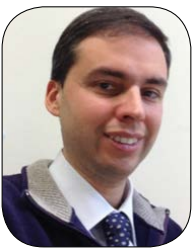

Dr. Gibelli is a physician specialized in Legal Medicine with a PhD in Morphological Sciences, and an associate professor in Human Anatomy.

His areas of expertise include 3D surface acquisition (laser scanner and stereophotogrammetry) and 3D image elaboration for documentation and analysis of faces and osteological and dental material, 3D segmentation from CT-scan and NMR, the validation of novel techniques for 3D acquisition and assessment of their reliability in the analysis of facial anatomy. The specific topics include the study of facial morphology in acquired and genetic pathologies, of facial mimicry in healthy subjects and patients affected by facial nerve palsy, the analysis of anatomical variants of the cranium, the assessment of skeletal morphology. He authored more than 120 articles published in peer-reviewed impacted journals.

\section{Ougstions}

\section{Which technique of acquisition is not $\mathrm{X}$-ray based?}

\author{
口a. Laser scanner; \\ ab. CT-scan; \\ ac. Conventional radiography; \\ ad. CBCT scan.
}

\section{Who analysed facial growth in children setting percentual modifications?}

口a. Leonardo da Vinci;

ab. Charles Darwin;

口c. Leslie Farkas;

ad. Alphonse Bertillon.

\section{Through which methods can facial morphology be analysed?}

Da. Laser scanner;

ab. CT-scan;

ac. NMR;

ad. All the above.

\section{Which facial measurements most increase between 6 and 11 years?}
a. Horizontal ones;
b. Vertical ones;
ac. Both of them;
ad. None. 


\section{Scan and connect}

digitally. Or treat it

in a single visit.

Either way, it's prime.

Enjoy the scan.

With the connectivity options of Primescan. 


\title{
INFLUENCE OF THE COVID-19 PANDEMIC ON DENTAL PRACTICE: WHY MEASURES TO BE TAKEN - THE EXPERIENCE OF AN EUROPEAN UNIVERSITY HOSPITAL (PART 2)
}

\author{
Constantinus Politis ${ }^{1 a^{*}}$, Annette Schuermans ${ }^{2 b}$, Katrien Lagrou ${ }^{3 c}$, Mia Vande Putte ${ }^{4 d}$, Jean-Pierre Kruth ${ }^{5 e}$ \\ 'Department OMFS, Department Imaging and Pathology, Faculty of Medicine, Leuven University Hospitals, Leuven, Belgium \\ 2Department of Hygiene, Infection Control and Epidemiology, Faculty of Medicine, Leuven University Hospitals, Leuven, Belgium \\ ${ }^{3}$ Department of Laboratory Medicine, Faculty of Medicine, Leuven University Hospitals, Leuven, Belgium \\ ${ }^{4}$ Hospital Hygiene and Infection Control Department, Faculty of Medicine, Leuven University Hospitals, Leuven, Belgium \\ ${ }^{5}$ Wet Engineering Department, Technical Service, Faculty of Medicine, Leuven University Hospitals, Leuven, Belgium
}

aMD, DDS, MM, MHA, PhD, Full Professor \& Chairperson OMFS; e-mail: constantinus.politis@uzleuven.be; ORCIDiD: https://orcid.org/0000-0003-4772-9897 bMD, PhD, Professor; e-mail: annette.schuermans@uzleuven.be; ORCIDiD: https://orcid.org/0000-0002-0998-8241

PharmD, PhD, Full Professor KU Leuven; e-mail: katrien.lagrou@uzleuven.be; ORCIDiD: https://orcid.org/0000-0001-8668-1350

IInfection Control Practitioner, Expert of the Higher Health Council; ICP; e-mail: mia.vandeputte@uzleuven.be;

ORCIDiD: https://orcid.org/0000-0003-0556-5345

eEng, Ir; e-mail:jean.kruth@uzleuven.be; ORCIDiD: $\underline{\text { https://orcid.org/0000-0003-0362-8875 }}$

di) https://doi.org/10.25241/stomaeduj.2020.7(4).art.6

Background The COVID-19 pandemic does not leave the dental practice unattended. In Part 1 the reason why measures should be taken was explored.

Objective The objective is to review the measures that can be taken to minimize the risk of tranmission in the dental practice.

Data Sources These measures can be classified according to the guidelines of the National Institute for Occupational Safety and Health (NIOSH).

Study Selection A qualitative approach explores the applicability of these guidelines to the dental practice. Data Extraction In order to prevent aerosol transmission in the dental practice a large number of changes are needed. It concerns hygiene protocols, organizational protocols and architectural changes, none of which are backed by a legal framework.

Conclusion Until a vaccination program is introduced to counter the COVID-19 pandemic in a country, the dental society will need to take measures to prevent aerosol transmission in the dental office. The pyramid of measures according to NIOSH offers a suitable frame to classify all measures. Any legal regulatory intervention could use this framework.

\section{KEYWORDS}

COVID-19; Aerosol; SARS-2-COV; Personal Protective Equipment; Respirator.

\section{INTRODUCTION}

After the outbreak of COVID-19 in Wuhan, China, the virus spread to the rest of the world and on March 11, 2020, the COVID-19 pandemic was formalized by the World Health Organization. Part 1 of the manuscript did answer the question why a lasting influence of the COVID-19 pandemic on the general dental practice could be expected in the absence of a vaccination program. The second part tries to list all measures that could be taken (hygiene measures, organisational and architectural changes) and to provide a framework according to NIOSH pyramid which is well-known in the industry [1].

(c) (1) (2) OPEN ACCESS This is an Open Access article under the CC BY-NC 4.0 license. Peer-Reviewed Article

Citation: Politis C, Schuermans A, Lagrou K, Vande Putte M, Kruth JP. IInfluence of the COVID-19 pandemic on dental practice: measures to be taken the experience of an European University Hospital (part 2). Stoma Edu J. 2020;7(4):275-285.

Received: September 13, 2020; Revised: September 18, 2020; Accepted: September 27, 2020; Published: September 29, 2020

*Corresponding author: Prof. Dr. Constantinus Politis, MD, DDS, MM, MHA, PhD; Full Professor \& Chairperson Oral \& Maxillofacial Surgery

Kapucijnenvoer 33B, BE-3000 Leuven, Belgium

Tel. +32 16 341780; Fax: +32 16 332437; e-mail: Constantinus.Politis@uzleuven.be

Copyright: @ 2020 the Editorial Council for the Stomatology Edu Journal. 

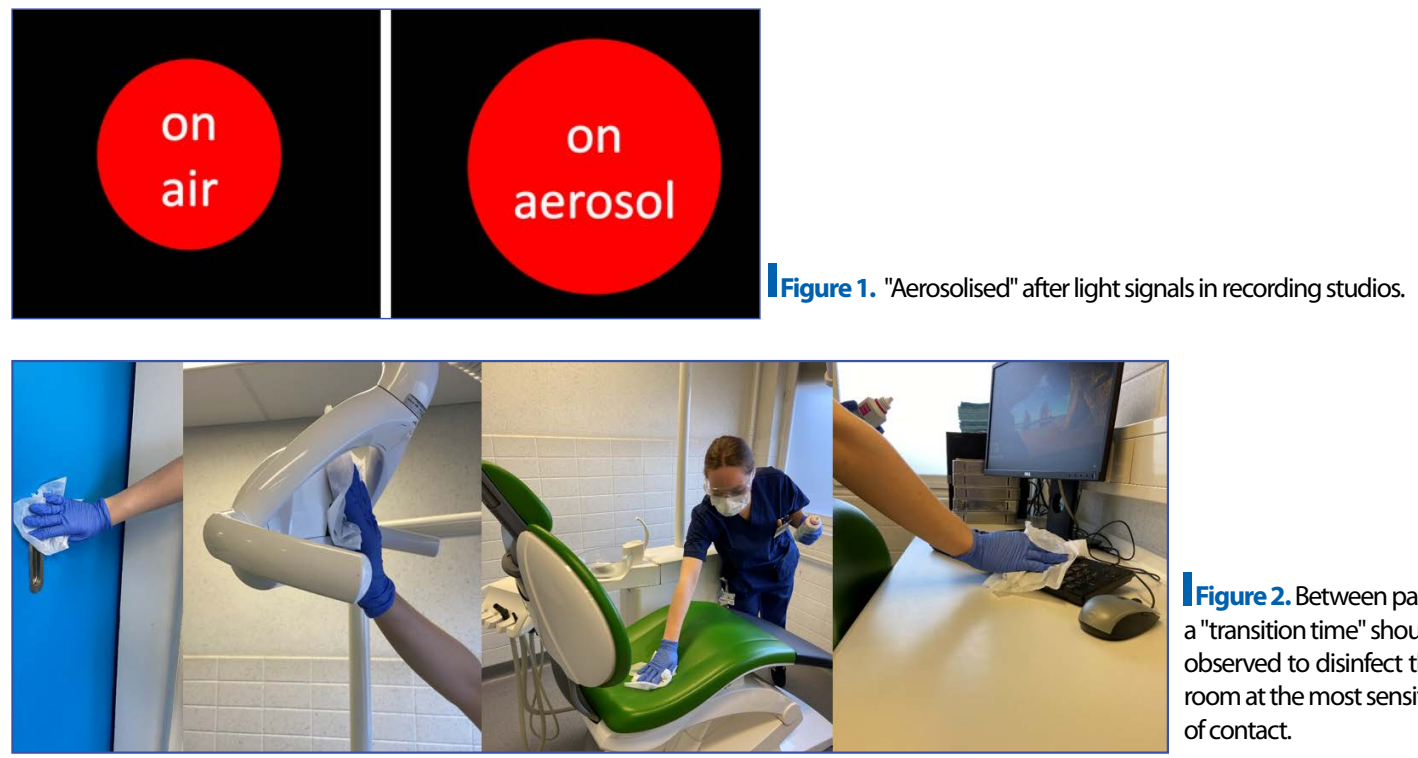

IFigure 2. Between patients, a "transition time" should be observed to disinfect the treatment room at the most sensitive points of contact.

\section{METHODOLOGY: CLASSIFICATION OF MEASURES}

When considering COVID-19 as a new infectious agent for dental practice, it seems wise to follow the pyramid of basic interventions that apply to every workplace, the "hierarchy of controls" as defined by the National Institute for Occupational Safety and Health (NIOSH) in the United States. Infection control measures can also be tested against this criterion in order to arrive at practice-oriented recommendations [2].

Five questions are asked:

- Can the agent be eliminated?

- Can the agent be replaced by a less harmful agent (substitution)?

- Can the employee be isolated from the agent (technical controls)?

-Can the working method be adapted (administrative control)?

- Is personal protective equipment (PPE) possible?

\section{RESULTS}

\subsection{Elimination}

Elimination means no exposure to the COVID-19 virus. This is the purpose of the lock-down, of the quarantine measures and PCR testing. By ensuring that, no COVID-19 positive patients in the dental practice undergo any aerosol generating procedure. Dental treatments in COVID-19 positive have been assigned to treatment centres equipped for this purpose if the treatment could not be posponed.

Another means is a vaccination schedule for the population that cancels out the virus spreading.

However, in the absence of a vaccine and systematic PCR screening, each patient must be considered as a possible source of infection for the COVID-19 virus and, mutatis mutandis, for all aerosol-transmitted germs (chicken pox, influenza, tuberculosis, measles, etc.). The elimination of the source of infection in the dental chair cannot be achieved conclusively, but in the hierarchy of measures it is preferable that it takes place as close as possible to the source, in fact as close as possible to the potentially infected patient. In concrete terms, the production and diffusion of aerosols must be tackled and contamination through direct and indirect contact with the source of contamination must be avoided or prevented.

The following measures, under the heading of elimination, will appear in infection control protocols in the future, if they are not already present :

- as soon as possible: vaccination

- questionnaires to prevent potentially infected patients coming into the dental practice

- point-of-care PCR testing

- other point-of-care diagnostic testing for COVID-19 - measuring the patient's temperature: if $>37.3^{\circ} \mathrm{C}$, the patient should contact the general practicioner.

- The patient washes his hands with soap and water and, after drying them with pure paper wipes, disinfects them with an alcohol hand solution (> $70 \%$ ) when entering the practice.

- the patient must wear a mouth mask up to the office chair

- the patient enters the practice alone (unless supervision is required)

- contactless access to the practice chair

- rinsing the mouth with $1 \%$ hydrogen peroxide or $1 \%$ povidone iodide mouthwash before any intervention causing aerosol production

- use of the rubber dam whenever possible

- use of surgical suction with a flow rate of $300 \mathrm{l} / \mathrm{min}$ where possible

- patients with drooling: scopolamine or atropine patch

- the use of mobile extra-oral fog extraction systems - the use of disinfectants in tap water of rotating instruments or ultrasonic instruments.

All current measures for cleaning and disinfecting surfaces remain valid both inside and outside the splash zone; in this case, the surface is first cleaned 


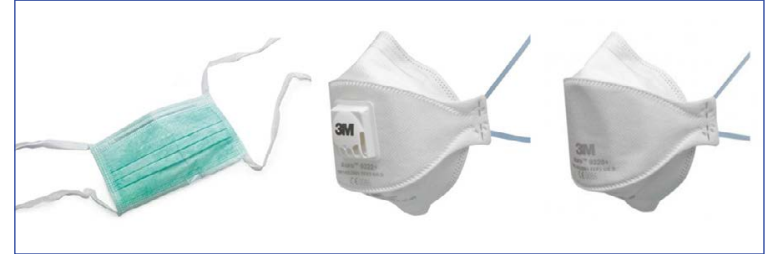

Figure 3. From left to right: a surgical nasal mask, an FFP-2 nasal mask with valve, an FFP-2 nasal mask without valve.

of visible dirt and only then disinfected following the guidelines for the correct use of disinfectant; as an example, but not exhaustively $[3,4,5,6,7,8,9,10,11,12$, $13,14,15,16]$ :

- Alcohol-free wipes (wipes) based on a mixture of several different quaternary ammonium compounds and a biguanide have a broad biocidal spectrum; this intermediate degree of disinfection is sufficient for the COVID-19 virus.

- A higher degree of disinfection can be achieved with concentrated sodium hypochlorite, but beware of chlorine applications on stainless steel: in the long term, stainless steel will be affected; especially with lower quality stainless steel, this effect will be more quickly noticeable.

- Surfaces can be disinfected with more than $70 \%$ alcohol after cleaning.

- Electrical or electronic appliances are rubbed with alcohol-based disinfectants to prevent damage. Computers, keyboards and accessories are disinfected with $70 \%$ isopropyl alcohol to prevent damage to the LCD screen.

In a hospital context, experience is gained by making the treatment room reusable during the transition period:

- Nocolysis: this involves atomisation with an $8 \%$ hydrogen peroxide solution; this hydrogen peroxide is transformed into oxygen radicals which inactivate viruses and bacteria; this mist is toxic; for a $50 \mathrm{~m}^{3}$ room, a spraying time of 3 minutes and an average waiting time of one hour (exposure time, ventilation time) is required; this solution is expensive.

- There are systems for disinfecting treatment rooms and entire operating theatres based on UV-C light, but they are not used in general dental practice because the UV-C light for this application is unprotected and toxic, but also because of the high cost of these devices [17].

The infectivity of the air depends on the size of the room, the number of air changes, the procedure (aerosol or not), the number of people in the room (coughing or not): allowing natural ventilation by opening the windows wide always has an important place in the prevention of infections $[18,19,20]$.

\subsection{Substitution}

Substitution of the infectious agent by a less harmful agent is not possible for COVID-19.

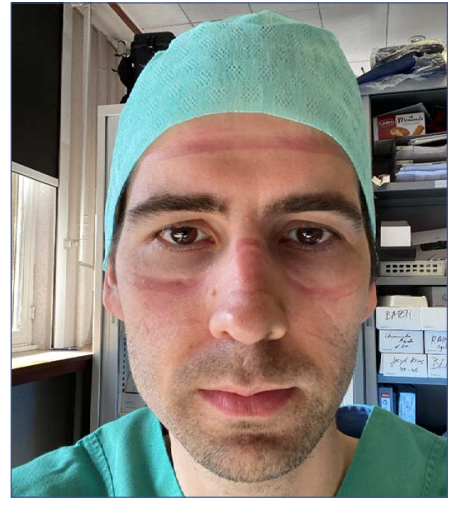

I Figure 4. Prolonged wearing of an FFP-2 mask causes pressure sores on the facial skin.

\subsection{Technical measures}

The main innovation that will be triggered by the COVID-19 virus is air treatment in dental practices. Hospitals have had to invest in this area for several decades, both for general air quality and for treatment rooms or operating theatres $[21,22,23]$.

We expect measures to be taken in both dental intervention rooms as in the general dental practice. 3.3.1.Treatment area

Hospitals have different "classes" of surgery or treatment rooms [24,25].

- A "treatment room" in a Belgian hospital has no "class", no clean or limited ventilation system, no HEPA air filtration, if possible, a ventilation rate of 6 is achieved. It is impossible to measure over- or underpressure because these treatment rooms are often not airtight. Ventilation can be achieved by opening the windows or using a ventilation device if there are no windows. Usually an ISO class 8 according to ISO14644 is obtained at rest (i.e. maximum 3520000 particles $>0.5 \mu \mathrm{m}$ and maximum 29300 particles $>5 \mu \mathrm{m}$ ). It is these particles or dusts that can serve as carriers for possible bacteria and viruses, just as aerosols can serve as carriers for the COVID virus. The number of colony-forming units allowed is $<500 \mathrm{CFU} / \mathrm{m}^{3}$. This is in fact also the situation in most dental practices.

- Class 2 operating theatres (also called performance requirement 2) have a mixed ventilation system, HEPA air filtration, a multiple ventilation factor of 6 to 30 times (criterion for new buildings). Usually an ISO class 7 according to ISO14644 is imposed at rest (i.e. max. 352000 particles $>0.5 \mu \mathrm{m}$ and max. 2930 particles $>5 \mu \mathrm{m}$ ). The permitted number of $\mathrm{CFU} / \mathrm{m}^{3}$ is $<200$. The operating theatre (zone 1 ) is normally over-pressurised compared to the rest of the hospital (zone 2) in order to protect the operating area from environmental contamination. Overpressure in the room is possible if it is constructed in a sealed manner. Different rooms can be operated by a common ventilation system. The exhaust air is always blown outside (no air recovery).

- A class 1 operating theatre (or performance requirement 1) is equipped with an unmixed ventilation system, laminar flow integrated in the plenum, HEPA filtration, a ventilation rate of between 30 and 60x per hour (criterion for new buildings), 


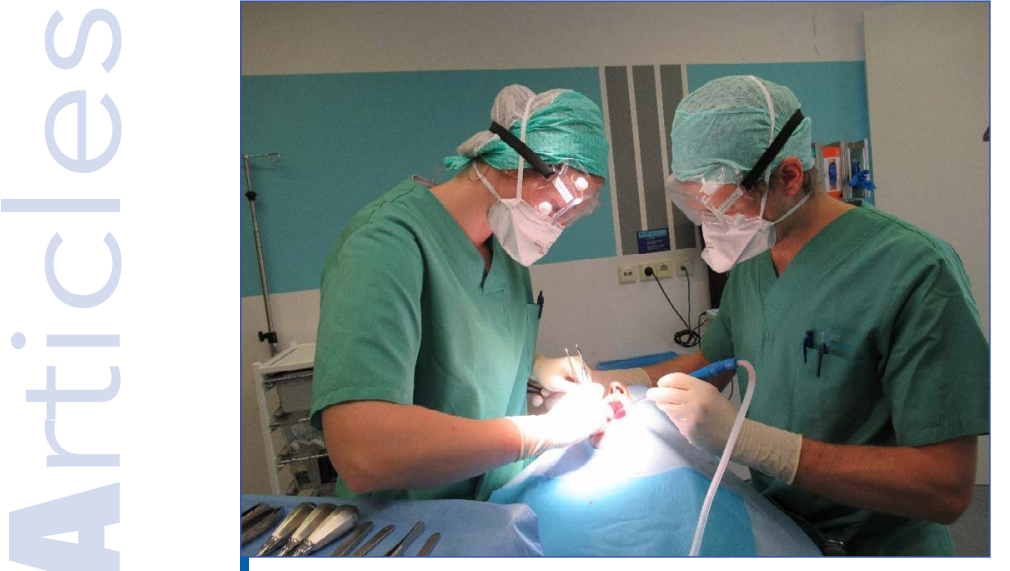

Figure 5. Procedure under local anaesthesia in a PCR negative patient with low aerosol production; no drilling. On the right, an FFP-2 mask is worn with a valve. A conventional surgical mask would have sufficed in this situation (PCR negative).

an ISO class 5 system at rest below the plenum and ISO class 7 at the periphery and a maximum of only $10 \mathrm{CFU} / \mathrm{m}^{3}$ allowed. The operating theatre (zone 1) is located in an operating room (zone 2 ) which is separated from the rest of the hospital (zone 3 ). The air flow is from zone 1 to zone 3. This type of operating theatre usually has one ventilation unit per operating theatre. The extracted air can be partially recirculated and re-injected through the HEPA- filters in the plenum.

- Fungal infections are not allowed in classrooms or treatment rooms.

- Operations under general anaesthesia usually take place in class 1 or class 2 operating theatres, while oro-maxillo-facial surgery and dental treatments which can be performed under local anaesthesia or IV sedation are located in treatment rooms.

The operating theatres operate with an overflow of air from the room to the environment to prevent pathogens from entering the operating room from outside and compromising the sterile field. This is achieved by blowing more air into the room than is sucked in. The excess air escapes from the room through the door slots or grilles. If the room is sufficiently sealed, the air flow can be properly controlled and even measured with differential pressure meters. This is called positive pressure. In the case of an infected patient in the operating room, the patient is the source of the pathogens and to maintain the source of infection in the operating room, it is necessary to modify the air flow from the environment to the operating room, or to create a negative pressure [26]. More air is then extracted than is blown in. If possible, the contaminated air is diverted to the outside by a powerful extraction system with a double filter (pre-filter and HEPA filter). If the air is recirculated anyway, as in class 1 operating rooms, it is returned through the HEPA filters into the plenum before entering the operating room again. In the dentist's treatment room, only the surgical suction is able to draw in the aerosol most powerfully

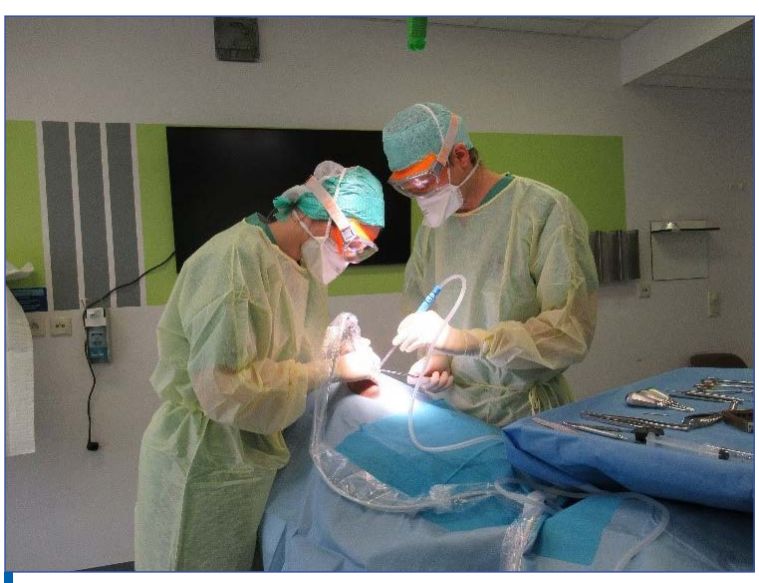

Figure 6. Procedure under local anaesthesia in a PCR-negative patient with high aerosol production; drilling takes place. In this case, it is preferable to wear safety glasses, an FFP-2 mask without a valve and a disposable apron. The FFP- 2 mask of the person on the right side of the operating table has an exhalation valve and is therefore defective.

because it is located in the aerosol production area. An ordinary saliva aspirator does little to control the production of aerosols. Surgical suction does have an effect on the transmission of droplets and droplet nuclei $[27,28]$. An extra-oral saliva aspirator may be effective in some situations, but it is designed for industrial use and is very bulky and intrusive in practice. As COVID-19 likes humidity, the installation of a dehumidifier can be defended on a theoretical basis [29]. A stand-alone dehumidifier is usually sufficient for a space of $100 \mathrm{~m}^{2}$. Humidity in a dental practice comes from the aerosols created during the dental treatments, from evaporation after disinfection of surfaces and spaces and from the autoclave. However, if regular natural (windows) or mechanical (ventilation devices) ventilation takes place, the room will already be dehumidified in this way. The added value of a stand-alone dehumidifier will then be much more limited or even non-existent. These are devices designed to purify the air quality and reduce the number of particles circulating in the air, but without any effect on the transmission of droplets :

- Air disinfection systems based on UV-C light with a peak emission wavelength of $253.7 \mathrm{~nm}$; the contaminated air is sucked into the unit where it is irradiated by a number (often 4) of UV-C lamps which inactivate all biological particles by damaging the DNA. These units can be operated during active dental treatment and do not allow UV-C radiation to escape thanks to the good shielding of the housing. There is no production of ozone or other by-products. These devices are suitable for killing bacteria, viruses and fungi. Care must be taken with UVC as UVC is harmful to plastics.

- Air disinfection systems based on HEPA filtration are realistic for the general dental practice because of the affordable price, the absence of any toxicity and because they do not require any interruption of practice. HEPA filters are well known in the hospital sector where they are integrated into the plenum of 


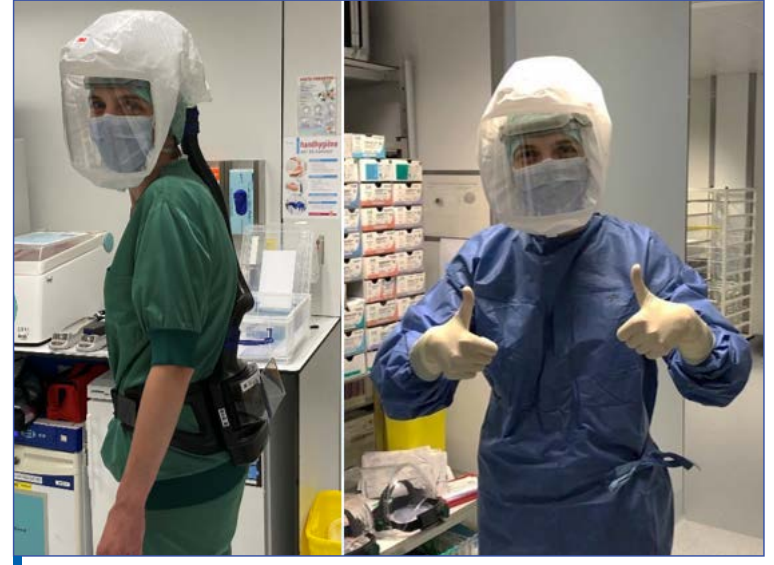

Figure 7. PPE in the form of PAPR when entering the operating room to perform an aerosol-producing procedure on a COVID-19-positive patient in the contagious phase.

operating theatres. The room air flows over a HEPA filter and an activated carbon filter with a filtration efficiency $>99.9 \%$ for all particles between $0.3 \mu \mathrm{m}$ - $0.4 \mu \mathrm{m}$. Simple commercial stand-alone units are generally suitable for treatment areas of $75 \mathrm{~m}^{3}$ and allow about 4 to 6 air changes per hour, depending on the filtration rate. The main disadvantage of these units is noise. The position of the unit must prevent aerosols from being sucked into the dentist.

- mobile or wall-mounted air purifiers based on ionisation are extremely effective and broadspectrum and are capable of removing viruses, bacteria, prions and odours [30,31,32]. The particles are, so to speak, electrocuted and collected in an activated carbon collector. In addition to pulverising the aspirated particles with negative electrons, the ioniser also creates reactive oxygen radicals. The cartridges of these air purifiers must be replaced regularly. These devices can also be installed in rooms where there is over- or underpressure. These devices have a low air flow rate. Approximately 2.5 air changes per hour are achievable for commercially accessible units. Larger units are available with more air changes per hour, but less suitable for general practice. It is important to check that the unit does not produce ozone as an end product. Most ionizers on the market are also equipped with some filters to stop coarse particles before the residue passes through the ionizer.

- Devices that inactivate micro-organisms on the basis of cold plasma (= ionised gas) and HEPAfiltration work by generating a high electric field of 10 $\mathrm{kV} / \mathrm{cm}$ in the cold plasma vacuum reactor by means of dielectric barrier discharges in which oxygen radicals disinfect the air, and the filters ensure that no particles leave the device $[33,34,35]$. These are fastacting devices (less than 2 minutes for a treatment room) with an inactivation efficiency of $>99.9 \%$ for particles greater than $0.3 \mu \mathrm{m}$ without leaving residues. The disadvantage is their weight (around $200 \mathrm{~kg}$ ) and the high cost of their maintenance. This technology was originally developed for the MIR space station. Fungi such as Aspergillus are resistant

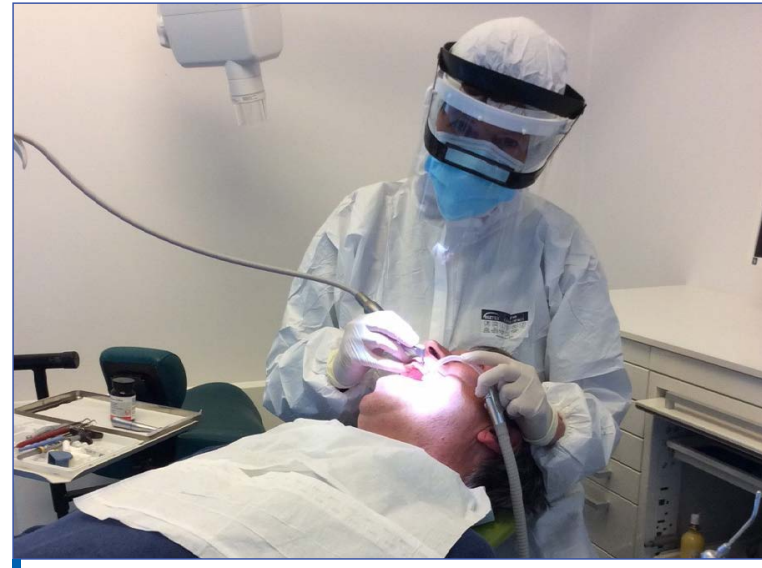

Figure 8. Even if a dentist takes maximum personal protective measures, he or she cannot prevent consecutive patients from becoming mutually infected with aerosols; additional ventilation measures are necessary.

to inactivation by cold plasma. Natural ventilation by opening windows can achieve up to 10 air changes per hour, but depends on a number of important parameters such as wind, outside temperature, window type, surface area, room orientation and opening duration of the windows. In order to reduce air contaminants by $90 \%, 2.5$ air changes are required $[36,37,38]$. The time required depends on the number of air changes per hour achieved. For the calculation of the required change time (= time needed between the last aerosol production and the entry of the next patient into the treatment room), any scientific studies carried out in a real dental practice environment are still missing. As a rough estimate, without a rocksolid scientific basis, it is assumed that the time required for 2.5 air changes with closed windows without mechanical ventilation can vary between 5 and 25 hours, whereas widely open windows on either side of the treatment room can complete the work in 5 minutes. Open windows and mechanical ventilation seem to achieve this in 15 to 30 minutes. In rooms producing aerosols, the World Health Organization does not recommend 2.5 air changes per hour, but 6 to 12. A unit with a flow rate of $400 \mathrm{~m}^{3} / \mathrm{h}$ placed in a standard $40 \mathrm{~m}^{3}$ box will provide 10 air changes per hour $[39,40]$.

3.3.2. General dental practice

In contrast to class 1 or 2 operating theatres, where the large amount of ventilation air is cooled and filtered in the ventilation system, in treatment rooms or in most dental practices, autonomous air conditioning units are required to achieve pleasant temperatures all year round. Harmful micro-organisms can escape through such systems $[41,42]$.It is therefore important to ensure that rooms, windows and doors are well sealed and to use air filters and air conditioners that are regularly maintained and replaced. In practice, filters should be replaced at least once a year and drip pans should be cleaned. For more sensitive operations, it is even recommended several times a year. Ventilation through natural or mechanical extraction works. Contamination of a dwelling adjacent to the practice by a collective ventilation 


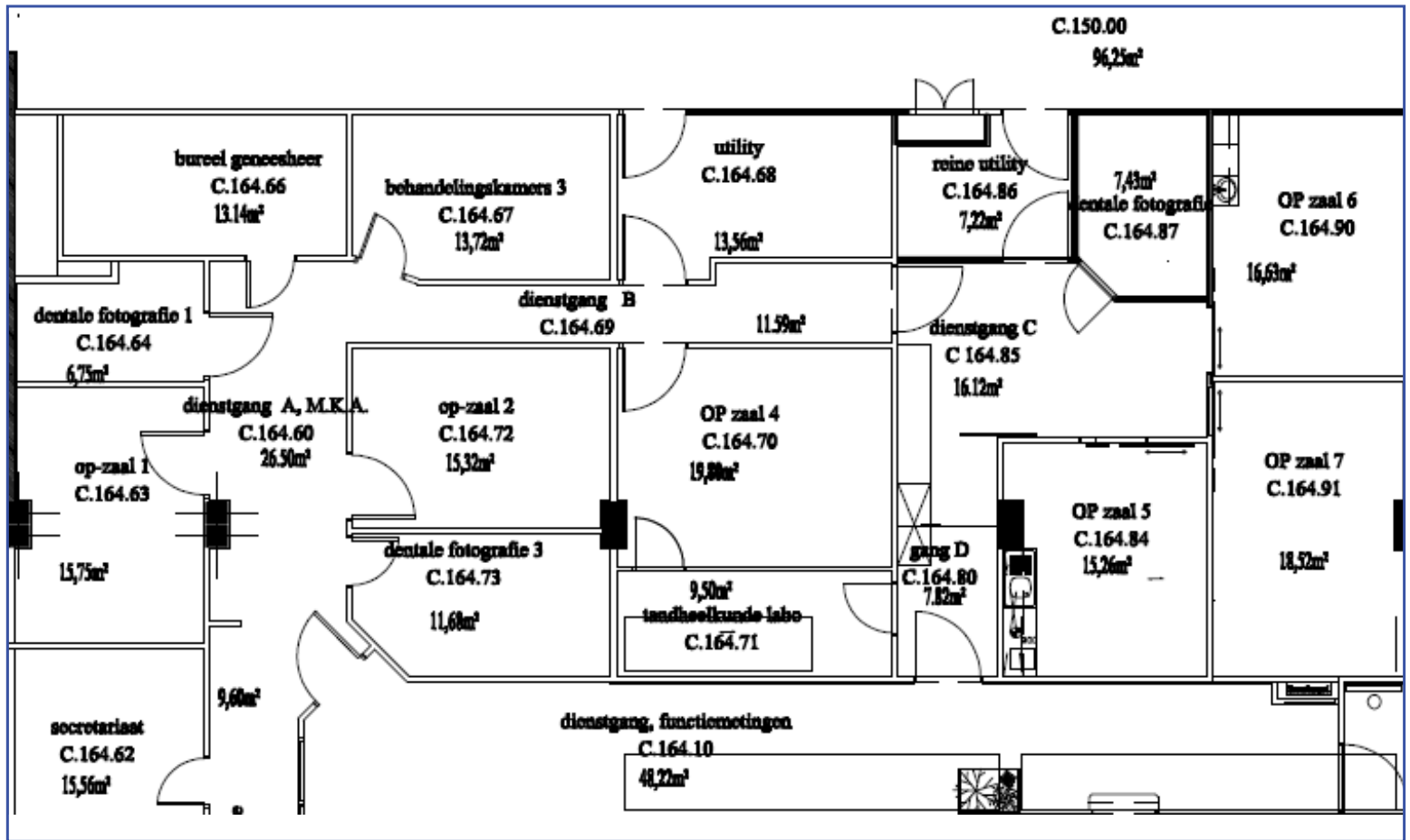

Figure 9. Most outpatient dental and oral surgery facilities are currently not equipped for aerosol control or ventilation, nor for physical separation or separate walking routes for patients and the provision of care.

system is unlikely, but it is recommended that, if possible, a distance of 5 to 10 metres should be kept between the discharge grille and open windows or the suction grille. The movement of impure air from central rooms to service rooms (garages, cellars, etc.) may be insufficient if, for example, the windows of these service rooms are open.

\subsection{Organisation of the practice}

Many trends already present in the hospital sector will accelerate their entry into the general dental practice: digital appointment management, numerous smartphone applications for contactless payment, filling in questionnaires, access and completion of one's own dental record [43].

A treatment room where an aerosol is produced will remain closed with an indicator light to prevent entry during treatment (Fig. 1). At the reception perspex creates a safe partition between the patient and the receptionist. In between two successive patients, there should be time for a complete cleaning of the unit and the contact points of the patient and the practitioner (door handle, lamp, chair, keyboard). In a conventional hospital environment, the "transition times or change-over time" in an operating theatre are known (Fig. 2) [44].

Wall posters, patient leaflets with instructions and guidelines, digital wall signs with information, signs, indicators and markings on floors and walls are among the possibilities.

In places where patients come, it should be possible to disinfect their hands and obtain a mouth mask.

The decoration of the rooms should be very sober; drinking fountains should be avoided.
Since using the toilet also causes hand disinfection by touching the glasses, the creation of an aerosol after flushing the toilet will also require technical innovations, e.g. the installation of UV-C light for decontamination, and the invitation to wash hands thoroughly after each use of the toilet should be displayed $[45,46,47,48,49]$. Pets will be left in the car park and personal belongings will remain at home or be stored in a locker. The practice is organised in such a way that contact with people and objects is kept to a minimum, including doorbells, door handles, payment terminals and other points of contact. Video consultations can be useful in general dentistry for triage, questionnaire completion, follow-up and assessment of problems that do not necessarily require an intra-oral examination.

Existing guidelines on waste management are sufficient [50]. Although less critical than not respecting deadlines in the legal profession, the expiry of storage periods for disinfectants should be monitored with the establishment of systems to record regular maintenance, cleaning, toilet cleaning. Water-based disinfectants may be stored for 7 to 14 days once opened; in the case of alcoholic solutions, no storage period is used unless limited by the manufacturer. Maintenance contracts and cost-benefit analyses and vaccination schedules for auxiliaries should not be missed.

\subsection{Personal protection measures}

As far as personal protective measures are concerned, all guidelines on hygiene and hand washing remain fully in force [51]. Nothing has changed with regard to gloves in dental practices 
either. It should be emphasised that hands must be washed or disinfected (alcohol $>70 \%$ ) before and after wearing gloves. This is because the gloves are not completely sealed. The penetration of the virus was demonstrated in $8-14 \%$ of the sterile gloves examined. Sterile gloves must also be changed every hour during critical medical procedures. The three reasons for regularly changing gloves are lack of complete occlusion, damage to the gloves by sharp objects (instruments) and contamination of the hands when removing the gloves.

Sciensano reports that it is necessary to wear professional clothing, including shoes. As aerosols can precipitate on clothing, contact contamination is possible afterwards. To avoid this, one of the following choices is recommended (Sciensano) [38]: - Wear a disposable long-sleeved apron and replace it between patients.

- Wear a long-sleeved overshirt made of washable fabric and replace it between each patient, and wash it at $60^{\circ} \mathrm{C}$ before the next use. Waterproof aprons are ideally made of polypropylene with a density of at least $25 \mathrm{~g} / \mathrm{m}^{2}$.

- Wear a washable short-sleeved fabric apron and wash the forearms between each patient.

- The aerosol-infected apron should be removed before leaving the treatment area and placed in the appropriate garbage bag or dish basket.

It makes sense to wear a surgical cap or headgear. Overshoes are not useful. Wearing professional silver-impregnated aprons makes no sense because silver usually disappears after about ten washes along with the supposed protection [52].

For patients who are known to be COVID positive and need urgent treatment, long-sleeved splash aprons and washable shoes should be worn.

The existing guidelines of the High Council of Health (Publication no. 8363) concerning the wearing of nasal masks, corrective glasses, splash goggles and face shields remain unchanged, with the difference that in addition to tuberculosis, COVID-19 can now be added [51]. The masks stop the drops that carry the virus [53,54]. An FFP-2 mask must be CE-certified and must not have an exhaust valve, as the health care provider is then protected, but not the patient (Fig. 3). Mouth masks are exorbitantly expensive in corona time: about 55 cents for a surgical mouth mask and about 10 euros for an FFP-2 mask. Theoretically, FFP3 masks offer better protection than FFP-2 masks with regard to COVID-19, but in practice FFP2 masks will suffice, also in the hospital sector. FFP stands for Filtering Facepiece Particle (filtering particle of the mask). FFP-2 is the European (EU) standard and the equivalent of the N95 nasal mask certified by the US National Institute for Occupational Safety and Health (NIOSH). An FFP mask has the disadvantage of causing pressure ulcers at pressure points and a common complaint is that it is difficult to breathe or work when worn for long periods of time (Fig. 4) [55]. In practice, this means that a dentist wears an FFP-2 mask under the surgical mask and behind the face shield or goggles during every aerosol-generating procedure, or will wear the FFP-2 mask only if he or she considers himself or herself to be one of the groups at risk of suffering from a potentially severe form of COVID-19 and therefore wishes to have additional protection during aerosol-generating treatments in the absence of PCR screening or vaccination (Fig. 5, Fig. 6). The usefulness of surgical masks and FFP-2 masks is lost if they get wet or are poorly fitted. A face shield or face mask can reduce short-term exposure to large infectious particles and thus reduce contamination of nasal mouth masks, but after 1-30 minutes, the total reduction in contamination is only $\pm 23 \%$ according to some publications [56]. Face shields are less effective against small particles. After all, these particles can stay in the air longer and can easily get behind the face mask. Nasal masks and splash goggles or face shields should not be touched by the healthcare provider in the infected area [57].

Dentists who prefer to wear a surgical mask rather than an FFP2 mask should preferably choose an FFP2 mask with a valve, which allows much more comfortable exhalation.

Reuse of surgical masks is not possible. Watering or moistening surgical mouth masks is not a good idea. FFP-2 masks can be reused twice after resterilization with hydrogen peroxide and low pressure gas sterilization [58,59]. Goggles and face shields are washed with soap and water and, after drying, disinfected with disinfectant alcohol or treated in the instrument washer. PAPRs (Powered Air-Purifying Respirators) are breathing apparatus in the form of a bonnet or full face mask with a battery-operated fan that conducts a positive air flow through a filter to the bonnet [60]. The filter is the equivalent of a HEPA filter that retains $99.7 \%$ of the particles in 0.3 $\mu \mathrm{m}$. This type of maximum protection is justified for the treatment of a COVID-positive patient in the contagious phase, but it is almost impossible to use in an ambulatory dental setting because communication with the patient is completely disrupted. There is also a high risk of infection if this PAPR is taken off (Fig. 7) [61]. Even if a dentist takes maximum personal protective measures, he cannot prevent consecutive patients from infecting each other through aerosols contaminating the air in the treatment room; additional ventilation measures are necessary (Fig. 8). An under-exposed chapter is one of the many mistakes made when putting on / taking off / removing personal protective equipment (PPE) [62]. It is almost impossible to carry out donation and removal protocols correctly without training. Wearing a beard under a mask is a common mistake. Keeping gloves on between surgeries or touching clean surfaces with soiled gloves or touching the surface of a mask with the hands explain why PPE does not figure prominently in the hierarchy of measures. 


\section{INSTRUMENTS}

With regard to dental instruments, no changes have been made to the policy described in policy document No. 8363 of the High Council of Health in 2011. The 1957 E.H. Spaulding risk categories continue to stand the test of time, even in coronary periods [63]! To grind bite plates and other tips on the chair, simply immerse them in $3 \%$ hydrogen peroxide for 30-60 seconds before sharpening.

It is also recommended not to allow unused instruments in the splash area or aerosol area to prevent contamination.

\section{ARCHITECTURAL INNOVATION}

There is no doubt that the new surgeries to be created offer great opportunities for architectural innovation, as most oral and dental surgeries are not equipped for aerosol and ventilation control (Fig. 9) [64]. Several options exist to improve ventilation,air quality and air disinfection in dental practice, apart from other architectural interventions influencing patient flows:

- The treatment cabinets could be designed to obtain negative pressure by extracting more air than it enters

- Good natural ventilation of the practice

- Air changes of at least 6 to 12 changes per hour

- Ventilation ducts that do not lead to another room where people are sitting

- Control of air inlets and outlets

- Installation of HEPA filters

- Working with several practices that allow for a time interval between practices

- Conversion of a parking space into a workspace for waiting and recharging electric cars

- Good connectivity between the practice and the car park with the necessary remote surveillance and, if necessary, automatic license plate recognition at the car park entrance or in the outside waiting area.

- The necessary facilities for maximum digitisation of the practice

- If waiting rooms are still provided, taking into account the rules of physical distance

- Concept allowing gateways with minimal contact

- Use of non-porous work surfaces and sinks impregnated with a homogeneous distribution of copper oxide (Cu-O). Copper is bactericidal and virucidal.

In dental practices, closed shelves are preferred to open shelves because open ones can be contaminated by aerosols.

Innovation will also be needed in the treatment unit to allow for quick and proper cleaning between patients:

- Swivel arms should be avoided as much as possible.

- Redesign of drill pipes, air syringe, suction for cleanability and disinfection.

- Screens must be hidden without cables

- The spit bowl should be redesigned to be extremely easy to clean and replace

- Automated pipe flushing.

It is not inconceivable that accreditation will be required in the long term for surgery rooms. This concept will have to take into account the existing ISO standards for clean rooms in order to keep pace with current regulations. ISO standards do not determine the number of air changes, but rather the maximum number of particles that can be found in the air in the room in question per cubic metre. This can be done by ventilation, filtration or both.

Again, it is possible to differentiate between orthodontic practices with many children where transmission problems (for COVID-19) have less consequences and less aerosol production compared to general dental practices where the practitioner and 28 patient are almost always connected at a short distance by an aerosol spray during intra-oral healing procedures.

\section{CONCLUSION}

The COVID-19 pandemic highlighted aerosol transmission in the chain of infection. Using the $\mathrm{NIOHS}$ pyramid of interventions a systematic approach can be utilized to combat aerosol transmission in dental practice. The development of new practices to be implemented is an excellent opportunity for architectural renewal. In addition, COVID-19 provides an impetus towards the development of new technologies that generate less aerosols and towards new concepts to facilitate the disinfection of dental facilities and practices. Extensive digitisation of the dental practice was a trend that is now becoming a necessity. Universities offer good education and training in PPE. Professional associations will be needed to maintain economically viable dental practices in the health care field, accessible to all social strata of the population.

\section{CONFLICT OF INTEREST}

The authors declare no conflict of interest.

\section{AUTHOR CONTRIBUTIONS}

All authors contributed to this paper. CP: contributed to its concept and writing. AS and MVP: contributed to the protocol. KL: contributed to the data gathering and analysis. JK: contributed to critically revising the manuscript.

\section{ACKNOWLEDGMENTS}

None. 


\section{REFERENCES}

1. Amara J. Reducing job-site risks through the hierarchy of controls [Internet]. (published Oct 16, 2019; last updated 2019-10-17; cited September 14th 2020). Available from:

https://search.proquest.com/docview/2306052949?account id $=17215$

2. Volgenant CMC, Pe rsoon IF, Ruijter RAG de, Soet JJ de. [Infection prevention in oral care during the SARS-CoV-2 outbreak.] Ned Tijdschr Tandheelkd. 2020;127(5):309-317. Dutch. doi: 10.5177/ntvt.2020.05.20031

3. von Rheinbaben $\mathrm{F}$, Wolff MH. [Manual of virus effective disinfection]. Berlin: Springer; 2002.

4. Miller $\mathrm{CH}$. Infection control and management of hazardous materials for the dental team. 5th Edition. St.Louis, MI: Elsevier; 2014. Google Scholar

5. DePaola LG, Grant LE. Infection control in the dental office. A global perspective. Cham, Switzerland: Springer; 2019.

Google Scholar

6. Volgenant CMC, De Soet JJ, Laheij AMGA. Hygiene and infection prevention in oral care practice. The Hague, Nederland: Prelum Publishers; 2018.

7. Molinari JA, Harte JA. Cottone's practical infection control in dentistry. 3rd Edition. Baltimore, MD: Wolters Kluwer-Lippincott; 2010.

8. Wood PR. Cross infection control in dentistry. London, England: Wolfe Publishing; 1992

9. McDonnell G, Sheard D. A practical guide to decontamination in healthcare. Hoboken, NJ: Wiley Blackwell; 2012.

Google Scholar

10. Pankhurst C, Coulter WA. Basic guide to infection prevention and control in dentistry. West Sussex, UK: Wiley-Blackwell; 2009. Google Scholar

11. Wattal C, Khardori N. Hospital infection prevention. Principles and practices. New Delhi, India: Springer; 2014.

12. Reybrouck G, Schuermans A, Vande Putte M. [Hygiene in Hospitals] 4th edition. Leuven, Belgium: Acco; 2000.

13. Scheurmans A. [Hygiene in Hospitals] 5th Edition. Leuven, Belgium: Acco; 2013.

14. van Ouwerkerk YM, Terpstra S. [Hygiene and infection prevention]. GA Houten, Nederland: Bohn Stafleu van Loghum; 2016.

15. Laheij A, Morsen W, de Soet $\mathrm{H}$, Volgenant C. [Infection prevention in oral practice]. DA Houten, Nederland: Prelum Uitgevers B.V.; 2017.

16. Voet DM, de Vries M. IInfection prevention from A to Z for oral care practice]. DL Houten, Nederland: Bohn Stafleu Van Loghum; 2017.

17. Yin R, Dai T, Avci $P$, et al. Light based anti-infectives: ultraviolet $C$ irradiation, photodynamic therapy, blue light, and beyond. Curr Opin Pharmacol. 2013 Oct;13(5):731-762. doi: 10.1016/j. coph.2013.08.009.

Full text links CrossRef PubMed Google Scholar Scopus WoS 18. Somsen GA, van Rijn C, Kooij S, et al. Small droplet aerosols in poorly ventilated spaces and SARS-CoV-2 transmission. Lancet Respir Med. 2020;8(7):658-659. doi:10.1016/S22132600(20)30245-9.

Full text links CrossRef PubMed Google Scholar Scopus WoS 19. Berlanga FA, Ruiz de Adana M, Olmedo I, et al. Experimental evaluation of thermal comfort, ventilation performanceindices and exposure to airborne contaminant in an airborne infectionisolation room equipped with a displacement air distribution system. Energy and Buildings. 158 (2018) 209-221. https://doi. org/10.1016/j.enbuild.2017.09.100.

Google Scholar

20. Cho J. Investigation on the contaminant distribution with improved ventilation system in hospital isolation rooms: effect of supply and exhaust air diffuser configurations. Applied Thermal Engineering. 148(2019);208-218. https://doi.org/10.1016/j.applthermaleng.2018.11.023

Google Scholar Scopus WoS

21. Andersen BM. Prevention and control of infections in hospitals. Oslo, Norway: Springer; 2019.

22. Xu Z, Zhou B. Dynamic isolation technologies in negative pressure isolation wards. Singapore: Springer; 2017 Google Scholar

23. Xu Z. Fundamentals of air cleaning technology and its application in cleanrooms. Singapore: Springer; 2014. Google Scholar

24. Belgian Superior Health Council. [Recommendations regarding infection control of the surgical wound during activities in the operating rooms] [Internet] 2013 (published May 2013; Updated 23/07/2014; cited September 14th 2020). Available from https:// www.health.belgium.be/sites/default/files/uploads/fields/ fpshealth_theme_file/19086106/Aanbevelingen\%20voor\%20 de $\% 20$ beheersing\%20van\%20de $\% 20$ postoperatieve\%20infecties\%20in\%20het\%20operatiekwartier\%20(mei\%202013)\%20 (HGR\%208573).pdf

25. DiDonna MB. Understanding what cleanroom classifications mean. [Internet] (May 2, 2017; Last Updated: 2017-05-10; Cited September 14th 2020). Available from: https://search.proquest. com/docview/1897057513?accountid=17215

26. Rebmann T. Management of patients infected with airbornespread diseases: an algorithm for infection control professionals. Am J Infect Control. 2005;33(10):571-579. doi:10.1016/j. ajic.2005.05.015

Full text links CrossRef PubMed Google Scholar Scopus WoS 27. Harrel SK, Barnes JB, Rivera-Hidalgo F. Aerosol and splatter contamination from the operative site during ultrasonic scaling. J Am Dent Assoc. 1998;129(9):1241-1249. doi:10.14219/jada. archive.1998.0421

Full text links CrossRef PubMed Google Scholar Scopus WoS 28. Harrel SK, Barnes JB, Rivera-Hidalgo F. Reduction of aerosols produced by ultrasonic scalers. J Periodontol. 1996;67(1):28-32. doi:10.1902/jop.1996.67.1.28

Full text links CrossRef PubMed Google Scholar Scopus WoS 29. Jedynakiewicz NM. A practical guide to technology in dentistry. London, UK: Wolfe Publishing; 1992.

30. Cachafeiro SP, Naveira IM, García IG. Is copper-silver ionisation safe and effective in controlling legionella?. J Hosp Infect. 2007;67(3):209-216. doi:10.1016/j.jhin.2007.07.017.

Full text links CrossRef PubMed Google Scholar

31. Skowron K, Grudlewska K, Kwiecinska-Piróg J, et al. Efficacy of radiant catalytic ionization to reduce bacterial populations in air and on different surfaces. Sci Total Environ. 2018;610-611:111120. doi:10.1016/j.scitotenv.2017.08.032.

Full text links CrossRef PubMed Google Scholar Scopus WoS

32. Escombe AR, Moore DA, Gilman RH, et al. Upper-room ultraviolet light and negative air ionization to prevent tuberculosis transmission. PLoS Med. 2009;6(3):e43. doi:10.1371/journal. pmed.1000043.

Full text links CrossRef PubMed Google Scholar Scopus WoS 33. Izadjoo M, Zack S, Kim H, Skiba J. Medical applications of cold atmospheric plasma: state of the science. J Wound Care. 2018:27(Sup9):S4-S10, doi:10.12968/jowc.2018.27.Sup9.S4. Full text links CrossRef PubMed Google Scholar Scopus WoS 34. Niedzwiedz I, Wasko A, Pawlat J, Polak-Berecka M. The State of Research on Antimicrobial Activity of Cold Plasma. Pol J Microbiol. 2019;68(2):153-164. doi:10.33073/pjm-2019-028.

Full text links CrossRef PubMed Google Scholar Scopus WoS 35. Hashim SA, Samsudin FN, Wong CS, et al. Non-therma plasma for air and water remediation. Arch Biochem Biophys. 2016;605:34-40. doi:10.1016/j.abb.2016.03.032.

Full text links PubMed Google Scholar Scopus WoS

36. Villani FA, Aiuto R, Paglia L, Re D. COVID-19 and dentistry: prevention in dental practice, a literature review. Int J Environ Res Public Health. 2020;17(12):4609. doi:10.3390/ijerph17124609.

Full text links PubMed Google Scholar Scopus WoS

37. Patini R. How to face the Post-SARS-CoV-2 outbreak era in private dental practice: current evidence for avoiding crossinfections. J Int Soc Prev Community Dent. 2020;10(3):237-239. doi:10.4103/jispcd.JISPCD 20220.

Full text links CrossRef PubMed Google Scholar Scopus WoS 38. Sciensano. [Control of SARS-CoV-2 infections in dental practices] [Internet] (Published: May 20th 202; cited: September 14th 2020).

Available from: https://covid-19.sciensano.be/sites/default/files/ Covid19/COVID19_procedure_dentists_NL.pdf

39. CDC. Guidelines for environmental infection control in healthcare facilities.[Internet] 2003 (2003; updated July 2019; cited: September 14th 2020). Available from: https://www.cdc.gov/ infectioncontrol/guidelines/environmental/index.html 40. WHO. Natural ventilation for infection control in health-care settings. [Internet] 2009 (2009; cited September 14th 2020). Available from: https://apps.who.int/iris/bitstream/handle/10665/44167/9789241547857_eng.pdf;jsessionid=A0F01390 E4A818F9D7A7F61EBAEC483D? sequence $=1$

41. Zemouri $C$, de Soet $H$, Crielaard W, Laheij A. A scoping review on bio-aerosols in healthcare and the dental environment. PLoS One. 2017;12(5):e0178007. doi:10.1371/journal.pone.0178007. Full text links CrossRef PubMed Google Scholar Scopus WoS 42. Chirico F, Sacco A, Bragazzi NL, Magnavita N. Can airconditioning systems contribute to the spread of SARS/MERS/ COVID-19 infection? Insights from a rapid review of the literature. Int J Environ Res Public Health. 2020;17(17):E6052. doi:10.3390/ ijerph17176052.

Full text links CrossRef PubMed Google Scholar Scopus 
43. Rekow D. Digital dentistry. Surrey, UK: Quintessence Publishing; 2018.

44. Mizumoto R, Cristaudo AT, Hendahewa R. A surgeon-led model to improve operating theatre change-over time and overall efficiency: a randomised controlled trial. Int J Surg. 2016;30:83-89. doi:10.1016/j.ijsu.2016.04.033

Full text links CrossRef PubMed Google Scholar Scopus WoS 45. Lai ACK, Nunayon SS, Tan TF, Li WS. A pilot study on the disinfection efficacy of localized UV on the flushing-generated spread of pathogens. J Hazard Mater. 2018;358:389-396. doi:10.1016/j. jhazmat.2018.07.003.

Full text links CrossRef PubMed Google Scholar Scopus WoS 46. Zakaria F, Harelimana B, Curko J, et al. Effectiveness of UV-C light irradiation on disinfection of an eSOS $\left({ }^{\circledR}\right)$ smart toilet evaluated in a temporary settlement in the Philippines. Int J Environ Health Res. 2016;26(5-6):536-553. doi:10.1080/09603123.2016.1 217313.

Full text links CrossRef PubMed Google Scholar

47. Johnson DL, Mead KR, Lynch RA, Hirst DV. Lifting the lid on toilet plume aerosol: a literature review with suggestions for future research. Am J Infect Control. 2013;41(3):254-258. doi:10.1016/j.ajic.2012.04.330

Full text links CrossRef PubMed Google Scholar Scopus WoS 48. Barker J, Jones MV. The potential spread of infection caused by aerosol contamination of surfaces after flushing a domestic toilet. J Appl Microbiol. 2005;99(2):339-347. doi:10.1111/j.13652672.2005.02610.x

Full text links CrossRef PubMed Google Scholar Scopus

49. Verani M, Bigazzi R, Carducci A. Viral contamination of aerosol and surfaces through toilet use in health care and other settings. Am J Infect Control. 2014;42(7):758-762. doi:10.1016/j. ajic.2014.03.026.

Full text links CrossRef PubMed Google Scholar Scopus WoS 50. Chartier Y, Emmanuel J, Pieper U, et al. Safe management of wastes from health-care activities. 2nd edition. Malta: WHO Press; 2014.

51. Superior Belgian Health Council. Recommendations for infec tion control in dental care. (May 2011; report $n^{\circ} \mathrm{CSS} 8363$ ). [Internet]. (2011; cited September 12th, 2020). Available from: https:// www.health.belgium.be/sites/default/files/uploads/fields/ fpshealth_theme_file/19069789/Aanbevelingen\%20met\%20 betrekking\%20tot\%20de\%20infectiebeheersing\%20bij\%20tandheelkundige\%20zorgverlening\%20\%28mei\%202011\%29\%20 \%28HGR\%208363\%29.pdf

52.Perelshtein I, Applerot G, Perkas N, et al. Sonochemical coating of silver nanoparticles on textile fabrics (nylon, polyester and cotton) and their antibacterial activity. Nanotechnology. 2008;19(24):245705. doi:10.1088/0957-4484/19/24/245705. Full text links CrossRef PubMed Google Scholar Scopus WoS 53. Zuo Z, Kuehn TH, Pui DY. Performance evaluation of filtering facepiece respirators using virus aerosols. Am J Infect Control. 2013;41(1):80-82. doi:10.1016/j.ajic.2012.01.010.

Full text links CrossRef PubMed Google Scholar Scopus WoS 54. Arellano-Cotrina JJ, Marengo-Coronel N, Atoche-Socola KJ, et al. Effectiveness and Recommendations for the use of dental masks in the prevention of COVID-19: a literature review [published online ahead of print, 2020 Jul 17]. Disaster Med Public Health Prep. 2020;1-6. doi:10.1017/dmp.2020.255.

Full text links CrossRef PubMed Google Scholar Scopus

55. Farronato $M$, Boccalari E, Del Rosso E, et al. A scoping review of respirator literature and a survey among dental professionals. Int J Environ Res Public Health. 2020;17(16):E5968. doi:10.3390/ ijerph17165968.

Full text links CrossRef PubMed Google Scholar Scopus WoS 56. Lindsley WG, Noti JD, Blachere FM, et al. Efficacy of face shields against cough aerosol droplets from a cough simulator. $J$ Occup Environ Hyg. 2014;11(8):509-518. doi:10.1080/15459624.2 013.877591.

Full text links CrossRef PubMed Google Scholar Scopus WoS 57. Ye G, Lin H, Chen $\mathrm{S}$, et al. Environmental contamination of SARS-CoV-2 in healthcare premises. J Infect. 2020;81(2):e1-e5. doi:10.1016/j.jinf.2020.04.034.

Full text links CrossRef PubMed Google Scholar Scopus WoS 58. Widmer AF, Richner G. Proposal for a EN 149 acceptable reprocessing method for FFP2 respirators in times of severe shortage. Antimicrob Resist Infect Control. 2020;9(1):88. doi:10.1186/ s13756-020-00744-3.

Full text links CrossRef PubMed Google Scholar Scopus WoS 59. Rubio-Romero JC, Pardo-Ferreira MDC, Torrecilla-García JA Calero-Castro S. Disposable masks: disinfection and sterilization for reuse, and non-certified manufacturing, in the face of shortages during the COVID-19 pandemic. Saf Sci. 2020;129:104830. doi:10.1016/j.ssci.2020.104830

Full text links CrossRef PubMed Google Scholar Scopus WoS 60. Dalli J, O'Keeffe DA, Khan F, Traynor O, Cahill RA. Powered Air Purifying Respirators (PAPR) for the protection of surgeons during operative tasks: a user perspective assessment [published online ahead of print, 2020 Jul 16]. Br J Surg. 2020;107(9):e328 e330. doi:10.1002/bjs.11782.

Full text links CrossRef PubMed Google Scholar

61. Licina A, Silvers A, Stuart RL. Use of powered air-purifying respirator (PAPR) by healthcare workers for preventing highly infectious viral diseases-a systematic review of evidence. Syst Rev. 2020;9(1):173 doi:10.1186/s13643-020-01431-5.

Full text links CrossRef PubMed Google Scholar WoS 62. Krein SL, Mayer J, Harrod M, et al. Identification and characterization of failures in infectious agent transmission precaution practices in hospitals: a qualitative study. JAMA Intern Med. 2018;178(8):1016-1057. doi:10.1001/jamainternmed.2018.1898 Full text links CrossRef PubMed Google Scholar Scopus WoS 63. Rutala WA, Weber DJ. Disinfection, sterilization, and antisepsis: an overview. Am J Infect Control. 2019;47S:A3-A9. doi:10.1016/j.ajic.2019.01.018

Full text links PubMed Google Scholar Scopus WoS 64. Malkin J. Medical and dental space planning. 4th Edition. Hoboken, New Jersey: Wiley; 2014.

Google Scholar

\section{Constantinus POLITIS \\ MD, DDS, MM, MHA, PhD \\ Full Professor \& Chairperson \\ Oral and Maxillofacial Surgery Department Faculty of Medicine \\ University Hospitals Leuven, KU Leuven

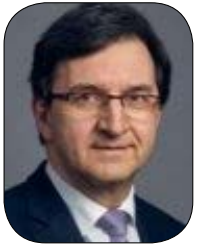

Leuven, Belgium

Dr. Politis is an Oral and Maxillo-Facial Surgeon. He is currently a Full Professor and Chairperson of the Department of OMFS at Leuven University Belgium. He is an invited Lecturer at EHSAL in Brussels. He graduated from the Catholic University of Leuven in medicine (MD) and dentistry (DDS), also specializing in oral and maxillofacial surgery at the same university. He defended his doctor's thesis on the subject of complications of orthognathic surgery (PhD). He followed additional postgraduate training in Arnhem (Stoelinga), Aachen (Koberg), Copenhagen (Pindborg), Göteborg (Bränemark) and San Francisco (Marx). He also holds a master degree in management (MM) and a master degree in Hospital Management (MHM). He is Secretary General of the Professional Union of Belgian Oral and Maxillofacial Surgeons. He is acknowledged trainer of OMFS trainees. Clinical research projects include prevention and repair of iatrogenic trigeminal nerve injury, transplantation of teeth and orthognathic surgery. 


\section{Ouestions}

\section{An operating room under negative pressure: which of the following is a correct statement?}

口a. Has no plenum;

b. Needs no HEPA-filtration;

口c. Is the de facto standard in hospitals with COVID-19 wards;

$\square d$. Is the standard when operating on COVID-19 patient.

\section{Which of following is not true or applicable when discussing humidity in a dental practice:}

$\square$ a. Humidity in a dental practice comes from the aerosols created during dental treatments;

b. Humidity in a dental practice comes from the autoclave;

ac. The added value of a stand-alone dehumidifier is only present if enough regular natural (windows) or mechanical (ventilation devices) ventilation takes place;

$\square d$. The added value of a stand-alone dehumidifier is limited or even non-existent if enough regular natural (windows) or mechanical (ventilation devices) ventilation takes place.

\section{Which of the following parameters does NOT fit the following statement: "Natural ventilation by opening windows can achieve up to 10 air changes per hour, but depends on a number of important parameters such as:"}

Da. Outside temperature;

Db. Circadian rhythm;

ac. Window type;

d. Surface area.

\section{PAPR (Powered Air-Purifying Respirator): which of the following statements is unjustified}

Da. Is synonymous for a FFP3 mask;

ab. Is a breathing apparatus in the form of a bonnet or full face mask with a battery-operated fan that conducts a positive air flow through a filter to the bonnet;

dc. Has a filter with the equivalent of a HEPA filter that retains $99.7 \%$ of the particles in $0.3 \mu \mathrm{m}$;

d. Carries a high risk of infection for the dentist when treating Covid-19 patients if this PAPR is taken off. 


\title{
CHILD ABUSE AND NEGLECT: UNDERSTANDING THE ROLE OF A PEDIATRIC DENTIST
}

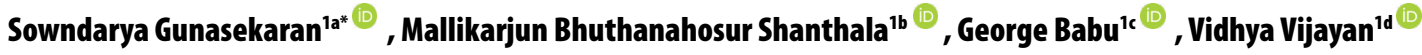 \\ 1Department of Pediatric and Preventive Dentistry, Coorg Institute of Dental Sciences - CIDS, SH 88B, Kodagu Coorg District, Virajpet, Karnataka \\ 571218 , India
}

aBDS, MDS, Post Graduate Student; e-mail: Sowndaryagunasekaran@gmail.com; ORCIDiD: https://orcid.org/0000-0002-3503-4927

bBDS, MDS,PhD, Professor and Head; e-mail: shanthalapedo@cids.edu.in; ORCIDiD: https://orcid.org/0000-0001-7566-6294

BDS, MDS, Reader; e-mail: georgebabu@cids.edu.in; ORCIDiD: https://orcid.org/0000-0002-5474-1299

'BDS, MDS, Post Graduate Student; e-mail:Vidhu.sainidhi@gmail.com; ORCIDiD: https://orcid.org/0000-0002-7410-2398

ABSTRACT

di) https://doi.org/10.25241/stomaeduj.2020.7(4).art.7

Background Child Abuse \& Neglect is a worldwide social and public health problem, which has a multitude of short- and long-term effects on children.

Objective Pediatric dentists are often the ones who, after a pediatrician, come to identify a child abuse victim, so this article addresses the importance of the pediatric dentist in identifying the oral health issues that can be associated with child abuse victims.

Data sources Web of Science, PubMed, Google Scholar were databases researched for peer review articles in indexed journals.

Method Literature search was conducted and articles were selected according to the data provided regarding child abuse and neglect and the relevant data were summarized.

Result Some medical providers may receive less education pertaining to oral health and dental injury that are related to abuse or neglect as readily as they detect those involving other areas of the body.

Conclusion Pediatric dentists are encouraged to collaborate with pediatricians to increase the prevention and detection of child abuse and neglect in children.

\section{KEYWORDS}

Child Maltreatment, Child Mistreatment, Child Neglect, Dentists, Pediatric Dentists.

\section{INTRODUCTION}

Child abuse and neglect is a problem that pervades all sections of society. Many children are denied the right to grow in a supportive and loving family environment, which promotes a person's development to his / her full potential. In 1997, three million children were reported to Child Protective Services (CPS) for some form of child abuse, and about 1 million cases were proven after the CPS investigation [1]. Statistics show that 1000 children die every year as a result of some form of child abuse, $78 \%$ under the age of five, $38 \%$ under the age of one year [2]. This makes the role of infant oral health care provider extremely essential for early detection of child abuse and neglect and proper management of the same. According to "Save the Children", a non profitable NGO, the recent statistics regarding child abuse in India are [3].

- The number of cases registered for child abuse rose from 8,904 in the year 2014 to 14,913 in the year 2015, under the POSCO act. Sexual offences and kidnapping account for about $81 \%$ of crime against minors.

- Preventive measures designed to ward off strangers were found to be ineffective as most of the offenders were either relatives, acquaintances or somebody they trust.

- Uttar Pradesh emerged as the state with the highest number of child abuse cases $(3,078)$, followed by Madhya Pradesh $(1,687)$, Tamil Nadu $(1,544)$, Karnataka $(1,480)$ and Gujarat $(1,416)$.

(c) (1) (3) OPEN ACCESS This is an Open Access article under the CC BY-NC 4.0 license. Peer-Reviewed Article

Citation: Gunasekaran S, Shanthala MB, Babu G, Vijayan V. Child abuse and neglect: understanding the role of a pediatric dentist. Stoma Edu J. 2020;7(4):286-293.

Received: August 26, 2020; Revised: September 18, 2020; Accepted: September 23, 2020; Published: October 10, 2020

*Corresponding author: Dr. Sowndarya Gunasekaran, BDS, MDS, Post Graduate Student, Department of Pediatric and Preventive Dentistry

Coorg Institute of Dental Sciences - CIDS, SH 88B, Kodagu Coorg District, Virajpet, Karnataka 571218, India

Tel: +91 9994506721; Fax: +91 9448500451; e-mail: sowndaryagunasekaran@gmail.com

Copyright: $\odot 2020$ the Editorial Council for the Stomatology Edu Journal. 


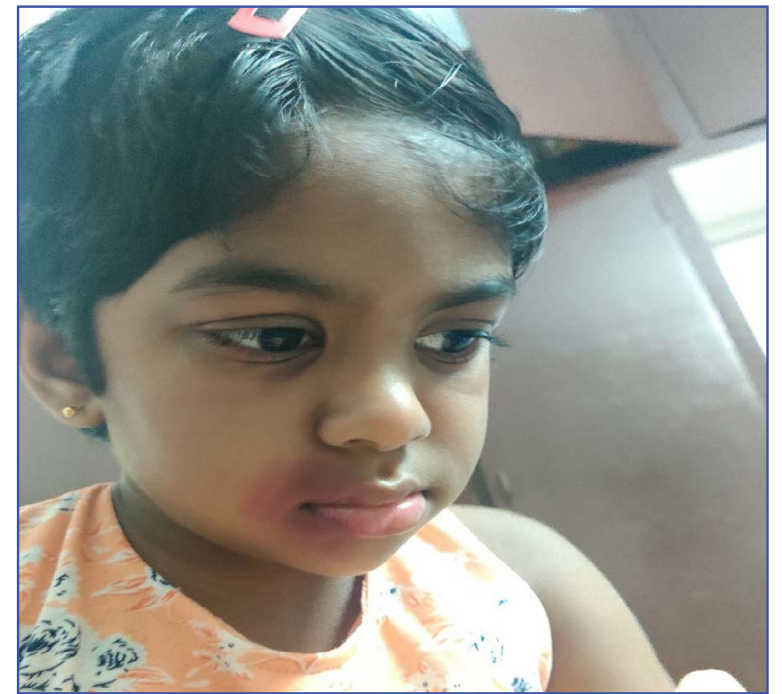

Figure 1. Bruising seen in the lip area indicating physical abuse.

There are reports of child abuse and neglect cases, but there are no definite guidelines to follow. Delay in reporting abuse or neglect in young children usually results in an arrest of the normal developmental process. Attitude and behavioural consequences depend on the time at which the child's developmental process is interrupted. The degrees of impact of such developments are the results of factors such as maltreatment of children, lack of a supportive home environment, peer pressure, and other immediate family members and outside support from individual children [4]. This paper attempts to explain the importance of reporting when such a situation is encountered in the dental setup.

\section{RECOGNIZING THE DIFFERENT TYPES OF CHILD ABUSE}

\subsection{Types of child abuse}

2.1.1. Emotional abuse includes failure to provide the children with an appropriate and sympathetic environment, and actions that have negative consequences on mental health and development. Children are most vulnerable; they need constant support from the family and mainly during their developmental period [4]. Mental abuse of children can be very harmful, disrupting their mental and physical health as well as their social and cognitive development. Despite evidence that child emotional abuse can cause long-term and serious harm to a child's development, health and safety, little attention has been paid to how best to protect children from child psychological abuse.

2.1.2 Child neglect is the most common form of child abuse, a pattern of failing to meet a child's basic needs, including inadequate food, clothing, hygiene or supervision [5]. Detecting child neglect is not always easy. Sometimes, parents may not be able to care for the child physically or mentally, for example a serious illness or injury, or untreated depression or

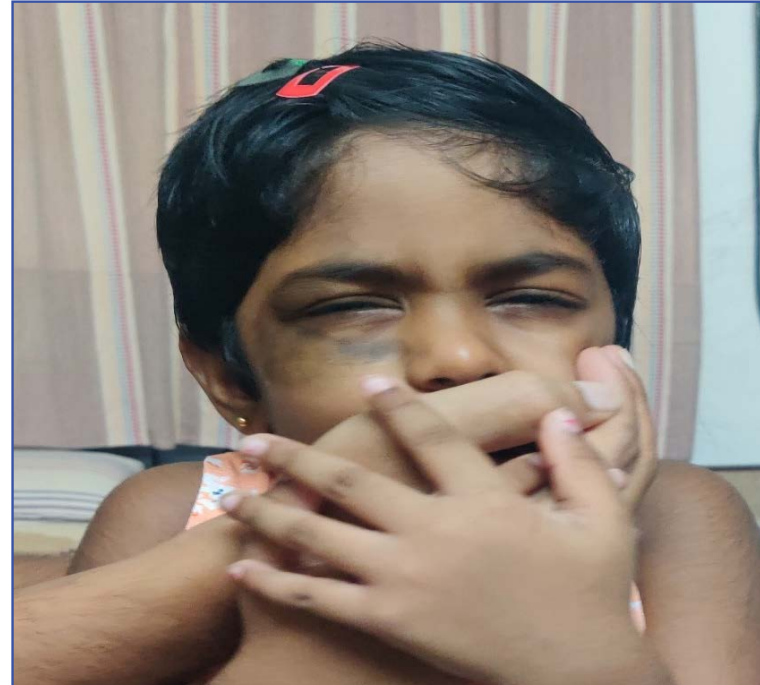

Figure 2. Emotional abuse.

anxiety. At other times, alcohol or drug abuse can impair judgment and the ability to keep a child safe.

2.1.3. Physical abuse involves physical injury or trauma to a child. It may be the result of a deliberate attempt to harm a child or excessive corporal punishment [6]. Many parents who are physically abusive emphasize that their actions are just disciplinary forms and ways for children to learn to behave. But there is a big difference between using corporal punishment for discipline and physical abuse.

2.1.4. Sexual abuse Child sexual abuse is a complex form of abuse caused by layers of guilt and shame. It is important to recognize that sexual harassment does not always involve physical contact [7]. Exposing a child to a sexual situation or subject is subject to sexual harassment, even without touching.

- Children who have been abused often suffer from shame and guilt. They think they are the cause of the abuse or have somehow been brought it upon themselves. It can lead to self-loathing and sexual and relationship difficulties as an adult.

- The shame of sexual abuse makes it very difficult for children to come forward. They think that others will not trust them, that they will be angry with them, or that it will break up their family. Because of these difficulties, false allegations of sexual harassment are not common. If a child confides in you, take them seriously.

\subsection{Indicators of abuse in infants}

\subsubsection{Physical abuse}

- Craniofacial, head, face and neck injuries [8].

- Children in Foster care should be screened for oral trauma, tuberculosis, gingivitis and other oral health problems because some authorities believe the oral cavity is a central focus of physical abuse because it is entangled in communication and nutrition [6].

- Oral injuries with utensils such as bottle during forced feeding, hands, fingers, or stained liquids or caustic substances. 
ITable 1. Recommendations for child abuse and neglect management.

\begin{tabular}{|l|l|}
\hline $\begin{array}{l}\text { What to do if you suspect a child is being } \\
\text { abused? Or if a child is confiding to you? }\end{array}$ & $\begin{array}{l}\text { Child abuse is difficult to accept and even difficult to talk about, for the dentist and } \\
\text { children. When talking to abused children, the best way to encourage them is to show } \\
\text { calm reassurance and unconditional support[24-28]. }\end{array}$ \\
\hline Avoid rejection and stay calm. & $\begin{array}{l}\text { Rejection is a general response to the news, which is as offensive and shocking as child } \\
\text { abuse. However, if the dentist exhibits rejection or disgust at what they are saying, the } \\
\text { child may be afraid to continue and shut down. No matter how hard it is, stay calm and } \\
\text { reassured. }\end{array}$ \\
\hline Do not question & $\begin{array}{l}\text { Let the child explain what happened in their own words, but do not ask the child any } \\
\text { leading questions. This can confuse the child and make it harder for them to continue } \\
\text { their story. }\end{array}$ \\
\hline $\begin{array}{l}\text { Reassure the child that they have not done } \\
\text { anything wrong. }\end{array}$ & $\begin{array}{l}\text { It takes a long time to come forward about child abuse. Assure them that you take } \\
\text { what they say seriously and that it is not their fault[29-32]. }\end{array}$ \\
\hline Security comes first. & $\begin{array}{l}\text { If you feel that your safety or the safety of the children may be threatened if you try to } \\
\text { intervene, leave it to the experts. You can provide more support later. }\end{array}$ \\
\hline
\end{tabular}

- Tongue, lips, buccal mucosa or pharynx, broken displacement or avalanche teeth or fractures of the facial bone and jaw.

- Appliance applied to the mouth can cause bruising, lichenification or scarring in the corners of the mouth.

- Physical Bite marks on a child's body are an indicator of a child's physical abuse. Dentists trained as forensic odontologists can help detect and diagnose bite marks related to physical or sexual abuse.

- Adult handprints or bilateral injuries are indicators of suspicion of child abuse.

The common site according to a study [8] for inflicted oral injuries was the lip (54\%) (Fig.1) followed by oral mucosa, teeth, gingivae and tongue.

\subsubsection{Sexual Abuse}

The oral cavity is a frequent site of sexual abuse in children [9] but oral lesions or infections are very rare.

- Diagnosis of oral and peripheral gonorrhoea in prepubertal children with appropriate culture methods and diagnostic testing sexual harassment [10-12].

- Unexplained injury or petechiae of the palate, especially at the junction of the hard and soft palate, may be evidence of forced oral sex.

\subsubsection{Emotional abuse}

- Extreme withdrawal, fear or anxiety to do anything [13-17].

- Extreme behaviour - Fig. 2 (very compliant, demanding, passive, aggressive).

- The parent or guardian does not seem to be attached [18-20].

- Acts either as an inappropriate adult (taking care of other children) or an inappropriate.

\subsubsection{Child neglect}

- Clothes may not fit properly, be dirty, or be unsuitable for the weather.

- Hygiene is consistently bad (matted and unwashed hair, noticeable body odour).

- Untreated illnesses and physical injuries.

- Often left unattended or left alone or allowed to play in unsafe conditions [21-23].

- Always often late or miss school.

\section{THE ROLE OF THE PEDIATRIC DENTIST IN CHILD ABUSE AND NEGLECT}

Whenever a pediatric dentist assesses a child, there is an intimate interaction between the child and the caregiver (parent or guardian) and every opportunity to see signs of child abuse and neglect. Most cases of child abuse involve oral exploration, which is provided as evidence [11].

\subsection{Child Abuse Victim Reporting}

Mandatory reporting[10] of child abuse and neglect should be recommended. Reporting by required / designated professionals (including pediatric dentist) to the appropriate authorities regarding suspected cases of physical and sexual child abuse and neglect should be mandatory [33-37]. In the case of false reporting, they are protected by law as long as they are in good faith. They will be legally fined if they fail to report. Under this law, no evidence is required to report and what is reported is only suspicious abuse. In India, such regulations have not yet been introduced.

3.1.1. Who to report to? India has a wide range of laws to protect children and child protection is recognized as a major factor in social development. Enforcement of laws is challenging due to inadequate field human resource capacity as well as inadequate quality prevention and rehabilitation services. As a result, millions of children are subjected to violence, abuse and exploitation. In the absence of 'mandatory reporting' regulations and child protection services in India, this is an important decision $[38,39]$. Reporting can usually be done to the police, the local child welfare committee and even the ChildLine. However, even after reporting, networking between different professionals is usually required to follow the case to its conclusion.

3.1.2. Childline. Launched by the Government of India, the service is a 24-hour free phone service that can be accessed by a distressed child or by dialling 1098 on his or her behalf on an adult telephone. Childline provides emergency assistance to children and then, depending on the needs of the child, the 


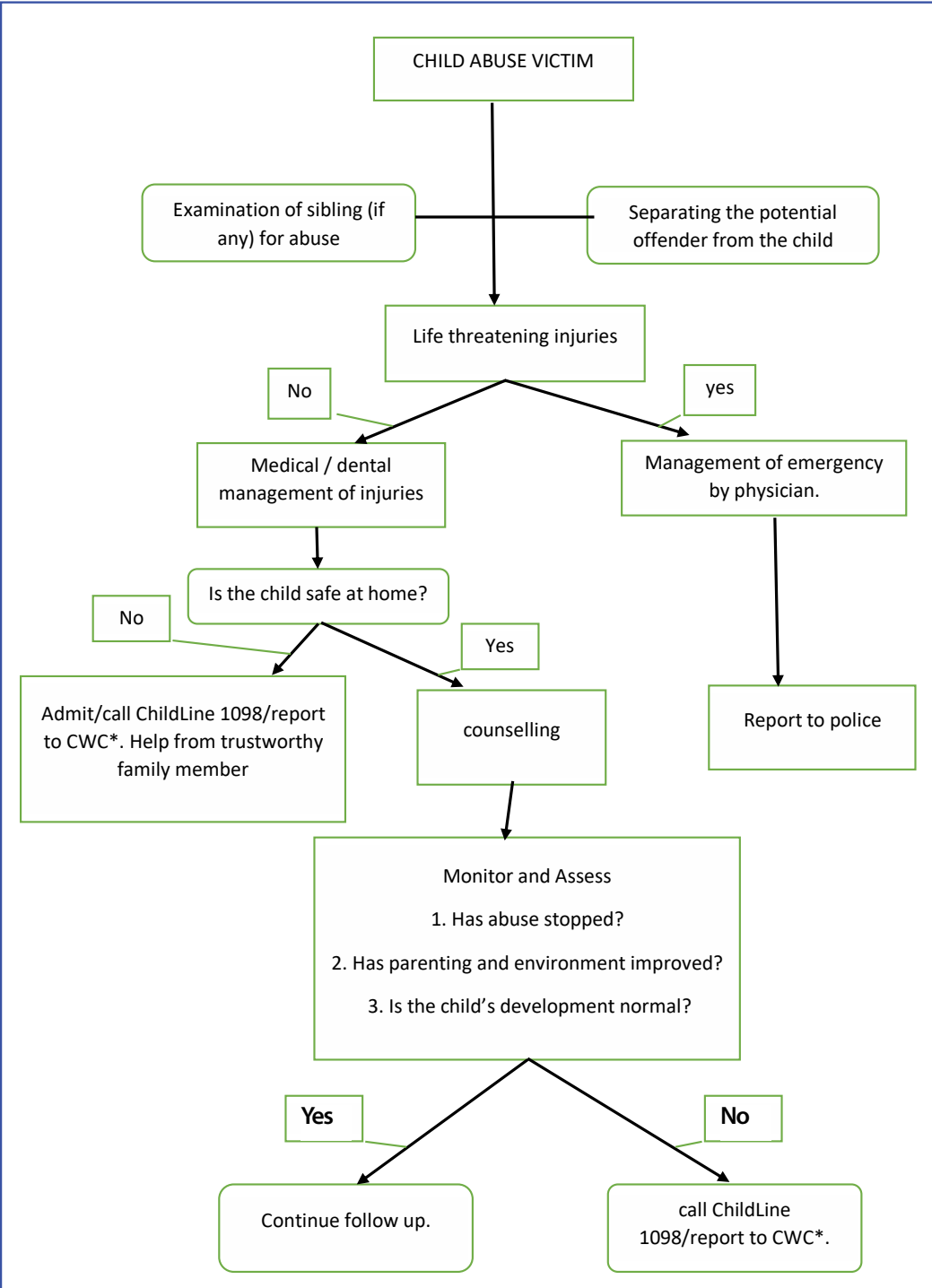

Figure 3. Flow chart describing recommendations for dental management and reporting of child abuse. ${ }^{*}$ Child Welfare Committee; Childline (phone number 1098)). child is referred to the appropriate institution for long-term adoption and care. It calls for medical help, asylum, repatriation, missing children, protection from abuse, emotional support and guidance, information and service referrals, calls related to death, and so on.

Child helpline contact details in India:

- Karnataka State - (080-47181177 (will operate from 10 am to $5 \mathrm{pm}$ )

- CHILDLINE India Foundation, Tamilnadu - 04328 276745

- Child helpline, Punjab -093175 05759

International Child helpline

- Japan Childline - 0120-99-7777

- Malaysia Child line - 12999, 15999

- South Korea - 1577-1391 (Child Protection Hotline) The reporting of child abuse and neglect cases can be done directly to the local bodies, there are child helplines and child protection Commission available in every state of India. (Fig.3)

3.1.3. Child Welfare Committee. Under the Juvenile Justice Act, which allows the Juvenile Justice Board, which includes psychologists and sociologists to determine the adoption process of orphaned, abandoned and surrendered children, the bill introduced concepts from the Hague meeting on child protection and cooperation. Inter-Country Adoption was missing in the previous action, 1993. This bill requires the Child Welfare Committee to notify any parent or guardian who severely abuses a child, or fails to protect a child from being abused; such persons are disqualified and an order is issued to remove the child from the custody of such persons. Crimes under this law are detectable and a person can be arrested without a special police officer or his subordinate needing a warrant and the premises can be searched without a warrant.

3.1.4. National laws and amendments to prevent child abuse and neglect [40]. The legislative framework for children's rights is being strengthened with the formulation of new laws and amendments to existing laws. These include the Food Safety Act (2013), the Protection of Children from Sexual Offenses (POCSO) Act[41], 2012, the Free and Compulsory Education Act (2009), the Child Marriage Prohibition Act (2006), and the Commissions for the Protection of Children. The Right to Information Act (2005), Juvenile Justice (Child Protection and 
Protection) Act 2000, amended in 2006, Right to Information Act (RTI) 2005, Goa Child (Amendment) Act 2005, Child Labor (Prohibition \& Control) Act, 1986 (2006 \& Two notifications in 2008), Prohibited and Dangerous Procedures and Expansion of Professional List) and Information and Technology (Amendment) Act 2008. In addition, there are new laws such as the HIV / AIDS Bill. Telephone helplines (Childline 1098) and Child Welfare Committees (CWCs) were established under the Juvenile Justice Act (2000), where child abuse or harm to children can be reported and help sought.

3.1.5. National programs for the rights and protection of children [40]. The Government of India has implemented a number of programs on social inclusion, gender sensitivity, children's rights, participation and protection. This approach is based on the UN CRC and the Millennium Development Goals (MDGs). These programs include: Integrated Child Development Services (ICDS), the Sabla Scheme for Adolescent Girls, and the Evidence Project for Adolescent Boys; Rajiv Gandhi Creche Scheme for Children of Working Mothers, Domestic Helping Scheme for Promoting Adoption in the Country (Shishu Greh), Dhanalakshmi-Conditional Cash Transfer Schemes for Girls, Program for Juvenile Justice, Child Line (24 Hour Toll-Free Telephone Helpline (No.1098), Integrated Child Protection Scheme[42] (ICPS), Integrated Program for Street Children, Ujjawala (Trafficking and Rescue Prevention Scheme, Rehabilitation, Reunification and Repatriation), School Education Campaign National Program for School Education, National Rural Health Mission (NRHM), Mid-Day Meal Scheme, Jawaharlal Nehru National Urban Renewal Mission (JNNURM), Universal Immunization Program (UIP) and Neonatal \& Childhood IIIness (IMNCI) Integrated Management.

\section{DISCUSSION - LONG-TERM CONSEQUENCES OF CHILD ABUSE AND NEGLECT.}

Children with a history of neglect or physical abuse are at risk of developing mental health problems or a chaotic attachment style. In addition, 59\% of the children who experience child abuse or neglect are arrested as children, $28 \%$ as adults, and 30\% are more likely to commit violent crimes [34]. When some of these children become parents, especially if they suffer from post-traumatic stress disorder (PTSD), dissociative symptoms and other sequels of child abuse, they may experience difficulties when dealing with their infant and toddler needs and general distress, which can lead to negative consequences for their child socio-emotional development [3238]. In addition, children may find it difficult to feel empathy for themselves or others, which can make them lonely and unable to make friends. Despite these potential difficulties, psychosocial intervention can be effective, at least in some cases, in changing the way abusive parents think about their young children. Outcomes for each child can vary widely and are affected by a combination of factors, including the age and developmental status of the child at the time of abuse; type of abuse, frequency, duration and severity, and the relationship between the child and the offender. In addition, children who experience abuse are often affected by other negative experiences (e.g., parental substance abuse, domestic violence, poverty) that make it difficult to distinguish specific effects of abuse.

\section{CONCLUSION}

Child abuse affects society as a whole, and the future well-being of any nation depends on children. It is the responsibility of everyone to ensure that they have atraumatic upbringing. Pediatric dentists are among the front-line professionals trained to detect child abuse and they play an important role in reporting such cases. The dentist should not continue the investigation, but is responsible for notifying the appropriate authorities, who will determine if a child has been abused or neglected. If not intervened, $50 \%$ of time abuse will be repeated and more severe $[10,42]$.

Statistics of child abuse and neglect will continue to rise if mandatory reporting is not followed and health care professionals fail. It is high time that professionals (pediatricians, pediatric dentists, general dentists and other health care workers) who come in close contact with children during examination and concerned regulatory bodies should join hands to protect today's children from any kind of child abuse. Health care professionals are especially required to report cases of child sexual abuse under the "Protection of Children from Sexual Offenses Act (POCSO), 2012"[40].

\section{CONFLICT OF INTEREST}

The authors declare no conflict of interest.

\section{AUTHOR CONTRIBUTIONS}

SG: have made substantial contributions to conception and design and have been involved in drafting the manuscript and revising it critically for important intellectual content; SBM: has made substantial contributions to conception and design, acquisition of data, analysis and interpretation of data and has given the final approval of the version to be published; GB: has made substantial contributions to conception and design, acquisition of data, analysis and interpretation of data and have given the final approval of the version to be published; VV: has made substantial contributions to conception and design and revisited it critically for major intellectual content.

\section{ACKNOWLEDGMENTS}

None. 


\section{REFERENCES}

1. Patil B, Hegde S, Yaji A. Child abuse reporting: role of dentist in India - A review. J Indian Acad Oral Med Radiol. 2017;29(1):74-77. doi: 10.4103/jiaomr.JIAOMR_30_16.

Google Scholar

2. Save the children. Recent statistics of child abuse [Internet] September 2016. [cited 2018 Sep 02]. Available from -

https://www.savethechildren.in/resource-centre/articles/recentstatistics-of-child-abuse

3. Townsend C, Rheingold AA. Estimating a child sexual abuse prevalence rate for practitioners: a review of child sexual abuse prevalence studies. Charleston, SC: Darkness to Light; 2013. Available from https://www.d2l.org/wp-content/ uploads/2017/02/PREVALENCE-RATE-WHITE-PAPER-D2L.pdf 4. Norman RE, Byambaa M, De R, et al. The long-term health consequences of child physical abuse, emotional abuse, and neglect: a systematic review and meta-analysis. PLoS Med. 2012;9(11):e1001349. doi: 10.1371/journal.pmed.1001349. https://doi.org/10.1371/journal.pmed.1001349

PMC free article PubMed Google Scholar Scopus WoS

5. Fisher-Owens SA, Lukefahr JL, Tate AR; American Academy of Pediatrics, section on oral health; committee on child abuse and neglect; american academy of pediatric dentistry, council on clinical affairs, council on scientific affairs; ad hoc work group on child abuse and neglect. Oral and dental aspects of child abuse and neglect. Pediatrics. 2017;140(2):e20171487. doi: 10.1542/ peds.2017-1487.

PubMed Google Scholar

6. Shackman JE, Shackman AJ, Pollak SD. Physical abuse amplifies attention to threat and increases anxiety in children. Emotion. 2007/7(4):838-852 doi: 10.1037/1528-3542.7.4.838.

https://doi.org/10.1037/1528-3542.7.4.838

PubMed Google Scholar Scopus WoS

7. Garrocho-Rangel A, Márquez-Preciado R, Olguín-Vivar Al, et al. Dentist attitudes and responsibilities concerning child sexual abuse. A review and a case report. J Clin Exp Dent. 2015;7(3):e428-e434. doi: 10.4317/jced.52301.

PMC free article PubMed CrossRef Google Scholar Scopus 8. Krug EG, Dahlberg LL, Mercy JA, et al. World report on violence and health. Geneva, Switzerland: World Health Organization 2002

Google Scholar

9. Aggarwal K, Dalwai S, Galagali P, et al; Child Rights and Protection Program (CRPP) of Indian Academy of Pediatrics (IAP). Recommendations on recognition and response to child abuse and neglect in the Indian setting. Indian Pediatr. 2010;47(6):493504. doi: 10.1007/s13312-010-0088-0.

Article PubMed Google Scholar WoS

10. Katner DR, Brown CE. Mandatory reporting of ora injuries indicating possible child abuse. J Am Dent Assoc. 2012;143(10):1087-1092. doi: 10.14219/jada.archive.2012.0038. PubMed Google Scholar Scopus WoS

11. Mathur S, Chopra R. Combating child abuse: the role of a dentist. Oral Health Prev Dent. 2013;11(3):243-250. doi: 10.3290/j. ohpd.a29357.

PubMed Google Scholar Scopus WoS

12. Cicchetti D, Rogosch FA, Gunnar MR, Toth SL. The differential impacts of early physical and sexual abuse and internalizing problems on daytime cortisol rhythm in school-aged children. Child Dev. 2010;81(1):252-269. doi: 10.1111/j.14678624.2009.01393.x.

PMC free article PubMed Google Scholar Scopus WoS 13. Cohen JA, Deblinger E, Mannarino AP, Steer RA. A multisite, randomized controlled trial for children with sexual abuserelated PTSD symptoms. J Am Acad Child Adolesc Psychiatry. 2004;43(4):393-402. doi: 10.1097/00004583-200404000-00005. PMC free article PubMed Google Scholar Scopus WoS 14. Coker TR, Elliott MN, Kanouse DE, et al. Prevalence, characteristics, and associated health and health care of family homelessness among fifth-grade students. Am J Public Health. 2009;99(8):1446-1452. doi: 10.2105/AJPH.2008.147785.

PMC free article PubMed Google Scholar Scopus WoS 15. Cougle JR, Timpano KR, Sachs-Ericsson N, et al. Examining the unique relationships between anxiety disorders and childhood physical and sexual abuse in the National Comorbidity SurveyReplication. Psychiatry Res. 2010;177(1-2):150-155. doi: 10.1016/j. psychres.2009.03.008.

PubMed Google Scholar Scopus WoS

16. Del Giudice M, Ellis BJ, Shirtcliff EA. The adaptive

calibration model of stress responsivity. Neurosci Biobehav Rev. 2011;35(7):1562-1592. doi: 10.1016/j.neubiorev.2010.11.007.

PMC free article PubMed Google Scholar Scopus WoS

17. Dong M, Anda RF, Dube SR, et al. The relationship of exposure to childhood sexual abuse to other forms of abuse, neglect, and household dysfunction during childhood. Child Abuse Negl. 2003;27(6):625-639. doi: 10.1016/s0145-2134(03)00105-4.

PubMed Google Scholar Scopus WoS

18. Easton SD. Understanding adverse childhood experiences (ACE) and their relationship to adult stress among male survivors of childhood sexual abuse. J Prev Interv Community. 2012;40(4):291-303. doi: 10.1080/10852352.2012.707446.

PubMed Google Scholar

19. Edwards VJ, Anda RF, Felitti VJ, Dube SR. Adverse childhood experiences and health-related quality of life as an adult. In K. A. Kendall-Tackett (Ed.). Application and practice in health psychology. Health consequences of abuse in the family: $a$ clinical guide for evidence-based practice (p. 81-94). American Psychological Association. https://doi.org/10.1037/10674-005 Google Scholar

20. Ehring T, Ehring T, Welboren R, et al. Meta-analysis of psychological treatments for posttraumatic stress disorder in adult survivors of childhood abuse. Clin Psychol Rev.

2014;34(8):645-657. doi: 10.1016/j.cpr.2014.10.004.

PubMed Google Scholar Scopus WoS

21. Finkelhor D, Shattuck A, Turner HA, Hamby SL. The lifetime prevalence of child sexual abuse and sexual assault assessed in late adolescence. J Adolesc Health. 2014;55(3):329-333. doi: 10.1016/j.jadohealth.2013.12.026.

PubMed Google Scholar Scopus

22. Finkelhor D, Turner HA, Shattuck A, Hamby SL. Violence, crime, and abuse exposure in a national sample of children and youth: an update. JAMA Pediatr. 2013;167(7):614-621. doi: 10.1001/jamapediatrics.2013.42. Erratum in: JAMA Pediatr. 2014;168(3):286. PMID: 23700186

PubMed Google Scholar Scopus WoS

23. Gillihan SJ, Aderka IM, Conklin PH, et al. The Child PTSD Symptom Scale: psychometric properties in female adolescent sexual assault survivors. Psychol Assess. 2013;25(1):23-31. doi: 10.1037/a0029553.

PMC free article PubMed Google Scholar Scopus WoS 24. Hillberg T, Hamilton-Giachritsis C, Dixon L. Review of meta-analyses on the association between child sexual abuse and adult mental health difficulties: a systematic approach. Trauma Violence Abuse. 2011;12(1):38-49. doi 10.1177/1524838010386812.

PubMed Google Scholar Scopus WoS

25. Lopez-Castroman J, Melhem N, Birmaher B, et al. Early childhood sexual abuse increases suicidal intent. World Psychiatry. 2013;12(2):149-154. doi: 10.1002/wps.20039. PMC free article PubMed Google Scholar Scopus WoS 26. McLaughlin KA, Green JG, Gruber MJ, et al. Childhood adversities and adult psychiatric disorders in the national comorbidity survey replication II: associations with persistence of DSM-IV disorders. Arch Gen Psychiatry. 2010;67(2):124-132. doi: 10.1001/archgenpsychiatry.2009.187

PMC free article PubMed Google Scholar Scopus WoS 27. McLean CP, Morris $\mathrm{SH}$, Conklin $\mathrm{P}$, et al. Trauma characteristics and posttraumatic stress disorder among adolescent survivors of childhood sexual abuse. J Fam Violence. 2014;29(5):559-566. doi: 10.1007/s10896-014-9613-6.

PMC free article PubMed Google Scholar Scopus WoS

28. Nixon RD, Nixon RD, Meiser-Stedman R, et al. The Child PTSD Symptom Scale: an update and replication of its psychometric properties. Psychol Assess. 2013;25(3):1025-1031. doi: 10.1037/ a0033324.

PubMed Google Scholar Scopus WoS

29. Nolen-Hoeksema S. The role of rumination in depressive disorders and mixed anxiety/depressive symptoms. J Abnorm Psychol. 2000;109(3):504-511. https://doi.org/10.1037/0021843X.109.3.504

PubMed Google Scholar Scopus WoS

30. Schoedl AF, Costa MC, Mari JJ, et al. The clinical correlates of reported childhood sexual abuse: an association between age at trauma onset and severity of depression and PTSD in adults. J Child Sex Abus. 2010;19(2):156-170. doi: 10.1080/10538711003615038.

PMC free article PubMed Google Scholar Scopus WoS

31. Shaffer D, Fisher P, Lucas C. The diagnostic interview schedule for children (DISC): Comprehensive handbook of psychological assessment. Vol. 2: Personality assessment. Hoboken, NJ, US: John Wiley \& Sons Inc; 2004

Google Scholar

32. Thornberry TP, Henry KL, Ireland TO, Smith CA. The causal impact of childhood-limited maltreatment and adolescent maltreatment on early adult adjustment. J Adolesc Health. 
2010;46(4):359-365. doi: 10.1016/j.jadohealth.2009.09.011. PMC free article PubMed Google Scholar Scopus WoS

33. Boullier M, Blair M. Adverse childhood experiences. Paediatr Child Health. 2018;28(3):132-137. doi: https://doi.org/10.1016/j. paed.2017.12.008

CrossRef Google Scholar

34. Holshausen K, Holshausen K, Bowie CR, Harkness KL.

The relation of childhood maltreatment to psychotic

symptoms in adolescents and young adults with depression.

J Clin Child Adolesc Psychol. 2016;45(3):241-247. doi:

10.1080/15374416.2014.952010.

PubMed CrossRef Google Scholar Scopus WoS

35. Vink RM, van Dommelen P, van der Pal SM, et al. Selfreported adverse childhood experiences and quality of life among children in the two last grades of Dutch elementary education. Child Abuse Negl. 2019;95:104051. doi: 10.1016/j. chiabu.2019.104051.

PubMed CrossRef Google Scholar Scopus WoS

36. Adams J, Mrug S, Knight DC. Characteristics of child physical and sexual abuse as predictors of psychopathology. Child Abuse Negl. 2018;86:167-177. doi: 10.1016/j.chiabu.2018.09.019.

PMC free article PubMed CrossRef Google Scholar Scopus WoS
37. Stoltenborgh M, Bakermans-Kranenburg MJ, Alink LRA, van ljzendoorn $\mathrm{MH}$. The prevalence of child maltreatment across the globe: review of a series of meta-analyses. Child Abuse Rev. 2015;24(1):37-50. https://doi.org/10.1002/car.2353.

CrossRef Google Scholar Scopus WoS

38. Gomis-Pomares A, Villanueva L. The effect of adverse childhood experiences on deviant and altruistic behavior during emerging adulthood. Psicothema. 2020;32(1):33-39. doi: 10.7334/ psicothema2019.142.

PubMed Google Scholar Scopus WoS

39. Merrick MT, Ports KA, Ford DC, et al. Unpacking the impact of adverse childhood experiences on adult mental health. Child Abuse Negl. 2017;69:10-19. doi: 10.1016/j.chiabu.2017.03.016. PMC free article PubMed CrossRef Google Scholar Scopus WoS 40. Saini N. Child abuse and neglect in India: time to act. Japan Med Assoc J. 2013;56(5):302-309. https://www.med.or.jp/english/ journal/pdf/2013_05/302_309.pdf

41. India Code. The protection of children from sexual offences act. 2012

https://www.indiacode.nic.in/

bitstream/123456789/2079/1/201232.pdf

42. Ministry of Women \& Child Development. Integrated Child

Protection Scheme (ICPS). 2009. http://wcdhry.gov.in/icps/

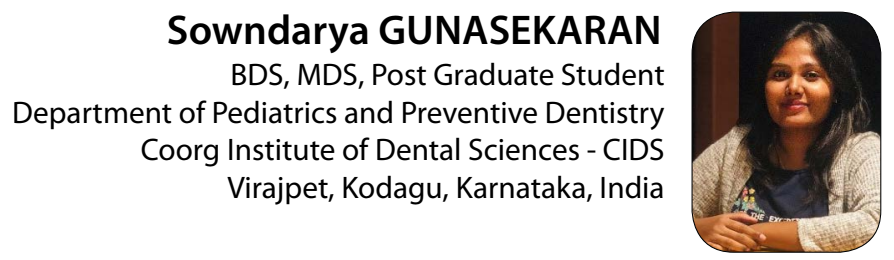

Dr Sowndarya Gunasekaran (DOB: 28th of March, 1995) obtained her bachelor's degree in Dental Surgery at the Sri Ramakrishna Dental College and Hospital, India (2012-2017). She is currently purusing her Master's in Pediatric and Preventive Dentistry (final year), Coorg institute Of Dental Science, India (2018-2021). Her academic interests include preventive health and child care. She strongly believes that every child should be given the right to live a happy and healthy childhood, it is very distressing to see children of young age suffer from abuse which affects their growth and development, as well as their confidence because of negligence and inadequate education about Child abuse and neglect and the consequences of ignoring the needs of the children. 


\section{Orestions}

\section{Which of the following is a sign of neglect?}

$\square$ a. Display unusual sexual knowledge;

ab. Extremely or overly compliant;

ac. Regularly upset stomach;

$\square$ d. Lacks hygiene and appropriate clothing.

2. A parent who continually teases a child in a mean way is committing which type of abuse?

a. Physical;

ab. Emotional;

ac. Sexual;

ad. Neglect.

\section{What is the term for people who are required by law to report suspected child abuse?}

a. ECE professionals;

ab. Police officer;

ac. Child welfare agents;

ad. Mandated reporter.

\section{When should teachers report abuse?}

Da. Once they have a suspicion;

ab. Once they have proof;

ac. Once the child tells them;

ad. Once it has happened twice. 


\section{Give your life some flow. We will fix it at work.}

Do something you love on your day off. It may lead you to a state of flow, where the difficult becomes easy and you can do anything-a wonderful and rewarding feeling.

Guess what? You can experience that at work too. Just tell us about your business needs, challenges and way of working. Based on that, we suggest solutions that save time and effort, while helping you achieve the best possible results for your patients.

Of course, anyone can promise this, but we are the ones who can really make your work flow.

Find your flow in implant dentistry

dentsplysirona.com/makingyourworkflow 


\section{The gold standard for visualizing the possibilities of aesthetic dental}

\section{makeover directly on the patient: IvoSmile}

During the latest International Dental Show (IDS) in Cologne, Germany, as a dental aesthetics enthusiast, I myself surveyed the market for materials, devices and appliances for dental aesthetics. While visiting the Ivoclar Vivadent AG stand, I met Dr. Andreea Czimermann, our representative who was kind enough to show me the latest news. My attention was immediately captured by the communication and counseling tool for dental professionals based on "augmented reality" called IvoSmile. This digital technology facilitates communication between dentists, patients and dental technicians and makes the design process simpler and easier to understand. The software application makes it possible to show the patients a preview of the aesthetic change undergone by their smile via aesthetic corrections (aesthetic dental makeover) of their teeth directly in the patient's own mouth in a short period of time. Dental corrections can be displayed in live, photo or video mode. Professionals are offered the opportunity to present patients on the iPad or iPhone with an aesthetic dental make-up, with no strings attached and without expensive photos or models, or time-consuming explanations. A virtual image or video helps patients to better understand the purpose of the treatment, to decide whether or not to spend their time and money on the planned cosmetic treatment.

The manufacturing company Ivoclar Vivadent AG recommends the software application for the following AREAS OF APPLICATION:

- Digital communication and consulting for a clear and motivating dialogue with patients

- Quick visualization of the potential results of the corrective aesthetic treatment, including the possibilities of personalized modification of the virtual teeth

- Simulated whitening of one's natural teeth

- Preview of the potential result of the aesthetic treatment during the orthodontic consultation by means of the IvoSmile ${ }^{\circledast}$ Orthodontics app.

There are a series of technical requirements conditioning the use of the IvoSmile software application: Apple iPad with 64-bit processor and iOS 10 or a subsequent version of the operating system. Using the IvoSmile software app generates a number of ADVANTAGES:

- Real-time visualization of the aesthetic corrections of the teeth directly in the patient's mouth

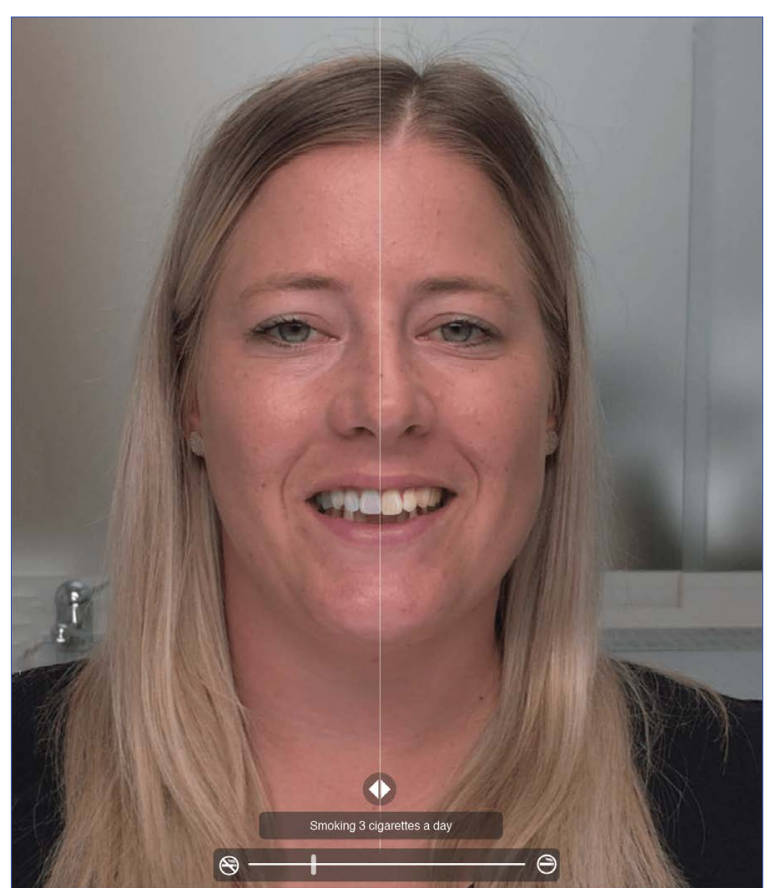

The IvoSmile software app for visualizing the possibilities for esthetic dental makeovers directly on the patient. Ivoclar Vivadent AG, Bendererstrasse 2, 9494 Schaan, Principality of Liechtenstein

https://www.ivoclarvivadent.com/en/dental-professional-/ivosmile

- Visualizations make complex treatments easier to explain

- Awakening the patients' emotions and gaining them as clients

- Facilitating communication between the clinic and the dental laboratory

-Avoid complicationsarising frommisunderstandings or disagreements

- Explain the potential limitations (due to the patient's anatomy) that have an impact on achieving an aesthetic treatment in words that patients understand.

- Customization options for: tooth shape, tooth size, color, brightness, etc.

- Virtual whitening (for instance, of the existing tooth or the virtual one)

- Archiving function (save and re-edit)

- Sending the viewing images by email

If, like me, you intend to position your clinical activity as an innovative modern practice, take advantage of the free 30-day trial period and get to know IvoSmile through the Apple App Store perspective. 


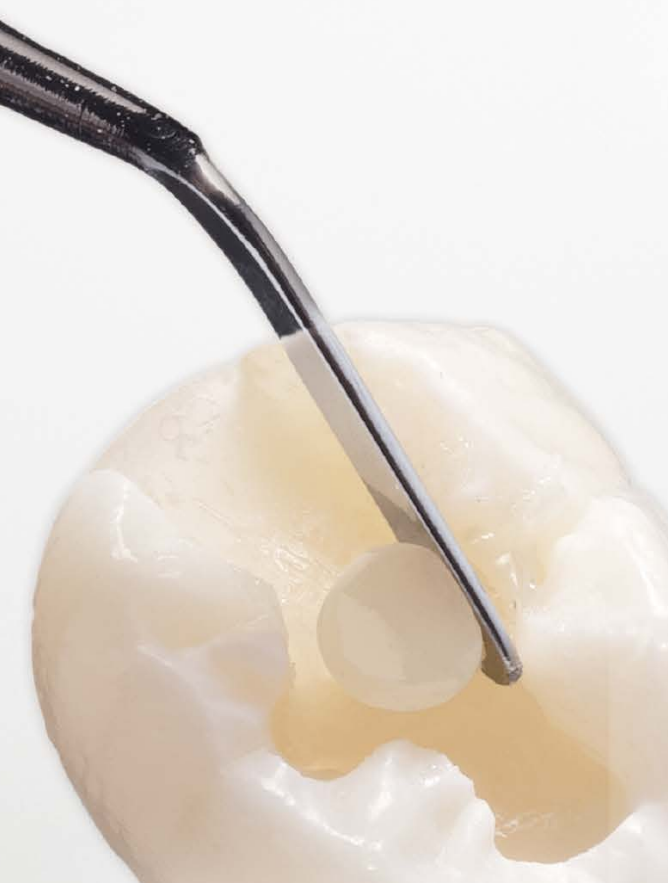

Neo Spectra ${ }^{\text {TM }}$ ST

Your most common cases, covered.
Neo Spectra ${ }^{\text {TM }}$ ST Effects

complex anterior cases, simplified.
Neo SpectraTM ST flow Efficient esthetic flowable versatility.

\section{Efficient esthetics with Neo Spectra ${ }^{\mathrm{TM}}$ ST Composites}

Our proven SphereTEC ${ }^{\circledast}$ formula now spans the full range, or 'Spectra', of shades and handling preferences, offering the perfect balance of everything that matters most to clinicians.

Easy adaptation \& handling

$\Rightarrow$ Spherical filler shape produces a "ball bearing-like" effect

Ingenious simple shading system \& accurate shade match

$\rightarrow$ Chameleon effect from precise match of fillers to resin matrix

High strength \& outstanding gloss

- Unique, pre-polymerized submicron glass filler particle structure

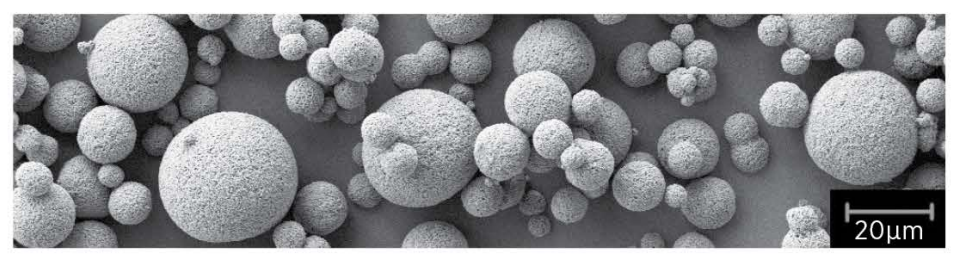

Made possible by

SphereTEC ${ }^{\circledR}$ Technology 


\section{Modern Sports Dentistry}

Editor: Mark Roettger

Publisher: Springer Nature, Switzerland

Language: English

ISBN: 978-3-319-44414-7

Edition: 1/e

Publish Year: 2018

Pages: 235, illustrated

Price: $€ 114,39$
Florin-Eugen

Constantinescu

DMD, PhD Student

Holistic Dental \& Medical Institute

of Bucharest - ROPOSTURO

Bucharest, Romania

e-mail:

dr.florin.constantinescu@gmail.com

The Academy for Sports Dentistry (ASD) defines Sports Dentistry as: "the branch of sports medicine that deals with the prevention and treatment of dental injuries and related oral diseases associated with sport and exercise".

Mark Roettger, Clinical Director (University of Minnesota Medical Center) and 23 contributors provide the readers with an original book to present an image of the science and art of sports dentistry as defined by ASD.

"Modern Sports Dentistry" is divided into 14 chapters and addresses dentists wanting to join the modern integrated team of sports medicine.

Chapter 1 introduces Sports Dentistry, presents its history and ASD, defines the field and establishes guidelines to become evidence-based sports dentistry.

Chapter 2, Epidemiology of Athletic Dental Injuries, clarifies epidemiological research and study design, epidemiology of dental trauma, injury surveillance and systems, and injury prevention and risk compensation.

Chapter Three, Sports-Related Oral and Dentoalveolar Trauma: Pathophysiology, Diagnosis, and Emergent Care defines injuries to the hard dental tissues and the pulp, injuries to the periodontal tissues, splinting in dentoalveolar trauma, soft tissue injuries, and orthodontic considerations in dental trauma.

Chapters 4, 5 and 6 shed light on the offer of Endodontics, Oral and Maxillofacial Surgery, and Restorative Dentistry in dental trauma.

Chapter 7, Prevention of Athletic Dental Injuries presents the mouthguard from design to materials and the role played by these devices in preventing dental trauma.

Chapters 8 and 9, Public Health discuss in detail the use of the mouthguard and the role of these devices on concussion in sports. Chapters 10, 11 and 12 address the issue of dental erosion in athletes due to the consumption of energy drinks, spit tobacco-related sequelae, performance-enhancing drugs and ergogenic aids. Chapter 13 develops the role of oral appliances in improving sports performance.

Chapter 14 analyzes the role of the dentist in the modern multidisciplinary sports medicine team. The book has rich illustrations in each chapter.

This book helps dentists in the primary care community, school nurses, sports doctors, sports coaches and emergency physicians who manage facial and dental trauma and sports-related oral diseases.

The Books Review is drafted in the reviewer's sole wording and illustrates his opinions. 
Marian-Vladimir Constantinescu DDS, MSc, PhD Holistic Dental \& Medical Institute of Bucharest-ROPOSTURO Bucharest, Romania

e-mail:

\section{Essential Endodontology: Prevention and Treatment of Apical Periodontitis}

Editor: Dag Ørstavik

Publisher: Wiley-Blackwell, Hoboken, NJ, USA

Language: English

ISBN: 978-1-119-27195-6

Edition: $3 / \mathrm{e}$

Publish Year: 2020

Pages: 408, illustrated

Price: $€ 135.60$

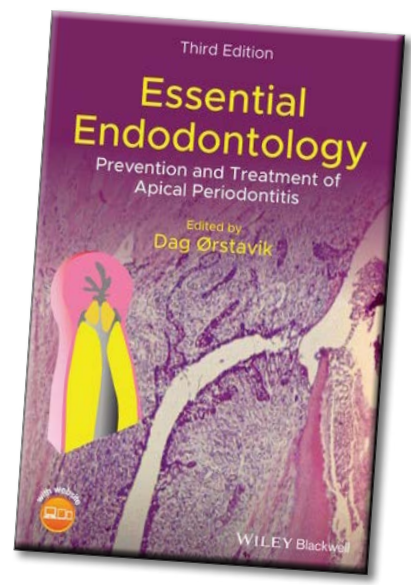

Infections of the pulpal and periapical tissues occupy a distinct field in the endodontic pathology which we frequently meet in dental clinical practice. The 3rd edition of Essential Endodontology: Prevention and Treatment of Apical Periodontitis edited by Dag Ørstavik Professor Emeritus of Endodontology at the University of Oslo,Norway along with 16 contributors, is the latest information source in apical periodontitis.

The book is divided into 12 chapters followed by an index. After being presented the terminology regarding apical periodontitis, we are informed about pulp infection, periapical inflammation, and biological and clinical significance. Dentin - pulp and periodontal anatomy and physiology, etiology, pathogenesis and microbiology of pulpitis and apical periodontitis are detailed below.

Data on epidemiology, treatment outcome, and risk factors for apical periodontitis are outlined in a separate chapter. Radiological aspects of normal apical periodontium, apical periodontitis, conventional radiography, and $\mathrm{CBCT}$ are presented to complete the diagnosis. Clinical manifestations starting with pulpal diagnostic terms, symptomatology of pulpal disease, clinical findings, diagnostic testing, formulation of a pulpal diagnosis, periapical diagnostic symptomatology of periapical disease are presented in order to establish a correct diagnosis. The biological basis for endodontic repair and regeneration, and treatment of the exposed dentine pulp complex are also developed.

Vital pulp extirpation, effective local anesthesia, canal shaping, irrigation and medication, root canal filling, and coronal restoration and data on surgical endodontic procedures are the notions presented in the last chapters.

The book contains images, tables, radiographs and the latest references to inform the reader as accurately as possible and also a website that presents the essentials of endodontology.

It is a systematic analysis of the scientific basis of endodontology, an accessible source for practicing endodontists, postgraduate students of endodontology, and those seeking professional certification in endodontology.

The Books Review is drafted in the reviewer's sole wording and illustrates his opinions. 


\section{Modern Operative Dentistry Principles for Clinical Practice}

Editor: Carlos Rocha Gomes Torres

Publisher: Springer Nature, Switzerland

Language: English

ISBN: 978-3-030-31771-3

Edition: 1/e

Publish Year: 2020

Pages: 715, illustrated

Price: $€ 135,19$

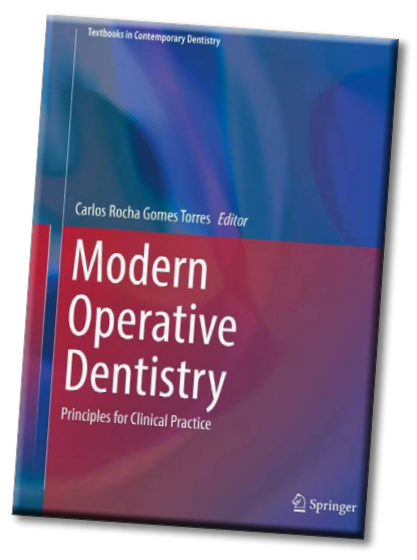

Iulia Ciolachi

DMD

Holistic Dental \& Medical Institute

of Bucharest - ROPOSTURO

Bucharest, Romania

e-mail: dr.iuliaciolachi@yahoo.ro

Springer Publishing Series of textbooks in Contemporary Dentistry provides the reader with a new book that addresses principles of clinical practice in operative dentistry.

Professor Carlos Rocha Gomes Torres from the Institute of Science and Technology, São Paulo State University, Brazil authored the book entitled „Modern Operative Dentistry" which is divided into 18 chapters.

The first step in modern operative dentistry is to have a protocol. The protocol presented in this book begins with the establishment of diagnosis and treatment planning. It explains how to perform a subjective exam, an objective exam, caries risk assessment, general treatment planning and interdisciplinary aspects.

It provides information on the ergonomics principles applied to the dental clinic, instruments and equipments, nomenclature and classification of cavities and tooth preparations, general principles of tooth preparation and carious tissue removal. The quality of the future restoration is conditioned by the use of matrix and wedge systems, isolation method, light-curing units as well as by the protection of the dentin-pulp complex, with everything described in detail.

Furthermore it offers essential information about amalgam restoration, composite restorations, preventive measures and minimally invasive restorative procedures, aesthetic veneers, dentin hypersensitivity and cracked teeth.

This book is written in a very comprehensible style, easy to understand, it is abundantly illustrated and it is very useful for young doctors and all those who want to improve their work protocol adapted to the most modern principles and technologies.

The Books Review is drafted in the reviewer's sole wording and illustrates his opinions. 
Marian-Vladimir Constantinescu DDS, MSc, PhD Holistic Dental \& Medical Institute of Bucharest-ROPOSTURO Bucharest, Romania

e-mail:

\section{Graftless Solutions for the Edentulous Patient}

Editor: Saj Jivraj

Publisher: Springer Nature, Switzerland

Language: English

ISBN: 978-3-319-65857-5

Edition: 1/e

Publish Year: 2018

Pages: 235, illustrated

Price: $€ 145,59$

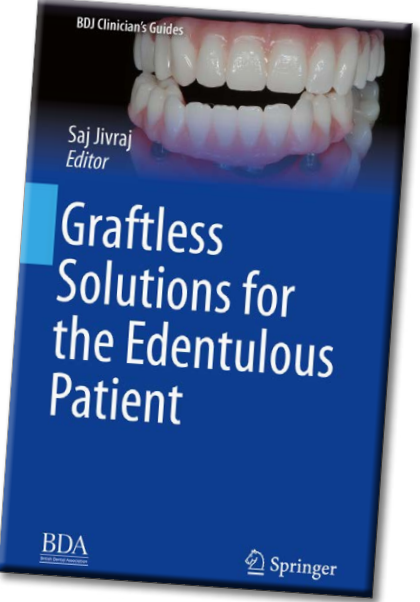

Treating edentulous patients with implant-supported restorations is a significant challenge for the treating clinician, as the patients' expectations with respect to aesthetics, phonetics, form and function are high. Dr. Saj Jivraj, Clinical Associate Professor at University of Southern California, USA and his 31 contributors, a group of world-renowned surgeons and restorative dentists, compiled this manual entitled "Graftless Solutions for the Edentulous Patient" to share with us the latest innovations in oral implantology.

This book is designed to meet the needs of clinicians experienced in placing and restoring dental implants. It initially presents diagnosis and treatment planning from a restorative and a surgical perspective. It then explains treatment planning and technique for guided surgery. It gives step-by-step descriptions of techniques when using the zygoma implant, immediate loading and the biomechanics of graftless solutions and comprehensive integrated digital workflow to guide surgery and prosthetics for full-arch rehabilitation. The book provides the reader with the protocol for All-on-4 and for zygoma implant to establish posterior support. It explains the rationale for immediate loading, material considerations for full-arch implant-supported restorations and clinical steps for the fabrication of a full-arch implant-supported restoration: metal ceramics, zirconia, acrylic titanium.

It also offers information on laboratory fabrication, prosthetic and surgical complications, management of failure and maintenance.

This book is very detailed, richly illustrated, with a whole chapter describing clinical cases.

The book targets clinicians experienced in the placement and restoration of dental implants based on a number of relevant clinical cases.

The Books Review is drafted in the reviewer's sole wording and illustrates his opinions. 


\section{Implant Restorations:}

\section{A Step-by-Step Guide}

Author: Carl Drago

Publisher:Wiley-Blackwell, Hoboken, NJ, USA

Language: English

ISBN: 978-1-119-53811-0

Edition: 4/e

Publish Year: 2020

Pages: 536, illustrated

Price: $€ 153.90$

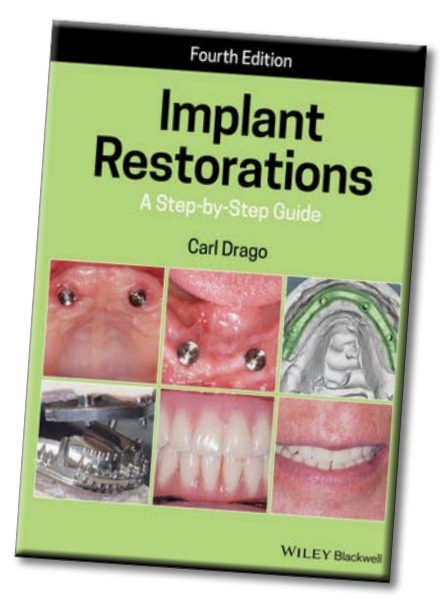

Florin-Eugen

Constantinescu

DMD, PhD Student

Holistic Dental \& Medical Institute

of Bucharest - ROPOSTURO

Bucharest, Romania

e-mail:

dr.florin.constantinescu@gmail.com

Dr. Carl Drago, DDS, MS, associate professor at the Marquette University School of Dentistry in Milwaukee, Wisconsin, USA, and his 6 contributors present the 4th edition of Implant Restorations: A Step-by-Step Guide to all those interested.

The book has 12 chapters and is accompanied by an index.

The first chapters are an introduction to implant dentistry, regarding conventional dentistry versus implant dentistry and treatment prognosis, and then present implants, implant / abutment connections and implant restorative components.

Following the specialized consultation and the diagnostic procedures (radiographs, CBCT scans, diagnostic articulator mounting), principles of treatment planning are established, following informed consent. The different treatment modalities are presented and significantly illustrated for treatment of edentulous mandibular patients, replacement of single teeth with CAD/CAM implant restorations, fixed dental prostheses, treatment of edentulous patients with immediate occlusal loading, treatment of partially edentulous patients with immediate non-occlusal loading protocols and computed tomography (CT) guided surgery / immediate occlusal loading with full-arch prostheses in edentulous patients. The final chapter presents guidelines and maintenance procedures for fixed, full-arch, implant-retained prostheses.

Each chapter is accompanied by carefully chosen radiological and clinical images to understand the text and current references on the subject.

Implant Restorations: A Step-by-Step Guide, 4th Edition is a necessary guide for modern dental practice, both for prosthodontists, general dentists, implant surgeons, dental students, dental assistants, hygienists, and for dental laboratory technicians.

The Books Review is drafted in the reviewer's sole wording and illustrates his opinions. 
Alexandra Popa

Holistic Dental \& Medical Institute of Bucharest - ROPOSTURO,

Bucharest, Romania

e-mail: alesandra17popa@gmail.com

\section{Essentials of \\ Dental Photography}

Author: Irfan Ahmad

Publisher:Wiley-Blackwell, Hoboken, NJ, USA

Language: English

ISBN: 978-1-119-31208-6

Edition: $1 / \mathrm{e}$

Publish Year: 2020

Pages: 360, illustrated

Price: $€ 79.10$

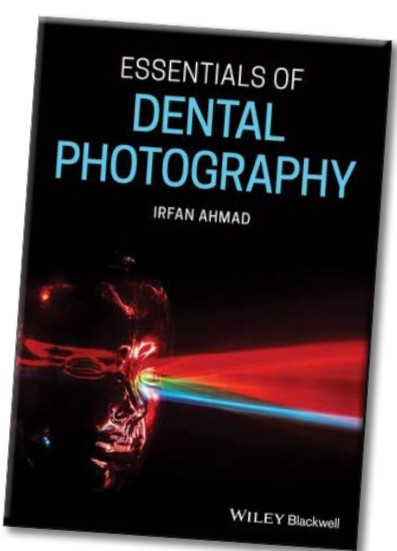

Photography have increasingly come to occupy an important place in medicine, in medical clinical specialties and a predominant role in dentistry.

Over time, a number of authors have been concerned with presenting their experience in photography, respectively in dental photography.

Dr. Irfan Ahmad, a member of the European Academy of Aesthetic Dentistry, author of numerous books on photography and dental aesthetics, presents over 10 chapters gathered in 3 sections detailing his experience in the book entitled "Essentials of dental photography".

Section 1, Equipment and Concepts presents the photographic equipment (cameras, lens, lighting and supports), dental armamentarium and clinical considerations, technical concepts and settings, composition (dominance, positioning, leading the eye, balance) and standardization.

Section 2, Photographic Set-ups describes extra and intra oral images, portraiture, bench images and special applications (detailed analysis of hard and soft tissue, color fidelity, shade analysis, scale reference markers, tooth whitening, phonetics, occlusal analysis and endodontic documentation).

Section 3, Processing Images discusses image processing (monitor calibration, imaging software, color spaces, white balance, orientation, scaling and cropping) and exporting, managing and using images.

Each chapter is richly illustrated and accompanied by significant recent references

"Essentials of dental photography" is a valuable guide for dental practice, useful for both dentists and dental assistants, dental technicians, but also young graduates for follow-up treatments, archiving information in the current activity and educating patients.

The Books Review is drafted in the reviewer's sole wording and illustrates his opinions. 


\section{ProTaper Next ${ }^{\circledast}$ \\ Flexible performance}

Dentsply Sirona Endodontics advocates medical standard care by packaging ProTaper Next ${ }^{\circledR}$ files in pre-sterilised blister packs for single patient use. Using two to three ProTaper Next ${ }^{\oplus}$ shaping files for each clinical procedure, instead of four to five previously, makes it affordable for the practitioner to implement a single use policy for endodontic instruments with numerous advantages, namely:

(D) Ergonomics

- Reduced risk of file breakage

\& Optimal cutting efficiency

80 No risk for cross contamination
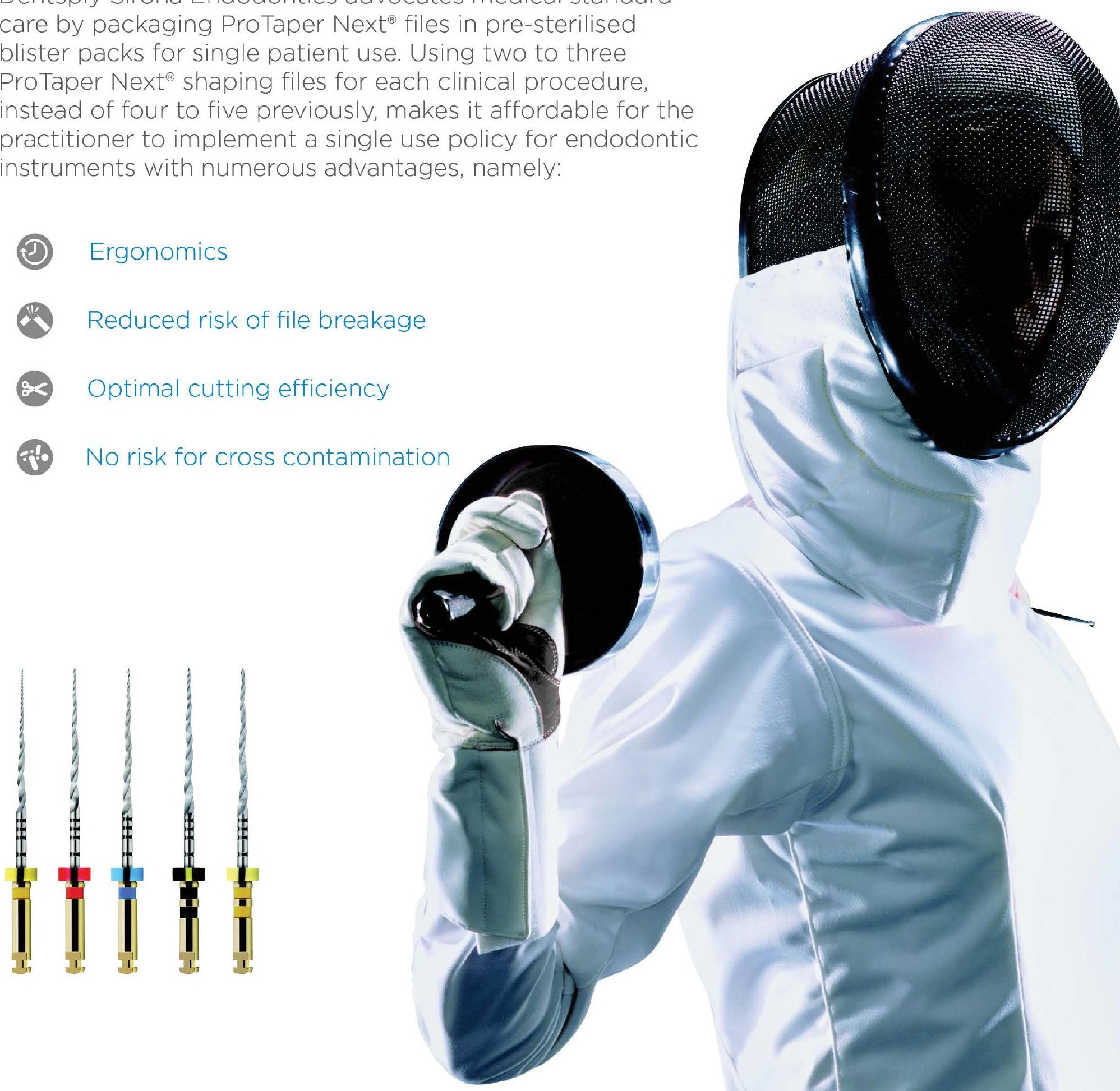
The Stomatology Edu Journal (Stoma Edu J) is one of the first Green Open Access journals in the field of dental medicine publishing well-established authors, but equally committed to encouraging early career researchers and professionals alike to publish their work after a non-partisan, objective, double-blind rigorous peer-reviewed process. Our aim is to publish in the shortest possible time frame and ensure the rapid dissemination of your work via our journal page, but also through our indexing partners (Dimensions, EBSCO, KUDOS Google Scholar, Scilit) which reach the vast mass of denta researchers, professionals and practitioners across the world This journal fully adheres and complies to the policies and principles of the Committee on Publication Ethics (COPE).

\section{Submission Instructions}

The Stomatology Edu Journal (Stoma Edu J) publishes articles written only in English. All articles will be accompanied by the signed copyright form which can be returned by e-mail, fax (as scanned documents). All the responsibility for the originality of the material sent belongs to the author(s) alone. Each article will be evaluated by the peer-review committee composed of two independent peer-reviewers, in a blinded fashion, according to the peer-review protocol. All manuscripts must be original and exclusive. The Stomatology Edu Journal Editor will consider only articles that are original, have not been published elsewhere and have been submitted exclusively to the Stomatology Edu Journal. The manuscripts should be submitted online at wWw. ManuscriptManager.net/stom.

\section{Ethics in publishing}

The Stomatology Edu Journal (Stoma Edu J) and its editorial board fully adhere and comply to the policies and principles of Committee on Publication Ethics (COPE) (https://publicationethics.org/files/2008CodeofConduct.pdf). Your manuscript should not contain any information that has already been published. If you include already published figures or images, please obtain the necessary permission from the copyright holder to publish under the CC-BY license. Plagiarism, data fabrication and image manipulation are not tolerated. Plagiarism is not acceptable in the Stomatology Edu Journal (Stoma Edu J) submissions. Plagiarism includes copying text, ideas, images, or data from another source, even from your own publications, without giving any credit to the origina source. Reuse of text that is copied from another source must be between quotes and the original source must be cited. If a study's design or the manuscript's structure or language has been inspired by previous works, these works must be explicitly cited.

If plagiarism is detected during the peer review process, the manuscript may be rejected. If plagiarism is detected after publication, we may publish a correction or retract the paper. Image files must not be manipulated or adjusted in any way that could lead to misinterpretation of the information provided by the original image. To verify the originality of content submitted to our journals, we use iThenticate (www.ithenticate com) to check submissions against previous publications All submitted manuscripts will be checked for any possible duplication or plagiarism with iThenticate (www.ithenticate com). Nevertheless, corresponding authors are responsible for any fraud, intentional or unintentional malpractice.

\section{Articles sent for publishing}

The Stomatology Edu Journal (Stoma Edu J) publishes: origina articles; reviews; case reports; technical procedures; consensus declaration coming from an association or from a group of specialists; letters to the editor. All articles must be up to 3,000 and 5,000 words for meta- analysis (the word count is for the manuscript text only). Letters to the editor must not exceed 400 words of text and have no more than 3 authors. Letters to the editor can be related to an article already published in the journal or it can represent original scientific contributions or events news/presentations etc. of interest for the reader.

\section{Permissions and Ethics}

For citations, tables, figures etc. which are not original, these must be accompanied by the written permission for their use and the full reference must be provided. Photographs of identifiable persons must be sent alongside the written permission of the person(s) and all regions that may allow the identification of the subject must be covered. The author must have obtained, for all studies including human subjects, the permission of the subjects to be part of the study whilst keeping their anonymity. By sending the article, the author declares that he obtained this permission from all his subjects. All studies must respect the Helsinki Declaration (2013). For human and animal studies, the authors must have obtained the approval of the ethics committee from the University/Institute/etc. where the study was done. Consent for publication is required for studies involving human subjects - ALL case reports, letters that describe cases and some original articles. Cohort studies are exempt; instead evidence of IRB approval (name of IRB, date of approval and approval code/reference number) must be provided.

\section{Manuscript preparation}

The article must be written in conformity with the general recommendations of the International Committee of Medical Journal Editors.

http://www.icmje.org/icmje-recommendations.pdf The Stomatology Edu Journal (Stoma Edu J) uses double-blind review, which means that both the reviewer and author name(s) are not allowed to be revealed to one another for a manuscript under review. The identities of the authors are concealed from the reviewers, and vice versa. To facilitate this, please include the following separately:

Title page (with author details): This should include the title, authors' names and affiliations, and a complete address for the corresponding author including an e-mail address, Author Contributions, Acknowledgements and Curriculum Vitae.

Blinded manuscript (no author details): The main body of the paper (including the references, figures, and tables) should not include any identifying information, such as the authors' names or affiliations.The articles must be sent either as a Microsoft Word 2000 document (*.doc) or as a Microsoft Word 2003 document $\left({ }^{*}\right.$.docx). The article will be written using Times New Roman font, size 12 for the characters with one and half $(11 / 2)$ spaces between paragraphs. The manuscript must be sent in its final form. The pages will be numbered with the manuscript containing the following sections: title, authors, abstract, keywords, the text of article, contributions, acknowledgments, references, the figures and the tables legend.

A. The title of the manuscript will have a maximum of 100 characters without spaces, written in title case, centered capitals, and in 12 point bold Times New Roman font at the top of page. Abbreviations should be avoided within the title.

B. The author(s) will send their full name(s) and surname(s) the highest academic position, their full titles and their affiliations. All names are listed together and separated by commas. Provide exact and correct author names as these will be indexed in official archives. Affiliations should be keyed to the author's name with superscript numbers and be listed as follows: Laboratory, Department, Institute, Organization, City, State abbreviation (USA, Canada, Australia), and Country (without detailed address information such as city zip codes or street names).

The correspondent author will send his/her full name and surname, the highest academic position, his/her full title, his/ her affiliation, his/her institution address, his/ her telephone, fax and e-mail. The authors will send this information in the same format as that in the published articles.

\section{The Structured Abstract}

The abstract can have a maximum of 250 words. After the abstract, the author(s) must mention a maximum of 5 keywords. Keywords must be selected from Medline Mesh. Abbreviations are not accepted in the title or the abstract.

The abstract for Original Scientific Articles should be no more than 250 words using the following structure: Introduction; Methodology; Results; Conclusion.

The abstract for Review Articles should be no more than 250 words with the authors covering all the following information regarding the subject presented under the following subheadings: Background, Objective, Data Sources, Study Selection, Data Extraction, Data Synthesis

The abstract for Case Reports should be no more than 250 words using the following structure: Aim, Summary and Key learning points: provide up to 5 short statements of the report. The abstract for Clinical Articles should be no more than 250 words using the following structure: Aim, Methodology, Results and Conclusions. 


\section{The Article Text}

Headings and Sub-headings

Except for special names (e.g. GABAergic), capitalize only the first letter of headings and subheadings. Headings and subheadings need to be defined in Times New Roman, 12, bold. You may insert up to 5 heading levels into your manuscript (not more than for example: 3.2.2.1.2 Heading title).

For original articles:

1. Introduction - a presentation of the most important aspects in the studied domain without doing a review of the literature. The purpose of this part is to present and backup the hypothesis on which the study was based.

2. Material and Methods - this section will include all required information so that the reader can verify the validity of the study including, but not limited to, subjects, measurements, statistics and ethics. The methods used should be discussed (why the methods have been chosen, which the limitations/ advantages). A paragraph about the statistical analysis is required as well.

3. Results - the results of the study will be presented in a descending order of importance. An interpretation of the results will not be done in this section.

4. Discussion - the authors will present the way the results backup the original hypothesis, as well as the way in which the results are backed up or contradicted by the published literature. A paragraph must be dedicated to presenting the limitations of the study.

5. Conclusion - The conclusion presents the implications of this latest work. In addition, authors may consider discussing future plans or recommendations for future research etc. For all other types of articles, we recommend the use of a clear structure based on sections and sub-sections.

\section{E. Author Contributions}

The Author Contributions section is mandatory for all articles, including articles by sole authors. The Author Contributions statement must describe the contributions of individual authors and, in doing so, all authors agree to be accountable for the content of the work. Please list only 2 initials for each author, without periods, but separated by commas (e.g. AC, AS). In the case of two authors with the same initials, please use their middle initial to differentiate between them (e.g. AEC, ASC). Each author must be able to prove his active participation in the study by contributing to the concept, protocol, data gathering or analysis, their interpretation or by critically revising the manuscript.

\section{F. Acknowledgments}

Acknowledge persons who have made substantive contributions to the study. Specify grant or other financial support, citing the name of the supporting organization and grant number.

\section{G. References}

- The references will be written using the Vancouver style (https://www.imperial.ac.uk/media/imperial-college/ administration-and-support-services/library/public/vancouver. pdf). All references that are identified with DOI (Digital Object Identifier) must be mentioned.

- For each reference use active links to the full text (DOI link), free PMC article, PubMed, Google Scholar, and Scopus pages, were they exist:

- For all references identified with DOI the full-text link must be the CrossRef hyperlink

\section{Examples}

\section{Articles with DOI}

Singbartl G. Pre-operative autologous blood donation: clinical parameters and efficacy. Blood Transfus. 2011;9(1):10-18.

[CrossRef] [Free PMC Article] [PubMed] Google Scholar Scopus Articles without DOI

Mehta H, Shah S. Management of Buccal Gap and Resorption of Buccal Plate in Immediate Implant Placement: A Clinical Case Report. J Int Oral Health. 2015;7(Suppl 1):72-75.

\section{[Full text links] [PubMed] Google Scholar}

- The references will be numbered, in the order they appear in the text, in square brackets, as such: [3], [5,7-9].

- All sources found in the text must be present in the bibliography and all the papers mentioned in the bibliography must appear in the text.

- For references with more than 5 authors, list the first 3 authors followed by "et al."
- Full-page ranges should be given in expanded form (e.g., 426 429, not 426-9).

- If non-English-language titles are translated into English, bracketed indication of the original language should follow the title.

- All journals will be abbreviated and italicized names of journals according to the style in PubMed; refer to the National Library of Medicine (NLM) Journals Database (http://www.ncbi.nlm. nih.gov/nlmcatalog/journals) if needed. Journal names will be abbreviated according to the List of Title Word Abbreviations - Information obtained from sources which are not published yet, but accepted for publishing will include at the end of the reference the mention "in print" between round parentheses.

- If the cited results have not been published yet the mention will be "personal communication" written in the text of article between round parentheses.

- Only references read by the authors of the article will be cited.

- An original article will have at most 50 references, a review will have at most 100 references, a letter to the editor 5 references, whilst all other types of articles will have the minimum number of references required.

\section{Curriculum Vitae - Ultra Short version}

Please provide a brief presentation of the first author and his contribution in the field, of maximum 130 words (with a $3.5 \times 4.5$ $\mathrm{cm}$ color photo)

\section{Figures, Images, Tables}

All illustrations must be numbered and cited in the text in order of appearance.

Figures and Images will be drawn professionally and sent in separate file(s) as jpeg, tiff or png files. Illustrations should preferably fill single column width $(54 \mathrm{~mm})$ after reduction, although in some cases $113 \mathrm{~mm}$ (double column) and $171 \mathrm{~mm}$ (full page) widths will be accepted. See the Image quality specifications chart for details. Image files also must be cropped as close to the actual image as possible.

In the text, each figure must be represented by a number, a title and a description. The authors will indicate where should the figure be placed in the text. All images or figures must come from the author's personal collection or the author must have rights to publish the image or figure. All images must be at or above intended display size, with the following image resolutions: Line Art $800 \mathrm{dpi}$, Combination (Line Art + Halftone) 600 dpi, Halftone 300 dpi. We do not accept images or figures taken from the Internet.

The Tooth Identification System used in manuscripts must conform to the FDI International System. Units used in manuscripts must conform to the Système Internationale d'Unités (SI).

Tables will be included in the text and each table will have a number and a short description if required.

\section{Ownership Rights}

By sending the article for publication the author(s):

- take full responsibility for the scientific content of the text and for the accuracy of the send data;

- become (co)author(s) of the manuscript (all further plagiarism accusation are addressed solely to the author(s) who signed the manuscript);

- declare they are the rightful owners of the images, figures and/or information sent for publishing and that they have the permission to publish all the materials for which they do not own the intellectual property rights;

- declare that the message/content of the manuscript is not influenced in anyway by commercial interests/previous engagements/ any sort of relations with other people or companies;

- transfer all rights for the manuscript to the Editorial Council for the Stomatology Edu Journal.

\section{Other}

Previously mentioned limitations can be ignored in special cases with the agreement of the chief-editor and/or the publisher. All published materials cannot be returned.

Not taking into consideration the recommendations mentioned before can lead to delay in publishing the materials or may lead to not publishing the article.

The Stomatology Edu Journal (Stoma Edu J) also helps authors measure the impact of their research through specialist partnerships with Kudos and Altmetric. 


\section{SUBSCRIPTION}

\section{I want to subscribe to}

stomacedij

- 1 year Subscription (4 issues of the journal) - 280 RON (72 Euro for foreign subscribers)

- 2 years Subscription ( 8 issues of the journal) - 540 RON (136 Euro for foreign subscribers)

- Single Issue - 80 RON (20 Euro for foreign subscribers)

Please send the filled subscription at the following e-mail: roposturo@gmail.com.

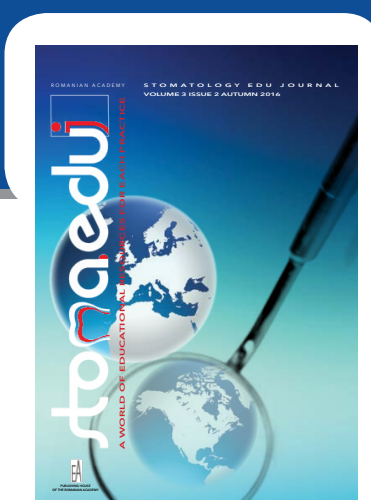

\section{PLEASE COMPLETE ALL THE SUBSCRIPTION FIELDS IN CAPITAL LETTERS!}

Name

Surname

Mrs. $\square$ Mr. $\square$ Ms.

Home Address

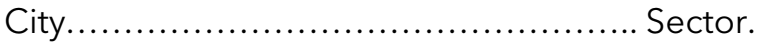

District

Post office code.

Mobile phone.

Web

E-mail:.

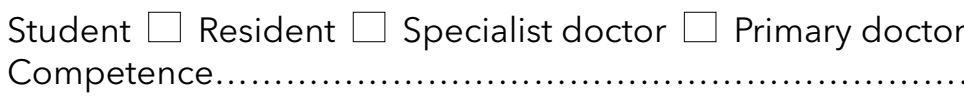

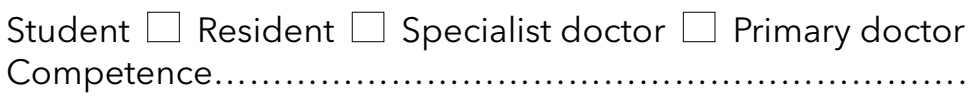

Institution....

Activity domain: $\square$ Private $\square$ Public

Department.

Position

Specialty

Institution address...

City.

Sector.

District

Post office code

Phone.

E-mail:

Web

CUI (Institution Unique Registration Code)

VAT Payer: $\square$ Yes $\square$ No

Invoice - please fill all the necessary details for invoice:

Name

CNP (Personal Identification Number)...

Or

Institution

CUI (Institution Unique Registration Code).

Date

After filling the subscription, please send it together with the proof of payment to:

\section{ROPOSTURO}

Romanian Association of Oral Rehabilitation and Posturotherapy

10, lonel Perlea St., ${ }^{\text {st }}$ District, RO-010209 Bucharest, Romania

Tel: +4021314 1062, Fax: +40213121357

e-mail: roposturo@gmail.com

www.roposturo.ro 


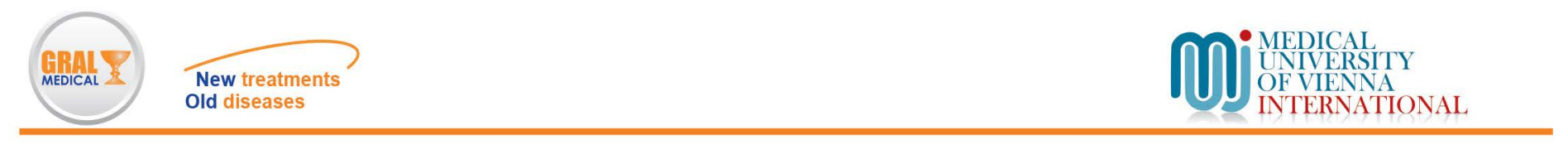

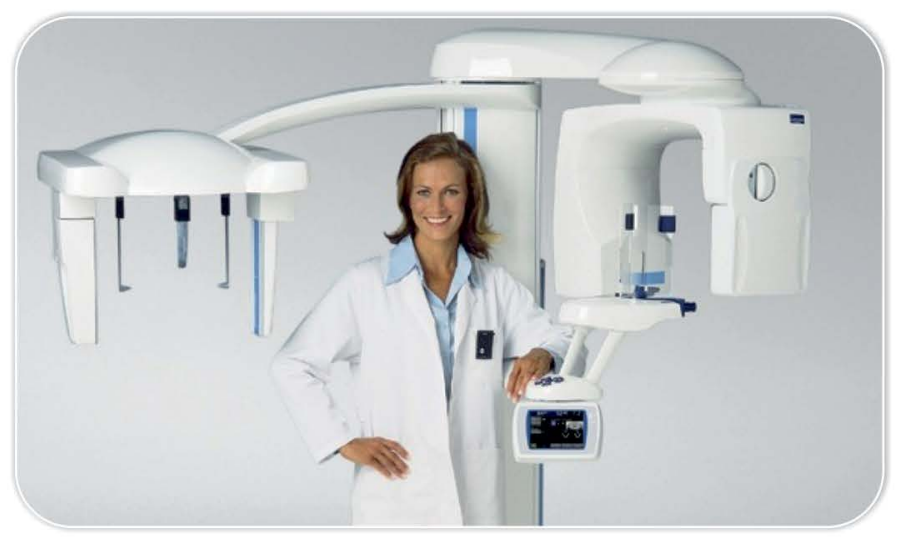

\section{ORTHODONTIC X-RAYS (RADIOGRAPHS)}

Profile (lateral) cephalometric views

Standard OPG (Orthopantomogram) for adults and children (magnification 1.3-1.6)

Orthodontic diagnostic photos

\section{X-RAYS (RADIOGRAPHS) FOR SPECIAL TREATMENTS} Standard OPG (Orthopantomogram) for adults and children (magnification 1.3-1.6)

Ortoradial orthopantogram for adults and

children (magnification 1.3-1.6)

Orthopantogram with reduced for adults and children

Combination for the same patient

(standard OPG +orthoradial+ reduced shadow)

Four-view TMJ- right to left joint

Anterior maxillary sinus panoramic radiographs

Posterior maxillary sinus panoramic radiographs

Salivary gland panoramic radiographs

Prophile (lateral) cephalometric radiographs

Orthodontic diagnostic photos

\section{D CT SCANS}

Full maxilla and mandible CT scan

Maxilla and maxillary sinus CT scan

Mandible and mandible

Mandible and mandibular canal CT scan

Partial maxillary and mandibular CT scan

TMJ CT scan

CT scan of included teeth

\section{MRI -CT}

Ortho-maxillofacial MRI

Ortho-maxillofacial CT

Examination of the throat using a special protocol for: cavum; oropharynx, oral cavity, tongue, soft palate, salivary glands, larynx and hypopharynx is conducted only at 79-91, Traian Popovici Street, $3^{\text {rd }}$ District,

RO-031422 Bucharest, ROMANIA

Tel: $021-323.00 .00$ | 0731-494.688
The Plevnei Gral Medical Dental Imaging Center provides dental imaging services dedicated to obtaining a quick and correct dental diagnostic in order to plan an adequate and efficient treatement.

Our state-of-the-art equipment provides dentists, implantologists or maxillofacial surgeons with accurate 2D and 3D images of the structures they will work upon, being of real service to the patients, by practically eliminating all major intervention-associated risks, both due to the use of very low radiation doses and the easy and comfortable positioning of the patient.
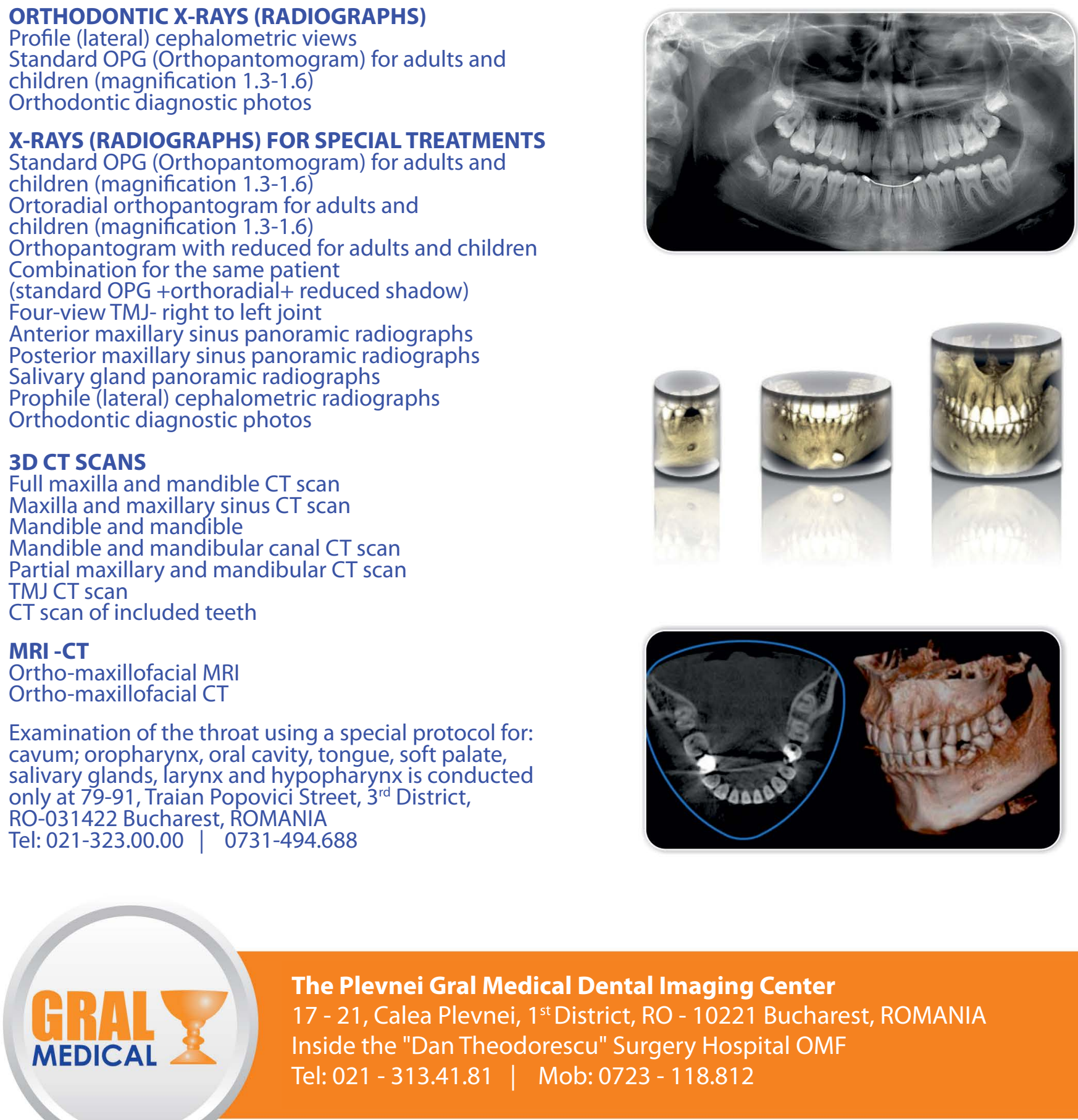


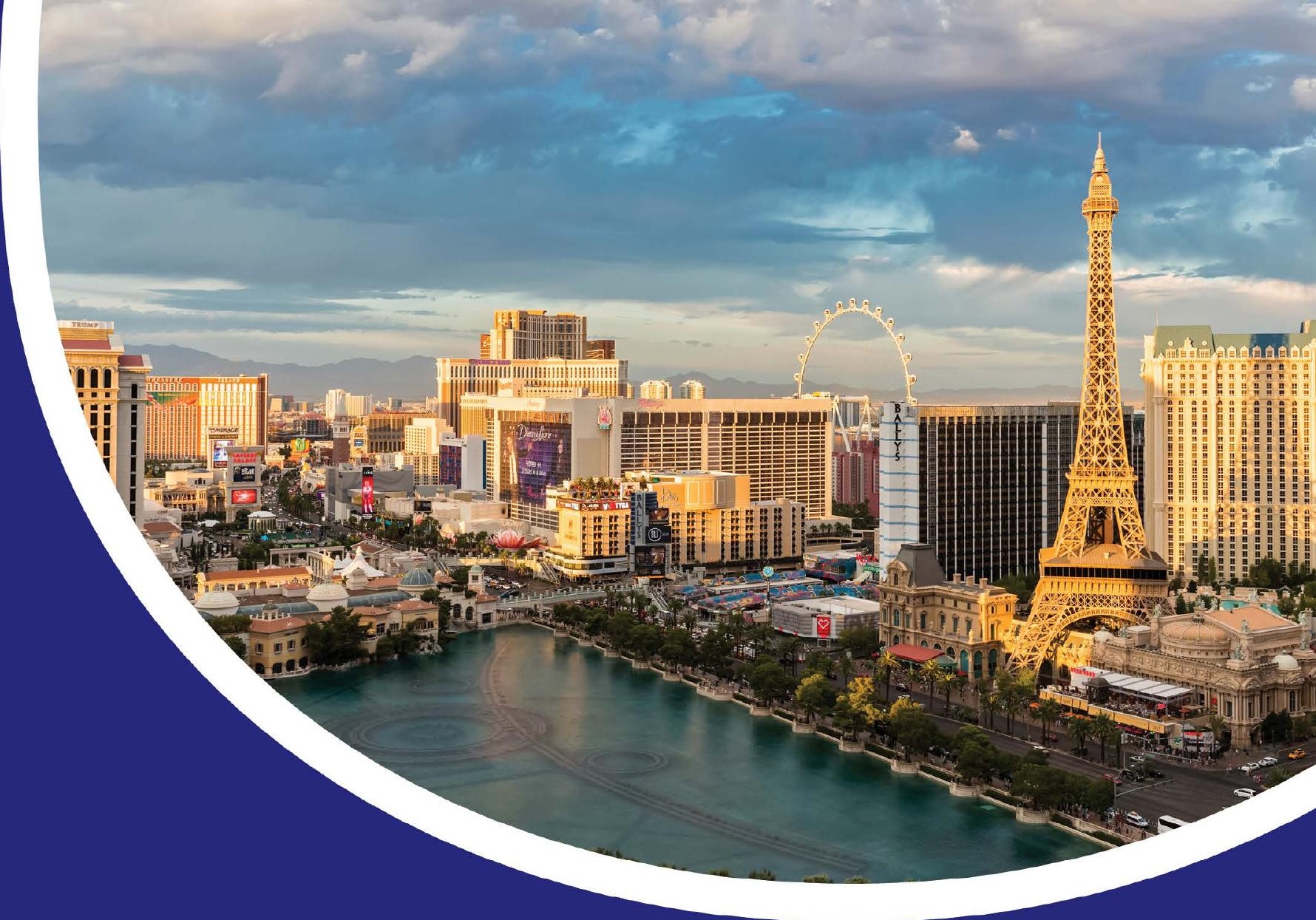

\section{Meet+}
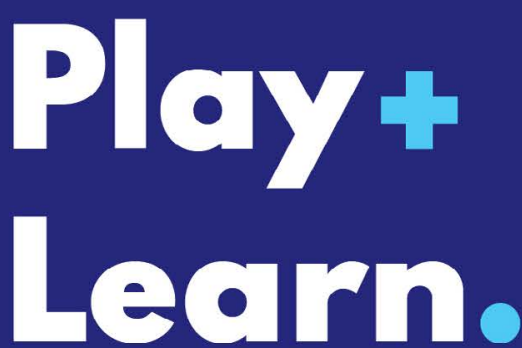

Smiles spark joy for all those around them. You and your team work tirelessly to create them and you should be rewarded with time of your own to smile-SmileCon will do just that!

Get ready to smile October 10-13, 2021. SmileCon 2021.

Get the latest updates at SmileCon.org 